\title{
Heavy Truck Engine Program
}

\section{Final Report for Caterpillar/DOE Heavy Truck Clean Diesel Cooperative Research Program}

\author{
DOE contract No. DE-FC05-000R22806
}

\section{Summary}

This report is the final report for the Department of Energy on the Heavy Truck Engine Program (Contract No. DE-FC05-00OR22806) also known as Heavy Truck Clean Diesel (HTCD) Program.

Originally, this was scoped to be a $\$ 38 \mathrm{M}$ project over 5 years, to be 50/50 co-funded by DOE and Caterpillar. The program started in June 2000. During the program the timeline was extended to a sixth year. The program completed in December 2006.

The program goal was to develop and demonstrate the technologies required to enable compliance with the 2007 and 2010 (0.2g/bhph NOx, 0.01g/bhph PM) on-highway emission standards for Heavy Duty Trucks in the US with improvements in fuel efficiency compared to today's engines. Thermal efficiency improvement from a baseline of $43 \%$ to $50 \%$ was targeted.

Key progress during the program, can be summarized as follows:

- 2007 emissions demonstrator truck in August of 2003.

o Presentation on the truck was given at DEER 2003

o 2007 emissions demonstrator truck publicly showcased at DEER August 2003

o 2007 emissions demonstrator truck publicly showcased at SAE Government/Industry Meeting May 2004

- $\quad$ Full load HCCI mode combustion demonstrated on a single cylinder test engine.

o Continued work in this area is being conducted under the High Efficiency Clean Combustion program also known as HECC

o Presentations on HCCI operation were given at the 2003, 2004, 2005, and 2006 DOE DEER conferences.

- $\quad$ Mixed Mode Injector concept demonstrated the ability to achieve an early cycle HCCI injection in conjunction with a traditional compression ignition injection from the same injector during one engine cycle.

- Design and build of an Advanced High Pressure fuel system

o Continued work with this engine, including testing of the engine, is being conducted under the HECC program.

- Design and build of a variable compression ratio engine VCR

o Continued work with this engine, including testing of the engine, is being conducted under the HECC program.

o Presentation on the VCR concept was given at the 2006 DOE DEER conference

- Demonstration of the ability to meet lower emissions while improving fuel economy using highly efficient aftertreatment

- Demonstration of 47\% overall thermal efficiency while achieving 2010 emissions levels for NOx and particulates.

o Presentation on the analysis to reach 50\% thermal efficiency was given at the 2005 DOE DEER conference. 
o Presentation on the status of high efficiency demonstrator engine was given at the 2006 DOE DEER conference.

O A half scale model of the High Efficiency Demonstrator engine was publicly showcased at the 2006 DOE DEER conference.

- Significant development of analysis models and analytical approaches to guide the technology development.

Results from these areas are presented in this public report. When appropriate, EPACT protected data is included in an EPACT protected appendix.

\section{Acknowledgment of support and disclaimer statement}

This material is based upon work supported by the U.S. Department of Energy under Award No. DE-FC0500OR22806. Any opinions, findings, and conclusions or recommendations expressed in this material are those of the author and do not necessarily reflect the view of the Department of Energy.

Clarification concerning HTCD program scope to include technical proof-of-concepts, and not as a program to address commercialization.

It is important to note that the Caterpillar / DOE cooperative research agreement described in this report was conducted by the Technology and Solutions Division (T\&SD) of Caterpillar Inc. One of the roles of T\&SD division is to conduct research in order to concept the technology strategy for the corporation. The cooperative research done in this program was primarily done to develop proof-of- concept options for technology to meet 2010 on-highway emissions while investigating technologies which had the potential of improving the peak thermal efficiency to $50 \%$. While cursory consideration was given to which technologies may have some ability to be commercialized by the engine divisions of Caterpillar which have commercialization responsibility, the process to validate these technologies as commercially viable was not in the original scope of the program, nor was this task undertaken.

As an example, technology building blocks like higher peak cylinder pressure with higher compression ratio would result in fundamental changes to the base engine. A new cylinder head was created under this program which used a different cast material along with different port arrangements than the baseline engine. These changes, while acceptable for a proof-of-concept, would mean major changes to the manufacturing lines and the tooling used on these lines. Any changes to a major component, like a cylinder head, would require significant, extended hour reliability \& durability validation. The costs of developing a new pressure level within the engine and changes to the manufacturing and assembly lines would need to be analyzed for cost/benefit prior to invoking such a major program. These aspects of commercializing the technologies developed under this program were not in scope and were not completed.

A second example is the incorporation of a turbo-compound along with major air system improvements to reach the 50\% thermal efficiency goal. Caterpillar works with strategic suppliers to provide air systems for their engines. The turbo-compound proof-of-concept system concepted under this program was done so internally and with only cursory input from our suppliers. No attempt was made to take this concept through the commercialization process that our suppliers would be required to undertake. Also, the costs of the improvements have not been fully analyzed. This step would need to be completed so that a comparison of the benefit to the cost of required could be analyzed in order to begin the commercialization process. Once the commercialization process would begin, significant validation (as with the core engine components referenced above) would need to occur to insure the reliability/durability along with the performance attributes were met.

In addition, the efficiency of the engine is only one aspect of truck or machine efficiency. To truly understand the improvement as experienced by the customer, system efficiency would need to be validated across 
varying cycles which would include multiple operating points. Only cursory work was completed to examine the advantage of the $50 \%$ system across the operating range because the primary focus was at peak torque. Also the $50 \%$ thermal efficiency number represents a peak number within the operating map with ultra low sulfur diesel. The efficiency with other fuels was not within scope and was not investigated.

The result is that high thermal efficiencies were reached both in proof-of-concept demonstrations and highfidelity simulations at a single point with a single fuel. However, the commercialization aspects such as cost/benefit analysis, reliability, durability, serviceability, and packaging across multiple applications were considered only at the cursory level. The net result would likely that the particular technology path chosen to reach 50\% will take considerable additional work to determine what building blocks would meet the commercialization hurdle. This determination would ultimately dictate the level of thermal efficiency that provides the highest value to our customers.

Future investigation and cooperative research could include the operating efficiencies across various load cycles, at the vehicle level, with varying fuels, and from a commercial viability standpoint could be areas. Until this next step is completed, any attempt to actually develop a commercial product as the result of the HTCD program alone is not justified. 
DOE Final Report

DE-FC05-000R22806

\section{Table of Content}

Final Program Summary $\quad 1$

Final Report Detailed $\quad 5$

Introduction $\quad 5$

$\begin{array}{lll}\text { Section } 1.0 & \text { Technology Development }\end{array}$

Section 1.1 Homogeneous Charge Compression Ignition (HCCI) Development 6

Section 1.1.1: $\quad$ Summary of Design Activities Occurring throughout the 6-Year Program 8

Section 1.1.2: $\quad$ HCCI Development: The mainstream path 10

Section 1.1.2.1: Initial HCCI Simulation Results 10

Section 1.1.2.2: Single-cylinder test results $\quad 12$

Section 1.1.2.3: Multi-cylinder test results $\quad 15$

Section 1.1.2.4: Single-cylinder demonstration of 100\% load capability 17

Section 1.1.2.5: Addressing other challenges of HCCI 18

Section 1.1.2.6: The challenge of high loads for the multi-cylinder engine 21

Section 1.1.3: HCCI Development: Alternate Paths 25

Section 1.1.3.1: Two-stroke HCCI 25

Section 1.1.3.2: Mixed-mode HCCI operation using the mixed-mode injector 27

Section 1.1.3.3: Air-assisted, port-fuel injected HCCI for increased homogeneity 28

Section 1.1.4: $\quad$ Design work $\quad 29$

Section 1.1.4.1: Design of the Ultimate Flow Head 29

Section 1.1.4.2: Design of the Variable Compression Ratio (VCR) C15 engine 32

Section $1.2 \quad$ Aftertreatment Development 35

Section $1.3 \quad$ Membrane System Development 53

Section 1.4 High Thermal Efficiency Building Blocks 55

Section 1.4.1: $\quad$ Turbo-Compound $\quad 55$

Section 1.4.2: Air System Development 59

Section 1.4.3: $\quad$ Combustion System Optimization 63

Section 1.4.4: $\quad$ Reduced Engine Parasitics/Friction 64

Section 1.4.5: $\quad$ Reduced Heat Rejection $\quad 69$

Section 1.4.6: $\quad$ Cooling System $\quad 70$

Section 1.4.7: $\quad$ Reduced Flow Restriction $\quad 72$

Section 1.4.8: $\quad$ High Efficiency Aftertreatment $\quad 77$

Section 1.4.9: $\quad$ Advanced Fuel Systems $\quad 79$

Section 2.0 System Integration / Technology Evaluation 82

Section 2.12007 (Phase 1) $\quad 82$

Section 2.1.1 2007 Emissions Capable System Development with competitive Fuel Economy 83

Section 2.1.2 2007 Emissions Demonstrator Truck 87

Section 2.1.3 2007 Virtual Test Cell and Truck Development $\quad 92$

Section 2.2 High Efficiency Engine Demonstration at 2010 emissions (Phase 2) 96

Section 2.2.1 HCCI System Demonstration of technology described in Section $1.1 \quad 96$

Section 2.2.2 HCCI Mixed Mode Operation $\quad 98$

Section 2.2.3 High Efficiency NOx Aftertreatment System Demonstration 98

Section 2.2.4 System Optimization for 50\% thermal efficiency at 2010 emissions 104

Section 2.2.5 System Design and Packaging 109

Date; $31^{\text {st }}$ March, $2007 \quad$ CATERPILLAR, Engine Research $\quad$ Page No. 4 
DOE Final Report

DE-FC05-000R22806

\title{
Heavy Truck Engine Program
}

\section{Final Report for Caterpillar/DOE Heavy Truck Clean Diesel Cooperative Research Program}

\author{
Project Title: \\ Heavy Truck Engine Program \\ Recipient: \\ Caterpillar Inc. \\ DOE Award No: \\ DE-FC05-00OR22806 \\ DOE Technology Development Mgr: Roland Gravel \\ DOE Project Officer: \\ Principal Investigator: \\ Carl Maronde \\ Program Manager: \\ David Milam \\ Period of Reporting: \\ David Milam \\ 7/1/00 to $12 / 31 / 06$
}

\section{Introduction}

This report is final technical report summarizing the technical progress on the 6 year Heavy Truck Engine Program also referred to as Heavy Truck Clean Diesel Project (HTCD) for the DOE under Contract No. DEFC05-00OR22806. The period of reporting contained in this report is 7/1/00 to 12/31/06.

The following report structure is being used:

1.0 Technology Development

$1.1 \quad$ Homogeneous Charge Compression Ignition (HCCI) Development

$1.2 \quad$ Aftertreatment Development

$1.3 \quad$ Membrane System Development

$1.4 \quad$ High Thermal Efficiency Building Blocks

2.0 System Integration / Technology Evaluation

2.12007 (Phase 1)

2010 Concept Options (Phase 2)

Technology Development is contained in Section 1.0. Work on the final development of the chosen concepts through two technology demonstrations is contained in section 2.0. Throughout the program best project management practices were utilized. This practice included internal project reviews, milestones reports to DOE, monthly updates to DOE, quarterly technical reports to DOE, and yearly technical program updates with the DOE. In addition Caterpillar Inc. reported on technical progress of this program at the annual DEER conferences. Below is a list of the DEER presentations, which are public information.

1. $\quad$ 2002, Diesel HCCI Development at Caterpillar, Kevin Duffy

2. 2003, Heavy Truck Clean Diesel (HTCD) Program: 2007 Demonstration Truck, David Milam

3. 2003, Diesel HCCI Development in Caterpillar, Kevin Duffy

4. $\quad$ 2004, Heavy-Duty HCCI Development Activities, Kevin Duffy

5. 2004, Transient Simulation of a 2007 Prototype Heavy-Duty Engine, W. Kent Rutan

6. 2004, Diesel Aftertreatment Systems Development, Maarten Verkiel

7. 2005, Heavy-Duty HCCI Development Activities, Kevin Duffy

8. 2005, The Path to a 50\% Thermal Efficient Engine, Will Easley

9. 2006, Demonstration of a 50\% Thermal Efficient Diesel Engine, David Milam 
DOE Final Report

DE-FC05-000R22806

\section{Section 1.0 Technology Development}

The purpose of this section of the report is to cover work completed in the technology development process or phase of the program. This program developed several technologies to a further state of understanding or in some cases to a point where they could be integrated into a system and demonstrated (Section 2.0.). The report addresses the challenges, options taken to overcome the challenges, and results from research. As the reader will see, not all of the technology in section 1.0 was deemed ready for technology evaluation.

\section{Section 1.1 Homogeneous Charge Compression Ignition (HCCI) Development}

This portion of the report summarizes the activities performed by Caterpillar and its partners related to the development of the homogenous charge, compression ignition (HCCI) engine technology. The goal of the HCCI work was to demonstrate a combustion system capable of meeting the 2010 emissions standards without the use of NOx aftertreatment and with good fuel consumption. Because it is a major challenge to extend the load capability of HCCI to the BMEP levels of on-highway trucks this was also a primary goal of the work. It is also important to note that work on HCCI continues under the cooperative research agreement between Caterpillar and the DOE known as the High Efficiency Clean Combustion (HECC) program - DOE Award No. DE-FC26-05NT42412

This section of the report is intended to be comprehensive concerning the development HCCI technology. In Section 1.1.1, a brief overview of the design activities occurring throughout the 5 years that HCCI was actively researched as part of the HTCD program will be presented. This will serve as a high-level overview of the work that was done and the ideas generated in order to make forward progress on HCCI. As with most research, some of the design concepts were pursued, were successful, and therefore became part of the mainstream HCCI technology that was developed over the course of the program. Other concepts were tested with only limited or no success. Some of the concepts were not developed beyond the idea generation phase.

Section 1.1.2, which is the majority of the report, is a summary of the work done to support the mainstream HCCI technology path that was pursued. As with most concept development, this path evolved over the length of the program. In summarizing this work, a balance has been made between presenting it chronologically versus presenting it in logical groupings to improve the readability of this section. The following subsections will be reported on:

$\begin{array}{ll}\text { Section 1.1.2.1: } & \text { Initial HCCI Simulation Results } \\ \text { Section 1.1.2.2: } & \text { Single-cylinder test results (up until multi-cylinder testing begins) } \\ \text { Section 1.1.2.3: } & \text { Multi-cylinder test results } \\ \text { Section 1.1.2.4: } & \text { Single-cylinder demonstration of 100\% load capability } \\ \text { Section 1.1.2.5: } & \text { Addressing other challenges of HCCI } \\ \text { Section 1.1.2.6: } & \text { The challenge of high loads for the multi-cylinder engine }\end{array}$

Section 1.1.3 details three of the technologies that were evaluated but that did not end up becoming a part of the mainstream path of the HTCD HCCI project. These include:

Section 1.1.3.1: $\quad$ Two-stroke HCCI

Section 1.1.3.2: $\quad$ Mixed-mode HCCI operation using the mixed-mode injector

Section 1.1.3.3: $\quad$ Air-assisted, port-fuel injected HCCI for increased homogeneity

Section 1.1.4 details two significant design efforts that were a part of the mainstream path. The Ultimate Flow Head was key to both the HCCI project and the thermal efficiency. The VCR engine design will also be described: 
DOE Final Report

DE-FC05-000R22806

Section 1.1.4.1: $\quad$ Design of the Ultimate Flow Head

Section 1.1.4.2: $\quad$ Design of the Variable Compression Ratio (VCR) C15 engine 


\section{Section 1.1.1: Summary of Design Activities Occurring throughout the 6-Year Program}

The reports begins with a summary of the design and hardware procurement activities occurring throughout the six year HTCD program.

\section{$\underline{\text { Year } 1}$}

In the first year of the program, design or simulation-related tasks were being performed in the following five areas:

1. $\quad$ Engine \& HCCI combustion system for a 4-stroke single-cylinder test engine (3401 SCTE)

2. $\quad$ Engine \& HCCI combustion system for a 2-stroke single-cylinder test engine (3171 SCTE)

3. $\quad$ Mixed-mode fuel injectors with the capability of injecting two different spray patterns.

4. Variable compression ratio mechanisms for the 3401 SCTE

5. Variable intake valve actuation mechanisms for the 3401 SCTE.

The 2-stroke engine was being pursued as an alternative to the 4-stroke because it was recognized that HCCI combustion systems would be challenged to achieve power densities equal to the conventional Diesel engine. The team investigated the 2-stroke concept as a means to resolve the power density issue for HCCI.

Multi-mode injectors were being pursued to investigate the possibility of shifting (either fully or partially) to conventional Diesel combustion at high loads, where a HCCI combustion event is difficult to achieve.

Early on, it was recognized that a variable compression ratio (VCR) system would be beneficial for HCCI. At high engine loads, HCCI prefers a lower compression ratio because it helps to restrain the combustion of the Diesel fuel. At low loads an elevated compression ratio is preferred because it helps with start-ability, combustion stability, hydrocarbons and CO emissions. The initial VCR-related design tasks were focused on coming up with a system for the SCTE.

An intake valve actuation (IVA) mechanism was also being pursued for the SCTE initially. The approach with the IVA mechanism would be to delay intake valve closing and thus lower the effective compression ratio and thus retard the combustion phasing.

Activities related to the development of the 4-stroke HCCI SCTE engine (listed above as item number one) included the following:

- Design and procurement of pistons blanks and bowls of various compression ratios

- $\quad$ HCCI injector tip designs for the HEUI fuel system installed on the 3401 SCTE.

- Design modifications to the cylinder head to accommodate cylinder pressure and heat flux sensors

- $\quad$ Design and fabrication of an exhaust gas system, and

- $\quad$ FEA analysis of the piston concepts

\section{$\underline{\text { Year } 2}$}

In the second year, design activities related to creating enhanced in-cylinder air motion (swirl) in the SCTE began. Ricardo, Inc. was asked to provide additional assistance to increase the swirl levels of the SCTE head beyond 1.5. They came up with designs that would allow for swirl levels 3.0, 4.5 and 6.0 to be tested. The intent was to investigate swirl effects on HCCI. 
DOE Final Report

DE-FC05-000R22806

A concept, known as Regenerative Cylinder Pressure Control (RCPC), was also being investigated during the $2^{\text {nd }}$ year. This concept was viewed as a way to control high peak cylinder pressures or increased rise rates as an alternative to VCR. The idea was to remove gas from the cylinder at peak cylinder pressure conditions by having it flow into a reservoir, then let it return from the reservoir back into the cylinder later during the cycle.

The design of an "ultimate flow head" (UFH) also began in the $2^{\text {nd }}$ year of the program. The goal of this work was to design a cylinder head with improvements to the ports that would improve fuel consumption. The benefits for HCCI resulting from such a head were expected to include: reduced fuel consumption, an extension in high-load capability due to higher peak cylinder pressure capability, and improved cylinder balance.

An air-assisted, port fuel injection system was also pursued in the second year. Caterpillar had contracted Southwest Research Institute Inc. to test such a system on a C15 engine. This was of interest for the HCCI project because it would allow for the possibility of examining a truly homogeneous HCCI mixture, versus the pseudo-homogeneous mixtures obtained via early injection.

\section{$\underline{\text { Year } 3}$}

During the third year, a multi-cylinder C15 HCCI engine was commissioned for testing. Pistons and injector tips were designed, along with a few EGR systems and fuel injector cam profiles.

The design for a variable compression ratio (VCR) multi-cylinder engine also began this year.

\section{Years 4-5}

No major new HCCI specific related design work was initiated during these latter years, although the VCR work continued through until the end of Year 5. An advanced High Pressure Fuel System was started this year of the program and was tested under the HECC program. Advanced air systems were also developed during this time period.

\section{$\underline{\text { Year } 6}$}

The HCCI program was no longer a part of HTCD during Year 6. It was then agreed to be transferred to the HECC program. The HECC program is a cooperative research program between Caterpillar Inc. and the Department of Energy beginning in late 2005 to develop Low Temperature Combustion engine technology with improved fuel economy as compared to today's engines. 
DOE Final Report

DE-FC05-000R22806

\section{Section 1.1.2: HCCI Development: The mainstream path}

Examination of the design work summarized in Section 1.1.1 demonstrates that a number of concepts were investigated to make HCCI successful as a technology for meeting the 2010 emissions standards without NOx aftertreatment and with acceptable fuel consumption. During the five-year HCCI project, several concepts were investigated with varying levels of success.

Through the development HCCI under the HTCD program, a mainstream path was identified. This path emerged through a series of decision points made throughout the program.

This report will present the progress on HCCI by first keeping focus on the engine technologies that emerged to become this mainstream path. This necessitates that any detailed discussions related to the alternate technologies that were investigated but not ultimately chosen will be deferred until a later section. This will allow the reader to better focus on the development of the engine technologies that have become the baseline HCCI engine delivered to the HECC program.

Also deferred until a later section are any design-related details pertaining to this mainstream path. For instance, a significant amount of design effort was spent in creating a variable compression ratio (VCR) engine as part of the mainstream path. This design work will be summarized in a later section so that focus can remain on the progress that has been made in overcoming the obstacles related to the HCCI engine system (combustion and air-system primarily).

The remainder of this section will be presented chronologically except where noted. In a few instances certain testing has been reported out of chronological order to enhance readability. The material is divided into the following six subsections:

Section 1.1.2.1:

Section 1.1.2.2:

Section 1.1.2.3:

Section 1.1.2.4:

Section 1.1.2.5:

Section 1.1.2.6:
Initial HCCI Simulation Results

Single-cylinder test results (up until multi-cylinder testing begins)

Multi-cylinder test results

Single-cylinder demonstration of $100 \%$ load capability

Addressing some other concerns of HCCI

The challenge of high loads for the multi-cylinder engine

\section{Section 1.1.2.1: Initial HCCI Simulation Results:}

Several simulations studies were performed prior to engine testing beginning on the SCTE. In the first study, an internally developed three-dimensional reactive fluid dynamics code, CAT3D, was used to determine the effects of an increased swirl ratio on HCCI combustion. As swirl ratio was increased from 0.5 to 1.5, NO emissions were found to decrease while unburned hydrocarbon emissions (HC) were found to increase. (2001, Q2)

A second study was conducted using the internally developed one-dimensional thermodynamic engine simulation code ("973") to investigate methods of obtaining efficiency improvements for HCCI operation. Geometric compression ratio changes, late-intake valve closing (Miller cycle) and cooled EGR were examined. Figure 1.1.2.1.1 shows the impact of compression ratio on BSFC for standard combustion, HCCI combustion (assuming a 10 degree heat release duration), Miller cycle with HCCI, and HCCI with a lower cetane number fuel. The analysis suggests that for HCCI, efficiency gets better at lower compression ratios. This was attributed to the fact that at lower compression ratios, the combustion phasing is not as overadvanced. The low cetane number fuel is also more efficient than the Diesel fuel at these conditions for the 
DOE Final Report

DE-FC05-000R22806

same reason. This data highlights an important difference between conventional Diesel operation and HCCI operation: For HCCI, because the choice of compression ratio can effect the combustion phasing in addition to the thermodynamic efficiency, an increase in compression ratio is not beneficial unless the burn can be prevented from over-advancing by some other means. (2001, Q3)

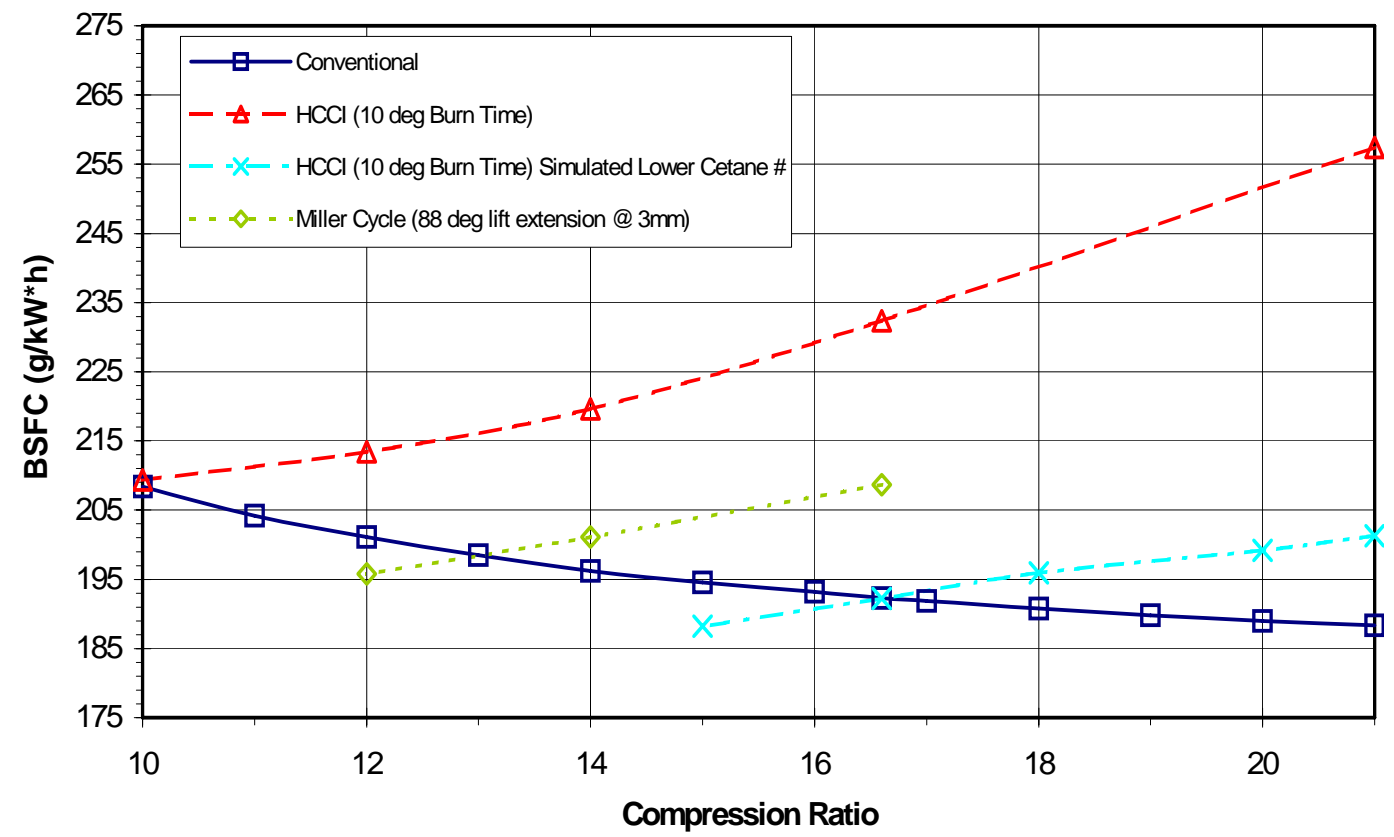

Figure 1.1.2.1.1: Modeled BSFC for Various Combustion Modes at Different Compression Ratios (1500 rpm, 1050kPa bmep)

A third simulation study was performed to better understand what limits the maximum operating load of an HCCI combustion system. For the simulation, the following limits were imposed: maximum peak cylinder pressure (PCP) of $17 \mathrm{MPa}$, maximum rate of cylinder pressure rise ("rise rate") of $2 \mathrm{MPa} / \mathrm{deg}$, maximum equivalence ratio of 0.3 (for system with no EGR) and a maximum boost pressure of $300 \mathrm{kPa}$ absolute. Figure 1.1.2.1.2 illustrates which limit arises first. Note that the pressure rise rate was found to be the most limiting factor. The data suggests that to improve the power density, a solution to the rise rates must first be found (e.g. cooled EGR). But it also shows that other limits like the air-system limitation and PCP limitation are also near. To achieve the power density desired, all of these limits must be addressed and their limits increased. The data also illustrates that dropping compression ratio is an effective way to extend operation beyond the rise-rate and PCP limits. This is one reason for the interest in variable compression ratio (VCR) systems. (2001, Q3) 


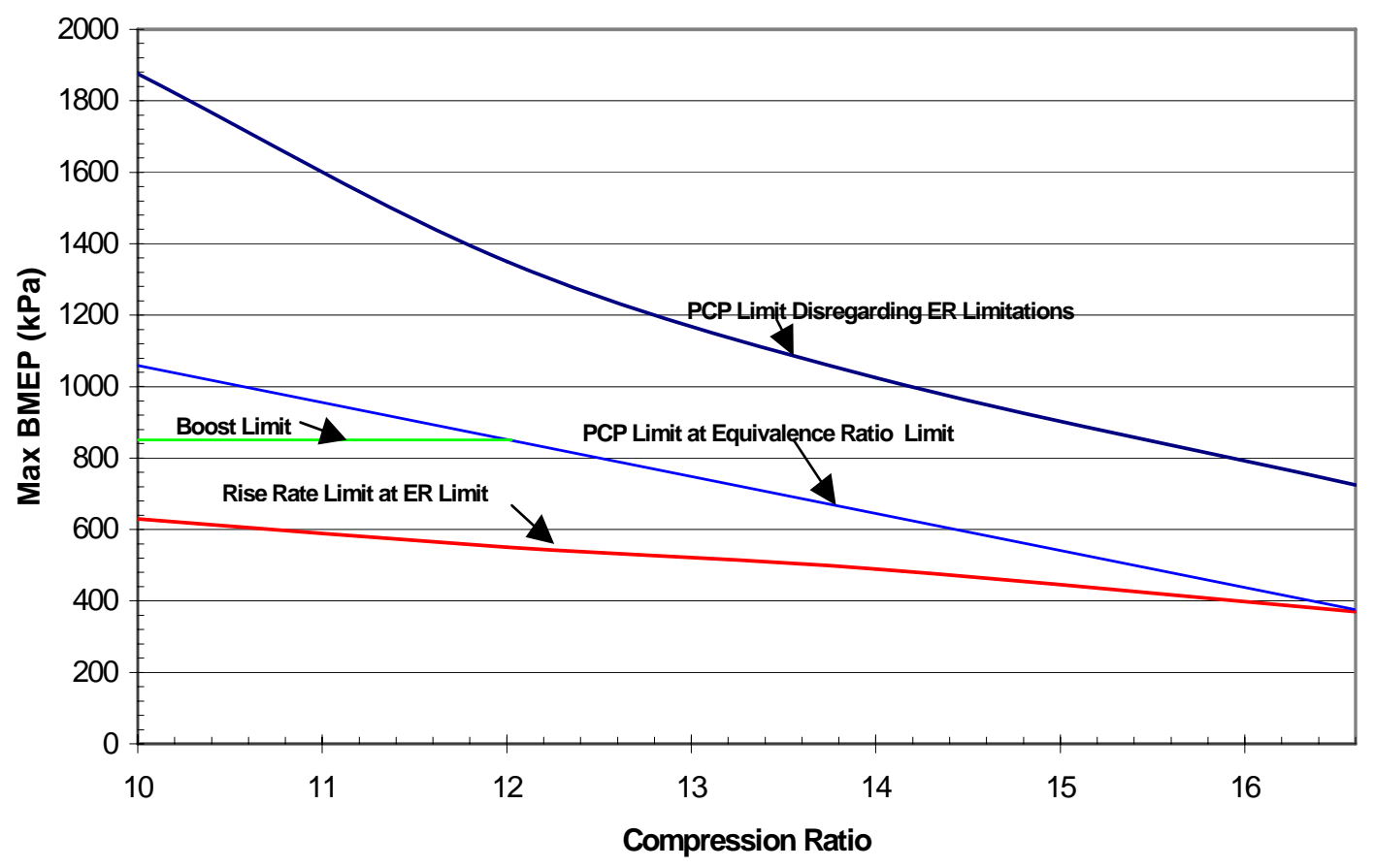

Figure 1.1.2.1.2: Max BMEP for 3401 SCTE (Based on PCP=17Mpa, Max Rate Cyl Pressure Rise= $2 \mathrm{Mpa} / \mathrm{deg}$ and Equivalence Ratio=0.3, Max Boost $=300 \mathrm{kPa}-\mathrm{a})$

\section{Section 1.1.2.2: Single cylinder test results (prior to multi-cylinder testing)}

The single cylinder HCCI engine was commissioned about one year into the program. Initially, six injector tips were designed for the HEUI injectors used for the 3401 SCTE. The details of these tips are included in the EPACT protected version. Other injector tips soon followed. Initial piston designs with compression ratios of 14,12 and 10 , were also procured.

Initial testing was performed at the 10:1 compression ratio with the tip listed in the EPACT protected section. The purpose of this testing was to obtain a more detailed understanding of combustion phasing with HCCI. Figure 1.1.2.2.1 illustrates what happens as intake temperature is increased. Combustion phasing was found to advance to the point of being over-advanced, but fuel consumption continued to be improved greatly. This was because combustion efficiency was very poor at the more retarded timings for this particular combustion system. One goal of the combustion system refinement would be to improve this combustion efficiency. Initial emissions results are listed in the EPACT protected appendix (2001, Q4) 


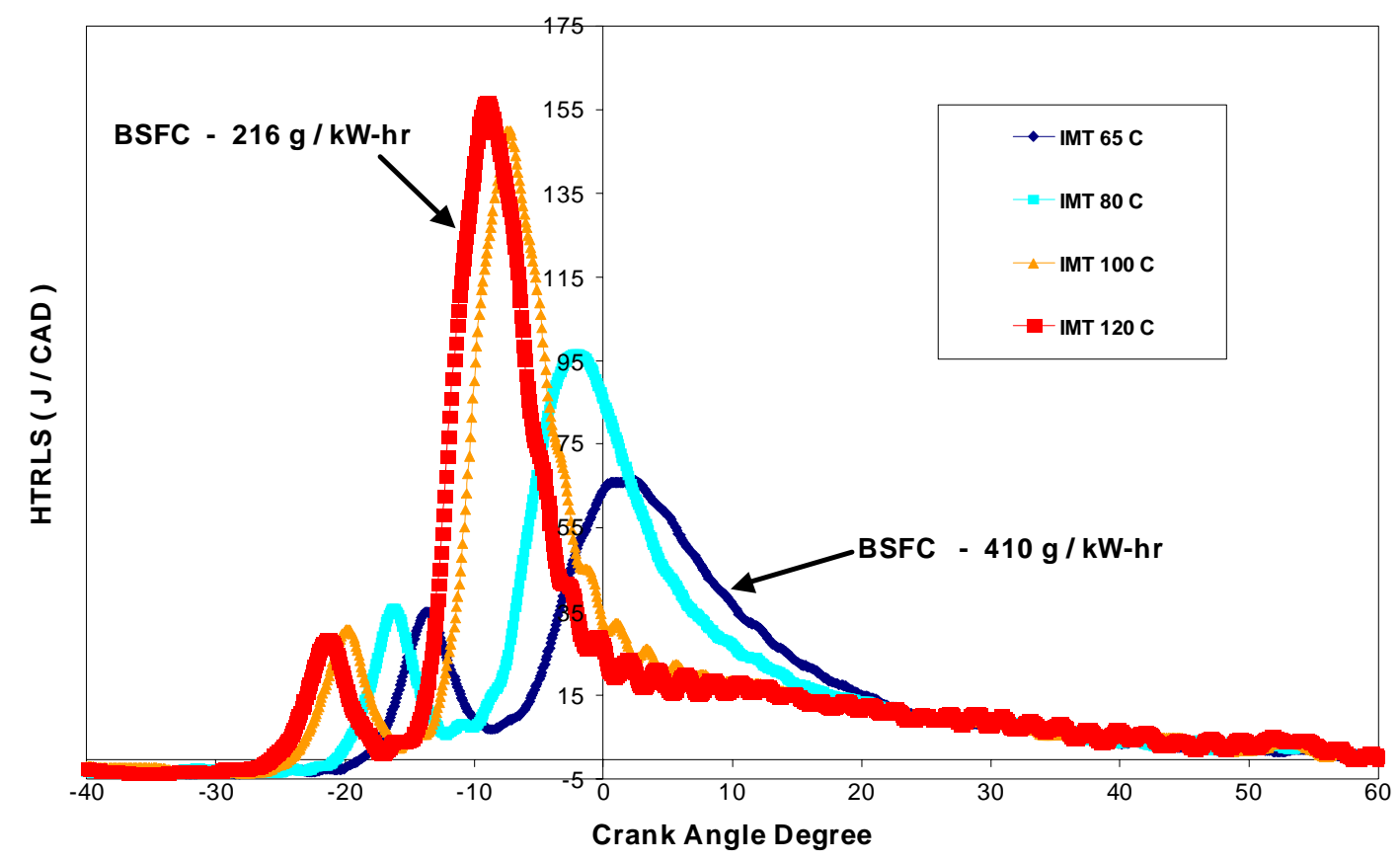

Figure 1.1.2.2.1: The effect of Combustion Phasing on BSFC from the 34014 stroke engine.

Testing next moved to the showerhead nozzle designs which showed promising emissions results when tested earlier on another engine platform. Two showerhead designs were initially tested: Details are in the EPACT protected appendix. (2002, Q1)

A compression ratio study was performed next to examine its effect on BSFC and engine load capability. Three compression ratios were examined: 16.6, 12, and 10. All of this work was with Diesel fuel and without EGR. For the 16.6:1 CR piston, high peak cylinder pressure and cylinder pressure rise rates limited operation to below $25 \%$ load. In addition, the BSFC with the high compression ratio piston was poor due to over-advanced combustion phasing. For the 12:1 CR piston, the engine operating range was increased to 33\% load before reaching the peak cylinder pressure or cylinder pressure rise rate limit. For the 12:1 CR piston, the BSFC was within 5\% of the production engines. For the 10:1 CR piston, the engine operating range was extended to $50 \%$ load which was significantly above any published data at the time. The emissions level achieved at $1200 \mathrm{rpm}$ and 50\% load were $0.22 \mathrm{~g} / \mathrm{hp}-\mathrm{hr}$ NOx and low smoke. At 50\% load, the BSFC was only within $10 \%$ of the production engines. This data illustrates the impact that compression ratio can have for load capability and highlights the motivation for looking into variable compression ratio engine systems (2002, Q1)

The effect of late-intake valve closing (LIVC) on combustion phasing was also explored at this time. A variable valve actuation system was used to delay the intake valve closing event. Specifically, for that delayed period the valve was being held open at $4 \mathrm{~mm}$ lift. The use of LIVC resulted in a retard of the peak rate of heat release by 7 degrees, pushing it from $12^{\circ}$ BTDC to $5^{\circ}$ BTDC. This retarding of the burn was attributed to the lower temperatures during the compression stroke that came about from the drop in effective compression ratio. These tests illustrated the ability of intake valve actuation (IVA) to control combustion phasing. Preliminary testing indicated that changing the effective compression ratio with IVA was less effective at controlling rise rates than changing the geometric compression ratio seemed to be. (2002, Q1) 
DOE Final Report

DE-FC05-000R22806

Additional SCTE testing was performed at the 10:1 compression ratio which allowed for higher load HCCI to be attained. Timing sweeps at 1200 and $1500 \mathrm{rpm}, 520$ and $800 \mathrm{kPa}$ BMEP were conducted to determine the minimum timing advance required to achieve ultra-low NOx. Also, a number of injector tip designs were investigated at this time. These tips are listed in the EPACT protected appendix. An additional injector tip geometry was tested. With this injector, the engine was able to demonstrate $1600 \mathrm{kPa}$ BMEP (75\% load) with 2010 compliant NOx emissions. It was reported that this load was the highest load achieved with HCCI combustion known to have been achieved anywhere in the world. It was also noted that several significant challenges remain to make this technology production viable. Also, the smoke emissions were not low enough to not require a DPF. (2002, Q2-Q3)

Additional testing was concentrated on understanding the effects of exhaust gas recirculation (EGR) and A/F ratio on emissions and performance with HCCI. Engine efficiency was improved by optimizing EGR rates and boost pressures at B25, B50, and B75 to yield 233, 217, and $215 \mathrm{~g} / \mathrm{kW}$-hr multi-cylinder equivalent BSFC respectively. This was achieved while maintaining the ultra-low engine-out emissions. (2002, Q3)

After successfully demonstrating $3 / 4$ load with HCCI combustion, plans were in place to characterize the mainstream injector in the spray visualization lab to better understand its characteristics. Focus in the test cell then shifted towards the control of combustion phasing. It was realized that getting the combustion phasing to occur at favorable crank angles over the entire operating region would be a significant challenge.

Approximately 480 data points were taken at various operating conditions (ranging from 1200-1800 rpm and from 500-1500 kPa IMEP) to study the effects of EGR percent, injection timing, boost, back-pressure, air-fuel ratio, fuel pressure and IVA position on combustion phasing. This data was then used for two purposes.

First, it was used to understand how each of the various control parameters can influence combustion phasing and the resulting HCCI performance and emissions. Optimization of these control parameters has led to many ultra-low NOx emissions points with acceptable smoke. Thermal efficiency numbers were also reported to be encouraging, and it was mentioned that HC, CO and rise rates were acceptable at many conditions as well. This data has been summarized in Figure 1.1.2.2.2.

(2002, Q4) 
DOE Final Report

DE-FC05-000R22806
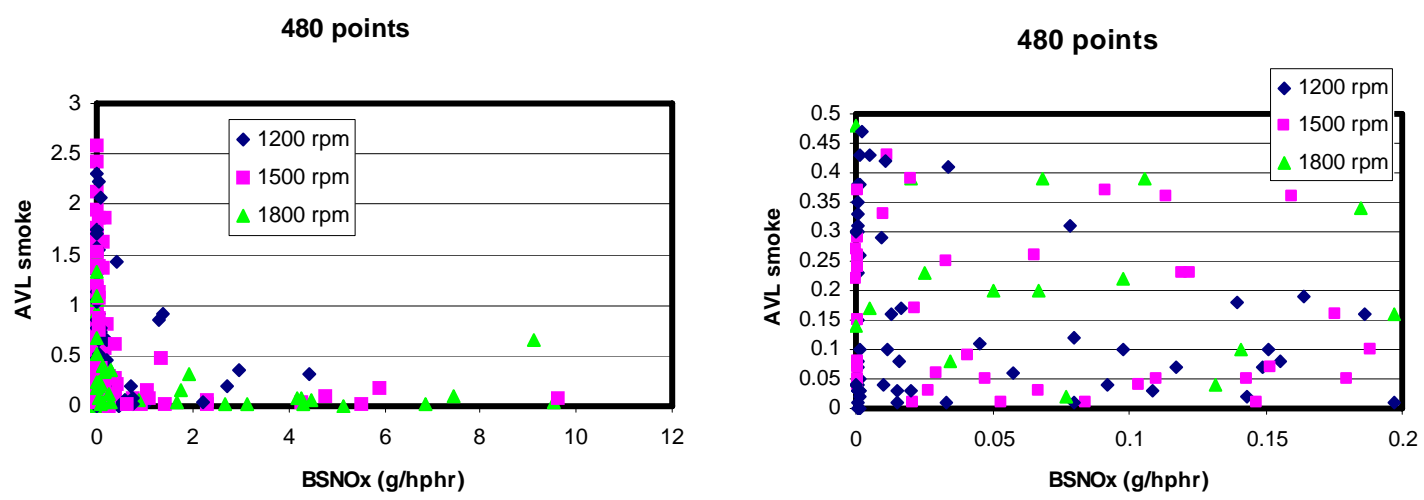

$\mathrm{HCCl}$ Data

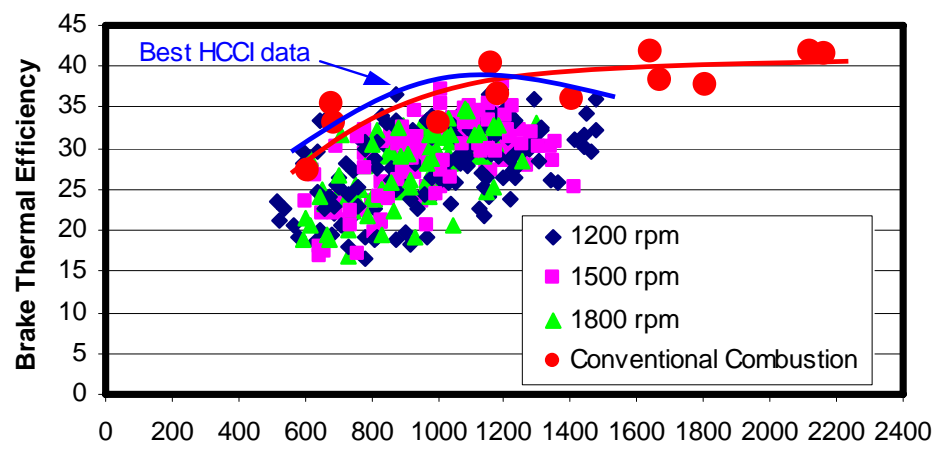

IMEP,g (kPa)

Figure 1.1.2.2.2: HCCI Control system Mapping Test Results

The data was also used to develop a neural network model of combustion phasing as a function of the various control parameters. Such a model would likely be required for feed-forward combustion phasing control. The data was sent to IAV Inc. and a neural network model was developed. It was found that while the engine outputs are modeled very well using just the engine control, the addition of in-cylinder pressure-derived parameters improves the predictions. (2003, Q2)

At this point of the project, testing on the multi-cylinder engine was beginning to ramp up.

\section{Section 1.1.2.3: Multi-cylinder test results}

HCCI injector tips were created for the MEUI-A fuel system of the C15. One set of tips was designed to replicate the showerhead nozzles that proved to be effective on the SCTE. The spray geometries of the tips were also designed with a specific injection timing in mind. These timings are listed in the EPACT protected section. There was a desire to investigate later injection timings as a means to improve fuel consumption, CO and hydrocarbons. The C15 being used for multi-cylinder HCCI testing was also equipped with a lowpressure loop (LPL) CGI (Clean Gas Induction) system, a special cam with HCCI injection lobes for the MEUI-A fuel system, a piston with a compression ratio of 12:1, and a DPF. Initial test work was aimed at improving combustion efficiency, expanding the operating range of HCCI and evaluating air-system enhancements needed to improve system performance. Further details are included in the EPACT protected section. (2003, Q1-Q2) 
DOE Final Report

DE-FC05-000R22806

Part load performance and emissions data were taken for two different showerhead nozzle configurations. The second set of tips allows for more retarded injection timings. This in turn resulted in lower HC and CO levels, and thus an improved combustion efficiency and lower fuel consumption. These results are shown in the EPACT protected version. During this initial testing, approximately 300 data points were taken spanning 1200-1800 rpm and reaching up to approximately $1 / 2$ load. The air flow match with the installed turbocharging system limited the maximum achievable power to $1 / 2$ load. Beyond $1 / 2$ load, the smoke levels increased to unacceptable levels. Stable idle operation was also achieved using HCCI combustion during this time period, and the ability of IVA to improve the cylinder balance with regard to combustion phasing was also demonstrated. (2003, Q2)

A MEUI-C fuel system with increased pressure and rate flexibility was installed on the HCCI C15 to test the effects of higher injection pressures for HCCI. The testing revealed that the elevated injection pressures of the MEUI-C fuel system enabled lower smoke levels at equivalent power. This in turn allowed the engine load range (during the testing, defined as the load at which AVL smoke exceeds 1.0) to be increased by approximately $200 \mathrm{kPa}$, which is shown in Figure 1.1.2.3.1. (2003, Q3)

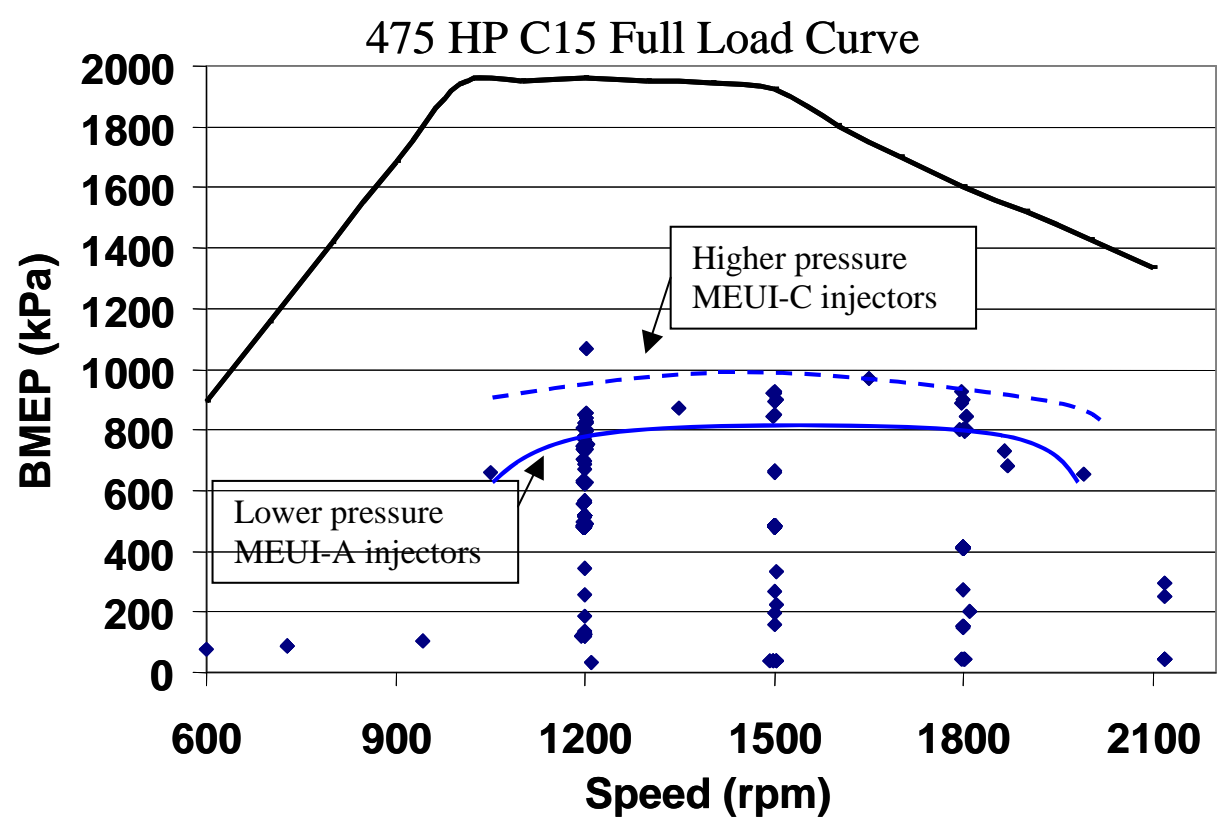

Figure 1.1.2.3.1: HCCI performance with the higher injection pressures allowed by the MEUI-C fuel system.

Several air-system modifications were made and several nozzle tips examined in an attempt to increase the load range of the multi-cylinder engine. A single variable geometry turbo was installed, as well as a VGT in series with a conventional low-pressure turbo. Slight increases in maximum load were achieved ( $\sim 50 \mathrm{kPa}$ BMEP) with the single VGT, but this benefit was offset by a fuel consumption penalty associated with the 15 $\mathrm{kPa}$ additional backpressure needed to drive the boost. The tests with the VGT in series with the conventional turbo produced similar results. (2003, Q4)

A demonstration of load capability was performed with several nozzle configurations. Details are provided in the EPACT protected version. The VGT was on the engine for these tests and located in series with one of several different low-pressure turbochargers. The injection timing, EGR rate, and the boost levels determined 
DOE Final Report

DE-FC05-000R22806

on the SCTE were repeated on the multi-cylinder engine (the VGT vane position was adjusted to achieve the desired boost) and the results appeared to scale well between the single and multi-cylinder platforms. Approximately $60 \%$ load was achieved at three speeds on the multi-cylinder engine before the smoke limit of 1.0 AVL came into effect. This load capability agreed well with the SCTE data obtained at the same compression ratio. At this time, the multi-cylinder engine was running with a 12:1 CR. (2004, Q1)

During the multi cylinder testing, the SCTE engine was continued as a research tool.

\section{Section 1.1.2.4: Single-cylinder demonstration of $100 \%$ load capability}

Full load operation was achieved on the SCTE at three engine speeds with a compression ratio of 8:1. This data is shown in Figure 1.1.2.4.1. At 1800 rpm, a multi-cylinder equivalent power level of over $600 \mathrm{HP}$ was achieved (2020 kPa BMEP). The performance and emissions values were: $\mathrm{NOx}=0.05 \mathrm{~g} / \mathrm{hphr}, \mathrm{HC}=0.4$ $\mathrm{g} / \mathrm{hphr}$ (no oxicat), $\mathrm{CO}=9.7 \mathrm{~g} / \mathrm{hphr}$, AVL smoke $=0.64$. BSFC was within $3.5 \%$ of then current production using boost levels that were within the range of current series turbo capabilities. An Elevated level of EGR was used as a diluent. The cylinder pressure was maintained within the production limits and the exhaust gas temperatures were much lower than with conventional Diesel operation. This demonstration was at the highest power level known in the world to be run using diesel fuel (or any fuel) in an HCCI engine. (2004, Q1)

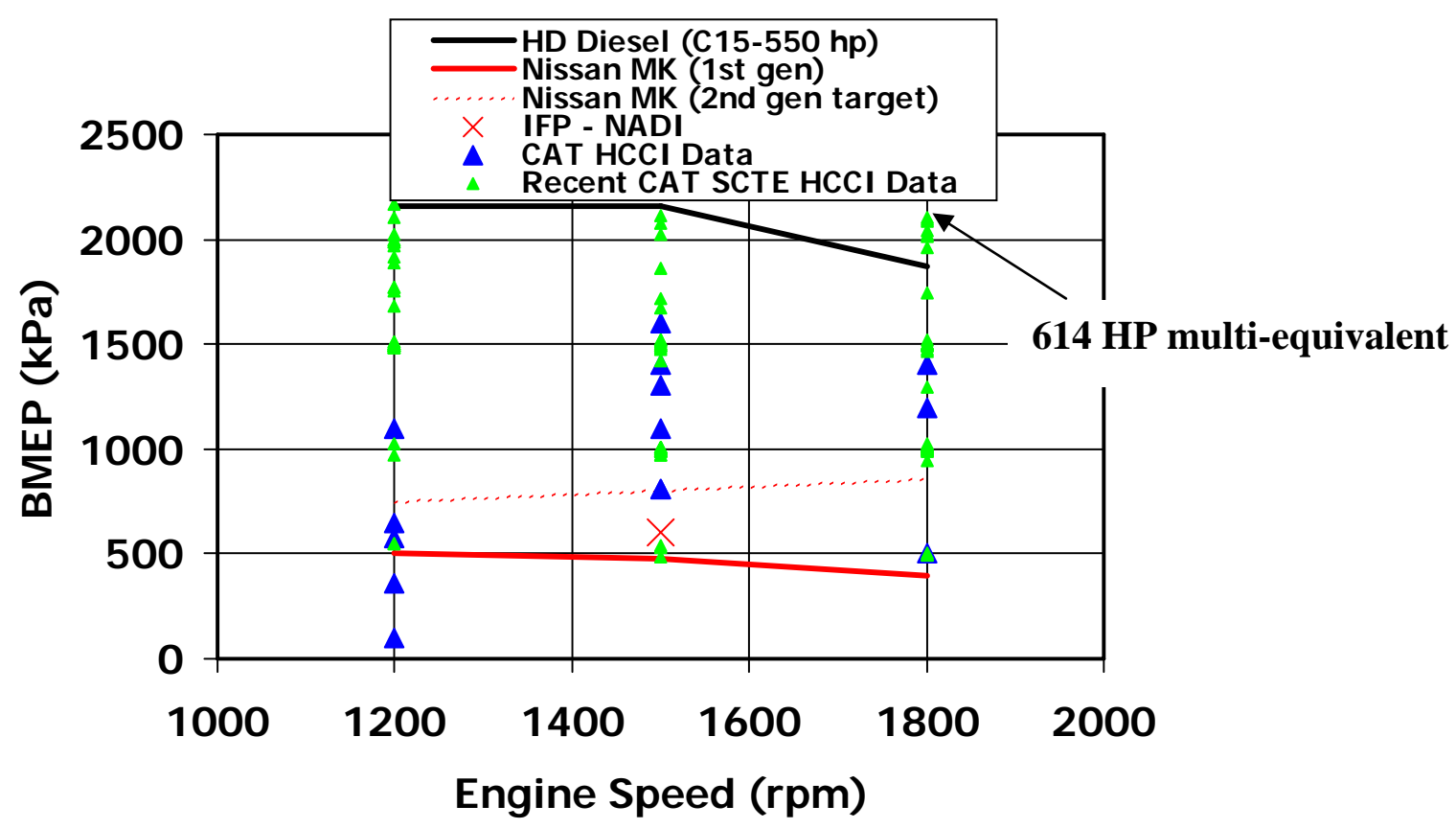

Figure 1.1.2.4.1: Demonstration of full load capability on the SCTE engine.

To better understand the air system requirements for multi-cylinder HCCI combustion, additional single cylinder tests were completed to evaluate different boost/back pressure levels. The objective was to determine the lowest possible boost level that yielded acceptable HCCI results. Tests were conducted at $1 / 4$, $1 / 2,3 / 4$ and full loads at 1200, 1500 and $1800 \mathrm{rpm}$ each. The results suggested that a series turbo configuration (with VGT as one stage) should be able to handle the boost requirements provided that IVA (late intake valve closing) is not used. The maximum pressure ratio needed from the SCTE data was approximately 4.3:1 (see Figure 1.1.2.4.2) and is fairly speed independent. However, these SCTE tests were not run with the exact inlet and exhaust restrictions since the DPF delta was unknown and the inlet restriction is different on the low 
DOE Final Report

DE-FC05-000R22806

pressure loop CGI system of the multi-cylinder engine versus the high pressure loop EGR system of the SCTE. These additional pressure deltas would likely lead to a pressure ratio greater than 5 which is currently outside of the capability of the current series turbo hardware. (2004, Q1)

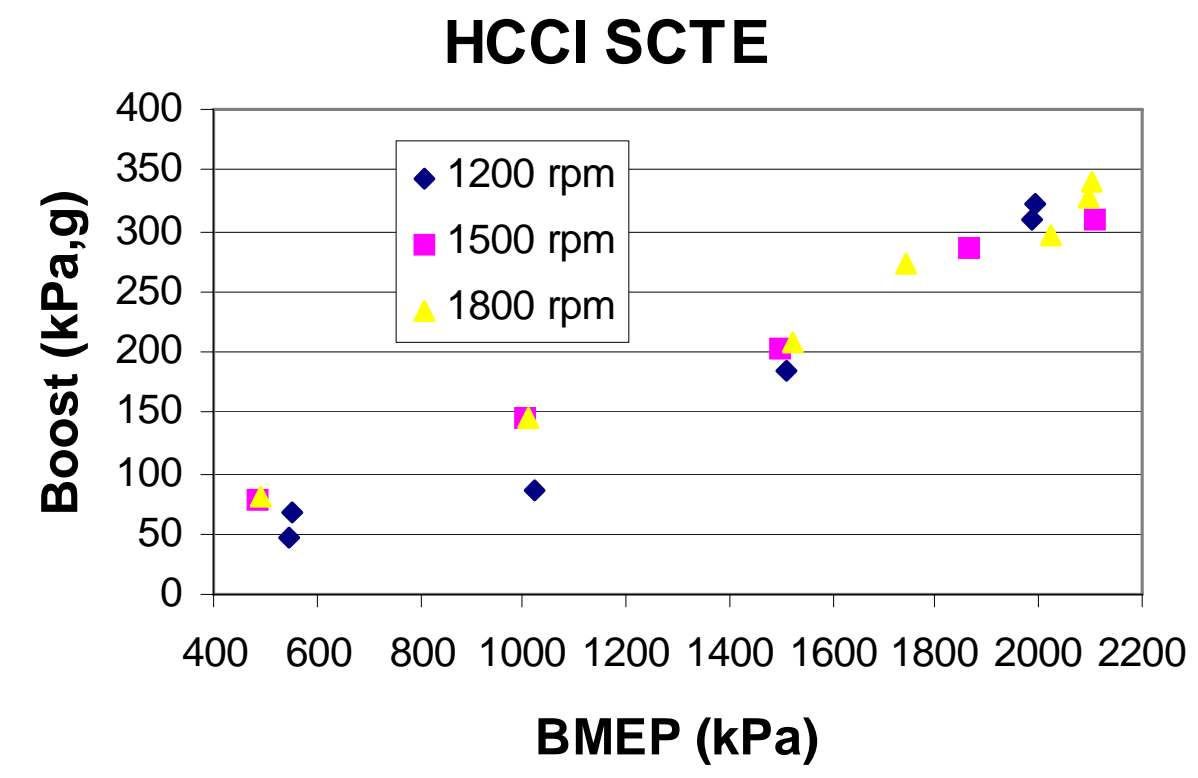

Figure 1.1.2.4.2: Required boost levels at different operating conditions.

\section{Section 1.1.2.5: Addressing some remaining concerns of HCCI}

After the successful demonstration of $100 \%$ load capability on the SCTE, attention was then focused on resolving some of the remaining challenges of HCCI. One of these challenges would be to recreate the success of the SCTE on the multi-cylinder engine (which at the time was only at $60 \%$ load capability). This meant either finding an air system that was capable of producing the boost levels of the SCTE combustion system that were detailed in Figure 1.1.2.4.2, or finding a way to reduce the pressure ratio requirements of the combustion system. Development on the multi-cylinder engine continued during this time period, and simulation was used as well to address this challenge. The simulation work performed related to this and the continued multi-cylinder engine development work will be presented in the section after this.

Below, some of the work done to address some of the other remaining concerns of HCCI will be detailed. These challenges included dealing with the hydrocarbon emissions, dealing with heat rejection and finding low-cost sensors to be used for combustion feedback control.

\section{Heat rejection}

Several studies were performed to examine and attempt to reduce the heat rejection loads associated with HCCI. The high levels of cooled EGR being used added to the heat load needing to be rejected, but it was 
also thought that processes occurring in-cylinder, unique to HCCI, combustion further contributed to the elevated heat loads.

One such study involved investigating the use of a water injection system to lessen the need for EGR (which in turn would reduce the heat rejection). The approach was that water vapor could be used in place of EGR for NOx control. For these tests, water was misted into the intake manifold. Data was taken at $1200 \mathrm{rpm}$ at one quarter, one third, and one half load, and at $1800 \mathrm{rpm}$ at quarter load and half load. Several discoveries were made. It was found that water injection was not as effective at reducing NOx as EGR was. It appeared that at moderate levels of EGR, adding water to the intake could reduce NOx significantly, but as the EGR percent was lowered the amount of water needed to maintain a $0.2 \mathrm{~g} / \mathrm{hp} / \mathrm{hr}$ NOx level increased drastically. The limits of the test setup only allowed a $2 \mathrm{X}$ water-to-fuel ratio at the $1200 \mathrm{rpm}$ quarter load and one third load points due to flow capabilities. At both of these conditions, a 25-30\% decrease in the amount of EGR needed was accomplished while maintaining a $0.2 \mathrm{~g} / \mathrm{hp} / \mathrm{hr}$ NOx level. At the $1800 \mathrm{rpm}$ points, the hardware had a difficult time maintaining flow. Limited data was acquired at these points but it generally agreed with the other data acquired. The conclusions from this testing at multiple operating conditions is that a $2 \mathrm{X}$ waterto-fuel ratio was able to reduce the amount of EGR needed by approximately 33\% and still maintain NOx at $0.2 \mathrm{~g} / \mathrm{hp}$-hr. It was also reported that water may be useful to augment a minimum level of EGR at engine conditions where higher NOx levels would normally be encountered. (2004, Q2)

Another study aimed to quantify the in-cylinder heat transfer differences between HCCI combustion and conventional Diesel combustion. This testing was accomplished with a cylinder liner instrumented with 20 thermocouples and a heat flux probe installed in the cylinder head. The heat flux data is shown in Figure 1.1.2.5.2. The data indicated that for both HCCI and conventional diesel combustion, the peak heat flux increased with advancement of the start of combustion. However, the peak heat flux for the HCCI combustion was approximately 2-3 times higher than for the conventional Diesel combustion. The cylinder liner temperatures, on the other hand, remained relatively constant between the two combustion types. One theory to explain these results is that the rapid rates of energy release associated with HCCI may enhance the convective coefficient and thus the heat transfer. (2004, Q4)

\section{Heat flux vs combustion phasing}

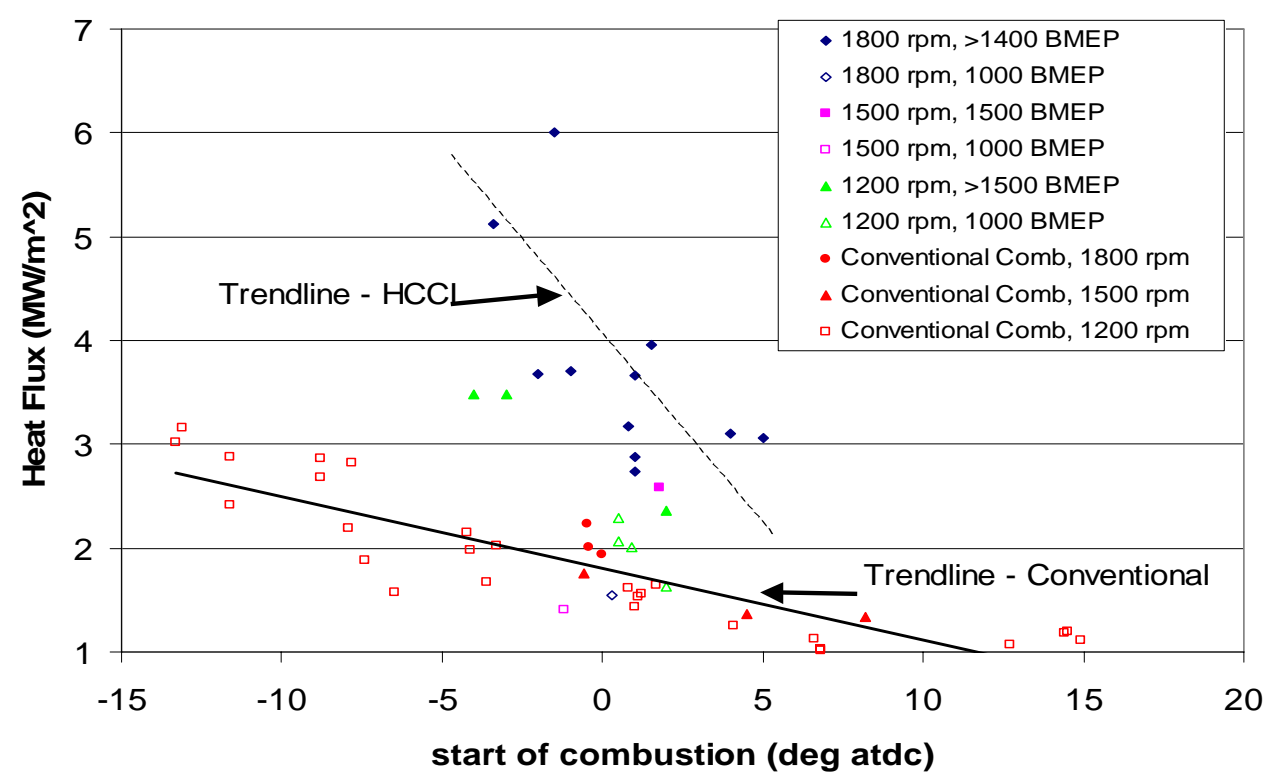


Figure 1.1.2.5.2: Peak heat flux comparison between HCCI and “conventional” diesel combustion.

A simulation study was also performed to investigate the possibility of using IVA in place of EGR in an attempt to reduce the heat rejection associated with the EGR. Simulated EGR sweeps were performed at $1500 \mathrm{rpm}$ for a condition with IVA being used and a condition with no IVA being used. Combustion phasing, pressure ratio requirement and the heat rejection attributed to the aftercooler and EGR cooler were computed. The results can be found in Figure 1.1.2.5.3. The results quantify the amount of EGR reduction possible (while maintaining the same combustion phasing) by using more IVA. The two yellow data points in the figure have this common combustion phasing. The results indicated that, on average, a 5-10\% reduction in EGR percent could be achieved by using IVA while maintaining the same combustion phasing. This was worth a $0.06 \mathrm{~kW} / \mathrm{kW}$ reduction in heat rejection, but came at the expense of a 0.7 increase in the pressure ratio requirement. The implication of the elevated pressure ratio requirement is that it would be more difficult to find an air-system capable of achieving full-load capability on the multi-cylinder engine. (2004, Q4) 

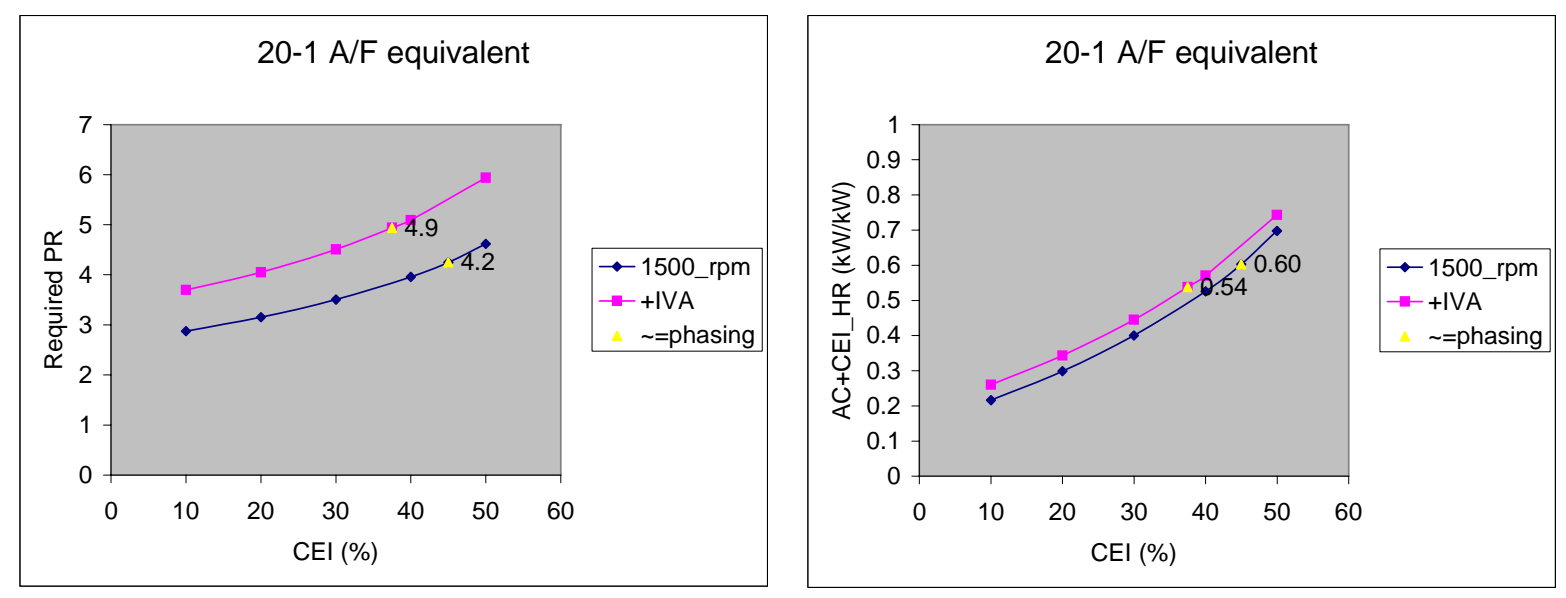

Figure 1.1.2.5.3: Effect of inlet valve actuation and CEI\% on required pressure ratio and heat rejection.

Simulations were also performed to analyze the HCCI heat load distribution. In this study it was found that CGI cooling accounted for about $25 \%$ of the heat load, inter-cooling and after-cooling for about $28 \%$, and jacket water cooling for about 48\%. (2005, Q2)

Additional simulations were performed related to the effects of head design changes on block heat rejection (2004, Q4), piston coatings (2005, Q1), and a selective cooling concept (2005, Q3)

\section{Low-cost sensors for combustion feedback}

The use of an ion sensor to detect the combustion event in place of cylinder pressure transducers was investigated during the program. The first tests were without much success, but during the $3^{\text {rd }}$ attempt, a configuration provided by Woodward Inc. provided "excellent" (>95\%) combustion tracking. Due to the success of that testing, testing of the ion sensors expanded into the multi-cylinder engine. There, the results were considered encouraging as well. While the system did not appear to be robust in its current state of development, it was thought that with some further testing of the ion sensor locations and lengths of the ion sensor probe, a more robust signal could hopefully be acquired.. (2005, Q1-Q2)

Low-cost pressure transducers were also investigated. A Texas Instruments prototype sensor was evaluated on the SCTE simultaneously with a lab grade Kistler sensor for comparison. Initial results indicated that the sensor might be accurate enough to act as a feedback sensor for HCCI controls. Further evaluation of this sensor was planned under the HECC program. (2004, Q4)

\section{Section 1.1.2.6: The challenge of high loads for the multi-cylinder engine}

This remaining section details the work done in an attempt to recreate the high-load success of the SCTE on the multi-cylinder engine (which was at $60 \%$ load capability when the SCTE demonstrated 100\%). This meant either selecting or developing an air system that was capable of producing the boost levels required by the SCTE combustion system or finding a way to reduce the pressure ratio requirements of the combustion 
system. Development on the multi-cylinder engine continued during this time period and simulation was used as well to address this challenge.

Simulation:

Simulations were performed to identify air systems that would be capable of meeting the pressure ratio requirements determined during the single cylinder engine testing. Over 40 air system combinations were identified and then down selected using a Pugh analysis. The smaller subset of 10 were then further analyzed in simulation as potential multi-cylinder systems capable of meeting the flow, pressure ratio, cost and efficiency goals.

Series turbo concepts with varying efficiencies and work splits were explored using different combinations of heat exchangers and camshafts. Early exhaust valve opening (EVO) was explored as a way to increase the exhaust enthalpy available to the turbines. Advanced air systems such as superchargers and assisted turbochargers were looked at as well, since using shaft or electric power to provide or supplement boost will improve the boost-to-backpressure ratio. All of these concepts listed were evaluated for low-pressure-loop CGI systems. Also, an axial LP turbine design was also simulated because it was thought to be a good solution for meeting the pressure-ratio requirements. (2004, Q2-Q4)

Additional analysis was performed to determine the optimum trade-off between low pressure loop (LPL) CGI and high pressure loop (HPL) CGI. An LPL system and an HPL+LPL system are shown in the EPACT protected Appendix. A combined (HPL+LPL) system was found to be best, with a 75/25 HPL/LPL split providing the most benefit. Most of the BSFC improvement was found to come from reducing the turbocharger compressor work, which in turn reduced the backpressure on the engine. Some additional benefit was attributed to the lower throttling losses associated with LPL CGI. A full duct model for the HPL+LPL system was then created and debugged to be used for a more in-depth analysis of that setup. (2004, Q4)

A parallel turbo HCCI air system was also analyzed for both the 100\% LPL and 50/50 HPL+LPL systems. The compressor was reasonable for the 100\% LPL system, but the turbine would have had to run fully closed even at the rated operating point. For the 50/50 system, the turbine was oversize. (2004, Q4)

A high efficiency turbocharger was also evaluated as a possible LP stage turbo and as a single-stage turbo. As an LP turbo, the resulting compressor pressure ratio was below target. As a single stage, the turbine was not well matched to be able to effectively drive the compressors. (2004, Q4)

Investigations of supercharging for the 100\% LPL and 50/50 HPL+LPL systems were also performed. A supercharger large enough to handle the 100\% LPL flow rates was not identified. Supercharging offers the potential to reduce backpressure which can lower the residual fraction and thus improve combustion phasing control. For the HPL+LPL system, the benefit of supercharging is largely forfeited because of the backpressure required to drive the high-pressure loop EGR. (2004, Q4)

In addition, analysis of a scaled axial LP turbine flow and re-matched HP turbo based on a preliminary turbine map (increased part load flow capacity of axial wheel relative to a radial design) was performed. The resulting average overall turbo efficiency is 3-8\% higher at $50-100 \%$ load at higher boost-to-backpressure by simulation. See Figure 1.1.2.6.1. (2005, Q1) 

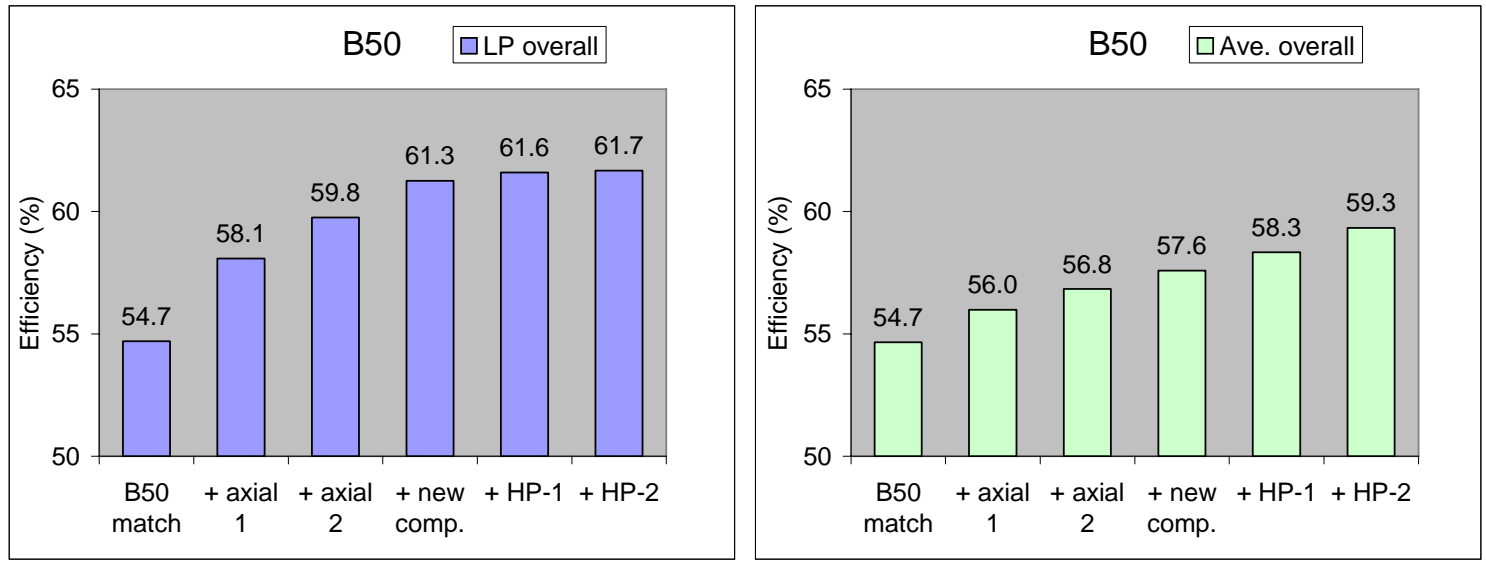

Figure 1.1.2.6.1: Analysis of axial LP turbo

\section{Continued Multi-cylinder testing:}

Around the time when the SCTE demonstrated 100\% load capability with its 8:1 compression ratio piston, the MCTE had demonstrated 60\% load capability with a 12:1 compression ratio piston and a VGT that was being used to provide additional boost at the expense of an elevated backpressure and fuel consumption. The engine was configured with a low-pressure-loop CGI system for this demonstration.

At this point, several air system modifications were made in an attempt to achieve the boost levels needed, but at a more optimum boost-to-backpressure ratio. Parallel turbocharging was investigated as part of this initiative and demonstrated very good boost to back pressure conditions. A 79\% turbine efficiency and a 77\% compressor efficiency was achieved for an overall turbo efficiency of 58\%. With this system, $400 \mathrm{HP}$ at 1950 rpm was demonstrated. During this demonstration, the emissions levels were near the regulations and the rise rates were slightly above the development targets. (2004, Q2)

The engine was then configured with 9.2:1 compression ratio pistons to explore HCCI operation at the low compression ratios that would be achievable with a VCR engine. Starting the engine at this compression ratio was difficult, but was achieved with the combination of an inlet air heater and a VGT. The VCR engine was intended to provide robust cold-starting by running at 18:1 compression ratios, yet would also permit high load operation by running at low compression ratios such as 9.2:1 to keep the burns retarded and rise rates under control, without requiring the excessive use of EGR which was known to penalize air-fuel ratio. From this testing, it was determined that operation below 25\% load was difficult at 9.2:1 compression ratio due primarily to cylinder-to-cylinder balancing. The ultimate flow head would be able to help in improving the cylinder balance for HCCI. All of the HCCI testing done in this configuration was done with a series turbo arrangement. (2004, Q3)

The C15 multi-cylinder engine was then reconfigured back to the original CR with a parallel turbo arrangement with a scaled compressor wheel. Due to a compressor wheel problem this engine setup could not be fully tested. (2004, Q4)

The engine was then configured with a HPL CGI system and work was done to resize an air system to match this HPL configuration. The engine configured with an LPL + HPL CGI system gave the best performance. 
DOE Final Report

DE-FC05-000R22806

At 1200 and 1500 rpm, 65\% load was achieved. At 1800 rpm, 75\% load was attained. The only limitation at these conditions was rise rates, but it was thought that VCR and IVA could be used to address that concern. The measured BSFC was also very competitive for the new combined EGR system. (2004, Q4)

The air-system was again re-sized to match the LPL + HPL CGI system for performance. At this point, 70\% load had been achieved at 1200 and $1500 \mathrm{rpm}$ and 90\% load had been achieved at $1800 \mathrm{rpm}$. The progress made on extending the load capability for the multi-cylinder engine is shown in Figure 1.1.2.6.1.

(2005, Q1)

\section{HCCI Power Density History}

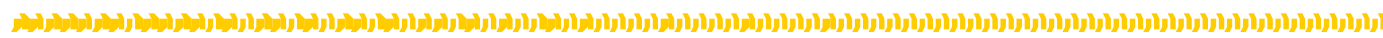

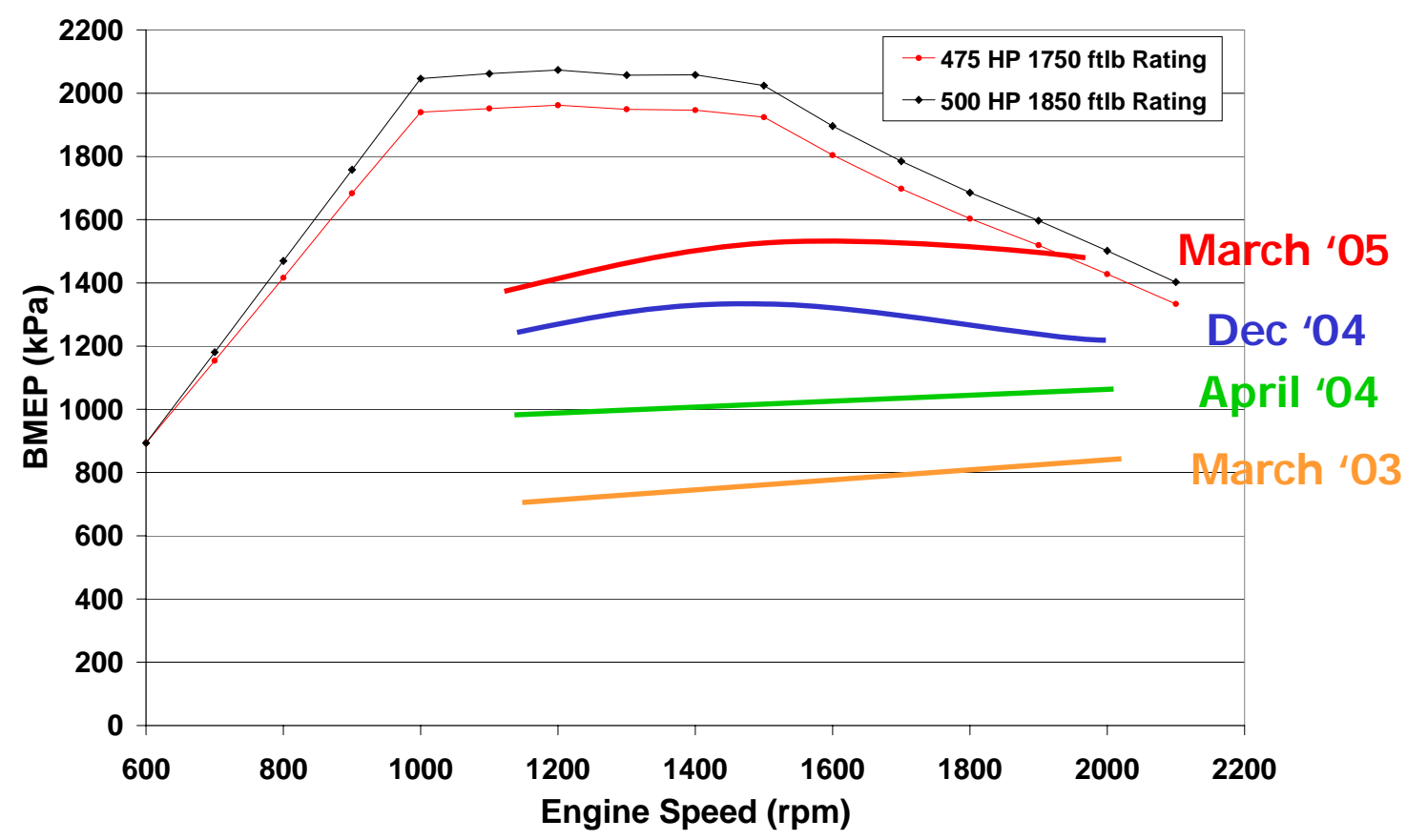

CATERPILLAR

Caterpillar Engine Research

Diesel \& EmissionsTechnology

Figure 1.1.2.6.1: The progress made on extending the load capability of the multi-cylinder HCCI engine. 
DOE Final Report

DE-FC05-000R22806

\section{Section 1.1.3: HCCI Development: Alternate Paths}

Several alternate paths were also pursued during the five years of HCCI development that are being summarized in this section of the final report. During the program, after data was available from test or analysis, it was decided that these alternate technology paths would not be further developed and instead focus would be on the mainstream HCCI technology path.

In the following three subsections, the technologies that were examined but not ultimately chosen to be used for HCCI will be presented.

Section 1.1.3.1: Two-stroke HCCI

Section 1.1.3.2: Mixed-mode operation using multi-mode injection

Section 1.1.3.3: Air-assisted port-fuel injection system for a more homogeneous HCCI

\section{Section 1.1.3.1: Two-stroke HCCI}

The 2-stroke HCCI engine concept was pursued aggressively at the beginning of the program because it was recognized that HCCI combustion systems would be challenged to achieve power densities equal to the conventional Diesel engine. The team investigated the 2-stroke HCCI concept as a means to resolve the power density issue for HCCI.

Much like the 4-stroke program, this project involved up-front analysis, hardware design and procurement activities, and single cylinder testing. Initial single cylinder testing would be performed on the 3171 SCTE, but the plan was to transition that work to a 3401 SCTE better optimized for 2-stroke operation later in the year.

A number of simulations were performed related to the 2-stroke HCCI concept. An analysis of the SCTE engine to determine load capability under 2-stroke operation with HCCI combustion was performed. A few problems surfaced during the analysis, which led to modifications to the SCTE. Engine cycle simulation was also used to focus on the engine performance characteristics for a 2-stroke HCCI engine versus a 4-stroke HCCI engine and a 4-stroke Diesel engine. (2000, Q4)

Enhancements were made to the one-dimensional performance engine simulation (973) to improve its analysis capabilities for a 2-stroke HCCI engine. These enhancements included improvements to the fuel ignition delay and cylinder scavenging models, as well as improvements to the optimization rules that are used in the optimization routines. The engine simulation results for 2-stroke HCCI indicated that excessive temperatures in the cylinder at the time the valves close were causing premature ignition. To resolve the problem, the simulation optimizer was delaying the valve closing event and reducing the compression ratio, which reduces the engine efficiency. Two methods were proposed for dealing with this problem: either changing the fuel composition to delay ignition or finding a way to reduce the temperature in the cylinder when the valves close. Both were being pursued. (2001, Q1)

A few 2-stroke scavenging studies were performed in CFD. The focus of one smaller study was on the quality of fuel-air mixing as a function of injection timing. The focus of the larger study was on the scavenging effectiveness as a function of head and port geometry for the 3401 engine, and its results were used to direct the design of that engine. Geometry was created and analyzed using CFD for four basic shapes of cylinder heads including pent-roof, flat head, large-valve pent-roof and the 3171 engine solid model. Other geometry iterations included piston stroke variation, valve shroud geometry, and valve lift curve variations. The CFD results for the engine with the pent-roof head indicated that depending on geometry and operating conditions, the scavenging efficiency could vary between $48 \%$ and $90 \%$. The results of these runs indicated 
DOE Final Report

DE-FC05-000R22806

that shrouds on the valves were effective at improving scavenging and that the optimum angle of the shroud appears to be about 108 degrees. The flat head design showed similar results. The results of the study pointed to several advantages of the large canted valve head layout (including breathing and scavenging advantages), so it was decided that that particular head would be designed for the 3401 SCTE. The design of the 34012 -stroke head was completed. The head had been analyzed to ensure adequate jacket water cooling, bottom deck temperatures and fatigue life (2001, Q1-Q4)

To allow for the 3171 SCTE testing, component redesign of the cam, crank, spacer deck, connecting rod, push-rods, valves, valve bridge, valve springs, and valve rotators was completed and the parts were procured. Analysis of the shrouded valve and crankshaft was completed and adequate life for prototype test operation was confirmed. The HEUI 300B injector that would be used for the testing was analyzed in the spray visualization lab for use in a 2-stroke application (spray tip penetrations and Sauter mean diameters were determined). Nine new injector tip designs for the HEUI 300B injectors were created for testing the twostroke HCCI concept. The engine was installed in the test cell by the end of 2001. (2001, Q1-Q4)

Testing of the 2-stroke 3171 engine was completed during the first quarter of 2002. The tests were conducted with a geometric compression ratio of 23:1 (yielding an effective compression ratio of 12.4:1). The engine did achieve "HCCI type" combustion. Performance and emissions were recorded for standard Diesel fuel and JET A (kerosene) between idle and $2 \mathrm{~kW}$ of dynamometer power. Power was limited due to concerns over the cylinder pressure rise rate. Figure 1.1.3.1.1 shows the cylinder pressure rise rate for the 2-stroke versus the 4-stroke HCCI concept.

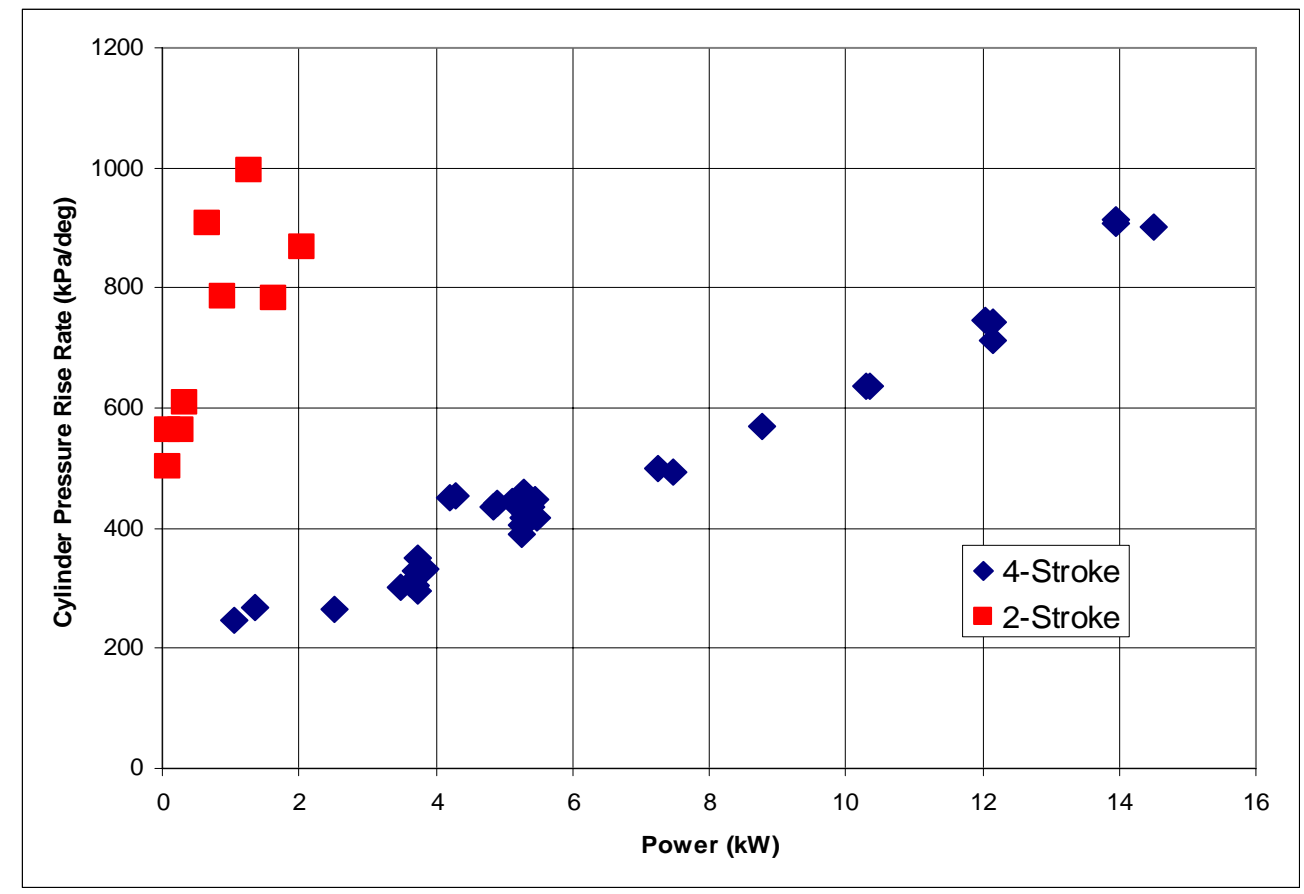

Figure 1.1.3.1.1: Cylinder pressure rise rates for 2-stroke HCCI combustion compared to 4-stroke HCCI combustion

Relative to the 4-stroke HCCI concept, the 2-stroke HCCI concept was severely limited in load capability due to rise rates. In addition to the cylinder pressure rise rate concern, several other issues surfaced during the 3171 2-stroke testing. These issues included: 
1. The intake and exhaust valve events limited the flexibility of the fuel injection timing. This issue prevented the 2-stroke engine from operating at the optimum injection timings defined by the 4-stroke engine.

2. Poor engine scavenging drove up boost pressure requirements, which adversely affected the engine system performance.

3. The 31712 -stroke engine exhibited high vibration and noise.

4. The 2-stroke engine yielded high CO emissions.

Post-test analysis was performed. The test data and subsequent analysis indicated that an excessive cylinder pressure rise rate and poor engine scavenging ultimately limited the power density of the 2-stroke HCCI concept. All activities related to 2-stroke HCCI were discontinued at this point. (2002, Q1-Q2)

\section{Section 1.1.3.2: Mixed-mode HCCI operation using the mixed-mode injector}

Several variants of a mixed-mode injector were designed and procured for the HCCI program. These injectors provided the ability to use HCCI operation (with its narrower cone angles) at light load, but to then use conventional Diesel (with its wider cone angles) at higher loads. Additionally, the injector would allow for a blend of the two modes to be used at high loads. The concept was that an injector with this capability would allow for the entire speed-load range of the engine to be covered even if the high-load challenge of HCCI could not be adequately overcome. This "HCCI Mixed-Mode operation" served as an alternative to the "Full HCCI over the operating range" option that was being evaluated for the 2010 Concept Options in addition to high-efficiency NOx aftertreatment option.

Details of this injector are included in the EPACT appendix.

A number of mixed-mode injector designs were conceived during these first three years of the HTCD program.

Cycle simulation analysis with the mixed mode injectors was performed to investigate the effect of pilot quantity (defined to be the fraction of fuel injected in the early HCCI pulse versus the later conventional Diesel pulse) on performance, boost requirements and peak cylinder pressure limits at various compression ratios. (2002, Q1-Q2)

The SCTE engine testing for these injectors occurred in two phases corresponding to the two phases of the MMI injector. The Phase I mixed-mode injector was tested across a portion of the 13 mode steady state operating conditions while sweeping pilot quantity and main injection timing. The emissions were found to be higher than those previously reported for the regular showerhead nozzles. Testing of the Phase I injector was postponed at this point due to the success of the $3 / 4$ load HCCI demonstration so that resources could be focused on the prime path HCCI solution. Testing did resume with the Phase I injector later, but the results were still not found to be promising. (2002, Q2)

Over a year later, testing of the Phase II mixed-mode injectors with a second showerhead nozzle was performed on the SCTE. Approximately 70 data points were acquired at various operating conditions to accomplish this objective. Because of the high minimum delivery of the fuel shot and the high compression ratio of the SCTE when these injectors were tested (16.6:1), the test conditions were extremely limited. For this reason much of the data was acquired at the single speed-load condition of 1200 RPM and 1/3 load. This operating condition was tested using both conventional Diesel combustion (single conventional injection) and mixed mode combustion. For the conventional strategy EGR percent and injection timing were optimized. 
DOE Final Report

DE-FC05-000R22806

For the mixed mode strategy EGR percent and the timing of the conventional injection were optimized while the timing of the HCCI injection was held constant at the optimal timing determined from the HCCI tests. The results indicate that similar $\mathrm{NO}_{\mathrm{x}}$ levels may be achieved with either form of combustion. Further results are located in the EPACT protected appendix. It was also noticed that operation of the injector was unstable at some operating points. (2003, Q4)

\section{Section 1.1.3.3: Air-assisted, port-fuel injected HCCI for increased homogeneity}

In early 2002, Caterpillar subcontracted Southwest Research Institute (SwRI) to test an air-assisted port fuel injection (PFI) system on a Caterpillar ${ }^{\circledR}$ C-15 engine, to see if a more homogeneous fuel-air mixture could provide benefits for the HCCI program. Prior to this, Southwest Research Institute had performed an internally sponsored research project with results indicating some advantages in NOx emissions.

There were two phases to the work. Phase 1 covered the design, fabrication, setup and instrumentation of the port fuel injection system and the control system. Phase 2 covered the baseline engine testing over the 13 modes of the ESC cycle, the spray studies of the port fuel injector to determine the best air-assist arrangement for diesel fuel, and parametric engine experiments over four engine conditions. (2002, Q1)

The spray tests were conducted at the SwRI Low Turbulence Atmospheric Spray Facility. The Sauter Mean Diameter (SMD) was measured using a Malvern Laser Diffraction Particle Sizer. The optics were configured to enable droplet resolution that ranged from 0.5 to 180 micrometers. Test results looked at quantifying the effect of injector cap geometry on the SMD characteristics through a range of air assist temperatures and pressures. Drop sizes on the order of 2 to 3 micrometers were measured in the optimized configuration. In parallel the engine test cell was configured. This involved design of the port fuel injection system as well as the development of a control strategy. The SWRI RPECS controller was used to govern the system. (2002, Q2)

The optimized port fuel injector (PFI) was then utilized in the engine tests. The engine tests were run at conditions ranging from 1200 - 1800 RPM, from 25 - 75\% load and with PFI fuel quantities ranging from approximately $10-70 \%$ of the total fueling. The tests showed that the $\mathrm{NO}_{\mathrm{X}}$ emissions did not decrease dramatically with the partial premixing. The test results also showed a poor tradeoff between $\mathrm{NO}_{\mathrm{X}}$ emissions and incomplete products of combustion ( $\mathrm{CO}$ and $\mathrm{HC}$ ) with partial premixing. It was also found that a slight increase in BSFC resulted. (2002, Q3) 
DOE Final Report

DE-FC05-000R22806

\section{Section 1.1.4: Design work}

This section details two major design efforts that were undertaken as part of the HTCD program in support of the HCCI solution:

Section 1.1.4.1: $\quad$ Design of the Ultimate Flow Head

Section 1.1.4.2: $\quad$ Design of the Variable Compression Ratio (VCR) C15 engine

\section{Section 1.1.4.1: Design of the Ultimate Flow Head}

The design of an "ultimate flow head" (UFH) commenced in the $2^{\text {nd }}$ year of the HTCD program. The goal of this work was to design a cylinder head with significant improvements to the ports that would improve fuel consumption. The benefits for HCCI were predicted to include fuel consumption, improved cylinder balance, and an extension in high-load capability.

The cylinder head of the current C15 engine had intake and exhaust port flow coefficients of 0.56 and 0.41 respectively at full valve lift. Preliminary designs and flow measurements obtained from stereo lithography (SLA) models showed that the coefficients for intake and exhaust could be increased to 0.63 and 0.78 at full valve lift, resulting in a $2.5 \%$ improvement in BSFC. Due to the valve train configuration and turbo machinery considerations, the exhaust port flow coefficient in the proposed ultimate flow head was expected to be around 0.60. (2002, Q3) The new cylinder head was also designed to support the HCCI options for 2010. This meant being designed for 22 MPa peak cylinder pressure levels during HCCI operation at that point of the program and being able to accommodate the mixed-mode strategy (2003, Q1)

Starting from the production C15 cylinder head, a new 6 cylinder head with modified intake and exhaust ports was designed. The port, manifold and water passage designs were optimized using CFD. Revisions to the water core were made and validated to achieve adequate cooling and acceptable pressure drop. Increased cylinder pressure levels and material requirements were reviewed to meet the 22MPa cylinder pressure target for HCCI. Models of the exhaust and inlet ports were flow bench tested to verify that the target port flow performance could be achieved. (2003, Q1)

Transient CFD calculations were performed for five new intake manifold designs. The results show that all five designs varied in port-to-port mass flow rates and temperature distributions. The simulation results showed that for the case of the conventional combustion Diesel engine, the cylinder-to-cylinder variations would have little or no impact on the overall BSFC or performance parameters of the engine. Since this was the case, the smallest sized intake manifold with the optimum performance was chosen for further development in order to allow for an easier fit into the current vehicle chassis for the 2007 Truck demonstration. (2003, Q2-Q3)

Heat transfer analysis was performed and compared with the current C-15 cylinder head measurements to reach an acceptable confidence level for the design. At the bottom deck, the UFH was projected to be $30^{\circ} \mathrm{C}$ hotter than the then current C15 cylinder head was due to the $5 \mathrm{~mm}$ larger exhaust valves. Several design changes were made to reduce the stress. The intake and exhaust ports geometries were modified slightly to allow adequate cooling to the injector. The final design of the head was completed, and is shown in Figure 1.1.4.1.1. (2003, Q3) 


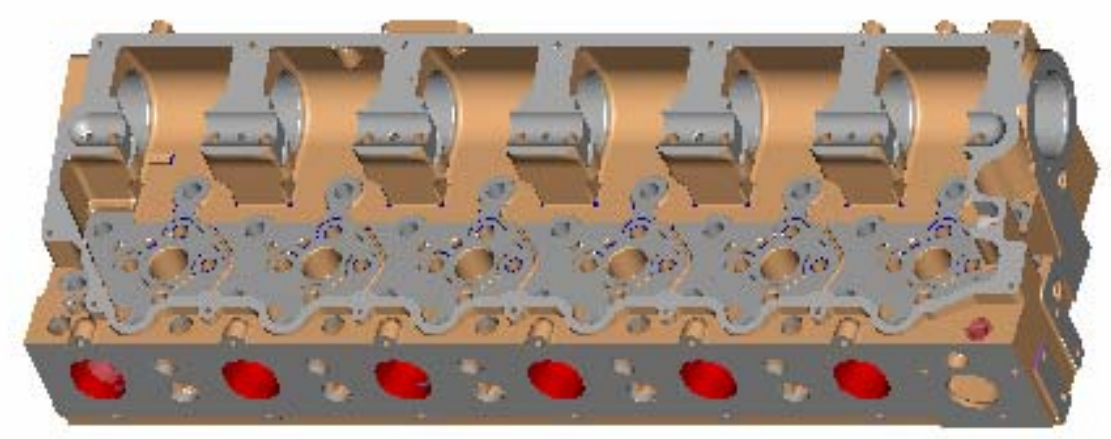

Figure 1.1.4.1.1: The Gen 1 Ultimate Flow Head

A stereo lithography model of the final ports design was flow tested to confirm the flow improvement. The results showed that the intake and exhaust port flow coefficients were 0.54 and 0.55 respectively at an L/D (lift/diameter of valve face) of 0.35 . FEA analyses on the head, which would be made from CGI, indicated that the prototype head was adequate for test up to $22 \mathrm{MPa}$ peak cylinder pressure as desired.

Since the location of the intake and exhaust valves differed from the production C15 engine, a new intake rocker, exhaust rocker, injector rocker, valve spring, camshaft and exhaust manifolds were required. FEA indicated that the new intake, exhaust and injector rockers which would be machined from stock material were adequate for the new head. An order was placed to procure two new camshafts and the supplier to fabricate and machine the prototype cylinder heads. Two prototype heads were ordered. (2004, Q1)

Because it was realized that HCCI combustion would require more balanced mass flows and temperatures for each cylinder than conventional Diesel combustion did, a new Gen II design of the ultimate flow head was initiated. In the Gen II design, the intake side of the ultimate flow head would be modified from the Gen I version by removing the integrated intake manifold and allowing for a bolt up manifold to be installed instead. It was thought that this would allow for easy modification and experimentation in order to achieve the desired balance. CFD work was being performed to determine the current balance of the ultimate flow head and would then be used to guide the design/development of the intake manifold for the Gen II head. (2004, Q2)

During the program, lab test data on the multi-cylinder HCCI engine with the current production C15 head showed that HCCI combustion requires a very good air balance between cylinders. The CFD analyses performed did indicate that the intake manifold designs of the current production C15 and the Gen 1 ultimate flow head were not optimized for HCCI combustion. For the Gen II UFH design, each cylinder was designed to have a separate entrance through which the air could enter the cylinder head. The intake side of the Gen II UFH is shown in Figure 1.1.4.1.2, while the intake and exhaust ports of the Gen II UFH are shown in Figure 1.1.4.1.3. (2004, Q3) 


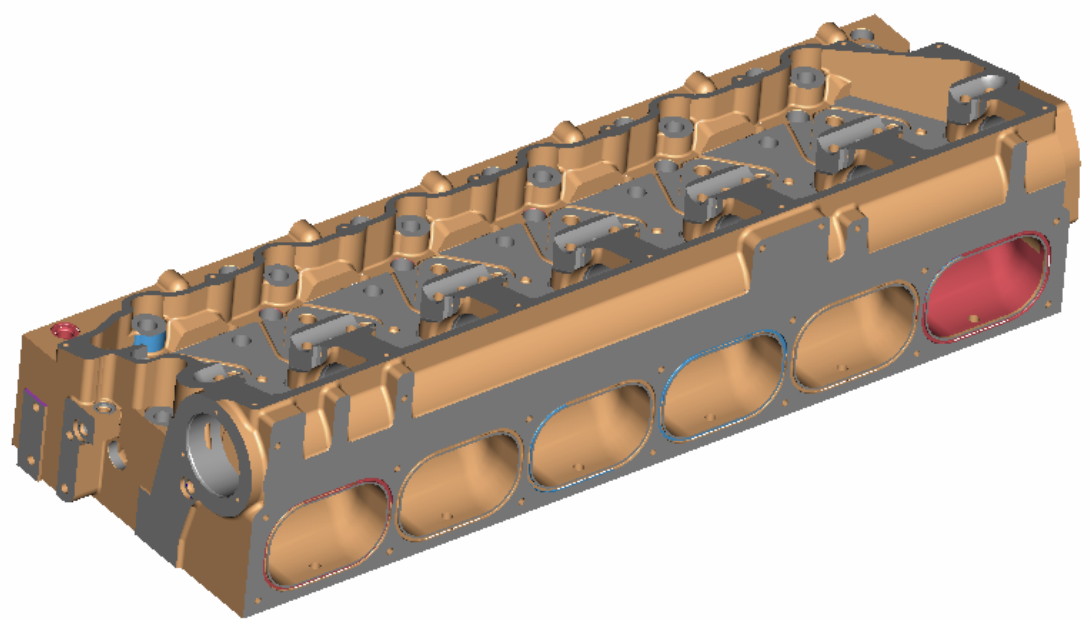

Figure 1.1.4.1.2: The Gen II Ultimate Flow head

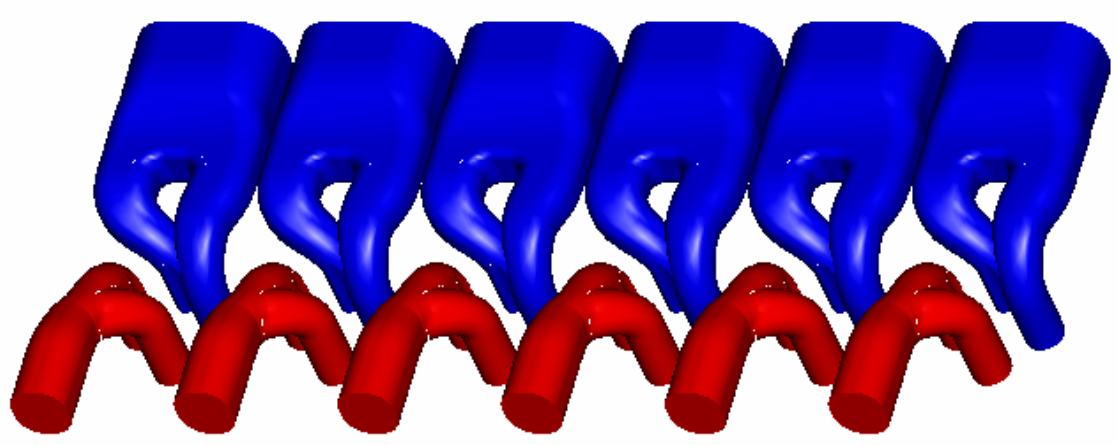

Figure 1.1.4.1.3: Ports in the Gen II Ultimate Flow head

The performance aspect of the Ultimate flow Head is covered in the Section 1.5 High Efficiency Building Blocks section of the report. 
DOE Final Report

DE-FC05-000R22806

\section{Section 1.1.4.2: Design of the Variable Compression Ratio (VCR) engine}

Early on in the HCCI project, it was recognized that a variable compression ratio (VCR) system would be beneficial for HCCI. At high engine loads, HCCI prefers a lower compression ratio because it helps to restrain the combustion. At low loads an elevated compression ratio is preferred because it helps with startability, combustion stability, hydrocarbons and CO emissions. The early VCR-related design tasks were focused on coming up with a system for the SCTE, not a multi-cylinder engine. When the SCTE successfully demonstrated $100 \%$ load capability with an 8:1 compression ratio piston, it was determined that an HCCI engine requiring an 8:1 compression ratio at the highest loads would need to be a variable compression ratio engine to accommodate starting and reasonable operation at low loads. Within a few months of that demonstration, the design of a VCR system for the multi-cylinder C15 engine began. That design will be detailed in this section.

Several different VCR mechanisms were considered and a comprehensive decision matrix was formulated to objectively select the best VCR concept for the detailed design phase. The concepts are included in the EPACT appendix.

Design reviews were held for the four VCR engine designs to review the key components of each VCR system. The Engine Research team completed its decision matrix and reached consensus on how to focus the VCR design efforts. Of the four concepts being developed, the winning concept was the Eccentric Crank. Subject matter experts from engine production teams also selected the eccentric crank as the leading VCR concept. 
The initial plan for the eccentric crank design was to have a keyed carrier arm (Figure 1.1.4.2.1) and a mono block (no bearing caps), which differentiated Caterpillar from other eccentric crank VCR design approaches. The design was such that the crank, main bearings and carrier could be assembled prior to being inserted into the mono block. With this design, the compression ratio changes from 18:1 to 8:1 when the carrier is rotated 50 degrees by a hydraulic cylinder. Structural analysis of the block sections was performed to insure adequate block strength under the high cylinder pressure forces required for heavy duty HCCI combustion. (2003, Q2-Q3)

Further details of the final design for VCR are in the EPACT appendix.

The engine build was completed in the $2^{\text {nd }}$ quarter of 2005 (Figure 1.1.4.2.2 and 1.1.4.2.3) and the engine was installed in a test cell that third quarter. The final design moved away from a keyed carrier to individual actuators. Testing of the engine has been documented under the High Efficiency Clean Combustion (HECC) program.

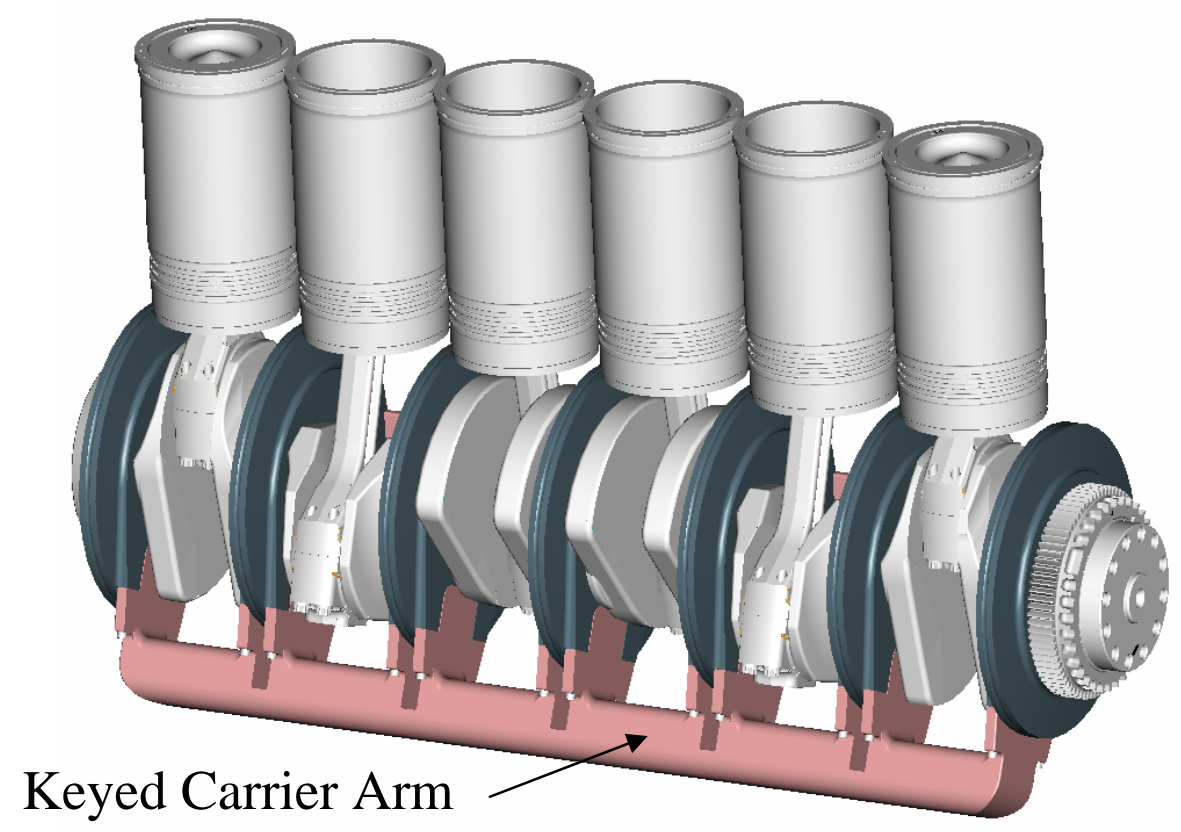

Figure 1.1.4.2.1: Keyed carrier arm of the initially proposed VCR design. 

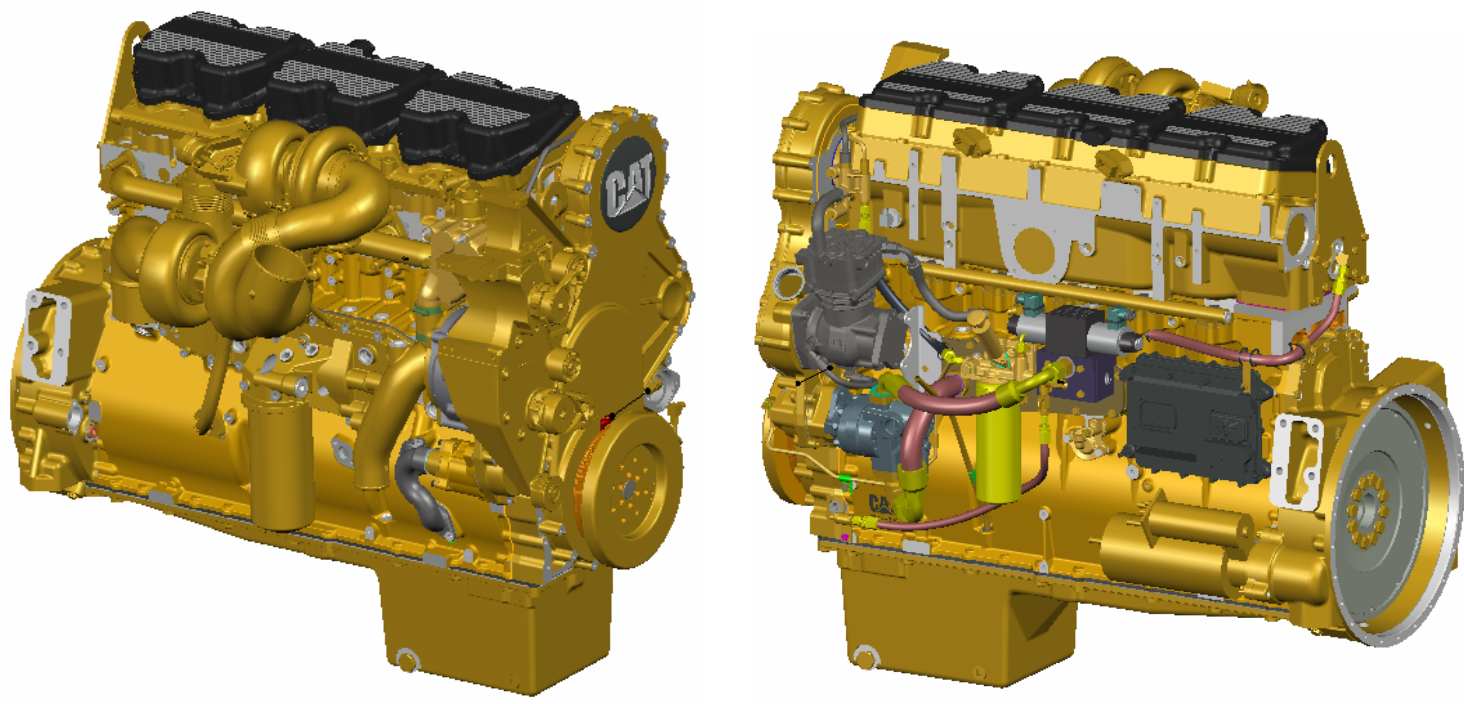

Figure 1.1.4.2.2: VCR engine views

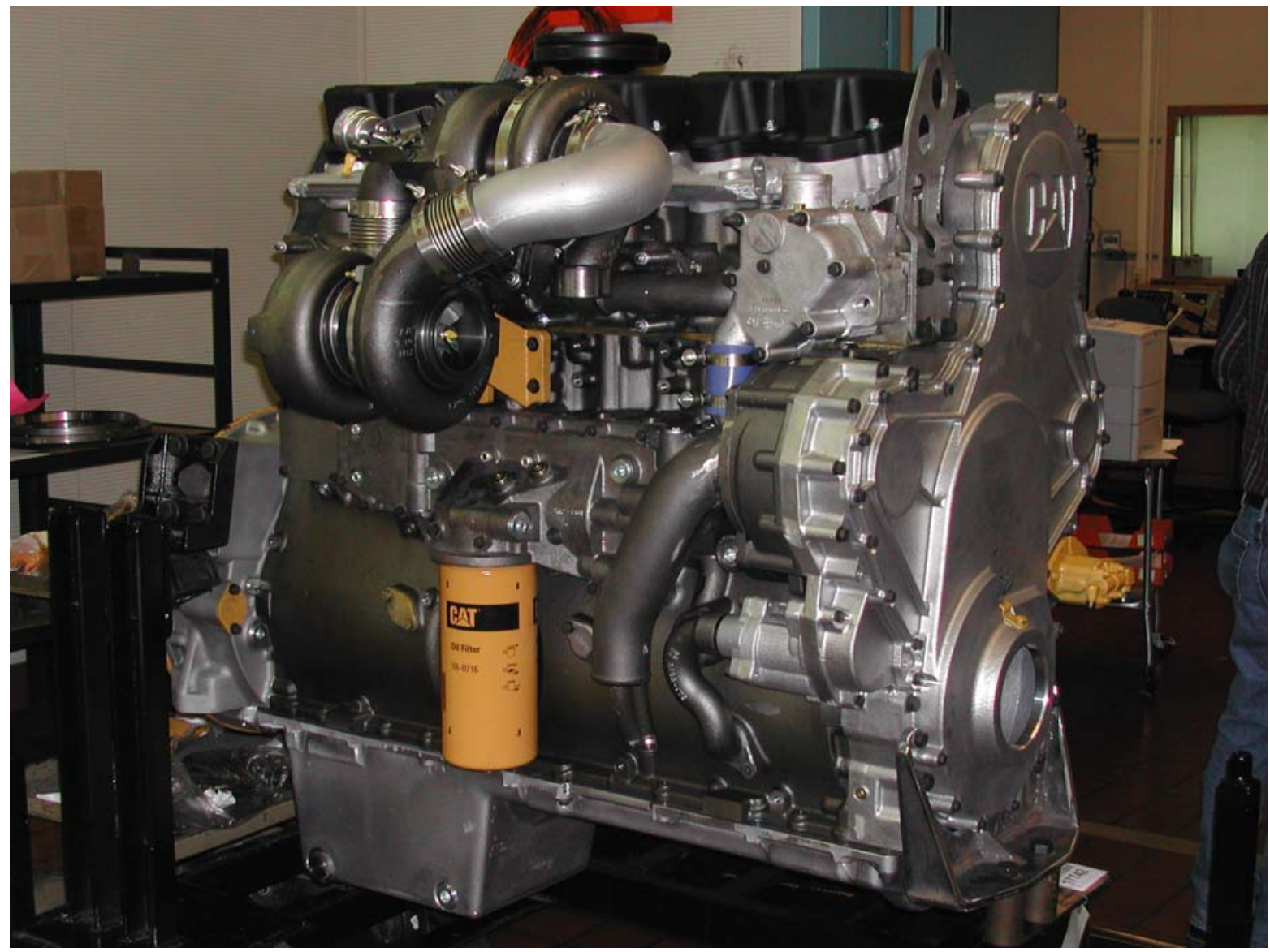

Figure 1.1.4.2.3: The variable compression ratio engine. 


\section{Section 1.2 Aftertreatment Development.}

Aftertreatment technology options to meet the 2007 and 2010 emissions were considered along with combustion technology from the beginning of the HTCD program.

In 2000, Arthur D. Little (ADL) was chosen as a subcontractor early in the HTCD program. ADL was been responsible for identifying concepts and combinations of concepts which had the potential to meet the program goals in terms of performance and practicality. This effort was aimed at identifying various possible on-board fuel and/or other hydrocarbon processing options, configurations of catalysts and desulfurizing reactors. On-board generation of reagents suitable for either Selective Catalytic Reduction (SCR) or NOx Storeage Reduction (NSR) were considered.

The process was for ADL to screen the system concepts with Caterpillar against the program goals using agreed upon Attractiveness and Fit criteria. Based on this, it was planned for a small number (2-4) of system design concepts to be selected for further simulation and experimentation in 2001.

Highlights for the Year 2000 are summarized below:

- Previous work on diesel exhaust gas lean-NOx aftertreatment was reviewed and summarized in a written report.

- Attractiveness and Fit criteria which were used to screen the systems concepts against the program goals were developed jointly by Arthur D. Little, Inc. (ADL), Caterpillar, Inc., and International Catalyst Technology, Inc. (ICT).

- Three concept generation workshops were held:

(1) A one-day concept generation workshop focusing on reagent generation and energy conversion was held in Boston on August 29th.

(2) A one-day concept generation workshop on lean NOx reduction and desulfurization was held in Peoria on October 5th. A one-day workshop on system concepts, controls, sensors and PM-traps was held in Peoria on October 25th, with a screening and synthesis workshop to develop systems on the following day.

- Following the workshops, the concepts and enabling components were refined, screened, and evaluated with the objective to identify a small number of systems and components for brief investigations.

- Brief investigations of the selected systems and components were initiated in December 2000 with the ultimate objective of identifying 2-4 preferred concepts for further detailed investigation by mid January 2001.

- An operational Pulse Flame Combustor experimental apparatus that can be operated on diesel fuel at controllable and representative equivalence ratios and with independent feedgas temperature control has been designed and assembled at Arthur D. Little’s Acorn Park facilities.

During the first quarter of 2001, these "enabling component” concepts were investigated and developed to a level of maturity sufficient to make judgements about further development, EGA system concept design, and R\&D planning.

Highlights for Quarter 1, Year 2001 are summarized below:

- $\quad$ Eight (8) main R\&D themes were selected to support the EGA program: (1) System Integration \& Controls; (2) PM Aftertreatment Strategies; (3) Enhanced SCR System Designs; (4) Engine-out NOx Reduction; (5) Gas Separation Technologies; (6) Combined System Designs; (7) Desulfurization Strategies; and (8) EGA Product and Market Strategy Development.

- A highly flexible "Generator of Exhaust” (GENEX) apparatus, which produces exhaust gas that simulates the combustion products of a diesel engine for the evaluation of EGA components, has been developed, assembled, and commissioned at Arthur D. Little’s Acorn Park facilities. The GENEX exhaust gas 
species concentrations are recorded by a data acquisition system. Preliminary testing has indicated that exhaust constituents can be varied over a wide range, simulating different HD diesel operating conditions. General uses of the GENEX test facility are likely include the following:

- Use in feasibility studies to screen emission reduction concepts using sub-scale components, when steady-state or slow transient testing is adequate;

- Provide data needed to develop and validate EGA component simulation modules; and

- $\quad$ Assess and validate the performance of sub-scale experimental EGA components and provide feedback to direct any design modifications that may be necessary.

- A GENEX apparatus similar to the one pictured in Figure 1.3.1, was set-up at Caterpillar.

- A program to explore advanced lean NOx catalyst materials has also been developed and potential partners approached.

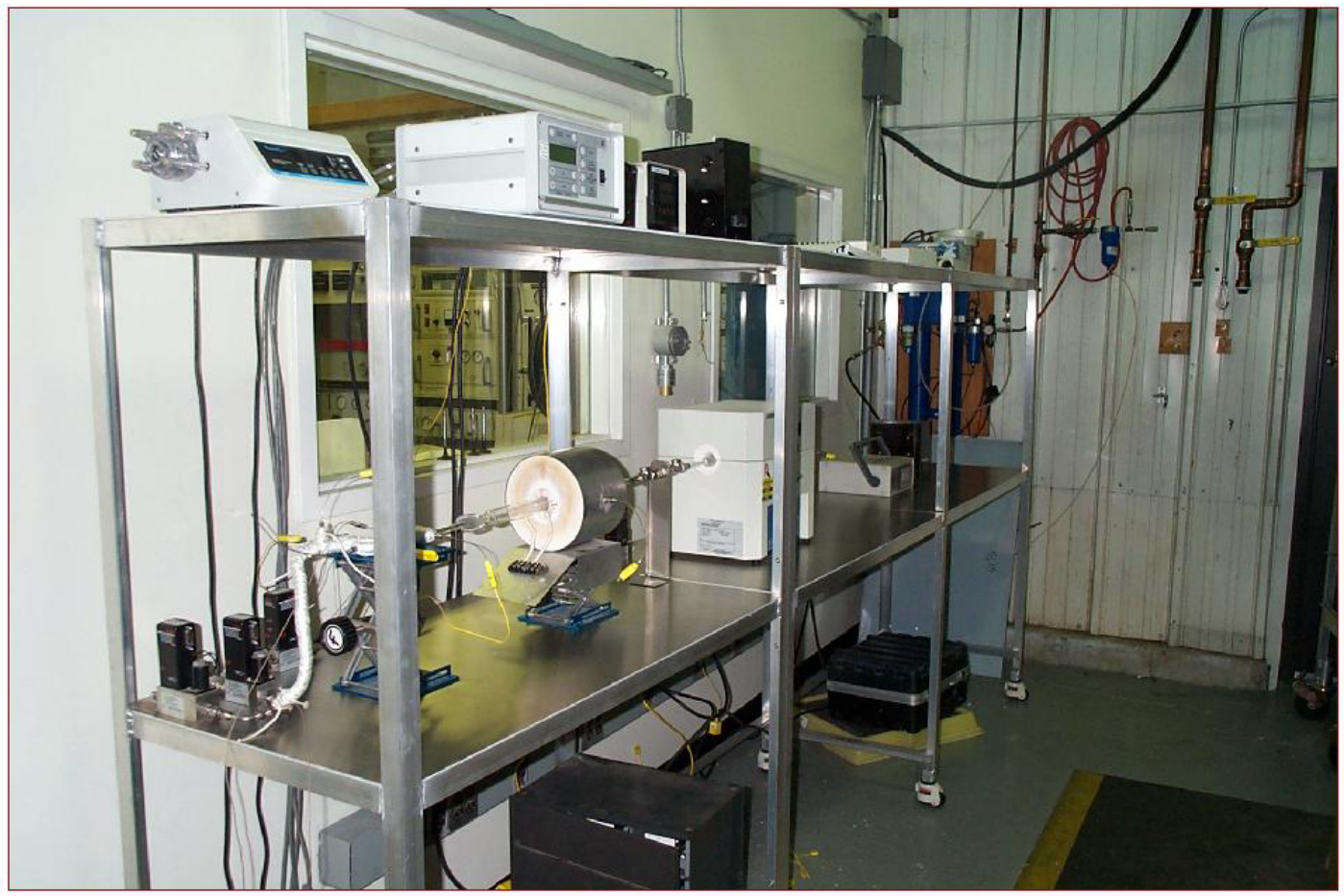

Figure 1.2.1. Arthur D. Little’s GENEX-apparatus has been redesigned to operate on diesel fuel

The objectives of the work performed by Arthur D. Little in the second quarter of year 2001 were to:

(1) Finalize the work plan (scope and approach) to meet the R\&D needs of the selected Exhaust Gas Aftertreatment (EGA) concepts for further investigation in the program

(2) Kick-off and start work on the selected R\&D activities.

Highlights for Quarter 2, Year 2001 are summarized below:

- Arthur D. Little was authorized to start of work on six selected R\&D activities, (1) System modeling as a tool for the other R\&D activities; (2) Rapid calibration and aging protocols (including optimization of the GENEX facility), (3) PM traps and filters, (4) Heat management, (5) Desulfurization, and (6) Finalizing the ongoing effort on EGA Product and Market Strategy.

- Following the successful commissioning of the "Generator of Exhaust" (GENEX) facility at Arthur D. Little, the apparatus has been exercised over a range of conditions to provide:

(i) Experimentally derived performance parameters for the GENEX operating on diesel, 
(ii) Feedback to direct any system design modifications

(iii) Feedback to provide guidance to controls protocol development. Based on feedback from these scoping tests, several modifications to the GENEX system design have been implemented to improve the system performance and controllability

- Aftertreatment Modeling - A new project aimed at building aftertreatment modeling tools was started. The objective is to generate a series of models describing various aftertreatment devices such as particulate traps, NOx traps, SCR, oxidation catalysts, etc. These models will be written in Matlab/Simulink/C++ and will be implemented in the Dynasty/Enterprise environment. The objective here was to enable full system modeling capabilities (whether engine + aftertreatment or full vehicle).

Highlights for Quarter 3, Year 2001 are summarized below:

- The systems modeling task progressed. Schematic showing the incorporation of exhaust gas aftertreatment (EGA) models into Caterpillar's proprietary Dynasty environment is shown in Figure 1.3.2 below.

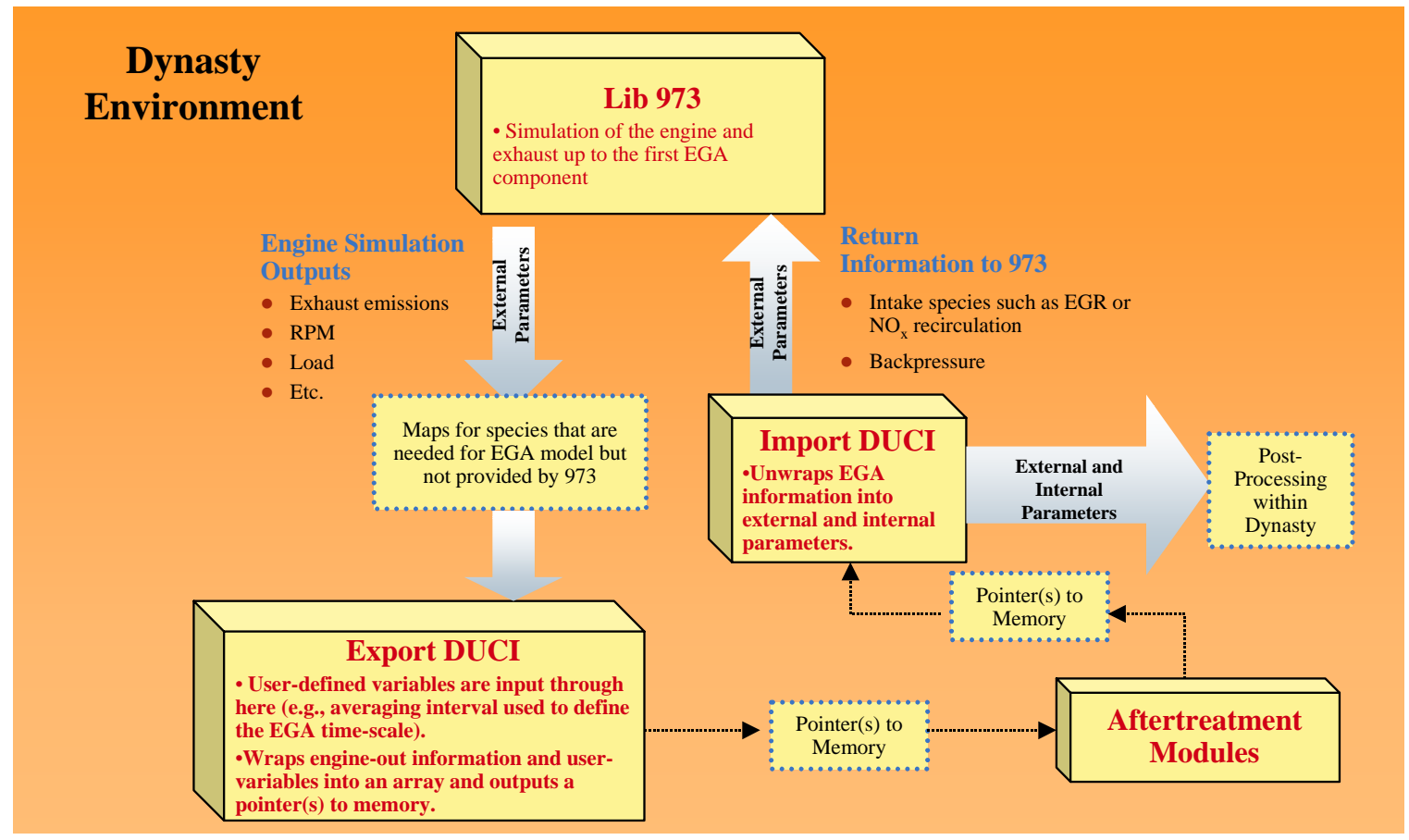

Figure 1.3.2: Schematic of the flow of data within Dynasty from engine to aftertreatment modules.

- The effort to refine the Diesel-GENEX apparatus operations and controls protocols was completed with the "Generation-II" facility (GENEX-II) commissioned at ADL.

- The heat management task was initiated in June 2001 and is scheduled for completion by the end of October 2001. Modeling of all the heat management concepts has been completed, and preliminary results were discussed 
Highlights for Q4, 2001 are summarized below:

- In Q4, 2001 progress continued primarily in the area of Dynasty models. The modeling task with about 30 simple phenomenological models created for modules representing generation, flow and conversion of exhaust stream species was nearing completion. Subsequent phases of work will concentrate on increased sophistication of the modules as warranted.

- The effort to refine the Diesel-GENEX apparatus was completed during Q3, 2001 with the "GenerationII” facility (GENEX-II) being commissioned at ADL. Q4, 2001 efforts focused on shakedown testing, optimization of operational procedures and development of control protocols. Extension of the facility to incorporate sulfur and soot was deferred to follow-on work in 2002.

- In parallel, the literature review of aging protocols continued and computer simulations for protocol development were commenced.

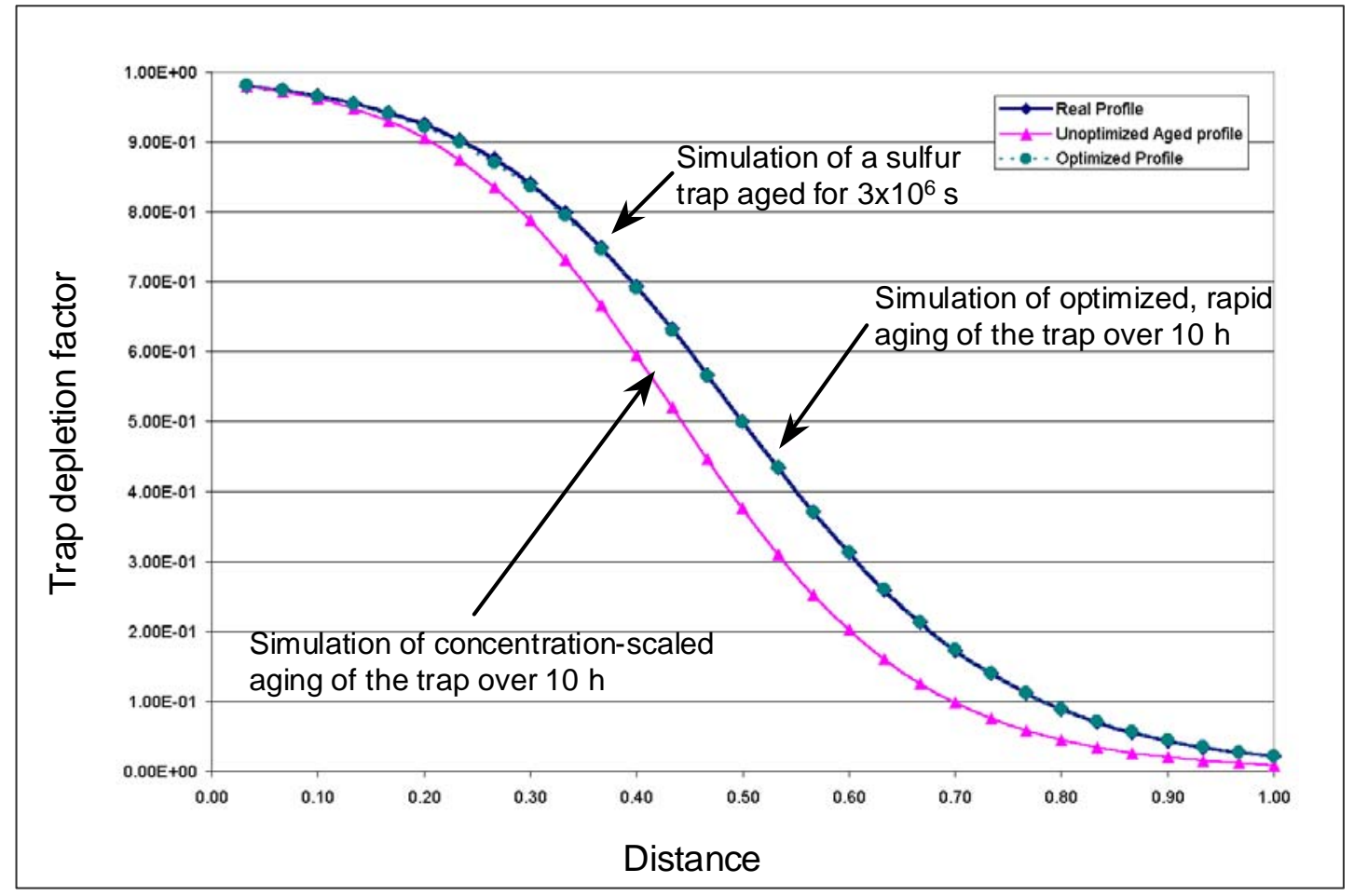

Figure1.2.3: Modeling, combined with optimization of experimental variables, is employed to develop rapid aging protocols

- $\quad$ Nine concepts were thermodynamically modeled then ranked for thermal performance, based on their ability to dampen thermal fluctuations during the FTP transient emissions test. The results were summarized and discussed with Caterpillar in several audio-conferences. The top four candidates which exhibited a combination of both high thermal performance and high design attractiveness were, (1) Thermal Storage High Capacity (phase change material); (2) Swing Beds; (3) Double Wall Active; and (4) Heat Pipes.

- The fuel sulfur task reviewed methods for removing sulfur compounds from fuel on board the vehicle. This was a critical activity to support the NOx adsorber program as current catalyst formulations can suffer irreversible poisoning from sulfur even with 15ppm Sulfur fuel and limited hours of operation. An experimental test rig was commissioned, and testing carried out on the first candidate trap material, including determination of breakthrough curves. Additional candidate materials for testing were procured from zeolite manufacturers and Argonne National Labs, in addition to sorbents from internal ADL sources. Additional effort focused on ways to fabricate sorbents into space effective structures that will also afford good access to sorbent material with low pressure-drop across the sorbent-bed. 
Highlights for Quarter 1, 2002 are summarized below:

\section{GENEX/Pulsed Flame Combustor Development}

- The objective of this task is to develop equipment and protocols that will permit both rapid screening and detailed analysis of emissions controls components. Quarter 1, 2002 GENEX efforts focused on shakedown testing and development of operational procedures. To finalize Phase 1 GENEX efforts, a series of validation runs were performed to illustrate that the GENEX-II facility is fully functional and ready to transfer into additional R\&D activities. $।$

Aftertreatment System Modeling

- The Phase 1 modeling task was completed in Quarter 1, 2002, with about 30 simple phenomenological models implement for modules representing generation, flow and conversion of exhaust stream species.

Fuel Sulfur Trap

- The fuel sulfur task has a goal of reviewing methods for removing sulfur compounds from the fuel on board the vehicle. An experimental test rig was designed and commissioned, and testing carried out on the first candidate trap materials, including determination of breakthrough curves. Additional effort focused on ways to fabricate sorbents into structured packing that will afford good access to sorbent material at low-pressure drop across the sorbent bed. The sorbent materials tested included zeolites and other sorbent formulations procured from zeolite manufacturers, a chemical adsorbents manufacturer and Argonne National Labs. Experimental results showed that the capacity of existing fuel desulfurization materials needs to be improved substantially to achieve acceptable performance for onboard operation. In the course of work, a dynamic modeling tool was created, see figure 1.2.4.

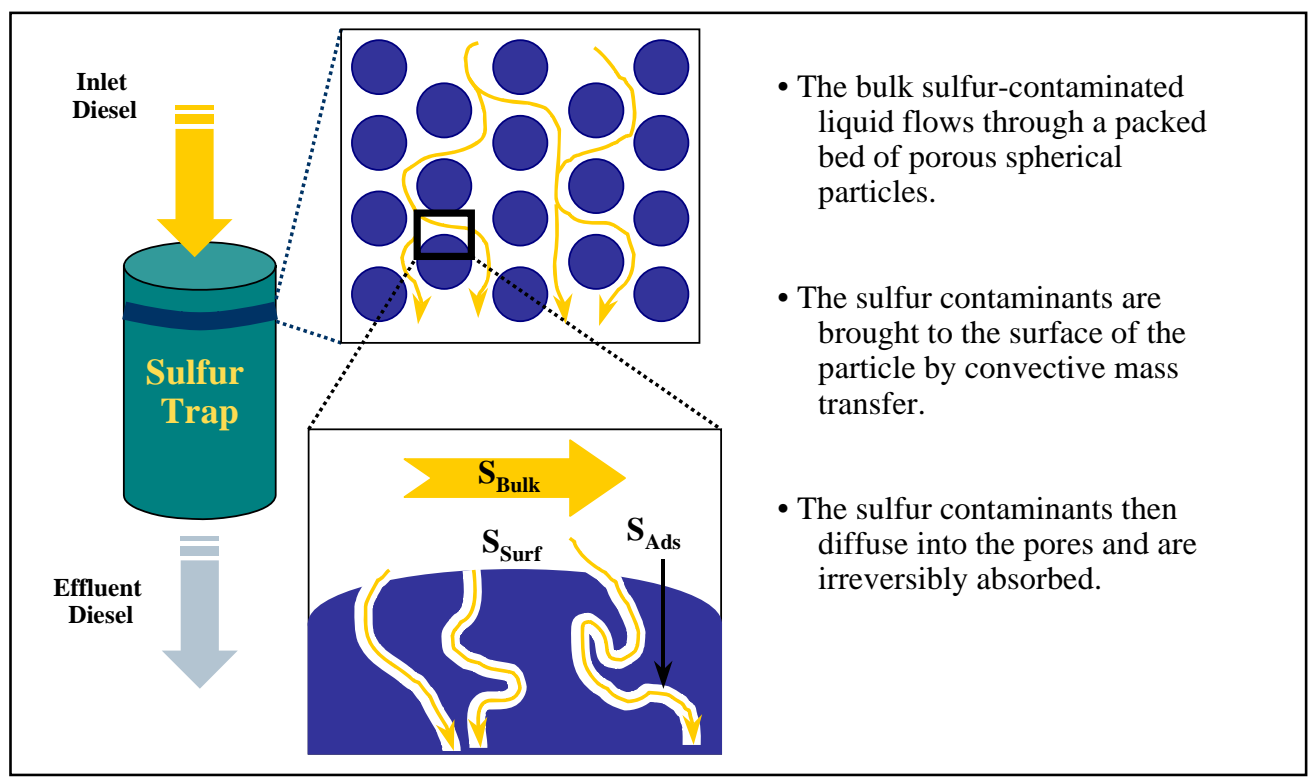

Figure 1.2.4: Simulation of a transient de-sulfurization trap that contains parameters for mass transfer and breakthrough capacity.

Thermal management: 
- As conventional catalyzed wall flow filters have problems regenerating during low exhaust temperature duty cycles, a study on active regeneration strategies was commissioned. The study looked at different engine related means to increase the exhaust gas temperature which is important even for catalyzed particulate filter regeneration. The technologies varied from injection timing retarding, exhaust gas heaters, variable valve timing and intake air throttling. The effects on fuel economy and emissions were calculated using Caterpillar's engine simulation code, 973 . The effects on temperature for a 3126 engine at $1440 \mathrm{rpm}, 10 \%$ load are shown in figure 1.3.5. Work on this project has been completed and the study concluded that throttling the intake air is the most effective and efficient way to increase exhaust gas temperature. The wastegate and variable valve technologies are very efficient in increasing the exhaust gas temperature, but the maximum achievable temperatures are very limited at low engine loads.

- A model of a catalyzed particulate filter was used to calculate how often the temperature increase was necessary in a very low duty cycle application. The model used the temperature data from the simulation study on the throttle valve. Regeneration strategies (exhaust gas temperature increase and regeneration frequency) were studied to keep the filter loading below an allowable limit. The fuel consumption penalty for regeneration for the low temperature driving cycle was found to be only about 2-3\% if a throttle valve was used.

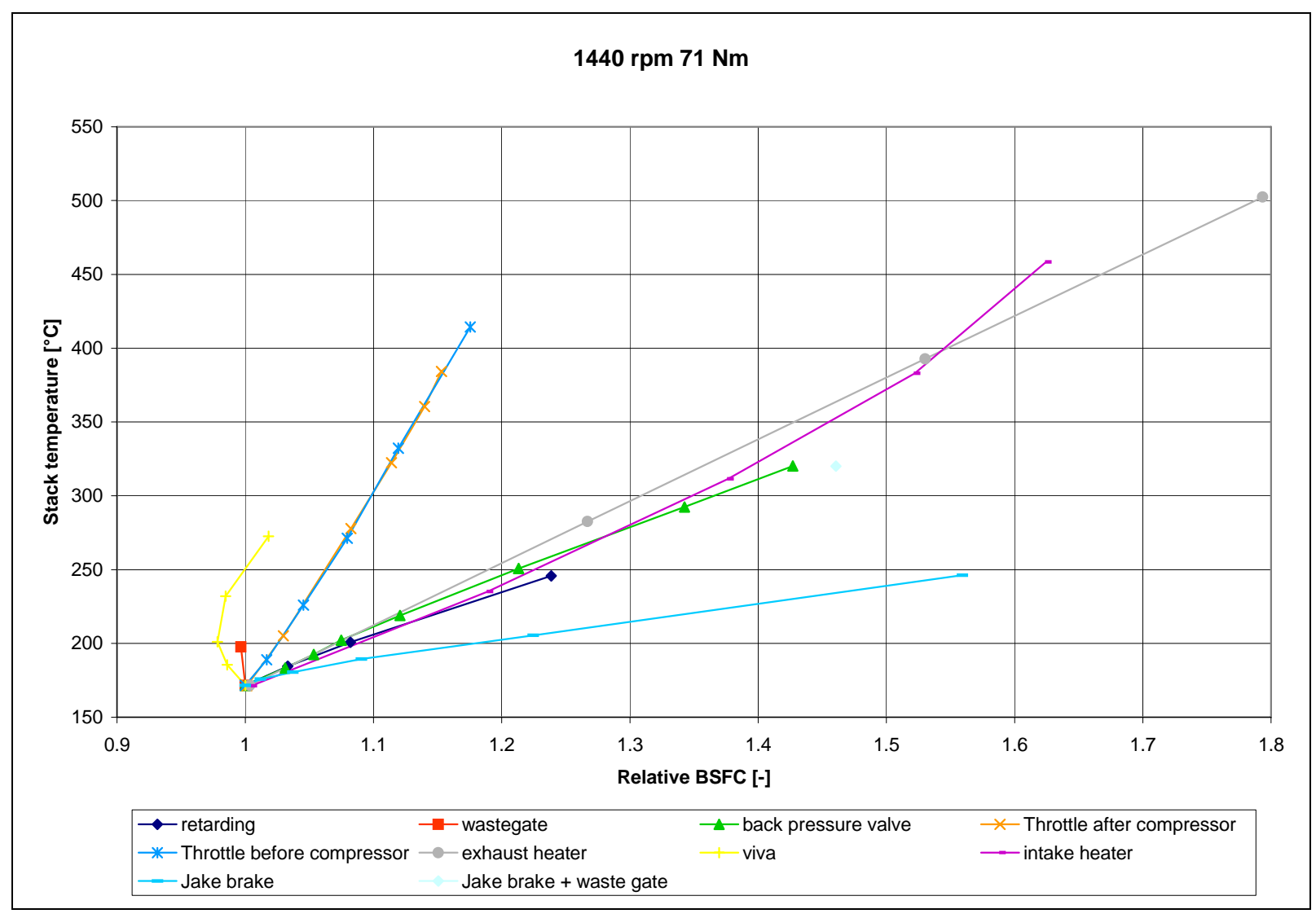

Figure 1.2.5: Exhaust gas temperature versus fuel economy for different technologies 
DOE Final Report

DE-FC05-000R22806

Highlights for Quarter 2, 2002 are summarized below:

The work breakdown progressed with TIAX (formerly Arthur D. Little) focusing on some of the tasks while Caterpillar focused on other tasks.

Work performed by TIAX (Formerly Arthur D. Little (ADL)) included:

(1) Aftertreatment System modeling.

(2) Diesel Oxidation Catalyst (DOC) detailed calibration.

(3) On-board fuel desulfurization.

Work at Caterpillar included:

(4) PM Filter development.

(5) Thermal Management.

(6) Exhaust Sulfur Trap.

(7) Fuel Reformer.

\section{1) Aftertreatment System Modeling}

During the $2^{\text {nd }}$ quarter 2002, the suite of modules was extended to include simulations of common ducting elements (straight tubing, bends, connectors) and catalyst monoliths so that the pressure drops and heat losses associated with an actual exhaust gas treatment system could be simulated. The modules estimated pressure drops and heat losses as a function of both internal conditions (temperature, flow rate) and external conditions (temperature).

\section{2) Diesel Oxidation Catalyst (DOC) detailed calibration}

During the $2^{\text {nd }}$ quarter 2002, TIAX employed a three-step process for calibrating and validating a model of a DOC. The model itself was created in Bistro ${ }^{\mathrm{TM}}$, TIAX's proprietary tool for creating microkinetics reaction networks. In the first step, the model was calibrated against light off data provided by Caterpillar. In the second step that preliminary model was further refined using data gathered at TIAX with the catalyst mounted on the GENEX ${ }^{\mathrm{TM}}$ bench, a bench-scale device previously developed that produces a simulated exhaust gas by pulsed combustion of an air/fuel mixture. The GENEX was operated over a matrix of conditions that spanned the exhaust gas conditions of a 13-mode test. In the third step, the refined model was run so as to simulate a full scale catalyst and the results were compared to those obtained when the catalyst was run on an engine dynamometer. A comparison of the model and experimental results are illustrated in figure 1.2.6 below, which shows integrated tail pipe emissions of $\mathrm{CO}$ and total hydrocarbons for the first 600 seconds of an FTP test. 


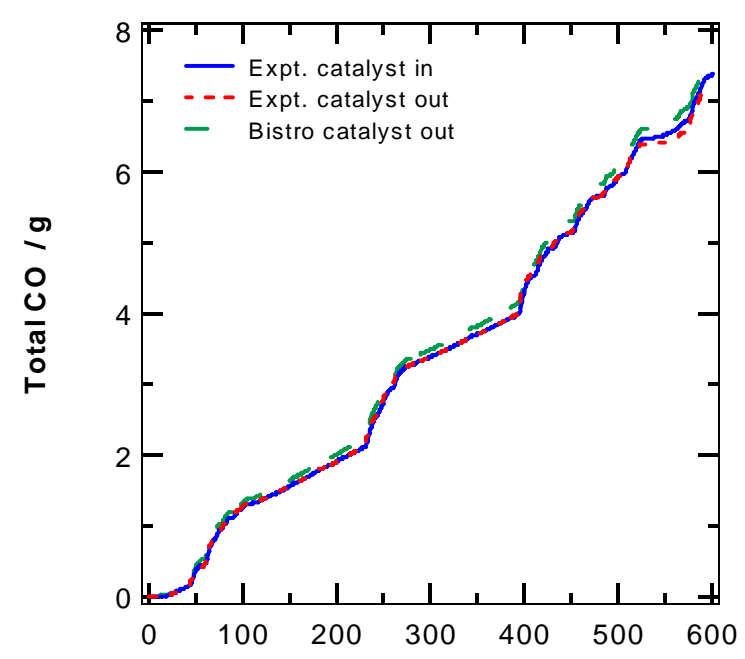

Time / s

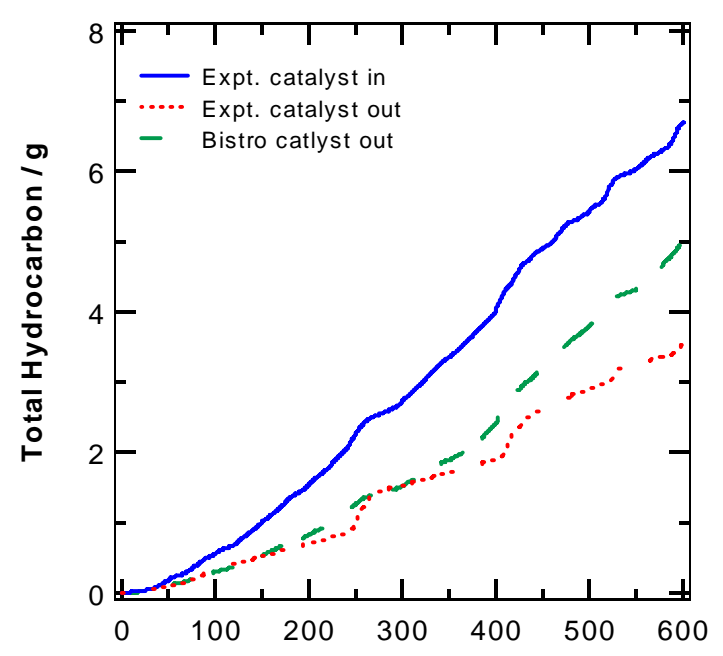

Time / s

Figure 1.2.6: Comparison of experimental and model results for the first 600 seconds of an FTP test on a current production Diesel Oxidation Catalyst (DOC).

\section{3) Fuel Sulfur Trap}

During the $2^{\text {nd }}$ quarter 2002, TIAX identified a sorbent with a capacity exceeding $0.2 \mathrm{wt} \%$ sulfur compared to a previous best result of $0.02 \mathrm{wt} \%$. The physical and chemical characteristics of that sorbent have been used to identify other possible candidates. TIAX have also contacted fuel suppliers, in preparation for Stage 3.

\section{4) PM Filter Development}

During the $2^{\text {nd }}$ quarter 2002, An Active Particulate Matter (PM) Trap using a metallic fiber substrate was procured for test. In this trap, the filter media can be electrically heated in segments for regeneration purposes. This allowed for regeneration, independent of the engine operating conditions. Bench testing has been done 
on the trap to ensure uniform heating of the filters and proper functioning of the control system/strategy for regeneration. Figure 1.2.7, show the ProE model of the complete assembly (left) and a filter segment being electrically heated (right).
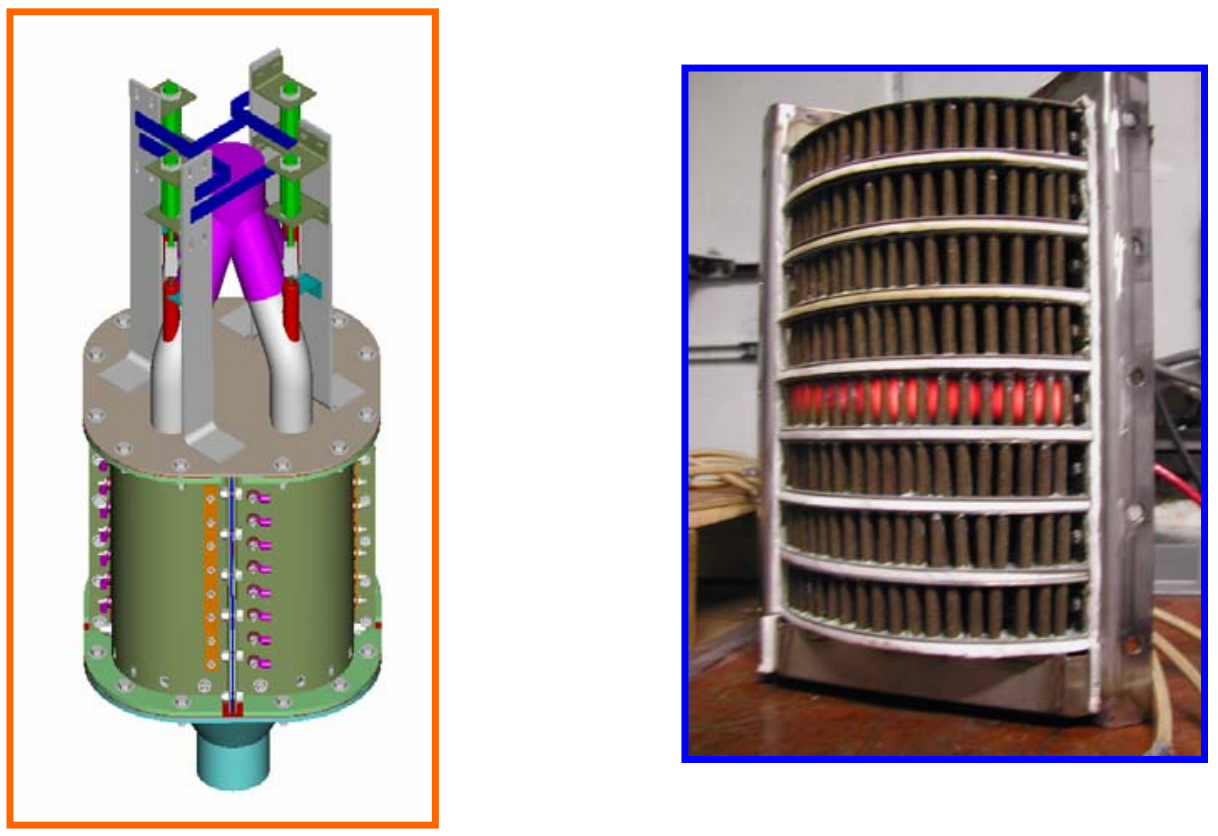

Figure 1.2.7: Electrically regenerated, metallic fiber substrate PM Trap.

A PM trap model was developed for simulating the active particulate trap shown above. This model was used to perform design optimization studies such as filter material specifications, total filtration area, filter volume, regeneration strategy, etc.

\section{5) Thermal management}

The thermal management requirements were identified for different catalyst technologies and different engines. Figure 1.2.8 shows an example of thermal management needs for a C12 engine over a 13-mode cycle. The most promising thermal management technologies are:

- Selective insulation and passive cooling system using a double wall system where the cooling flow between the walls can be changed.

- High heat capacity material such as a phase change material, which control the exhaust gas temperature passing through it.

- Reduction of airflow through the engine to increase exhaust gas temperatures. 


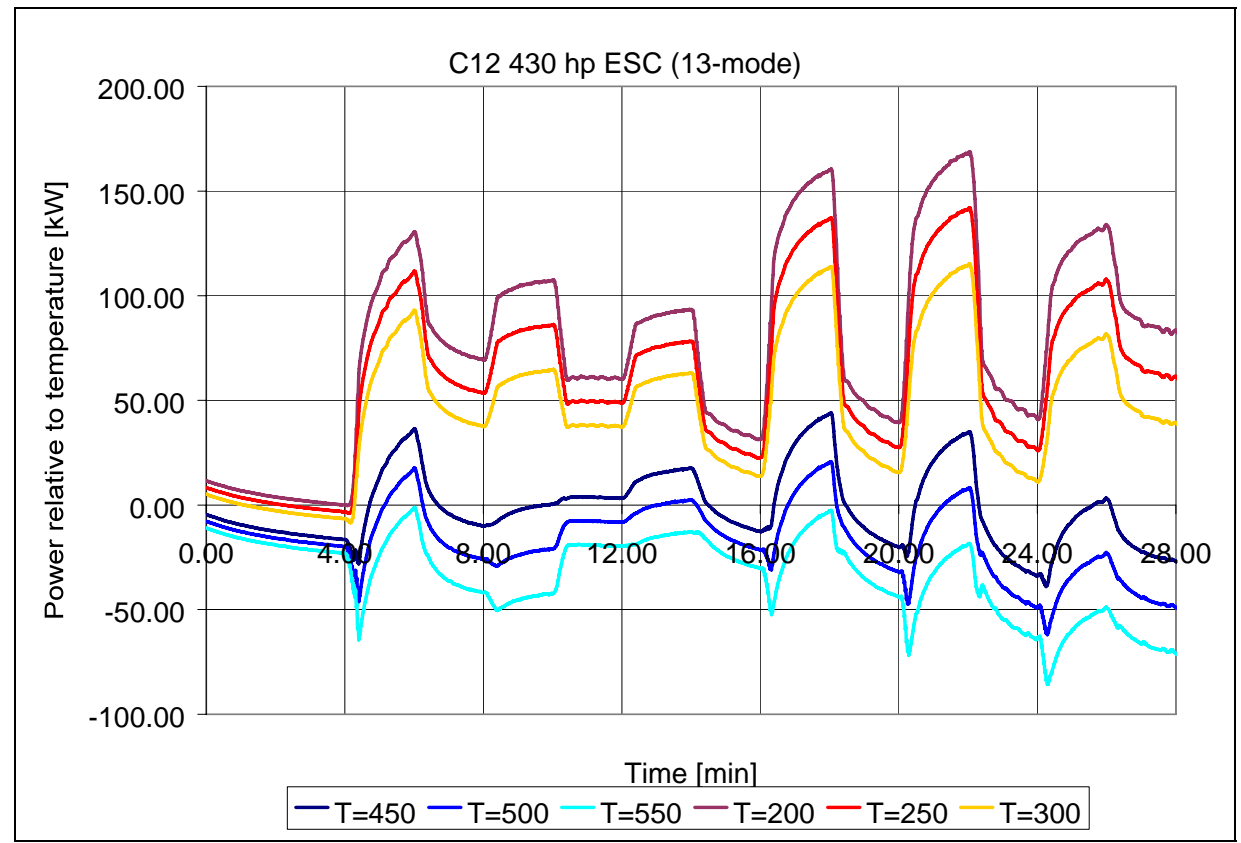

Figure 1.2.8: Heating/Cooling Power requirements for achieving a range of exhaust gas temperatures for a C12 engine over the 13-mode test cycle.

\section{6) Exhaust Desulfurization}

During the $2^{\text {nd }}$ quarter 2002, Temperature Programmed Reduction (TPR) testing of the first generation of oxide and zeolite SOx absorbing materials was completed. Five samples were tested for SOx adsorption, based on temperature and storage capacity.

\section{7) Fuel Reformer}

The objective of this task is to investigate the feasibility of using a diesel fuel reformer to generate $\mathrm{CO}$ and $\mathrm{H}_{2}$ for the regeneration of a NOx adsorber catalyst. This work is being performed by the University of Minnesota and is a development of the millisecond reactor but using instead diesel fuel.

During the $2^{\text {nd }}$ quarter 2002, the test bench system was upgraded. Reformation studies using decane, hexadecane and diesel fuel are being repeated in order to determine the product selectivity with improved accuracy.

Figure 1.2.9: Fuel Reformer rig at University of Minnesota.

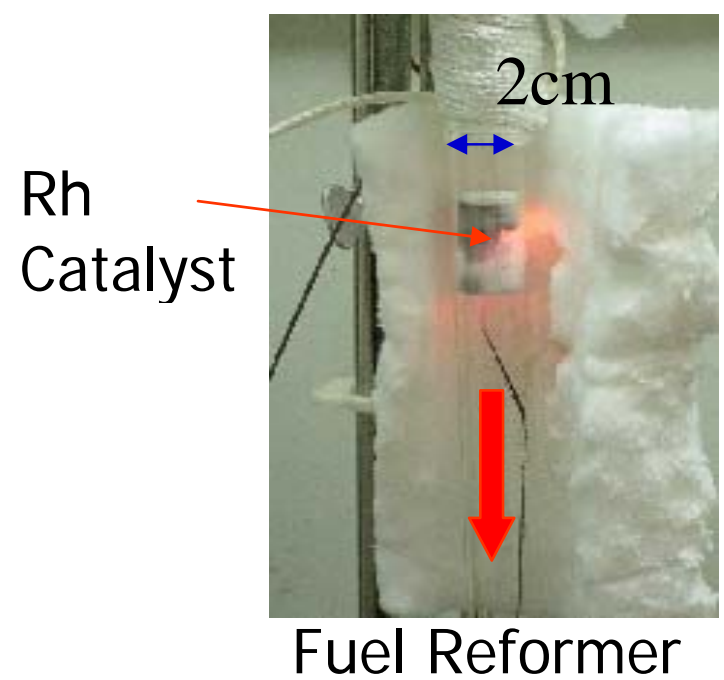


DOE Final Report

DE-FC05-000R22806

Highlights for Quarter 3, 2002 are summarized below:

Work performed by TIAX (Formerly Arthur D. Little (ADL)) included:

(1) Aftertreatment System modeling.

(2) Diesel Oxidation Catalyst (DOC) detailed calibration.

(3) On-board fuel desulfurization.

Work at Caterpillar included:

(4) PM Filter development.

(5) Exhaust Sulfur Trap.

(6) Fuel Reformer.

\section{1) Aftertreatment System Modeling}

During the past quarter Caterpillar and TIAX worked to resolve issues associated with implementing aftertreatment simulation in conjunction with Dynasty.

\section{2) Diesel Oxidation Catalyst (DOC) detailed calibration}

In quarter 3, the calibration procedure was improved by including additional points to span the range of temperatures and concentrations with better resolution. The method discriminates well among production catalysts and agrees, directionally, with lightoff data measured using simulated exhaust created with bottled gases. The current reaction network makes an attempt to account for hydrocarbon adsorption on the catalyst washcoat.

\section{3) Fuel Sulfur Trap}

In quarter 3, TIAX subjected second round candidate materials to 3 increasingly severe tests. Even the most promising samples were foiled by the presence of heavier hydrocarbons in the simulated or actual fuel. Altogether 9 samples have been tested. It appears that the current family of sorbents fails because they sorb the sulfur-containing molecules by a size selection.

\section{4) PM Filter Development}

Initial testing of the active PM trap was started this quarter. The test matrix was developed to include steady state as well as transient engine tests. Various parameters such as filtration area, regeneration time and strategy are included in the test matrix. Trap performance parameters being monitored include trap pressure drop, regeneration characteristics, electrical power input and filtration characteristics.

Preliminary results indicated that the pressure drop across the system is well below the target backpressure levels. Initial filtration efficiency results indicate that the porous material needs to be further improved. 


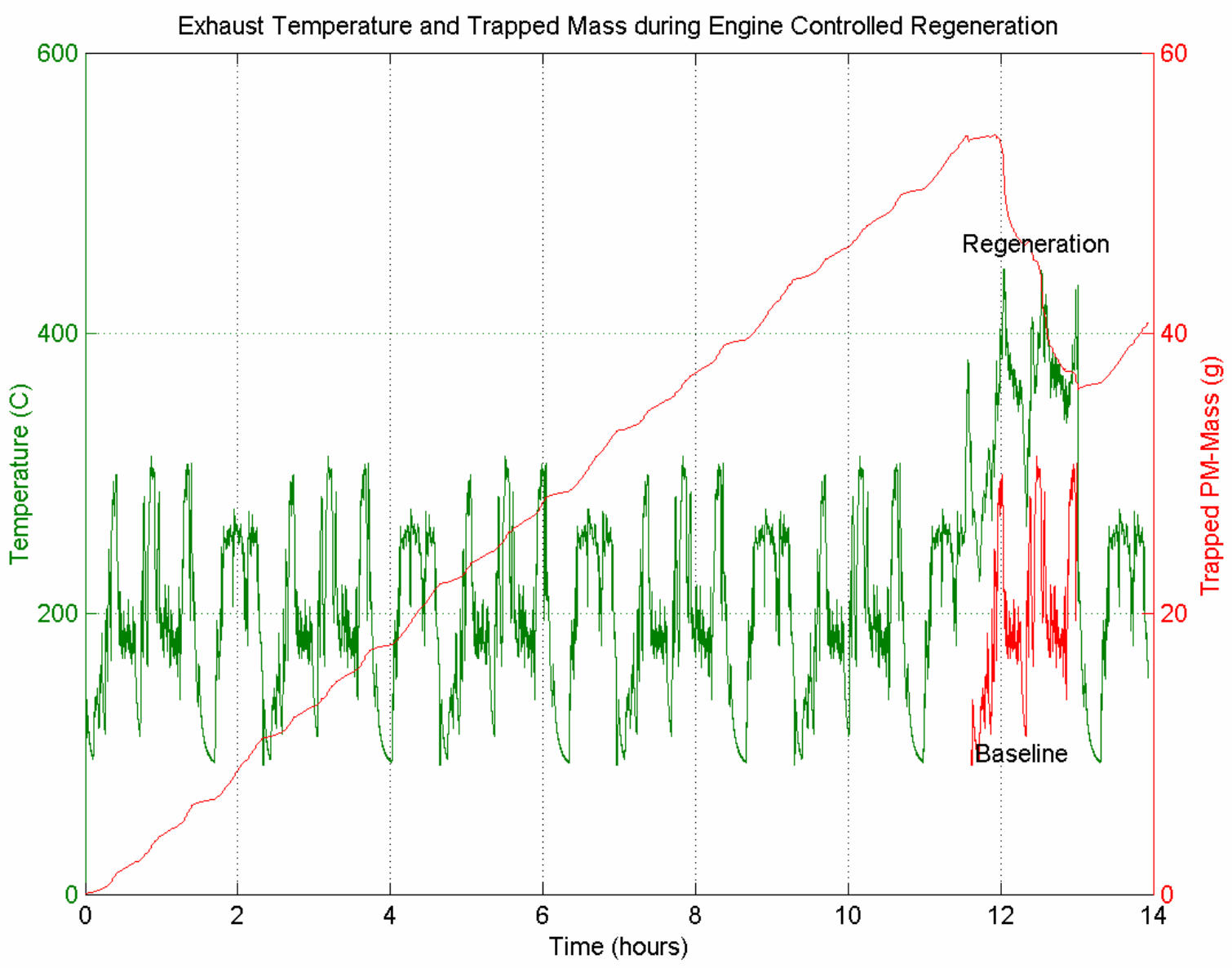

Figure 1.2.10: PM Filter Regeneration Strategies

PM filter Modeling efforts this quarter were focused on improving the existing PM-trap models. Improvements to allow short term effects (such as rate of loading and pressure drop), as well as long term effects (e.g. ash accumulation) to be assessed within engineering accuracy were implemented. Examples of results obtained using this modeling tool are depicted in figure 1.2.10.

\section{5) Exhaust Desulfurization}

During this quarter, a catalytic powder test bench was updated to test several zeolite and oxide sorbant materials in conjunction with a NOx adsorber. This test measured the efficiency of a SOx Trap in terms of how it enhances the durability of the NOx adsorber. 


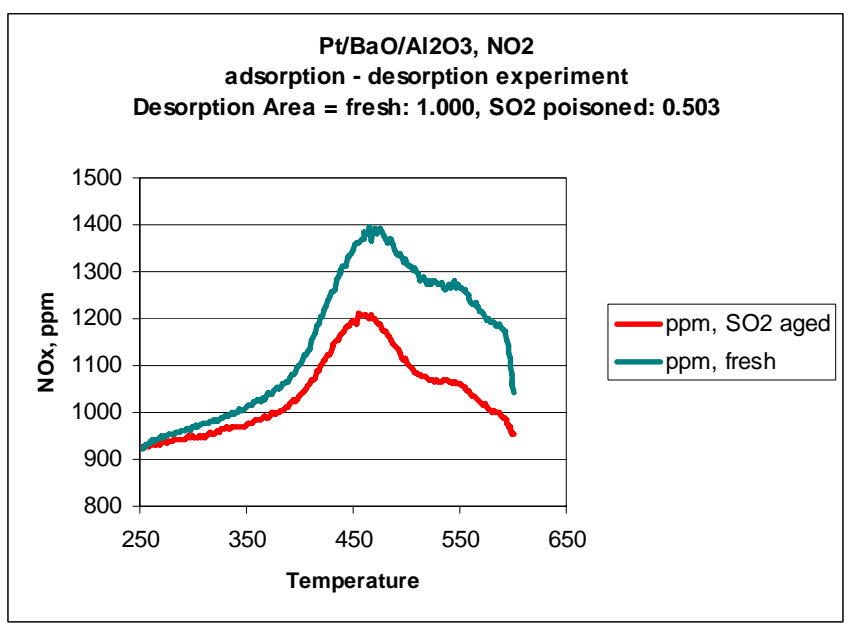

Figure 1.2.11: Effect of SO2 on Adsorption Capacity of Baseline $\mathrm{Pt} / \mathrm{Ba} / \mathrm{Al} 2 \mathrm{O} 3$

Figure 1.2.11 gives an example of the data that was considered as a baseline. After $\mathrm{SO}_{2}$ exposure, the NOx trap material lost about $50 \%$ of original $\mathrm{NO}_{2}$ adsorption capacity. SOx trap performance was determined by increases in $\mathrm{NO}_{2}$ storage capacity of the model $\mathrm{NOx}$ trap after exposure to $\mathrm{SO}_{2}$. The experiments are currently underway.

\section{6) Fuel Reformer}

During the past quarter, the test bench system was upgraded. Decane and hexadecane were run in the upgraded millisecond reactor. Both decane and hexadecane were converted into syngas with selectivities exceeding $80 \%$ for both $\mathrm{H}_{2}$ and $\mathrm{CO}$. Other products formed included carbon dioxide, water, and shortchained alkanes and olefins.

Highlights for Quarter 4, 2002 are summarized below:

\section{1) Aftertreatment System Modeling}

During the $4^{\text {th }}$ quarter of 2002, the Aftertreatment Tool Development Project progressed well and it reached the Pilot part of the Implement Phase. The Pilot phase consists of an alpha- and a beta testing phase. The alpha testing was completed.

\section{2) Diesel Oxidation Catalyst (DOC) detailed calibration}

During the $4^{\text {th }}$ quarter of 2002, TIAX applied the improved calibration techniques developed in quarter 3 , 2002, to further improve the oxidation catalyst models.

\section{3) Fuel Sulfur Trap}

In the quarter 3, 2002, candidate materials identified had failed to sorb enough sulfur compounds to warrant further testing. In this quarter, the decision was made to stop work at this time until further more promising materials can be identified.

\section{4) PM Filter Development}

During the $4^{\text {th }}$ quarter of 2002, initial testing (approximately 200 hours of operation) of the Caterpillar designed Electrically Regenerated Trap (Gen I) was performed this quarter. Test results indicated that the electrical energy required to regenerate the trap while operating a 2000 model year, $190 \mathrm{bhp}, 3126$ engine at 
EPA Mode 11 was equivalent to $0.25-0.5 \%$ bsfc penalty. After a "break-in” period of about 6 hours the filtration efficiency stabilized at around $80 \%$. The engine backpressure was maintained at very low levels throughout each of the tests (typically 24 hour long each). These levels were approximately half of what a typical wall flow filter would exhibit.

Several porous media samples were obtained from two different media suppliers. The bench tests were aimed at identifying filtration efficiency as well as pressure drop characteristics for each of the obtained samples. Furthermore, as these materials were considered candidates for replacing current filtration material in the electrically regenerated trap, a series of thermal and electrical tests were performed to identify the suitability of these samples as media replacement.

\section{5) Exhaust Desulfurization}

During the $4^{\text {th }}$ quarter of 2002, a series of tests were performed to evaluate the total sulfur removal capacity from potential SOx trapping materials, which were exposed to excess $\mathrm{SO}_{2}$ at $200^{\circ} \mathrm{C}, 300^{\circ} \mathrm{C}$, and $350^{\circ} \mathrm{C}$ in an aging furnace. Afterwards, the 32 samples were analyzed and evaluated with a total sulfur analyzer. Results are summarized in Figure 1.2.12. Materials A and B exhibited the best storage capacity; approaching 20\% total sulfur (i.e. $40 \% \mathrm{SO}_{2}$ ) by weight. Note that the greatest $\mathrm{SOx}$ removal capacities were exhibited at temperatures above $300^{\circ} \mathrm{C}$.

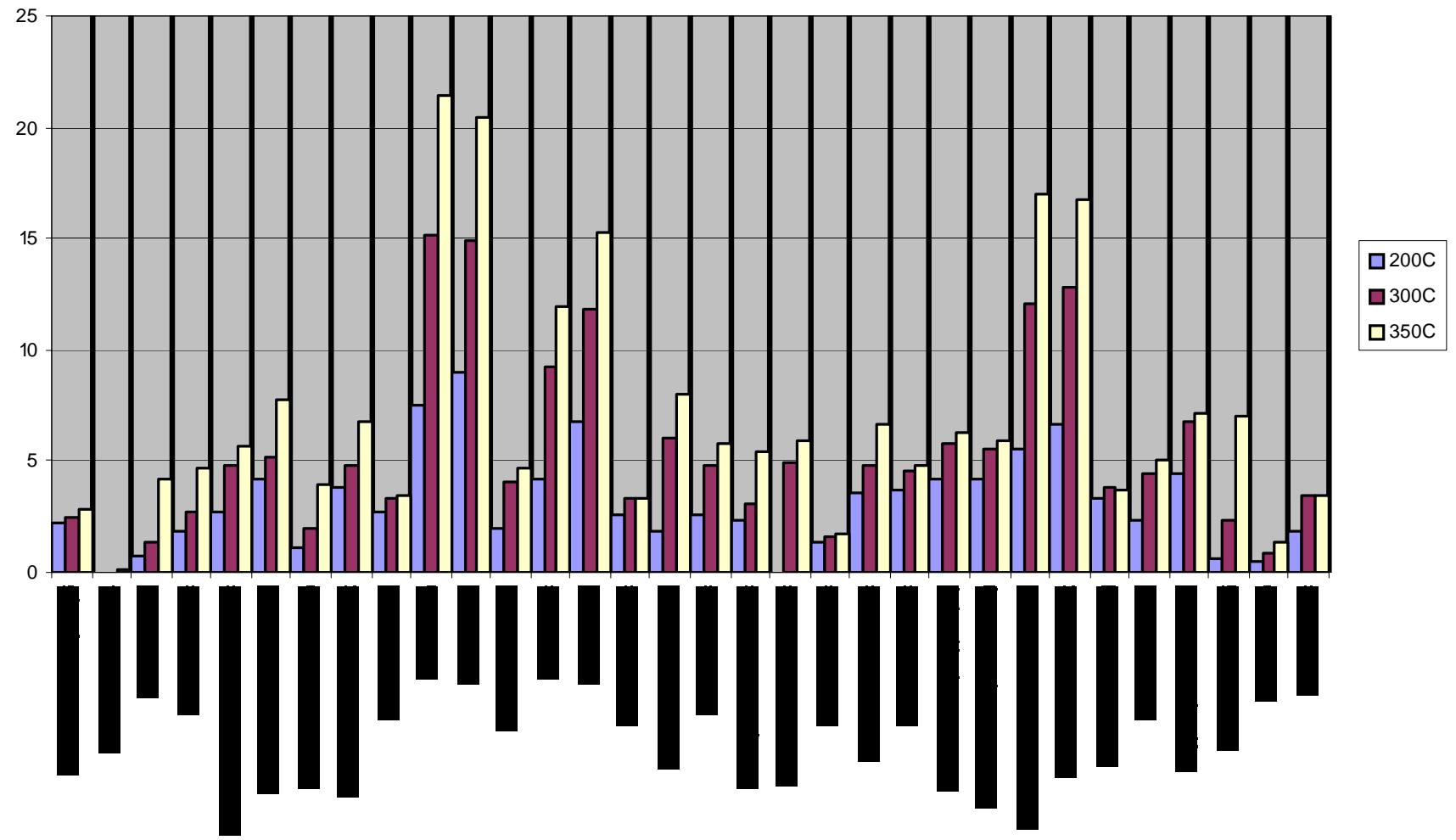

Figure 1.2.12: Storage Capacity of candidate SOx Trap Materials. (Percent Total Sulfur)

In this study, the materials that would have potential for being regenerable exhibited the lowest sulfur capacities. Thus indicating low prospects for developing a regenerable SOx trap material.

\section{6) Fuel Reformer}


DOE Final Report

DE-FC05-000R22806

During the $4^{\text {th }}$ quarter of 2002 , hexadecane $\left(\mathrm{C}_{16}\right)$ fuel spiked with thiophene to 500 ppm sulfur content was tested on the millisecond reactor to determine the sulfur effect and to accelerate sulfur aging. Preliminary results showed minimal deterioration after 16 hours.

\section{7) Thermal management}

During the $4^{\text {th }}$ quarter of 2002,, the work on thermal management re-started.

Highlights for Quarter 1, 2003 are summarized below:

\section{1) Aftertreatment System Modeling}

During the $1^{\text {st }}$ quarter of 2003, efforts have been focused on the validation of existing TIAX models as well as new code development and validation. New modeling capabilities include simple oxidation catalyst models as well as three specific catalyst models of different DOCs currently in production. Simple PM trap models as well as models for CRT's and CCRT's were incorporated and were used in conjunction with the 2007 Demo System integration tasks. Over 600 code-validation runs as well as approximately 110 actual Technology Development runs were performed.

\section{2) PM Filter Development}

During the $1^{\text {st }}$ quarter of 2003, most of the efforts were focused on improving GEN-I. Various minor modifications were incorporated into the hardware. New filtration materials were received and tested. Preliminary results indicated that the new materials had filtration efficiencies in the 95\% range, up from $80 \%$ efficiencies shown with earlier material. The trade-off for this improvement was higher pressure drop. However, the overall system pressure drop is still significantly lower as compared to the wall flow cordierite type filters.

\section{3) Exhaust Desulfurization}

During the $1^{\text {st }}$ quarter of 2003, a new multi-reactor catalyst test bench was installed, debugged, and was being commissioned (about 95\% complete). Several Caterpillar synthesized materials were sent to an external test lab for additional testing.

\section{4) Fuel Reformer}

During the $1^{\text {st }}$ quarter of 2003, plans were developed to test a commercially available diesel fuel reformer on the NOx adsorber equipped engine. Testing with this device, which was specifically developed to function with a NOx adsorber, will provide the most expeditious way of judging the likely benefit of a fuel reformer.

\section{5) Thermal management}

A simulation study showed that high heat capacity (phase change) materials was not beneficial for an aftertreatment system. The heat stored in these materials (like molten metals or molten salts) under high temperature conditions is used to heat up the exhaust gasses at lower temperature conditions. However, in the engine certification cycles it would take too long to heat up the materials, actually lowering the exhaust gas temperatures at the beginning of the cycles, resulting in a net negative effect on the efficiency of the aftertreatment. The selective insulation device, capable of insulating or cooling depending on operating condition, did seem to be viable to increase the efficiency of the aftertreatment system. 
DOE Final Report

DE-FC05-000R22806

Highlights for Quarter 2, 2003 are summarized below:

\section{1) Aftertreatment System Modeling}

During the $2^{\text {nd }}$ quarter of 2003, the efforts were focused on incorporating many physical models in the EGA (Exhaust Gas Aftertreatment) code for broader code application. Examples included 7 different oxidation catalyst models, three different PM trap models, pipe models and others. One significant milestone this quarter was the successful validation of the co-simulation feature where the EGA-code can be run simultaneously with Dynasty / Enterprise (Caterpillars full engine simulation code) allowing the users to simulate complete engine and exhaust aftertreatment systems. This allowed for the preliminary development of the PM Trap Regeneration control strategies for the 2007 Truck Demonstrator.

\section{2) PM Filter Development}

The engine tests on a $1 / 10^{\text {th }}$ scale Non-Thermal Plasma Trap System were started at Accentus this quarter. Initial results indicated that while the Non-Thermal Plasma concept has the potential of meeting trap regeneration needs, more work needs to be done for proper sizing and design of the reactor and power supply for a full flow system.

The Electrically Regenerating Particulate Trap (ERT) development continued for possible application in 2007 or 2010 to meet the stringent particulate emission standards. Advantages of the ERT over other devices were the ability to function independently of the engine operating cycle, no precious metals, low backpressure hence good overall fuel consumption.

The focus in quarter 2, 2003 was in the following areas:

1) To conduct an in-depth analysis of the prototype 'Gen1a' to identify and rectify the cause of some unreliabilities. The results showed the main cause to be oxidation of the electrical connectors caused by poor material selection for this acidic high temperature environment.

2) A 'Gen1b' was designed with improved connectors and improved filtration efficiency. This involved extensive bench tests.

3) To reduce the size and cost of the 'Gen1a' flow control system.

\section{3) Exhaust Desulfurization}

During the $2^{\text {nd }}$ quarter of 2003, a new multi-reactor catalyst test bench was still being commissioned.

\section{4) Fuel Reformer}

During the $2^{\text {nd }}$ quarter of 2003, a fuel reformer was tested on a Caterpillar 3126E engine equipped with a NOx adsorber. The reformer developed specifically for use with this application, generated $\mathrm{H}_{2}$ and $\mathrm{CO}$ reductants from diesel fuel to regenerate the NOx adsorber.

The primary objective of the testing was to determine the potential low temperature advantages of regenerating a NOx adsorber with the $\mathrm{H}_{2}$ and $\mathrm{CO}$ reformate versus that of "more conventional” strategies.

Preliminary data on NOx conversion versus fuel penalty showed mixed results with the reformer contributing to superior low load performance when compared with an in-pipe fuel injection strategy. At high loads, the fuel reformer had a greater fuel penalty for the same equivalent NOx reduction. 
DOE Final Report

DE-FC05-000R22806

Highlights for Quarter 3, 2003 are summarized below:

\section{1) Aftertreatment System Modeling}

The efforts this quarter were focused on releasing the code for wider use within Caterpillar. Activities included code validation, the addition of various graphical user interface enhancements and the identification of and resolution of minor bugs in the code. The result was the release on a pilot basis. Additional code enhancements focused on a better description of the Electrical Regenerating Trap System, as well as NOxadsorber technology.

\section{2) PM Filter Development}

Electrically Regenerated Trap: The focus in quarter 3, 2003 has been in the following areas:

1) Replace the filtration material and assemble Gen $1 b$

2) Test Gen $1 b$

3) Complete the optimization study for the Gen II

Gen $1 \mathrm{~b}$ was assembled and the testing was started in quarter 3 2003. However, several delays in the start of the testing lead to extending the testing into $4^{\text {th }}$ quarter, 2003.

The Gen II optimization study was performed using Taguchi methods for Robust Engineering. Preliminary results indicate that the trap size could be reduced by $25 \%$. The filtration material was further optimized

\section{3) Exhaust Desulfurization}

This quarter, bench commissioning continued. It will be used to further characterize SOx trapping materials, with new test protocols that incorporate NOx adsorber catalysts.

Highlights for Quarter 4, 2003 are summarized below:

\section{1) Aftertreatment System Modeling}

The efforts this quarter were focused on various improvements to the code graphical user interface. Additional code developments focused on improving the co-simulation interface between the EGA code and Dynasty $^{\mathrm{TM}}$. Minor modifications were implemented to improve model predictive capability. Over 4,000 runs were performed in 2003 using the Caterpillar developed code.

\section{2) PM Filter Development}

\section{Electrically Regenerated Trap:}

The Electrically Regenerating Trap (ERT) Gen1b that was built during Q2 completed its 500 hr test without electrical failure. This test demonstrated that the material selection and connection development work done during Q2 was successful. Although the trap did demonstrate regeneration capability, the trap did not meet the targets for filtration efficiency. The reasons for this are currently being investigated in detail but are thought to stem from 3 main areas. First, failure of the seal between filter material and cartridge, so allowing soot loaded gas to pass directly to the exit. Second, there were miscellaneous leaks in the general trap construction. The third area to address is filter media design.

In conclusion, this project has demonstrated regeneration capability both steady state and basic transient performance. The filtration efficiency has shown some success to $70 \%$ but needs improving to reach the $90 \%+$ level required..

\section{5) Combined NOx/PM Control}


The diesel fuel burner test bench was modified to run lean/rich cycles. This capability will allowed a combined DPF with NOx aftertreatment technology "One-Box NOx system” to be evaluated for NOx regeneration while being loaded with particulate. Test protocols of the modified instrument are currently being developed. See Figure 1.2.13.

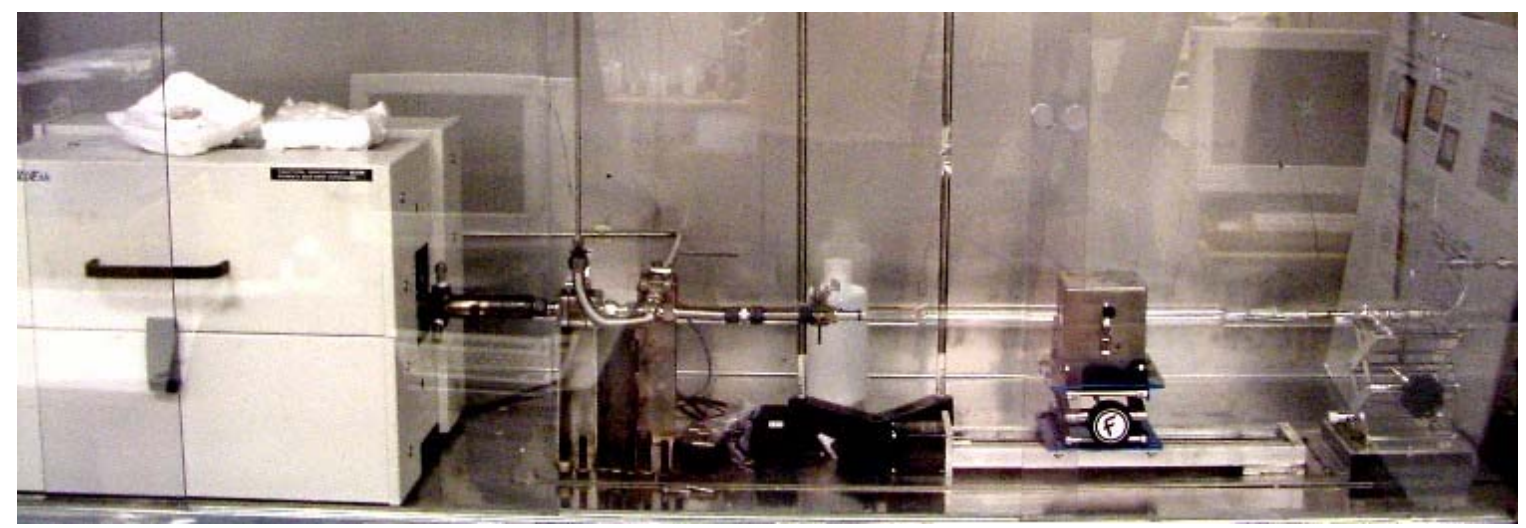

Figure 1.2.13. Diesel Fuel Burner Test Bench

To help our fundamental understanding of the soot burning process, an internal to Caterpillar bench referred to as the Xytel bench was modified to add pressure sensors before and after the catalyst. This allowed measurement of the differential pressure across the catalyst and to gain a better understanding of what happens to the loaded particulate trap during NOx regeneration cycles.

Highlights for Quarter 1, 2004 are summarized below:

\section{PM Filter Development}

\section{Electrically Regenerated Trap:}

The next generation configuration optimization has been completed. This configuration was developed and tested with funding from the production teams.

From Quarter 2, 2004 to Quarter 1, 2005, the focus was on NOx Adsorber Technology Development. This is summarized in section 2.2.

Highlights for Quarter 2, 2005 are summarized below:

\section{Combined NOx/PM Control (Combined System)}

A test plan was developed to evaluate combined systems. The plan consists of four different protocols, beginning with comparing the PM trap function of the combined system to a conventional uncatalyzed DPF. Another set of experiments will compare the NOx reduction function of the combined system to a conventional NOx control catalyst.

Test protocols were also developed to explore the impact of thermal aging and the potential synergies of soot and NOx on the same support. Several samples of combined system catalysts have been requested from Johnson Matthey, Engelhard and Umicore. Tests were planned to be conducted to identify the best supplier sample. Combined system samples are expected to arrive and testing is expected to begin next quarter. However, the program then shifted to focus on HCCI. 
DOE Final Report

DE-FC05-000R22806

\section{Section 1.3 Membrane System Development.}

The objective of the Air Separation Membrane program was to provide a Nitrogen enriched air supply to the engine as a possible alternative to Clean Gas Induction (CGI). Engine performance was to be maintained while emissions levels lowered (50\% NOx reduction). The system consisted of four membrane cartridges assembled in a housing which was mounted in the test truck as shown in Figure 1.3.1. The project ran from 2000 Q4 through 2003 Q4.

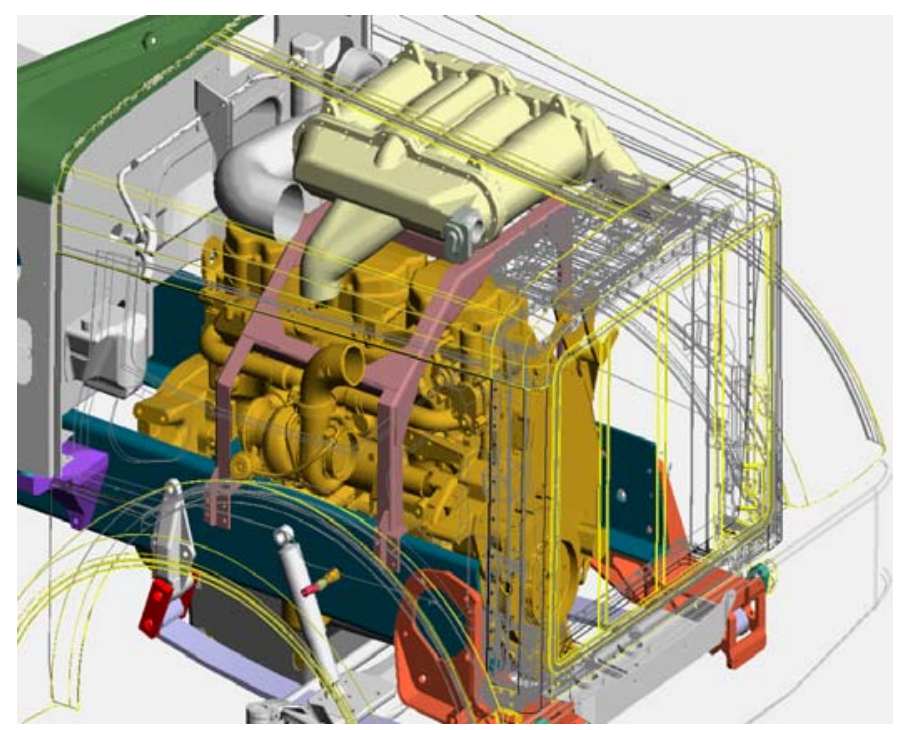

Figure 1.3.1. Schematic of field test truck layout.

Innovative Membrane Systems (IMS) supplied the membrane cartridges. Early challenges involved cartridge durability. IMS continued to improve durability by incorporating results from pressure cycling rig tests.

Figure 1.3.2 shows the membrane cartridges and the housing.

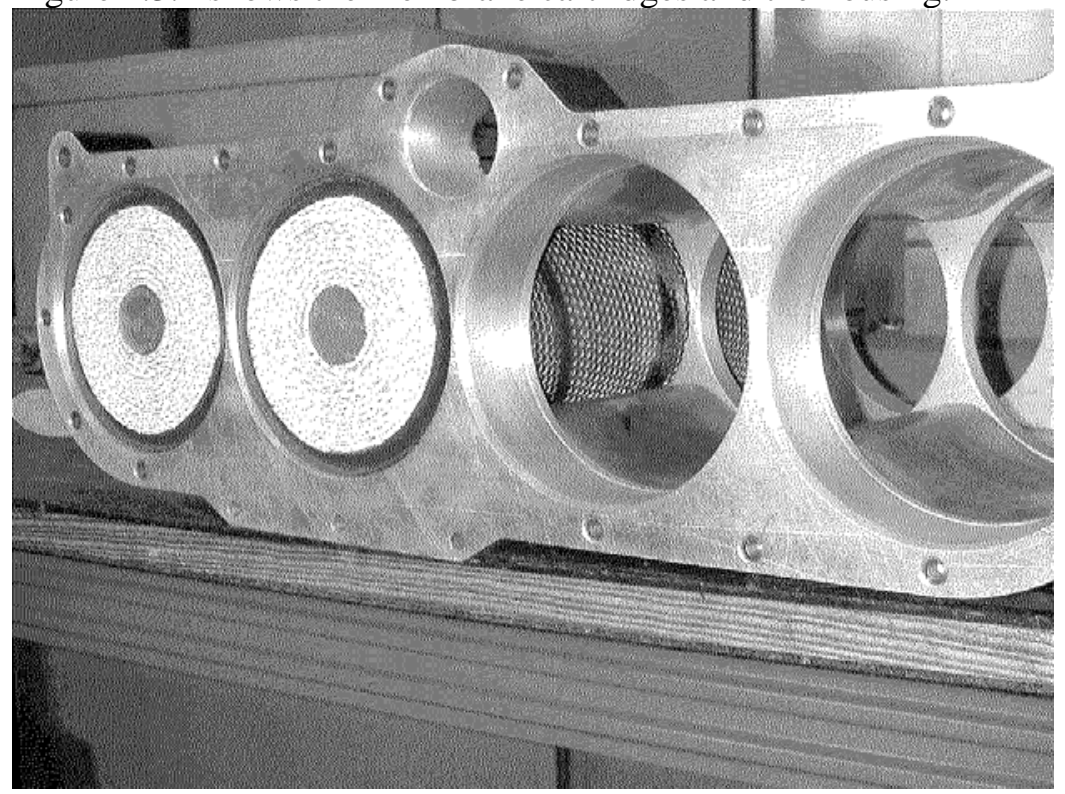

Figure 1.3.2. Inside view of field test housing and bypass port 
For the Durability Field Test, five 2000 Peterbilt 379 trucks powered by 430 hp C-12 engines were supplied by Decker Trucking from Fort Dodge, IA. The first membrane system was installed 2001 Q3, illustrated in Figure 3. Installation went well, with the membrane operating as expected. After some adjustments to the acceleration-fueling map, the engine provided acceptable acceleration, power, and transient smoke. The truck was driven for 1200 miles around the Peoria area to gain confidence, and then released to Decker Trucking for normal service.

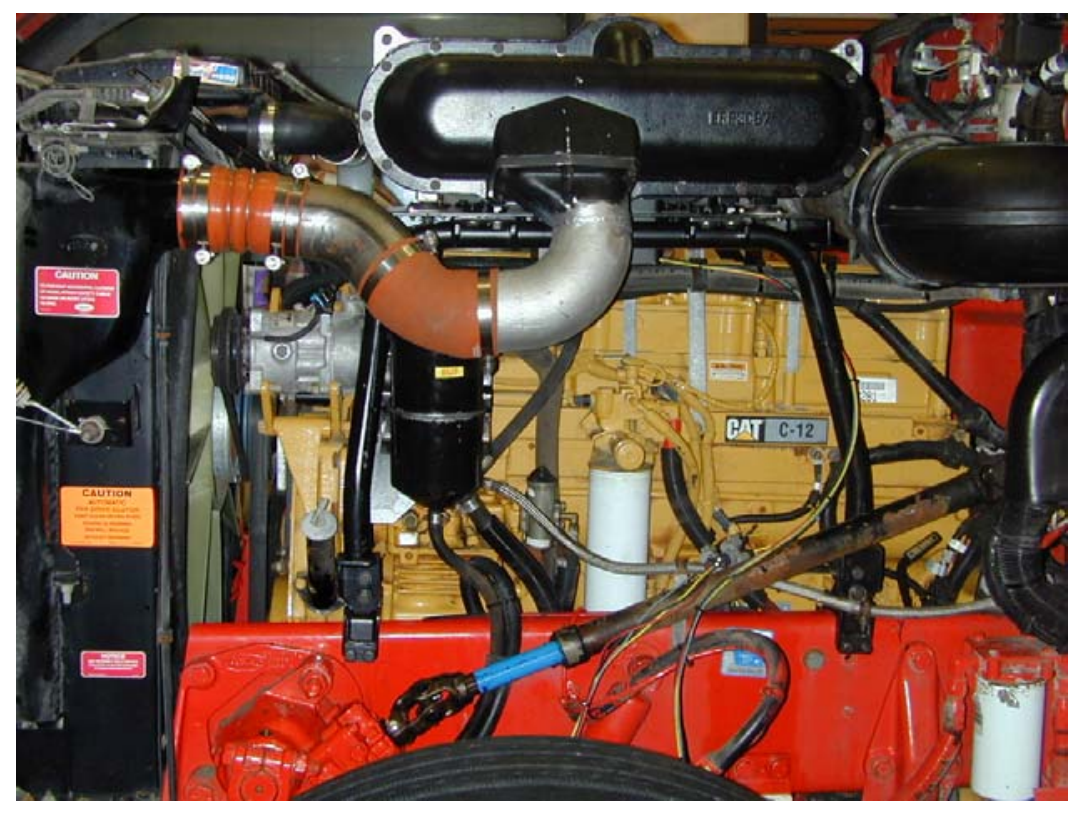

Figure 1.3.3. Membrane unit installed in Truck for field trial

Details about the field test:

2002 Q2 IMS completed membrane development, durability improved, did not achieve target performance with required durability. 2002 Q3 Southwest Research Institute contracted to perform dust fouling tests. 2003 Q2 First truck to be removed from test - 151,000 miles 2003 Q3. Second truck encountered membrane failure - 220K miles. Total accumulation 940K miles. 2003 Q4 test complete. Third truck encountered failure. Accumulation greater than $1 \mathrm{M}$ miles.

Due to durability concerns and with other options for NOx compliance such as CGI, research on membranes was concluded. 
DOE Final Report

DE-FC05-000R22806

\section{Section 1.4: High Thermal Efficiency Building Blocks}

\section{Section 1.4.1: Turbo-Compound}

Even after the extraction of exhaust energy using a series turbocharger air system such as in the Caterpillar truck engines with ACERT ${ }^{\circledR}$ technology, there is still significant energy in the exhaust stream. This energy can be extracted through a third turbine. Since enough intake mass flow is already available from the 2 series compressors, additional stages of compression are not needed. This power can then be returned and added to the crankshaft power. This technique is termed adding a turbo-compound. To extract this energy efficiently, a highly efficient turbine and geartrain is required. Below is a graph (Figure 1.4.1.1) showing that as more power is provided through the turbo-compound unit (x axis). The power required from the piston or reciprocator, is reduced ( $2^{\text {nd }} y$ axis) and the system thermal efficiency is improved (y axis). However, the thermal efficiency does reach a maximum value because the addition back pressure to extract work eventually offsets the gain. This principle was discussed in the 2005 and 2006 DEER presentations.

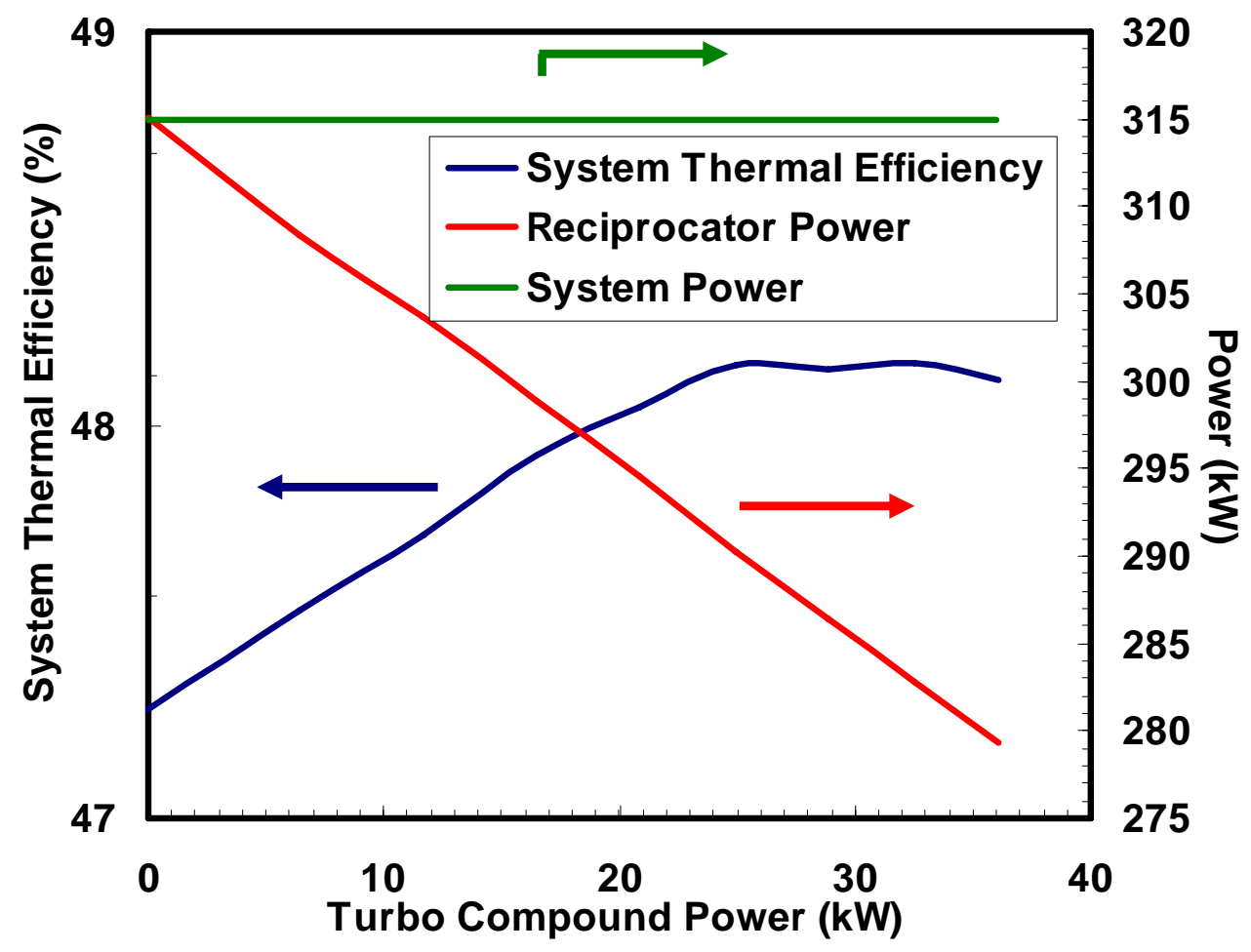

Figure 1.4.1.1: Turbo-Compound thermal efficiency benefit.

The objective of this section is to describe work done to complete an iron demonstration of this technology. The task was to develop a high efficiency, durable turbo-compound system. As mentioned above, to accomplish this goal a high efficiency power turbine (discussed further in following section), high efficiency gearing, and a fluid coupling (to dampen torsionals) were required.

The design of the power turbine was a scaled version of an axial turbine wheel used for the HCCI air system. It was decided to put the turbo-compound power into the rear of the engine by the flywheel to help with the overall air-system layout and due to a lesser degree of torsional dynamics at the rear. A fluid coupling has been incorporated to dampen torsional vibrations between engine and power turbine as well as help with speed variations throughout operation. A picture of the turbo-compound layout can be seen below in Figure 
1.4.1.2, 1.4.1.3. and 1.4.1.4. Several design and analysis iterations produced the final gear and bearing selections employing high contact ratio helical gears with rolling element bearings.

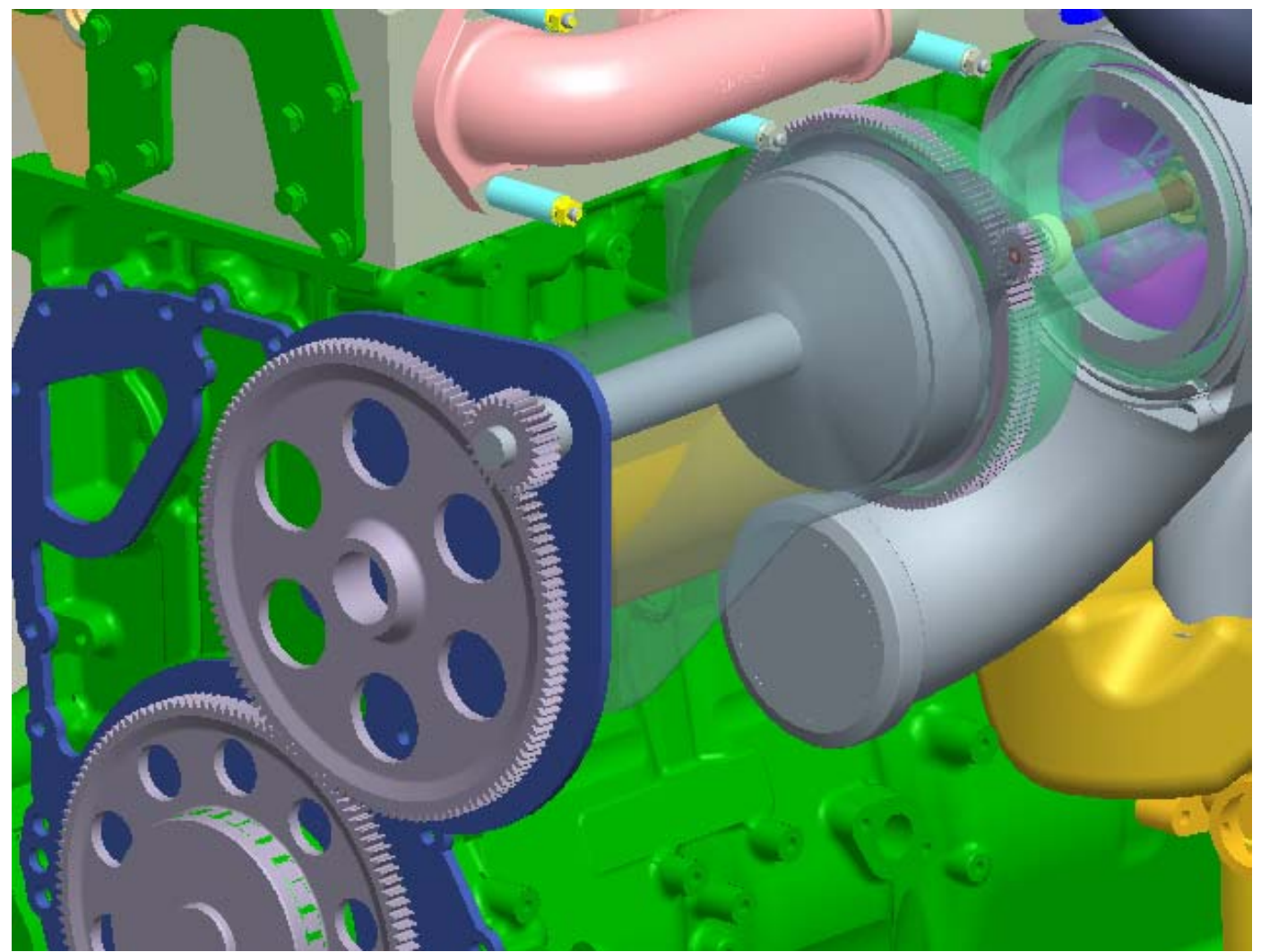

Figure 1.4.1.2: Turbo-Compound Design.

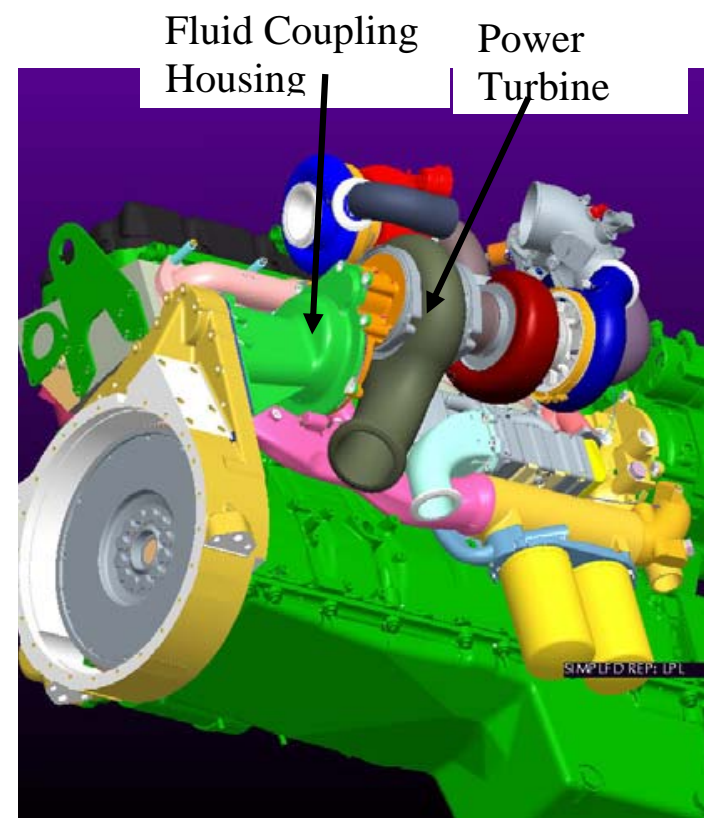

Figure 1.4.1.3: Picture showing the turbo-compound and turbochargers. The gear train coupling the turbocompound to the rear of the engine can also be seen. 


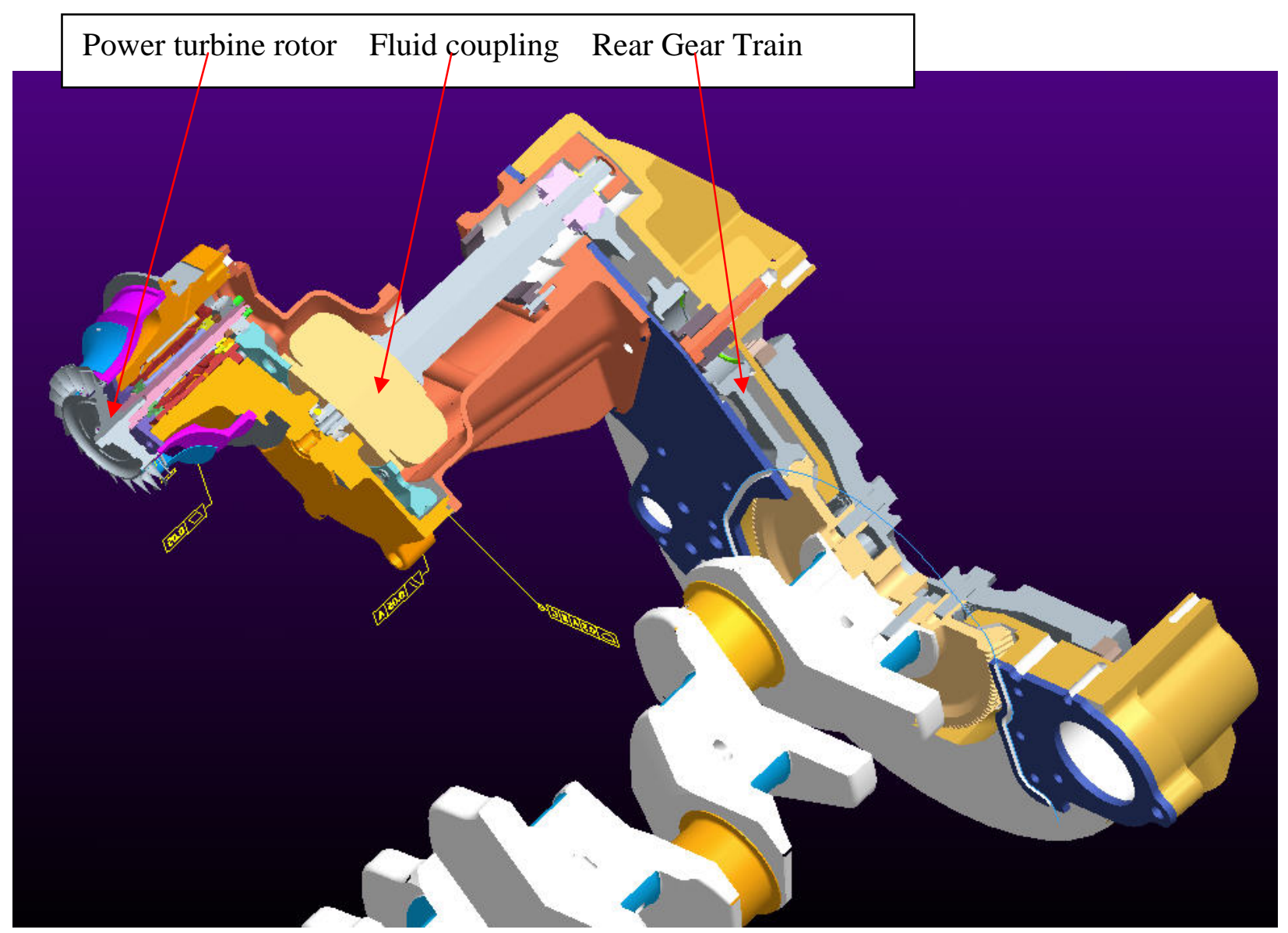

Figure 1.4.1.4: Turbo-compound cross section showing power transfer from the power turbine to the crankshaft.

Engine architecture and component inertias were input into Tomahawk analysis software (A Caterpillar, Inc. proprietary code) to predict gear train loads, efficiency, and bearing resultants. The design meets targets of $82 \%$ aerodynamic and $95 \%$ mechanical system efficiency. The result was a powertrain that was designed to transfers $23 \mathrm{~kW}$ and $62 \mathrm{~kW}$ of useable power back into the crankshaft at peak torque and rated speed, respectively. Working with key suppliers, the design team used these inputs in conjunction with available bearing specifications to optimize bearing life while meeting packaging constraints, cost, and delivery timelines.

The result of testing indicated that the turbocompound powertrain recovered $\sim 25 \mathrm{~kW}$ of useable power from the exhaust stream. However, due to a design error creating a situation where a gear rubbed against the bearing housing and a rotor dynamic causing the turbine to rub its housing, much of the power was not transferred back into the crankshaft at peak torque speed. This amount of power absorbed from the exhaust stream was the amount predicted in the analysis. The engine ran 50 hours in this time period. Instrumentation for the turbocompound unit included shaft speeds, pressures and temperatures before and after the power turbine. Fig. 1.4.1.5 shows a picture of the engine with the turbocompound.

The final result was that the turbocompound predicted benefit of 1.7 points of thermal efficiency was not realized in iron. However, due to the good match between simulation and the measured amount of energy extracted from the exhaust, it is believed that the benefit would be realized in an improved design. 


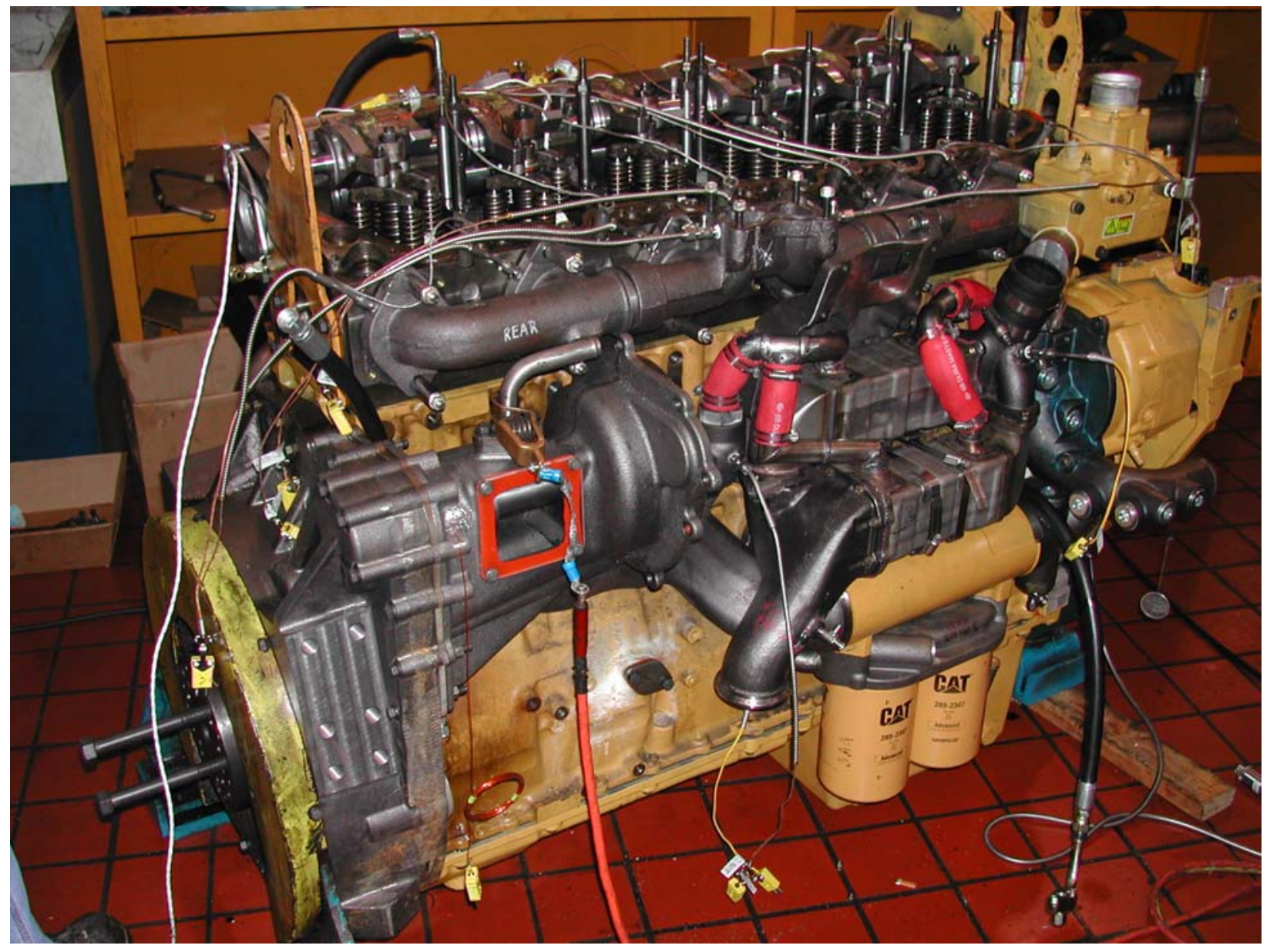

Figure 1.4.1.5. Turbocompound unit installed on the High Efficiency Engine System Demonstration (milestone 4 engine). 
DOE Final Report

DE-FC05-000R22806

\section{Section 1.4.2: Air System Development}

Air systems improvement is a key area for focus on improving engine efficiency. Turbochargers extract energy from the exhaust stream using a turbine and transfer the power to the compressor to bring more intake charge into the engine. The benefit of improved air systems is shown in the Figure below. As improvements to air system are made, the back-pressure on the engine is reduced for a given boost level, which effectively increases the expansion of the products of combustion and thus the increases the work, for the same level of intake pressure created. It is also important to note that the baseline engine was equipped with ACERT ${ }^{\circledR}$ technology including series turbocharging in conjunction with variable intake valve timing. The decision was made to keep the series turbocharging as part of the $50 \%$ demonstration system. The chart also shows the benefit of intercooling between low pressure and high pressure compression stages. Intercooling is also one of the technologies used in the demonstration engine and is covered in a following section. Both of these principles were discussed in the 2005 and 2006 DEER presentations.

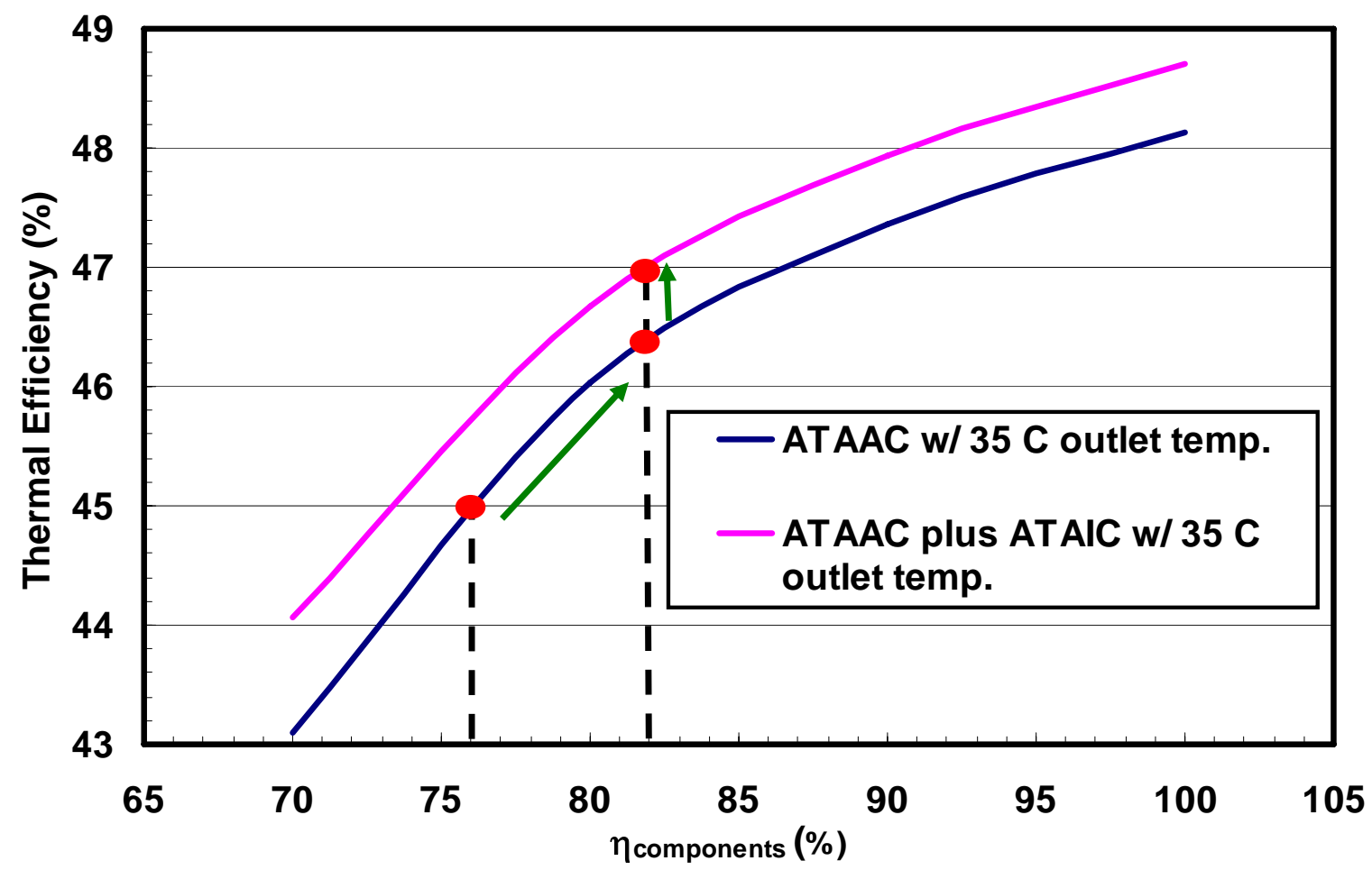

Figure 1.4.2.1. Graph of improvements to thermal efficiency from improving air system component efficiency. Also shown is the benefit of intercooling.

To meet the goal of 50\% thermal efficiency, efficiency levels of $80 \%$ or higher were determined to be required for

1) HP Stage Compressor

2) LP Stage Compressor

3) HP Stage Turbine

4) LP Stage Turbine

5) Power Turbine

Radial compressors with efficiencies of close to $80 \%$ at the peak design point are currently in production. Production turbines, however, were not close enough to the required efficiency of $80 \%$. Therefore within the program, designs for new turbines for the high pressure and low pressure turbochargers and the power turbine 
were developed. These turbines must be matched to the system properly in terms of mass flow, pressure and temperature, in order to achieve peak efficiency.

1D turbine aerodynamic analysis was completed on the high pressure and low pressure radial turbines for the series air system. Optimized blade geometry and the addition of nozzle blades were predicted to meet the $80 \%$ efficiency level for the turbines. 3D CFD of the turbine wheel passages was completed along with FEA analysis.

An axial turbine wheel and nozzle ring design was chosen to be used for high efficiency and improved packaging of the power turbine portion of the turbo compound system. 1D aerodynamic analysis was completed on this design along with 3D CFD and FEA analysis. Pictures of each turbine are provided in Fig. 1.4.2.2. After the completion of the aerodynamic design, all turbine wheels were modeled in ProE to facilitate the detailed design, procurement, and finite element analysis (FEA).

a)

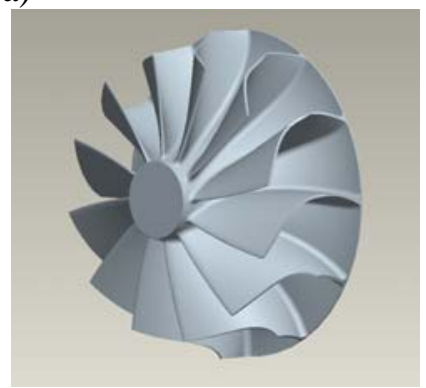

b)

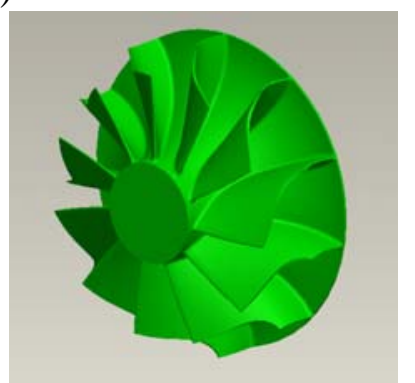

c)

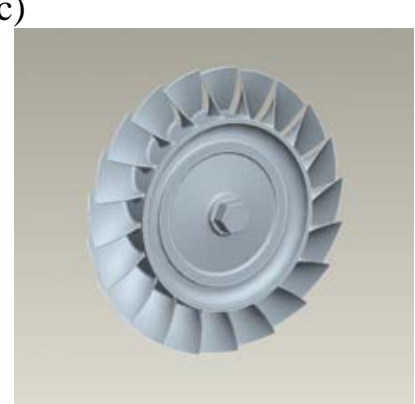

Figure 1.4.2.2: (a) Low pressure, (b) high pressure, and (c) power turbine wheels.

Finite element analysis was completed on all turbines wheels with thermal and centrifugal loading applied. Several design modifications were incorporated based on the results of the FEA in order to meet production stress levels in the turbine wheels. The material selected for the radial turbine wheels is Inconel 713LC, which is the same cast material used in current production turbines. Due to lead times associated with casting the axial turbine wheel and nozzle for the turbo-compound turbine, these parts were machined which led to a material selection of Inconel 718 for both the turbine wheel and nozzle ring.
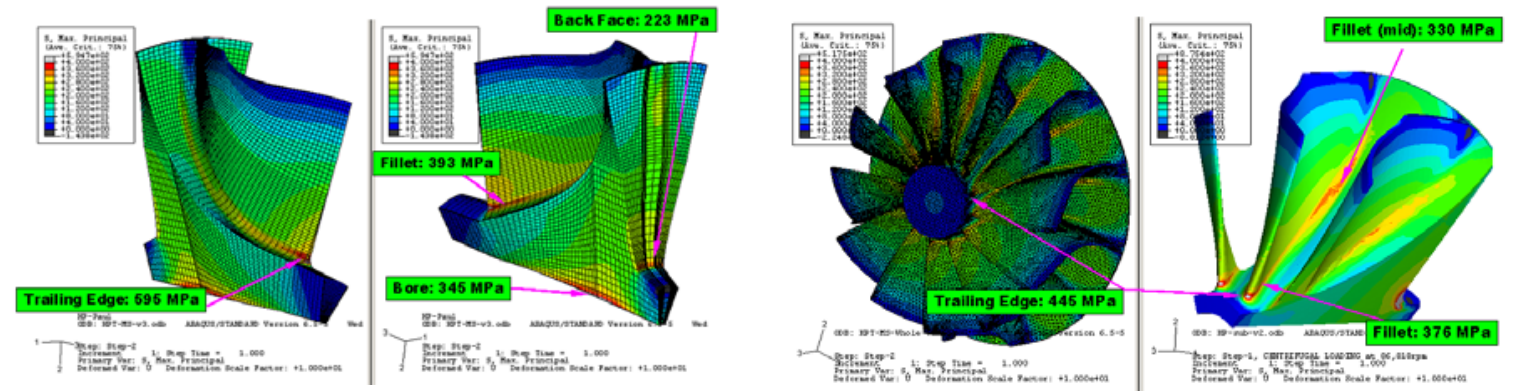

Figure 1.4.2.3: Finite element analysis results for the LP turbine wheel.

Pictures of the low pressure stage turbocharger and high pressure stage turbocharger are shown below. The design for the turbocompound unit is also shown below in Figures 1.4.2.4 and 1.4.2.5. 

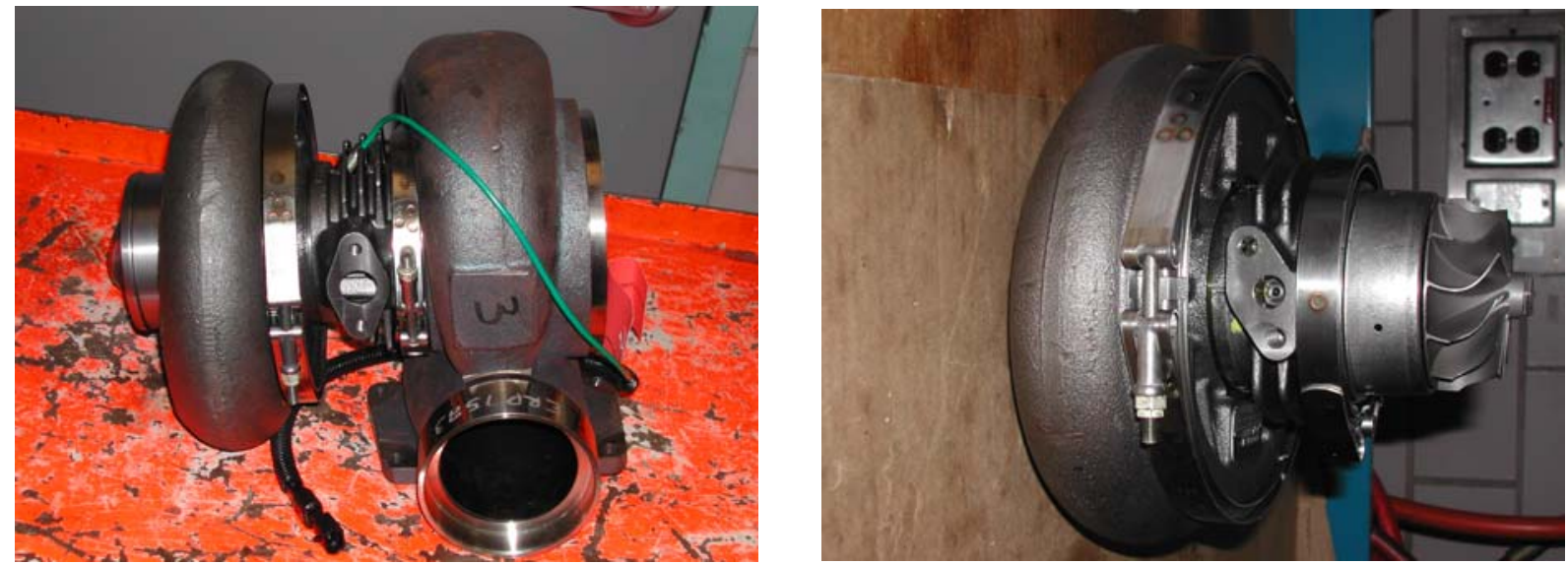

Figure 1.4.2.4: Pictures of (a) low pressure turbocharger and (b) high pressure turbocharger.

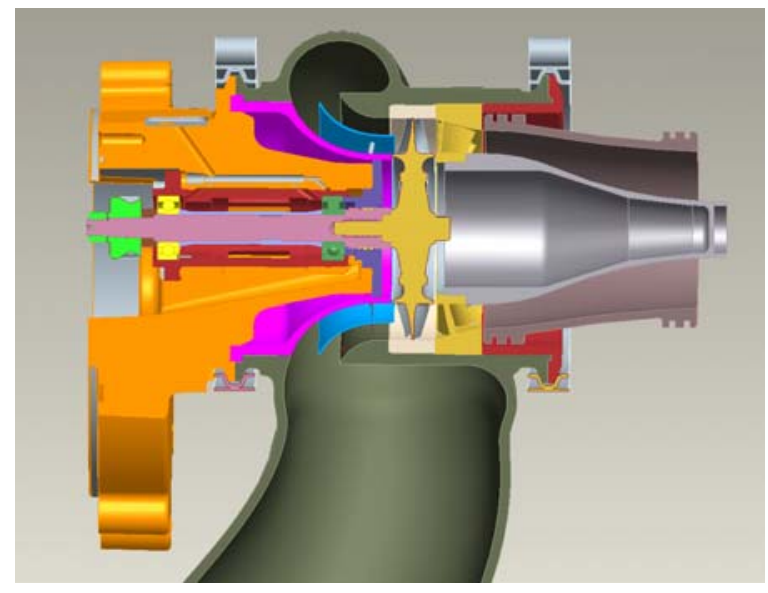

Figure 1.4.2.5: Pictures of the power turbine stage

In addition, a compressor designed as part of the EWHR program was scheduled to be tested as part of the final demonstration engine. This compressor design replaces the baseline high pressure stage design and was sized to better match with the lower mass flows for the $50 \%$ demonstration engine.

The high pressure and low pressure turbochargers were gas stand tested and were included on the High Efficiency Engine System Demonstration (milestone 4 engine). Figure 1.4.2.6 and 1.4.2.7 show the performance of the turbines relative to their baseline on the gas stand. As can be seen in Figure 1.4.2.6, the low pressure turbine stage data is better than the baseline. However, the efficiency needed to reach $50 \%$ thermal efficiency was $80 \%$. Therefore the full benefit of 1.2 pts from the improved air system was not realized. However, it is important to note that designs for compressors and turbines above $80 \%$ have been built and tested in other programs and therefore, the 1.2 points of increased thermal efficiency is still viewed as possible to achieve. 
DOE Final Report

DE-FC05-000R22806

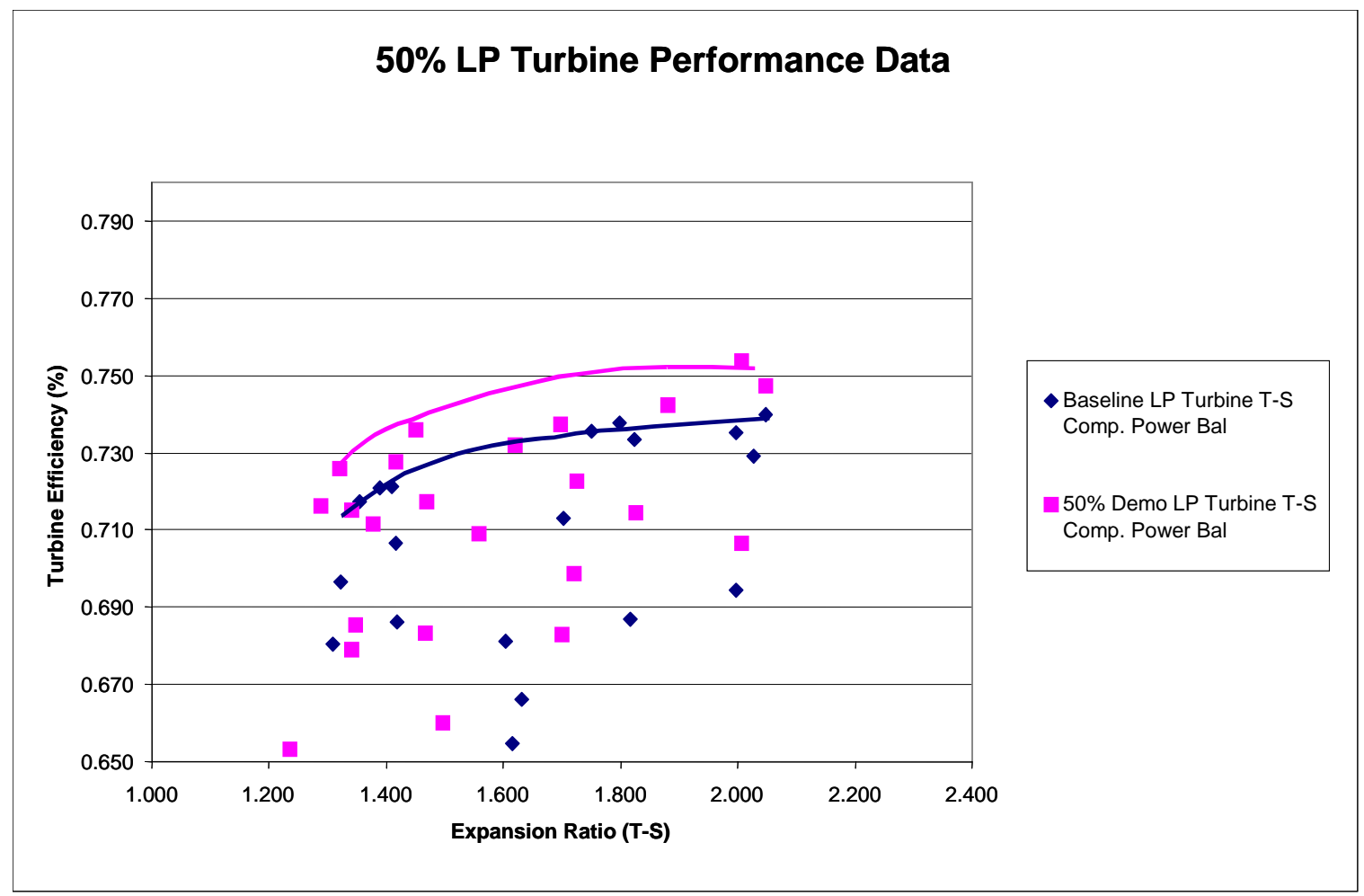

Figure 1.4.2.6: Performance curves for the low pressure turbocharger.

As can be seen in Figure 1.4.2.7, the data for the high pressure turbine stage is much better than the baseline. This design incorporates the use of vanes in a divided housing. However even with the measured gains, the efficiency needed to reach 50\% thermal efficiency was 80\%. Therefore as stated above, the full benefit of 1.2 pts from the improved air system was not realized. Again, it is important to note that designs for compressors and turbines above $80 \%$ have been designed and tested in other programs and therefore, the 1.2 points of increased thermal efficiency is still viewed as possible to achieve. 


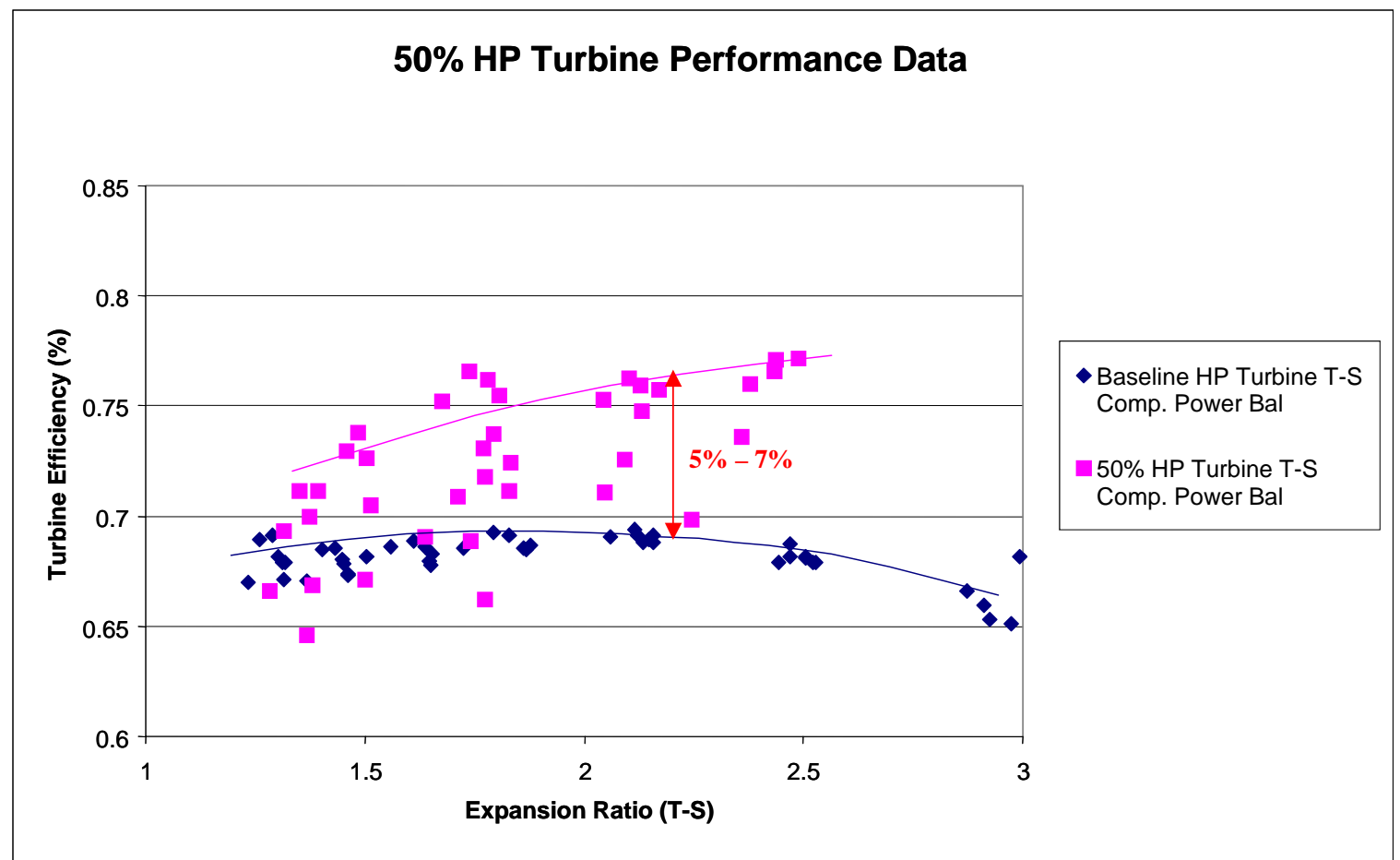

Figure 1.4.2.7: Performance curves for the high pressure turbocharger.

The improved high pressure stage compressor was procured but not in time to be tested on the milestone 4 demonstration engine. The improved high pressure stage turbine and improved low pressure stage turbine were used in the milestone 4 demonstration engine.

\section{Section 1.4.3: Combustion System Optimization}

To reach the program goal of 50\% thermal efficiency the compression ratio and peak cylinder pressure were increased. The ability to increase peak cylinder pressure was enabled by the ultimate flow head which permitted $22 \mathrm{MPa}$. The challenge was to increase the compression ratio of the engine without a detrimental impact on $\mathrm{PM}$ and $\mathrm{NO}_{\mathrm{x}}$ emissions.

The target compression ratio was 22:1 compared to the production 18:1 compression ratio. The combustion chamber was redesigned to reduce piston to head and piston to valve clearances and the piston bowl geometry was redesigned. CFD and 3D combustion analysis were completed to pre-screen the new design for emissions impact and interactions between the fuel injection spray and the piston bowl. Velocity and $\mathrm{NO}_{\mathrm{x}}$ profiles within a 2D cross-section in the bowl are shown in Fig. 1.4.3.1. The CFD results indicated that the desired compression ratio and injection timing could be achieved without a detrimental impact on $\mathrm{NO}_{\mathrm{x}}$ and PM emissions.

a)

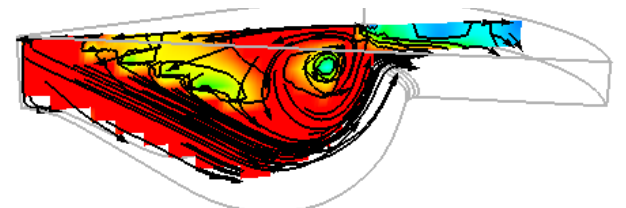

b)

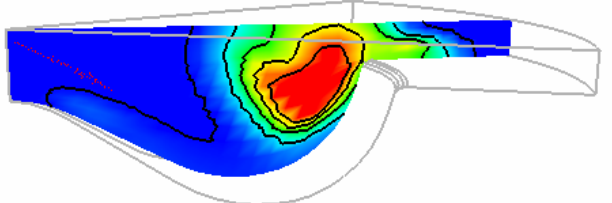

Figure 1.4.3.1: (a) Velocity and (b) $\mathrm{NO}_{\mathrm{x}}$ profiles. Red indicates higher intensity and blue lower. 
DOE Final Report

DE-FC05-000R22806

Following the positive results of the CFD analysis, pistons were procured with the new bowl geometry and testing was completed on a multi-cylinder test engine. Test results showed a 3-4\% improvement in thermal efficiency at equal NOx and smoke when compared with the current production piston as shown in Fig. 1.4.3.2. These results agreed well with the simulation results presented at the DEER conference in 2005. This 22:1 bowl geometry was selected for the demonstration and was duplicated in the air-gap piston (see Section 1.4.5.).

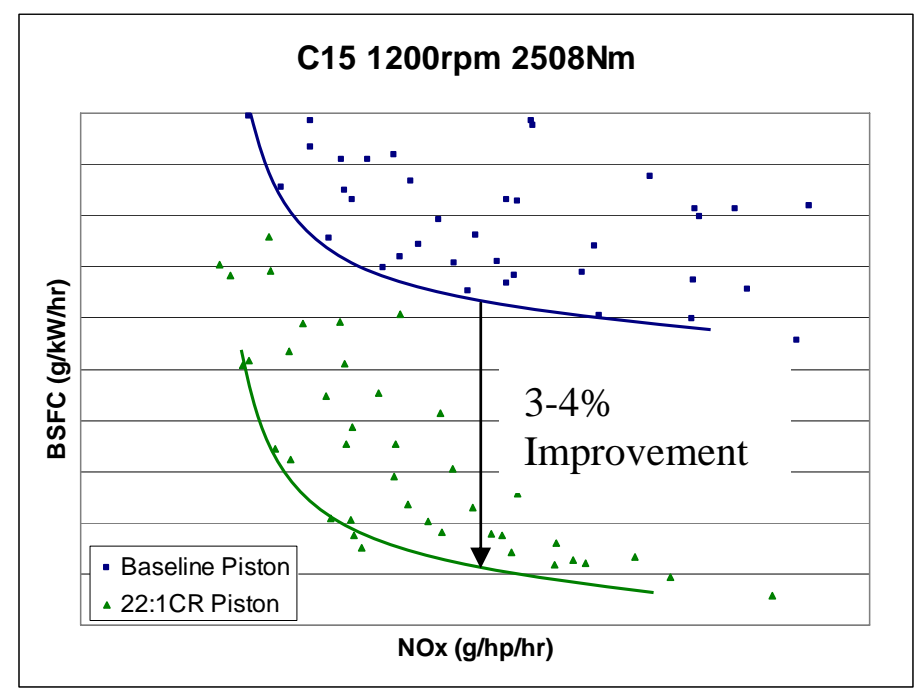

Figure 1.4.3.2: $\mathrm{NO}_{\mathrm{x}}$-BSFC trade-off for multi-cylinder test engine.

However, after the data was taken, a problem with oil consumption was identified which had effectively shifted the 22:1 piston data to better BSFC because the energy content of the oil burned was not counted.

To further improve the fuel economy benefit from the power cylinders of the engine, camshafts with optimized valve timing and injection timing events were also designed for the milestone 4 engine.

The improved combustion system including 22:1 compression ratio, 22 MPa Peak cylinder pressure levels, optimized IVA settings, optimized CGI, and camshafts with optimized valve timing and injection timing events was tested as part of the High Efficiency Component Testing on MCTE (milestone 3 engine). This work built on the results listed above. The improved combustion system including 22:1 compression ratio, 22 MPa peak cylinder pressure levels, optimized IVA settings, optimized CGI, and camshafts with optimized valve timing and injection timing events were also included as part of the High Efficiency Engine System Demonstration (milestone 4 engine).

\section{Section 1.4.4: Reduced Engine Parasitics/Friction}

The objective of this work was to reduce engine friction and parasitics in order to achieve an improvement in thermal efficiency. A major focus area was the reduction of piston-ring-liner (PRL) boundary friction by $50 \%$, which will improve fuel consumption by $\sim 1 \%$. Other concepts considered included reductions to crank and rod bearing losses, lower friction oil, and variable displacement oil pumps. The reductions to crank and rod bearing losses were not pursued in terms of prototype hardware due to design challenges of changing bearing types. Below is a chart (Figure 1.4.4.1) showing the predicted advantages for the other 3 friction reduction technologies. 


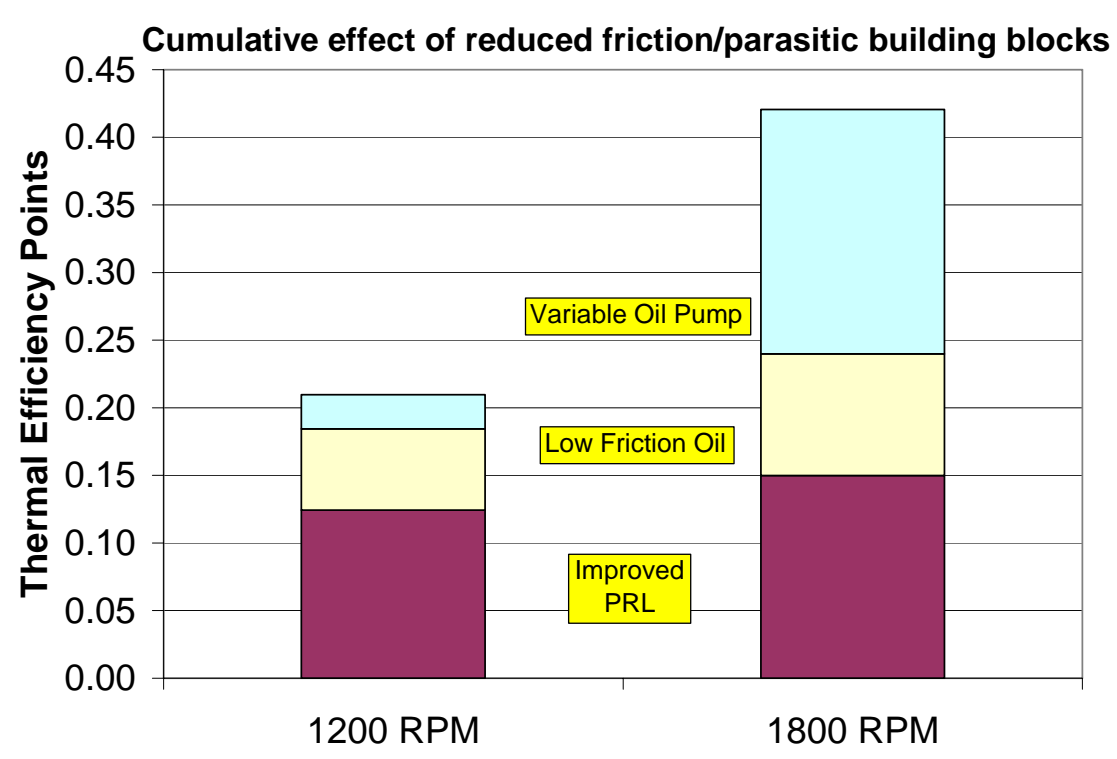

Figure 1.4.4.1: Benefit from friction reduction technologies at 2 operating speeds.

\subsubsection{Analysis and focus area identification:}

In the early years of the program, the much focus was placed on testing engines for friction contributions and determining the ability of analysis codes to properly predict the friction. Codes evaluated included Ringpak, Pisdyn, Orbit codes from Ricardo, and internal Caterpillar codes. Several load cases were run with and without predicted land and liner distortions. Sensitivities to oil supply conditions were also investigated as part of the analysis. To insure all necessary mechanisms were being modeled correctly, predicted blow-by and oil consumption levels were compared to measured levels. The linkage between friction and oil consumption and blow-by is critical to understand as crankcase emissions are counted in 2007 and beyond emissions regulations. Predicted friction levels were compared to tear-down measurements.

To further gain data for the analytical code validation, a C-15 piston and skirt was instrumented with a telemetry system. The sensor was used with a telemetry transmission system to identify ring groove position, land to liner position and (skirt to liner) position (Figure 1.4.4.1.1.).

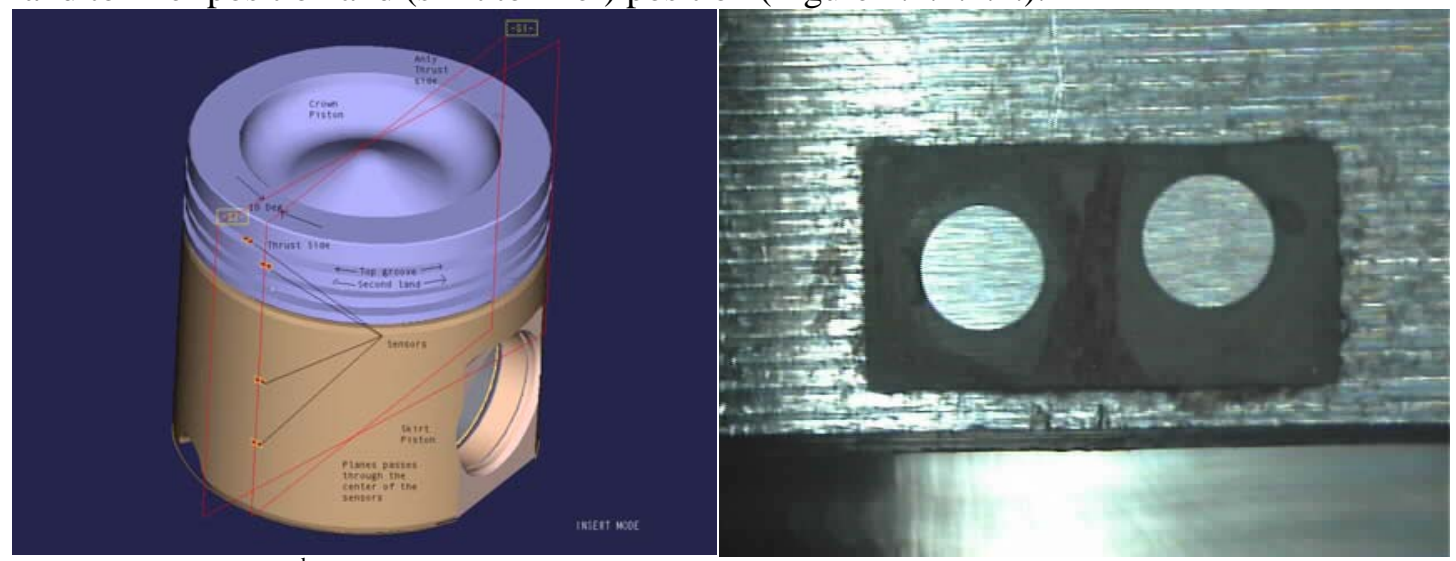

Top ring groove, $2^{\text {nd }}$ land and skirt sensor locations

finish machined 2nd land contact sensor

Figure 1.4.4.1.1. Instrumented piston skirt for friction prediction code validation. 
DOE Final Report

DE-FC05-000R22806

Comparisons with measured PRL performance parameters were mixed. Motored ring and skirt friction levels and trends were similar to preliminary teardown results. Predicted oil consumption trends versus load and speed were also promising. Blow by levels particularly at load were disappointing. Inaccurate predicted liner thermal growths at load were suspected.

\subsubsection{Measurements of Engine Friction:}

Measurements for engine friction on a C15 were made with the turbocharger, air-to-air aftercooler, fuel injector rocker arm and valves removed. Motoring torque and cylinder pressure data were reduced and IMEP and FMEP variations with speed determined. Results indicate the loss contributions in the major categories are as follows:

$\begin{array}{lrc}\text { Pumps } & 25 & \% \\ \text { Piston and Rings } & 42 & \% \\ \text { ConRod \& Crankshaft } 25 & \% \\ \text { Camshaft } & 8 & \%\end{array}$

\subsubsection{Friction Reduction Building Blocks Testing:}

It was understood from literature and from engine tear-down friction tests referenced above that piston ring and liner friction (PRL friction) would be a significant area for focus in reducing engine friction. In the later years of the program, the focus shifted to identification of technology to reduce the PRL friction through improved design and advanced coatings.

To further understand the ability to reduce friction from the PRL, three ring groove combinations, 2 ring coatings, 2 piston geometries and 3 liner options were evaluated to identify the individual components that would contribute to a $1 \%$ fuel economy improvement that was previously predicted. BSFC, motoring torque, and 13 mode steady state emissions data were taken for 1) The baseline C-15 engine with steel crown articulated pistons and piston rings with widths of 4,3 and $4 \mathrm{~mm}$, with the production liner and 2) The monotherm piston with a 3,2,3 mm ring set with a smooth liner and 3) same as the second configuration but with an etched liner. The 3,2,3 piston and ring configuration demonstrated a $1 \%$ BSFC gain relative to the baseline. BSFC and motoring torque remained virtually unchanged going from the smooth to etched liners.

Test work also assessed the effects of oil types, coolant and oil temperature on motoring friction. Motoring torque levels using 15W40, 10W30, and 5W20 oils were measured. Reductions in motoring mean effective pressures (mmep) using the 10W30 and 5W20 oil types were 6 and $18 \mathrm{KPa}$, respectively, at $1500 \mathrm{rpm}$. This data was used for model validation

C15 baseline and Phase I PRL analytical work was completed in order to layout options for reduced PRL friction. In addition to the PRL loss estimates, losses for the rod and main bearings, camshaft and valve actuator system were made. Rods, mains and camshaft bearings were predicted to operate in the hydrodynamic range. Predicted losses and minimum film to roughness ratio levels at motored and full load conditions are summarized in table I below. Rings, skirts and valve and injector rocker arms were predicted to operate in the mixed and boundary lubricated regimes. Predicted losses, total and boundary, are summarized in table II below in Figure 1.4.4.3.1. 
DOE Final Report

\section{DE-FC05-000R22806}

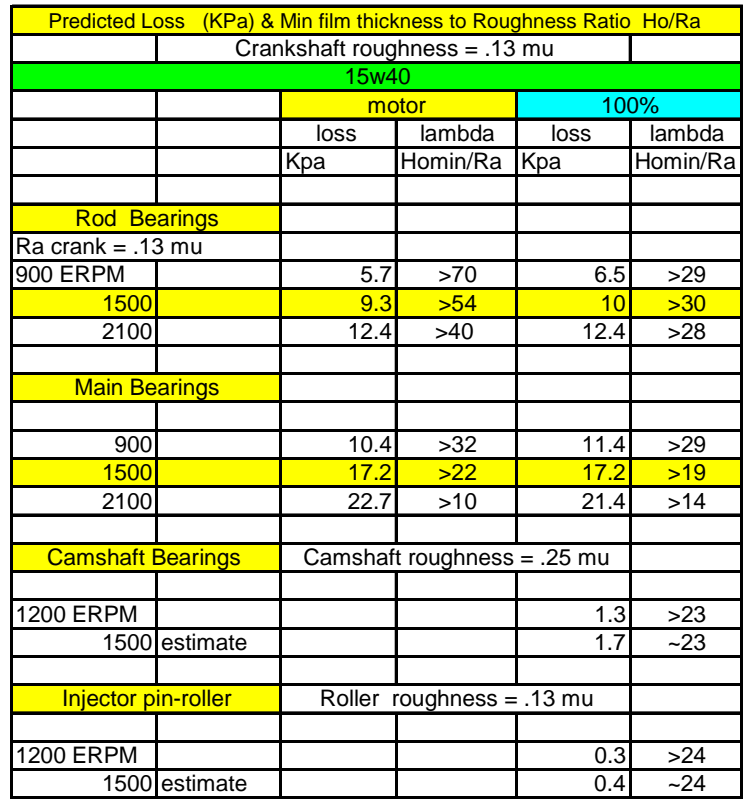

Table I

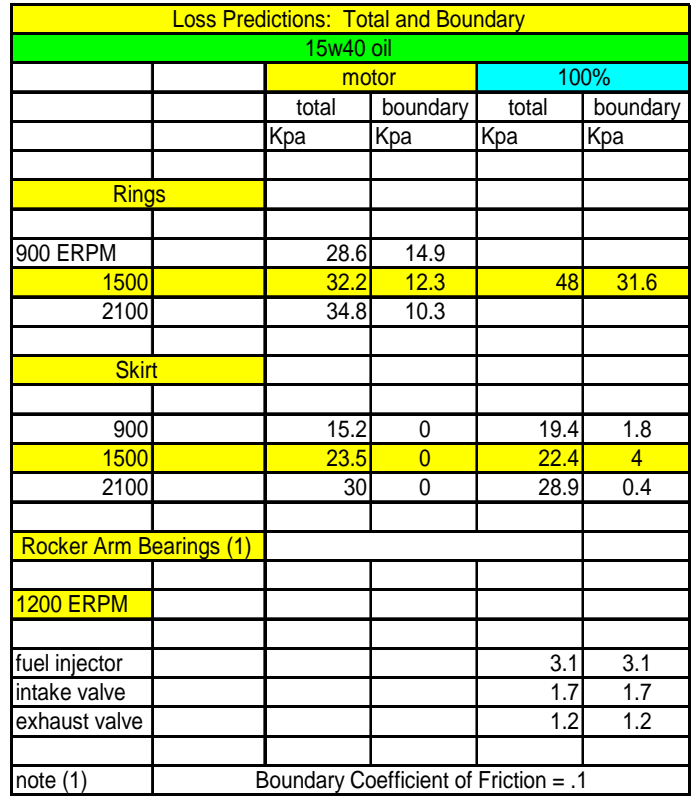

Table II

Figure 1.4.4.3.1. Predictions of friction contributions from bearings and piston ring and liner group

It was determined that a 50\% reduction in the boundary coefficient of friction in the ring - liner interface was required to improve tank mileage BSFC by an additional $\sim 1 \%$. In the $4^{\text {th }}$ quarter of 2005 a coating was identified using bench tests that reduced the PRL friction coefficient by $\sim 50 \%$. In the $1^{\text {st }}$ quarter of 2006 , hardware was procured to test this coating on a single cylinder test engine (milestone 2 engine), the objective of these tests being to confirm that the reduction in friction coefficient found on the test bench translated into a reduction in friction on engine. The results were that a measured benefit could not be determined.

After the coating testing did not yield the expected results, another improved piston ring pack was identified. This included the use of offset barrel design rings on a thinner ring pack. This ring pack was included in the High Efficiency Component Testing on MCTE (milestone 3 engine) and the High Efficiency Engine System Demonstration (milestone 4 engine). Figure 1.4.4.3.2 shows the features of the design tested. 


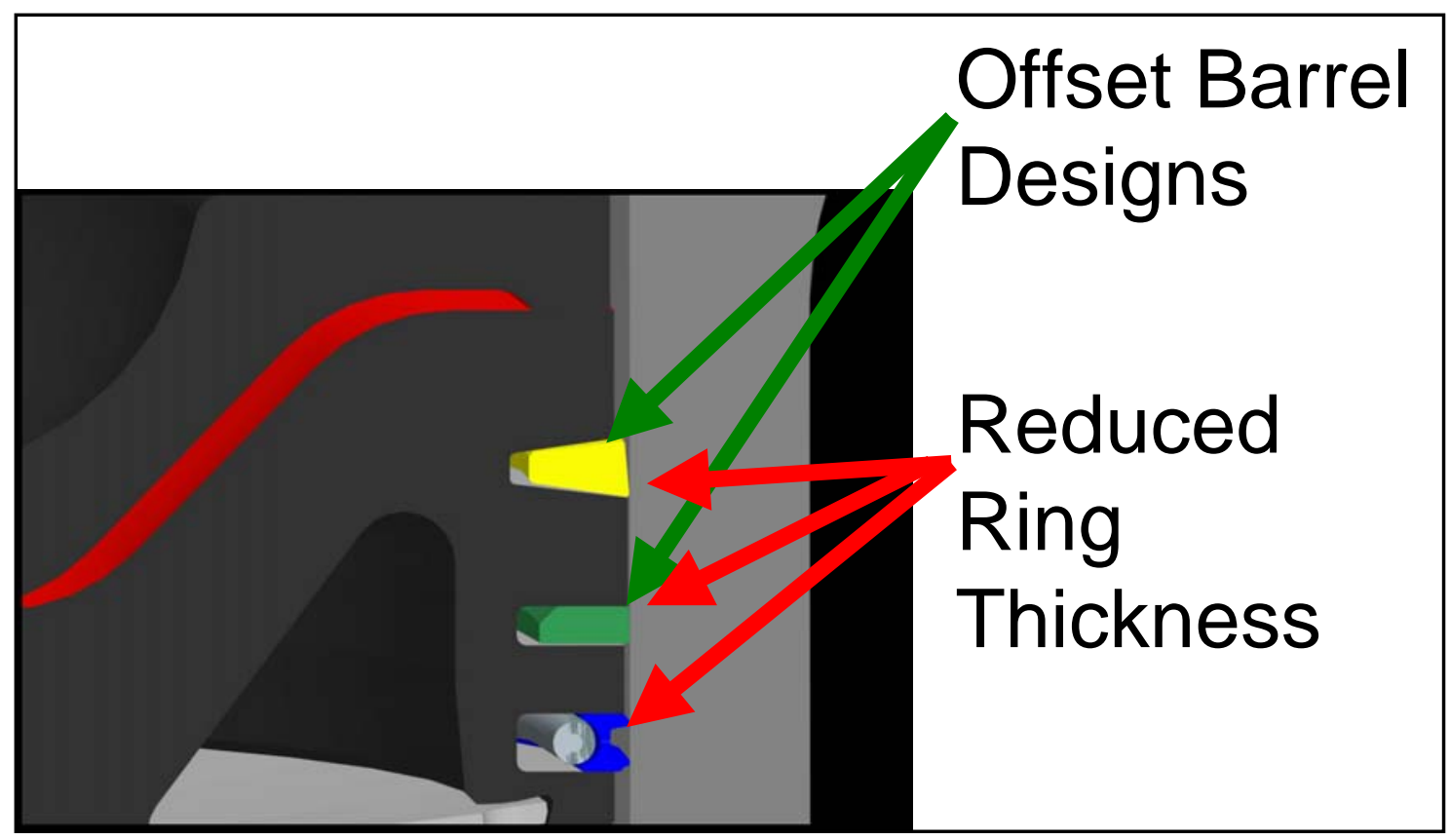

Figure 1.4.4.3.2: Improved piston ring pack.

As noted above, the three areas pursued for reduced friction for the 50\% thermal efficiency demonstration included improved PRL design, lower friction oil, and a variable speed oil pump. The results of the lower friction oil were too small to be measured accurately. Similar conclusions were reached for the variable flow oil pump at the peak torque (1200 rpm) demonstration point.

\section{A note on the reduced conrod and crankshaft fricion.}

To reduce the conrod and crankshaft friction an external company provided a preliminary design for installing roller bearings in the main and rod large end bearings. The results were not encouraging. Required bearing diameters were more than twice the current diameters. 


\section{Section 1.4.5: Reduced Heat Rejection}

The objective was to reduce the heat rejection to the coolant and ambient in order to retain more energy for mechanical extraction by the piston or turbo-machinery. Heat rejection from the $50 \%$ thermal efficiency demonstration engine was reduced using insulated pistons, insulated exhaust ports in the cylinder head, and increased coolant and oil temperatures. The increased coolant and oil temperatures are discussed in Section 1.4.6.

The insulated piston (also referred to as air gap pistons) were tested. Fig. 1.4.5.1 shows the design of the pistons. The results from the High Efficiency Component Testing on MCTE (milestone 3 engine) showed that the heat transfer was reduced by 50\% through the piston, however, during the testing, a design issue with the bolt heads was verified. As reported, the analysis of the life prediction was uncertain. An improved design that could be created from the existing parts was identified and was procured. The air gap piston design has not yet been tested as part of the High Efficiency Engine System Demonstration (milestone 4 engine).

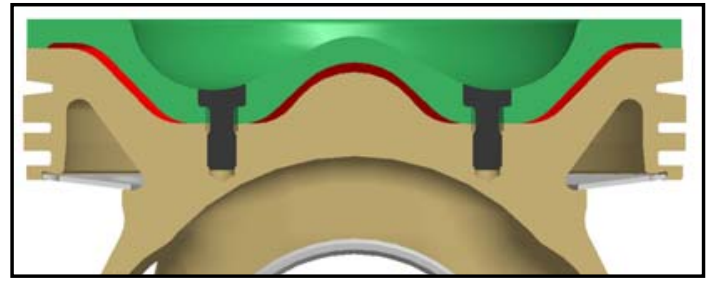

Figure 1.4.5.1: Cross section of the air gap pistons.

The exhaust port liners have been designed to create an air gap between the liner and the exhaust port that is cast into the head (see Fig. 1.4.5.2), thus decreasing the rate of heat transfer from the exhaust gases to the port. Procurement of the liners and modification to the head was completed. The liners were thermal cycle tested to verify the designs were structurally sound. The exhaust port liner head is scheduled to be tested in the future.
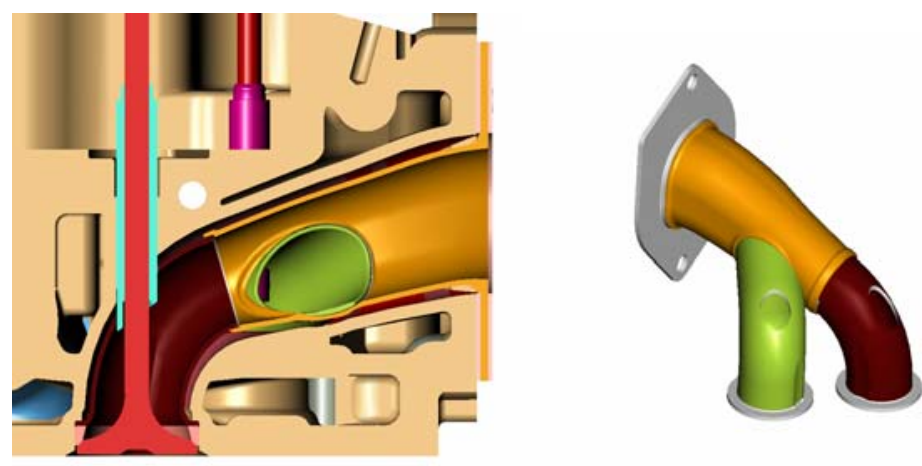

Figure 1.4.5.2: Exhaust port liner design. (a) Cross section through one of the exhaust valves and the exhaust port. (b) Exhaust port liner shown without head or valve assemblies. 
DOE Final Report

DE-FC05-000R22806

\section{Section 1.4.6: Cooling System}

The objective of this work was to design a cooling package capable of meeting the $50 \%$ thermal efficiency demonstration system specifications and packaging within a class 8 on-highway truck such as the Kenworth T2000 chassis. A detailed analysis of the cooling package was conducted previously using Caterpillar Inc. proprietary cooling system software. A summary of the system specifications and design are provided in Table 1.4.6.1. The associated delta in temperatures for the oil, coolant, air to air aftercooler (ATAAC) and air to air intercooler (ATAIC) is found in Figure 1.4.6.2 along with the predicted benefit in thermal efficiency.

Testing of the increased oil and coolant temperatures on the High Efficiency Component Testing on MCTE (milestone 3 engine) was completed and did not show any measurable change to fuel economy. This increased temperature was tested to verify that the engine and cooling circuits could run acceptable under these conditions. As explained in previous reports, the increased oil and coolant temperature allowed for a smaller radiator and for the placement of an intercooler in the cooling stack.

Testing of an intercooler placed between the low pressure and high pressure compression stages was completed as part of the High Efficiency Component Testing on MCTE (milestone 3 engine) and the High Efficiency Engine System Demonstration (milestone 4 engine). The results showed up to a 3\% improvement in fuel economy.

A model showing the improved cooling package packaged in the hood lines of a Kenworth T2000 chassis is provided in Figure 1.4.6.3

Table 1.4.6.1: Cooling system simulated performance compared with targets.

\begin{tabular}{|c|c|c|}
\hline Specification & Target & Predicted performance \\
\hline ATAIC/ATAAC Outlet Temp. & $35^{\circ} \mathrm{C}$ & $33.2^{\circ} \mathrm{C} / 34.2^{\circ} \mathrm{C} \quad\left(\mathrm{PT} @ 25{ }^{\circ} \mathrm{C}\right)$ \\
\hline ATAIC/ATAAC dP & $<7 \mathrm{kPa}$ & $4.1 \mathrm{kPa} / 3.8 \mathrm{kPa} \quad\left(\mathrm{PT} @ 25^{\circ} \mathrm{C}\right)$ \\
\hline CGI Gas Outlet Temp. & $<120{ }^{\circ} \mathrm{C}$ & $107.9^{\circ} \mathrm{C}$ (PT@25 $\left.{ }^{\circ} \mathrm{C}\right)$ \\
\hline CGI dP & $<6 \mathrm{kPa}$ & $0.6 \mathrm{kPa} \quad\left(\mathrm{PT} @ 25^{\circ} \mathrm{C}\right)$ \\
\hline Radiator Top Tank Temp. & $<110^{\circ} \mathrm{C}$ & 109.9 ${ }^{\circ} \mathrm{C}$ (Rated@43 ${ }^{\circ} \mathrm{C}$ ) \\
\hline Engine Oil Max Outlet Temp. & $<120{ }^{\circ} \mathrm{C}$ & 110.6 ${ }^{\circ} \mathrm{C}$ (Rated@43 ${ }^{\circ} \mathrm{C}$ ) \\
\hline Package on T2000 & Yes & Yes \\
\hline
\end{tabular}




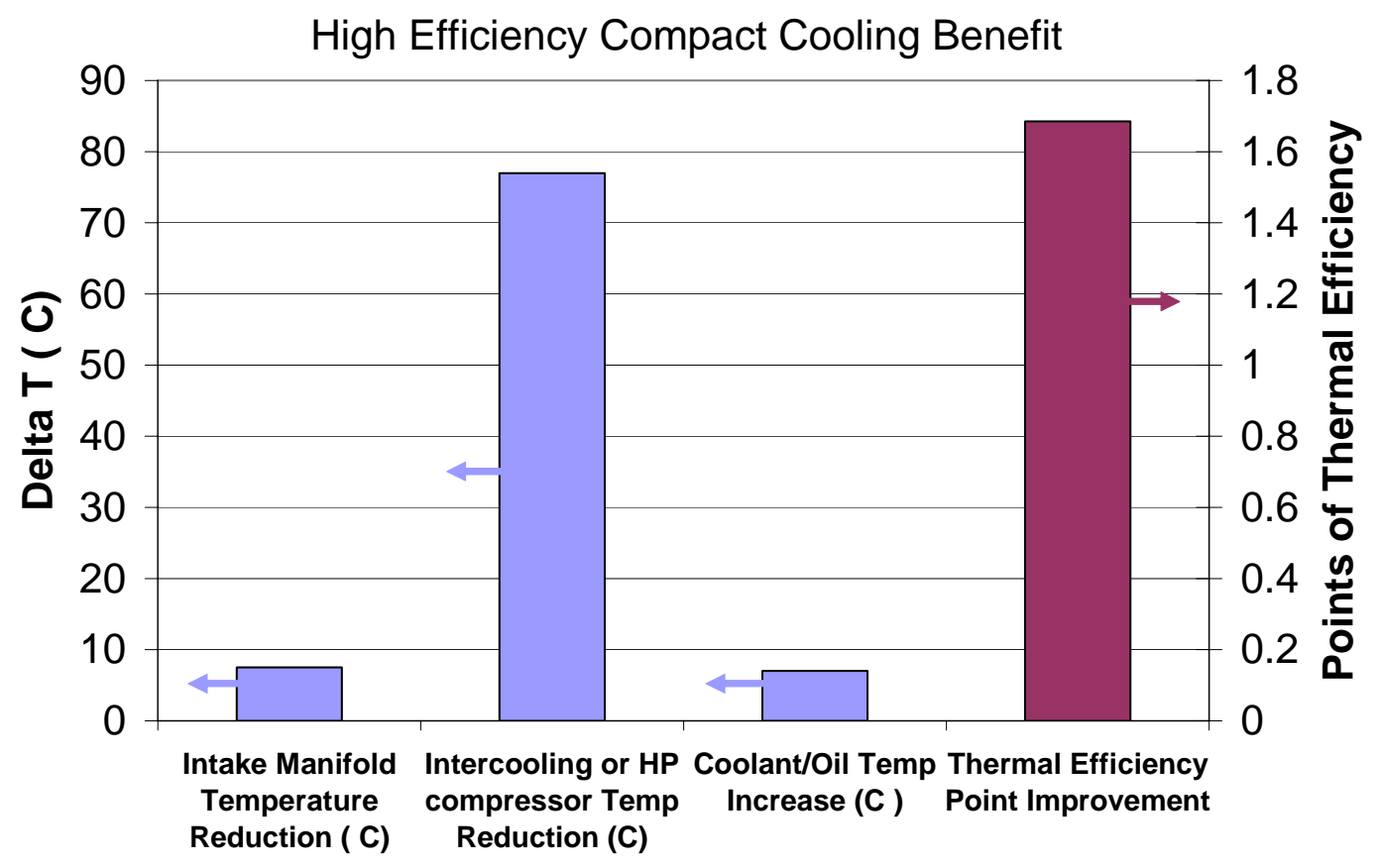

Figure 1.4.6.2: Cooling system performance and associated thermal efficiency improvement.

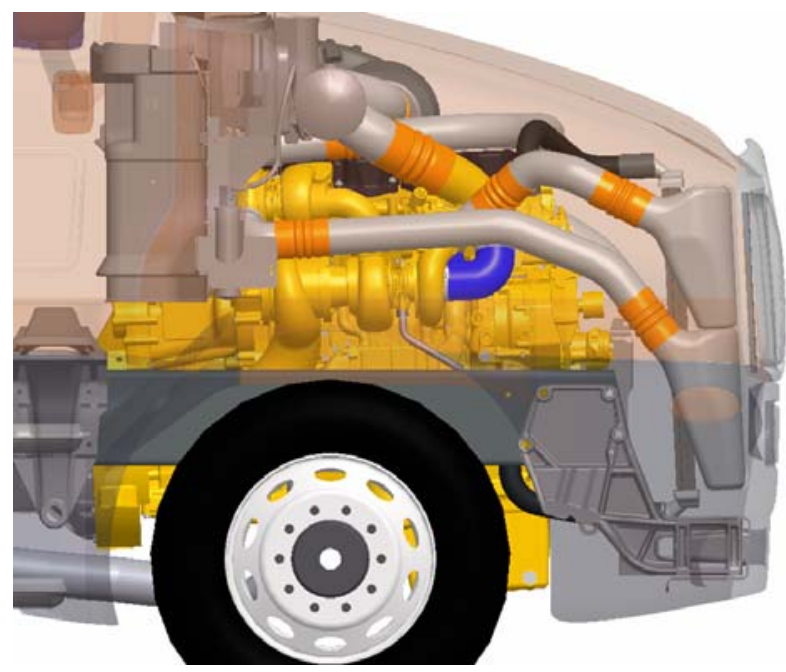

Figure 1.4.6.3 Cooling system performance packaged in a Kenworth T2000 chassis. 
DOE Final Report

DE-FC05-000R22806

\section{Section 1.4.7 Reduced Flow Restriction}

The goal of the ultimate flow head (UFH) was to improve the fuel economy of the baseline engine by reducing the restriction to flow into and out of the cylinder. This was accomplished by reducing the resistance to airflow in the intake and exhaust ports and valves.

There were multiple versions of the ultimate flow head designed and procured within the program. These are listed below in the table below. The Gen I ultimate flow head flow parameter (which is a measure of the flow relative to the bore area) was determined by flow test on a flow bench. This data was then compared to previous tests on the stereo lithography (SLA) model and the current C-15 cylinder head. The results for the intake ports are shown in Figure 1.4.7.1. Note that the ultimate flow head and the production C15 head both have an integrated intake manifold which attaches to a single intake elbow. The flow tests were performed with the integrated manifold but without the intake elbow attached. The SLA model of the head was a simplified representation and did not include the integral intake manifold. The results for the exhaust ports are shown in Figure 1.4.7.2. (2004, Q4)

\begin{tabular}{|l|l|l|}
\hline Name & Description & Status \\
\hline Gen. 1 UFH & $\begin{array}{l}\text { Improved port flow with intake manifold } \\
\text { internal to the head }\end{array}$ & $\begin{array}{l}\text { Designed, procured, and tested on gas } \\
\text { stand and engine without intake valve } \\
\text { actuation system }\end{array}$ \\
\hline Gen. 2 UFH & $\begin{array}{l}\text { Improved port flow with intake manifold } \\
\text { external to the head for better cylinder to } \\
\text { cylinder balancing }\end{array}$ & $\begin{array}{l}\text { Designed , procured and performance } \\
\text { tested on gas stand and engine with } \\
\text { intake valve actuation system }\end{array}$ \\
\hline Gen. 3 UFH & $\begin{array}{l}\text { Same as Gen. 2 UFH, except exhaust } \\
\text { manifold and exhaust ports have been } \\
\text { modified for exhaust port liners to insulate } \\
\text { against heat loss }\end{array}$ & $\begin{array}{l}\text { Designed, procured and performance } \\
\text { tested on gas stand, thermal cycle tested } \\
\text { on engine }\end{array}$ \\
\hline
\end{tabular}

The following conclusions were drawn from these flow measurements:

1. The flow measurement in the exhaust ports of the ultimate flow head matched well with the exhaust SLA model.

2. The integrated intake manifold reduces the flow in the intake ports. The flow in the intake may be improved with a better intake manifold design.

3. The exhaust flow in the ultimate flow head is much better than the production C15 head.

4. The intake flow in the ultimate flow head was found to be about the same as the production C15 head. (2004, Q4) 
DOE Final Report

DE-FC05-000R22806

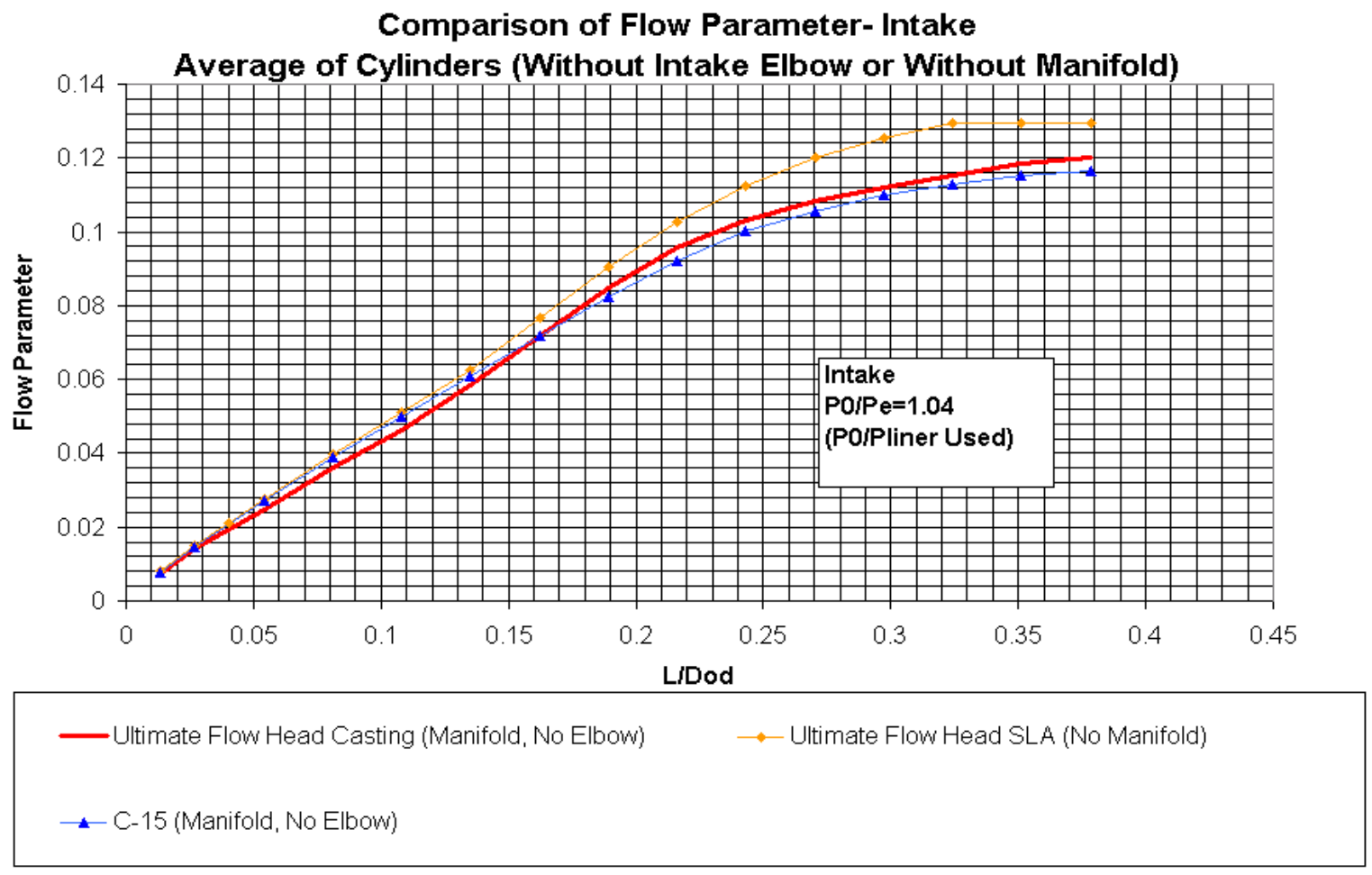

Figure 1.4.7.1: Intake flow parameter for the Gen I UFH.

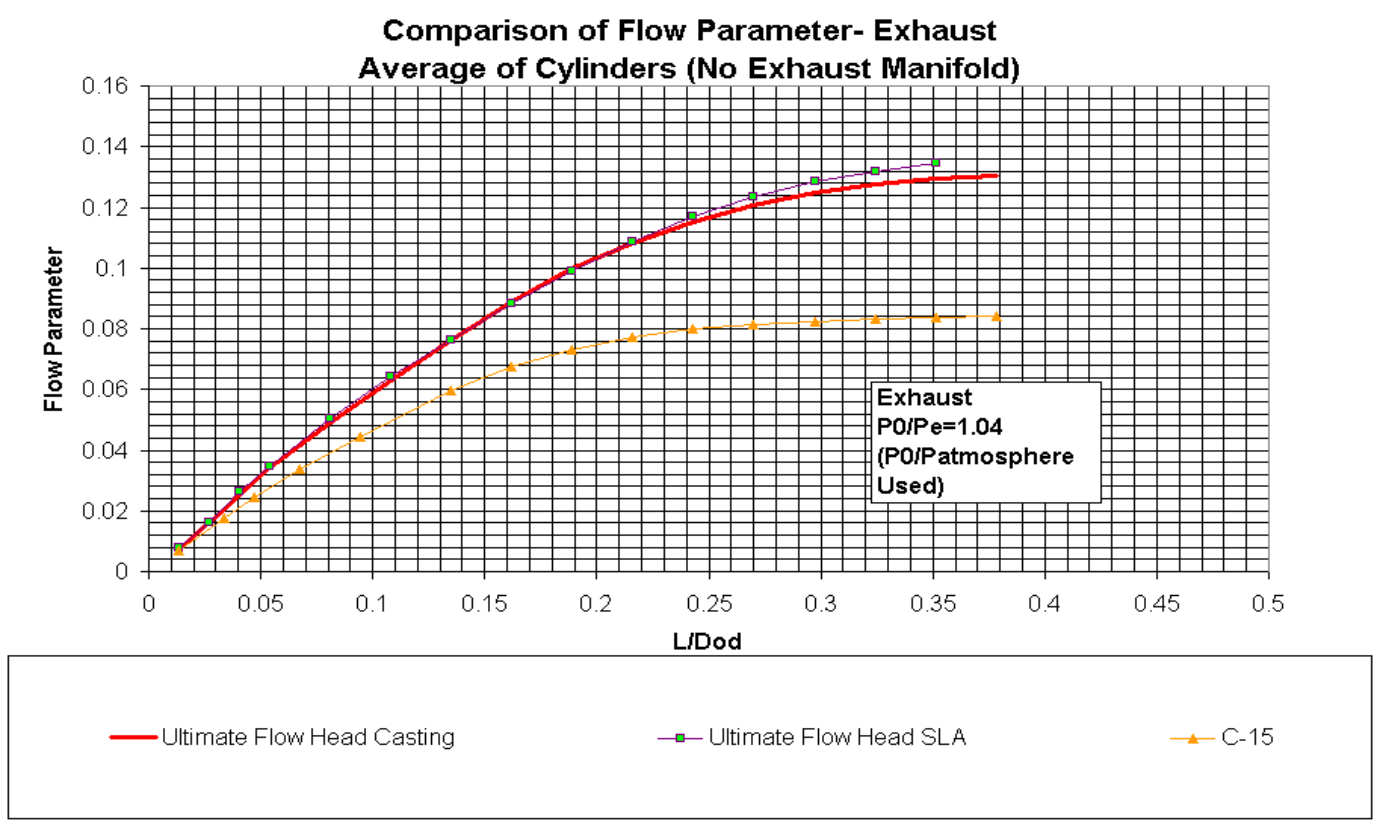

Figure 1.4.7.2: Exhaust flow parameter for the Gen I UFH.

After the flow testing on the flow bench was complete, the Gen 1 ultimate flow head baseline tests were conducted with a production C-15 head installed on an engine rated $475 \mathrm{HP}$ at $2100 \mathrm{RPM}$ with a peak torque 
of $1850 \mathrm{lb}-\mathrm{ft}$ at $1200 \mathrm{RPM}$. Once the baseline tests were complete the production C-15 head was replaced with the ultimate flow head and the tests repeated.

Steady-state tests were conducted for 21 operating conditions. The test speeds were 1000, 1200, 1500, 1800, and 2100 RPM. In the following figures these are referred to as a, A, B, C, and D speeds, respectively. At each of these speeds the load was varied between $25 \%$ and $100 \%$ in $25 \%$ increments. The speed and load are described by a letter-number combination. For example, A25 is 1200 RPM and 25\% load, while D100 is 2100 RPM and full load. The B100 test condition (1500 RPM, full load) was repeated five times throughout the test period in order to ascertain the repeatability of the measurements. Low idle was also tested. (2005, Q1)

The pumping mean effective pressure (PMEP) is a measure of the work required to pump the exhaust gases out of the cylinder and draw the fresh charge into the cylinder. It is defined as the indicated work done during the exhaust and intake strokes divided by the engine displacement volume. In Figure 1.4.7.3 the PMEP values for both the baseline and ultimate flow heads are presented. Positive values indicate that work is produced during the intake and exhaust strokes while negative values indicate that the engine is having to do work during this period. Therefore, the higher the PMEP value the better the performance. The UFH outperformed the baseline head for the B, C, and D speeds while for the lower speeds the baseline head performed better.

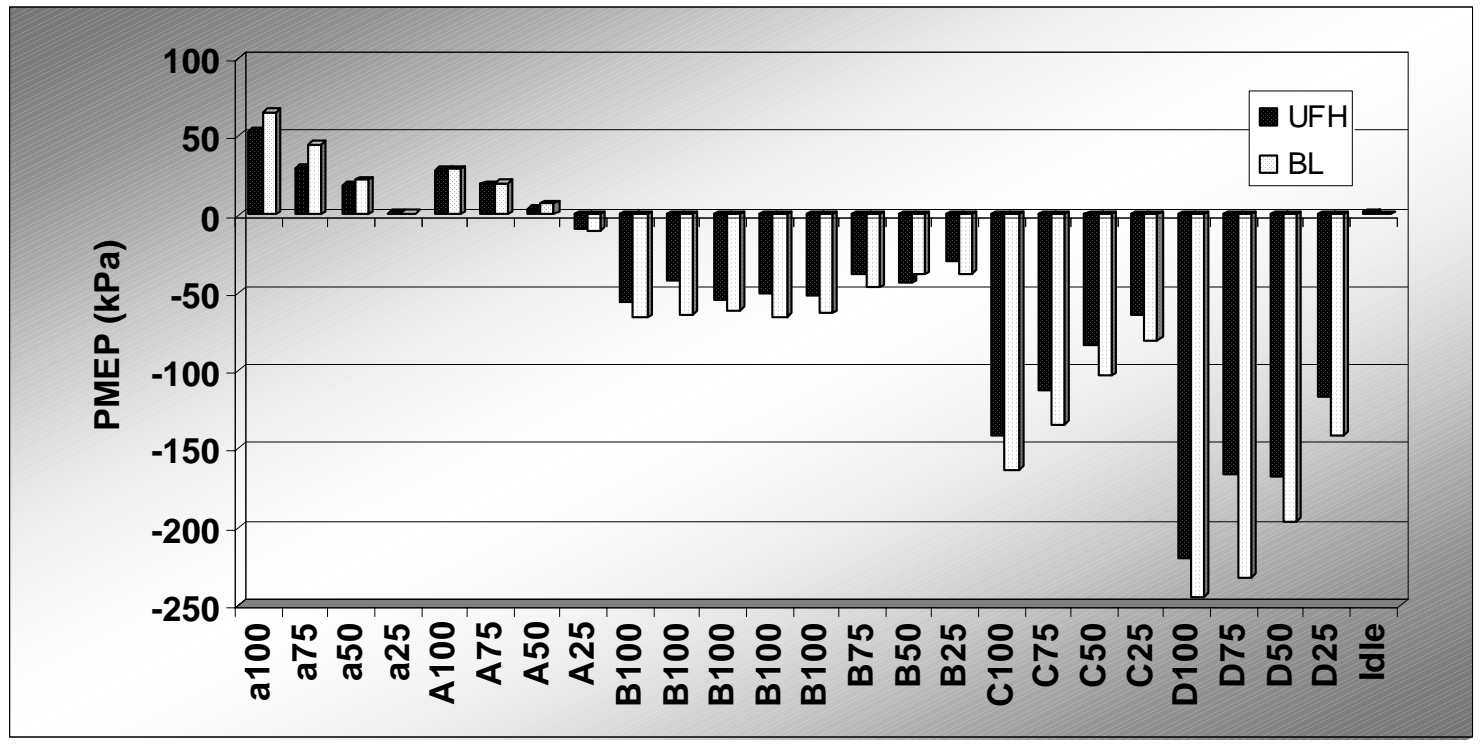

Figure 1.4.7.3: Pumping mean effective pressure (PMEP) results for the baseline (BL) and the Gen I ultimate flow head (UFH). The higher the PMEP value the better the performance of the head.

In Figure 1.4.7.4 the change in brake specific fuel consumption (BSFC) is presented. Positive values indicate an improvement in BSFC. As with the PMEP results, the UFH head outperformed the baseline head at the B, C, and D speeds, but showed slightly worse performance at the lower speeds. The ultimate flow head performed best at high speed and light load, showing over a 3\% improvement. It performed worst at low speed low load showing a 1.25\% degradation in BSFC. 


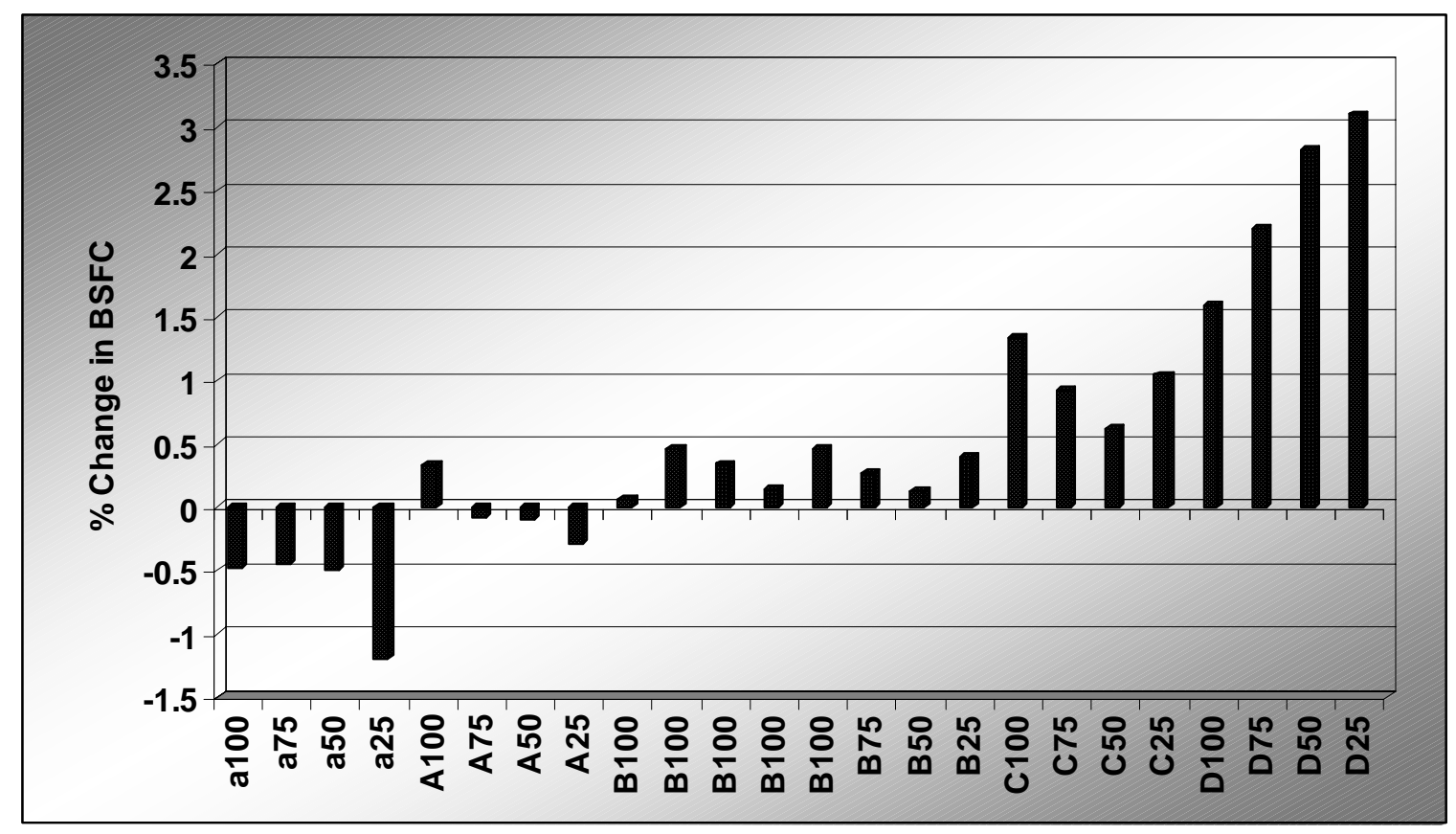

Figure 1.4.7.4: Percent change in brake specific fuel consumption (BSFC) for the test conditions. Positive values indicate that the ultimate flow head performed better.

Upon completion of the ultimate flow head testing the head was disassembled and the parts examined closely. Inspection of the camshaft revealed indications of excessive wear. This was determined to be the result of the cam lobes being misaligned relative to the rocker which results in the rocker rollers resting on the edge of the cam lobes. A camshaft made to the correct specifications was ordered. The wear marks found after testing are an indication of increased friction, which could have negatively influenced the ultimate flow head BSFC values.

While the results presented in Figure 29 were encouraging, especially at high speeds, the ultimate flow head was determined to have greater value than shown. The production engine system is finely tuned. When one piece of the system is changed the rest of the system is no longer operating at its optimum. The production C15 engine uses an intake valve actuation system, but this system was not ready for the ultimate flow head and so both the baseline and ultimate flow head tests were run without valve actuation. Without the valve actuation the turbo machinery does not operate at optimum design conditions. Further, by changing heads the system operated at different points on the turbocharger maps, thus resulting in differences in performance not solely due to head design. (2005, Q1)

At this time a new IVA system was designed, based off of the current production IVA unit. Since the location of the intake valves was different from current production, system dynamic analysis was performed to ensure that the intake valve motion was as close as possible to the production system. (2005, Q2)

The Gen. 2 UFH has separate intake ports that allows for a customizable bolt on intake manifold. At this time, a new intake manifold was designed as shown in Figure 1.4.7.5. CFD analysis indicated that the Gen 2 head with the new bolt on manifold would have slightly improved flow characteristics relative to the Gen 1 head. This data is shown in Figure 1.4.7.6. (2006, Q1) 


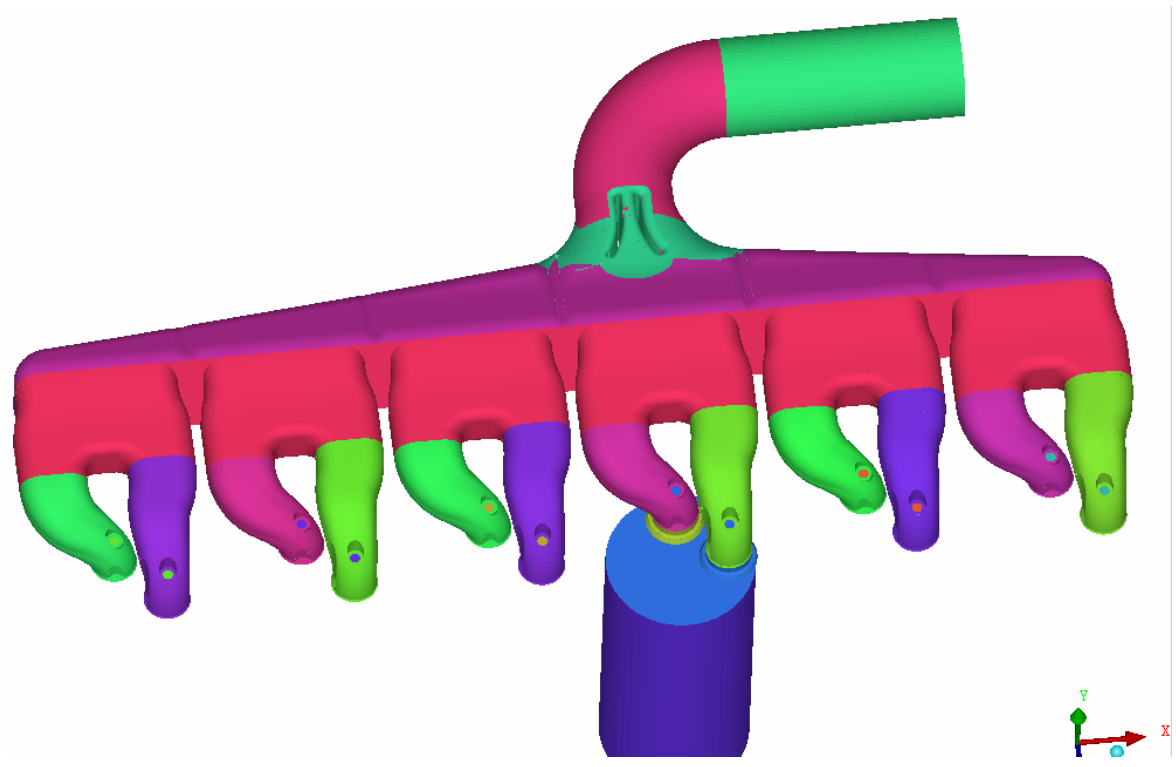

Figure 1.4.7.5: Gen 2 intake manifold CFD core model

\section{Flow Coefficients At Max. Valve Lift (16 mm)} Comparison of Gen 1 and Gen 2 (CFD)

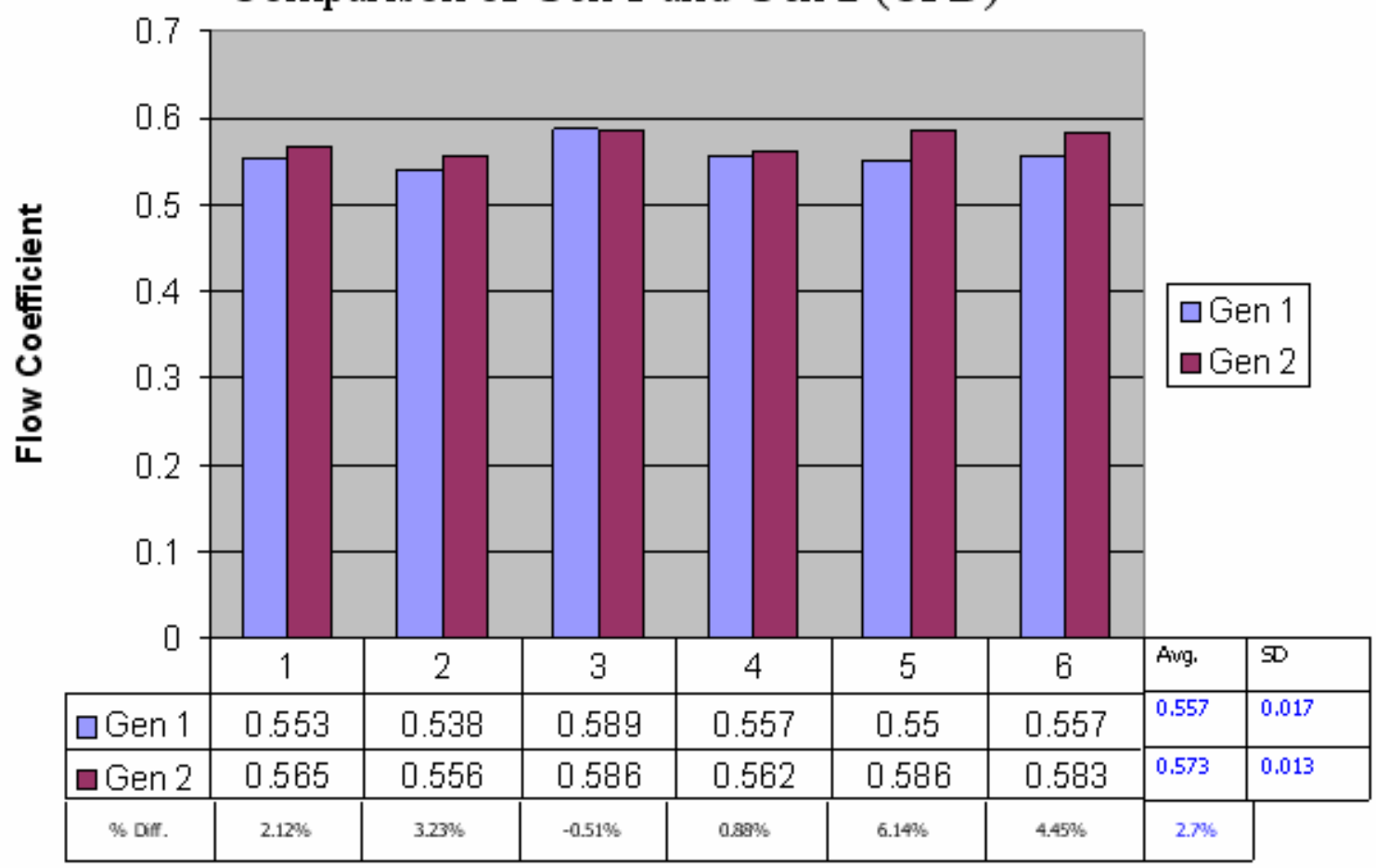

Figure 1.4.7.6. Generation 2 intake manifold CFD results for all 6 cylinders 
DOE Final Report

DE-FC05-000R22806

Exhaust port liners were added to the Gen 2 UFH design as discussed above. As described in section 1.4.5 the intent was to create an air gap between the liner and the exhaust port that is cast into the head in order to decrease the rate of heat transfer from the exhaust gases to the port. This would allow the energy to remain in the exhaust gas where it can be extracted by the air system or turbo-compound to improve thermal efficiency. The Gen 2 design with the exhaust port liners is referred to as the Gen 3 UFH. (2006, Q1)

A new exhaust manifold was also designed for use with the Gen 3 UFH and made to be compatible with the exhaust port liners and a new high-pressure stage turbo position. The flow passage cross-sectional area has been reduced to correspond to the exhaust port liners. The change has been analyzed using steady-flow CFD. The predicted steady-flow coefficients for the new manifold are slightly worse than those for the Gen. 1 UFH, but are better than those for the production head. These steady-flow results are expected due to the change in cross-sectional area. However, by decreasing the cross-sectional area, and thus the manifold volume, the exhaust blow-down pulse effect will be amplified. (2006, Q1)

A gas stand test of the baseline vs. all generations of the UFH was completed. An engine performance test of the baseline vs. Gen. 2 or 3 UFH has not been completed. Thus the isolated effect has not been determined. (2006, Q3)

\section{Section 1.4.8: High Efficiency Aftertreatment}

The use of high efficiency aftertreatment was not only part of the emissions strategy for the 2010 demonstrator engine but also system efficiency improvement opportunity. The technology included a. Low Pressure Drop Diesel Particulate Filters

b. High Conversion efficiency NOx Aftertreatment-Urea SCR

The efficiency benefit comes from lowering the backpressure on the engine which reduces the pumping loop. The other important benefit came from allowing the engine to be recalibrated to higher engine-out NOx levels as shown in Figure 1.4.8.1which generally mean more thermodynamically favorable injection timings while still meeting the regulated emissions levels after passing through the aftertreatment.

The benefit was simulated through high quality analysis, focused testing, and demonstrated in final demonstration engine.

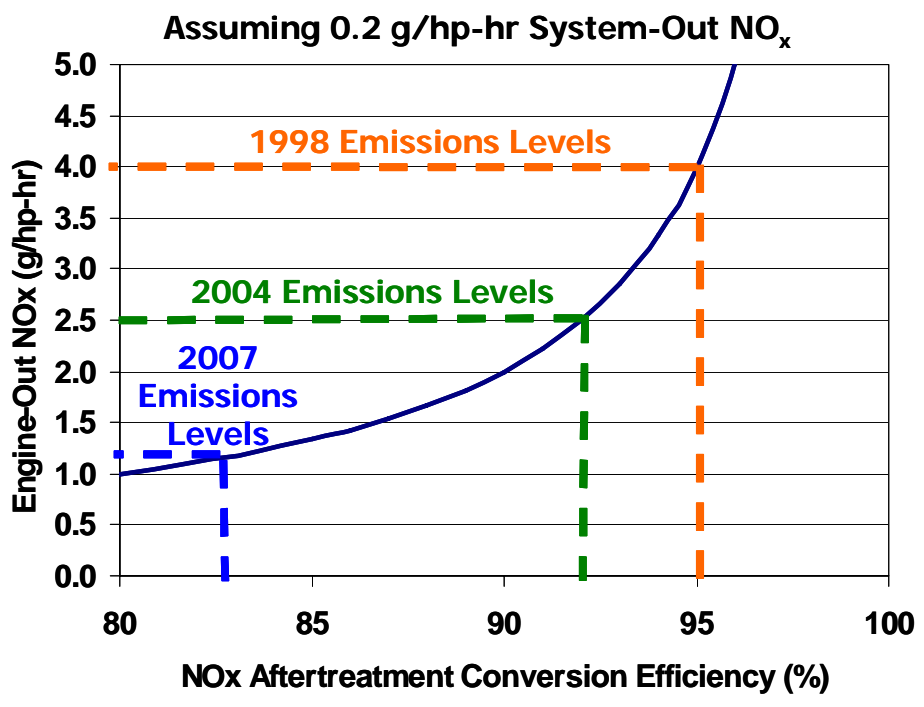

Figure 1.4.8.1 Showing the effect of NOx aftertreatment efficiency vs Engine out NOx 
DOE Final Report

DE-FC05-000R22806

Another important note with this technology was that with new catalysts, the aftertreatment package demonstrated very high performance. As shown in the chart below, Figure 1.4.8.2, the effect of aging was accounted for by using a 5\% degradation factor for the NOx aftertreatment. If this had not bee accounted for, the engine out NOx levels could have been run at a higher level and higher engine efficiencies would have been achieved. The assumption of $5 \%$ degradation resulted in the thermal efficiency benefit of the lower curve in the Figure 1.4.8.2 in the simulation and engine testing.

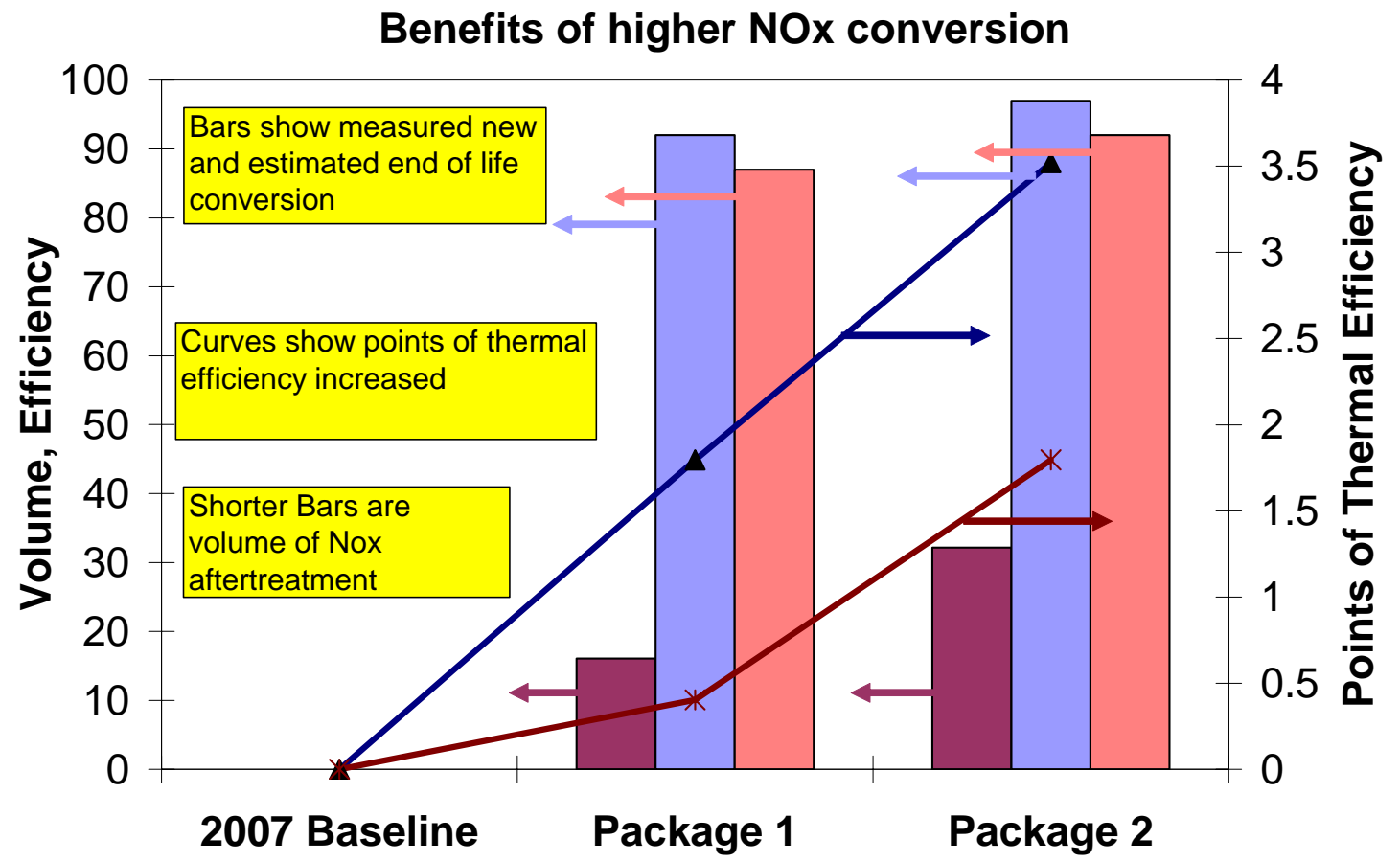

Figure 1.4.8.2. Generation 2 intake manifold CFD results for all 6 cylinders

The fuel economy effect for the back pressure of $13 \mathrm{Kpa}$ at the $1200 \mathrm{rpm}$ peak torque condition was accounted for in our demonstration by actually having the aftertreatment on. This backpressure also limits the effectiveness of the turbocompound building block and therefore was accounted for by having the aftertreatment actually plumbed into the exhaust stream. For the demonstration, the engine was allowed to reach steady state. This insured any particulate loading on the DPF reached steady state. However at the exhaust temperatures, precious metal loading, and NOx/soot ratio of the peak torque demonstration point, the passive regeneration capability of the DPF resulted in the Diesel Particulate Filter operating in a self regenerating range. Therefore no active high temperature regeneration was needed at the demonstration. Also at the increased injection pressures of the demonstration, the engine out soot was low and the diesel particulate filter loading across the operating range would likely be limited and thus the passive regeneration assumption remains valid for a majority of operating points. 
DOE Final Report

DE-FC05-000R22806

\section{Section 1.4.9: Advanced Fuel Systems}

Throughout the HTCD program, advanced fuel system work was completed to support the projects. This included work on small hole nozzles for use in the HCCI program and mixed mode injectors described in the HCCI section above and more fully described in the EPACT protected appendix. In the FY04 and FY05 of the program, a design for an advanced injection system capable of multiple tightly controlled injections at pressure levels greater than $250 \mathrm{MPa}$ was also developed.

The plan was to produce two versions of a research injector for an on-engine investigation of fuel injection characteristics as they relate to emissions and performance requirements for 2010 and Tier 4. The first version (Phase 1) features the ability to perform very small, close-coupled, pilot and split injections at very high injection pressure (above 250MPa).

In late FY05, a prototype injector was installed on the test bench, and testing was conducted. General performance characterization of the injector and pumping system was completed up to $250 \mathrm{MPa}$ rail pressure and an injector was prepared for engine testing (this testing on engine was transferred to the HECC program in $4^{\text {th }}$ quarter 2005). Additionally the pumping system installed in the engine test cell was started and checked out for use with the single cylinder test engine. Some initial engine testing was completed but there was an issue with the design and the injector was modified. The results from the next round of engine testing showed much improvement. This testing of the improved design was completed under the HECC program and is reported within those reports. 
DOE Final Report

DE-FC05-000R22806

Figure 1.4.9.1 shows photographs of the test bench and Figure 1.4.9.2 shows a model of the injector.
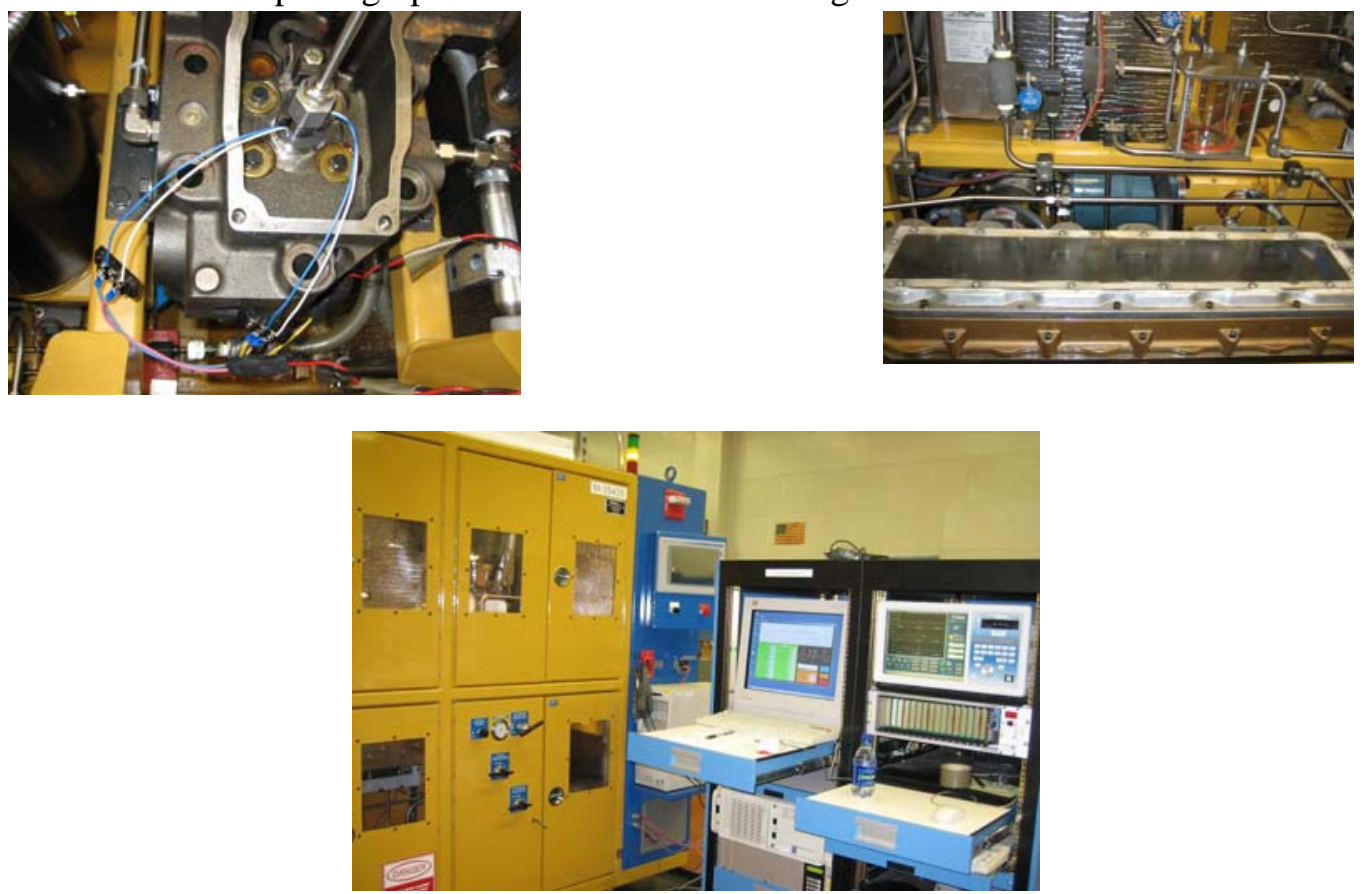

Figure 1.4.9.2. Photographs of High Pressure Test Bench

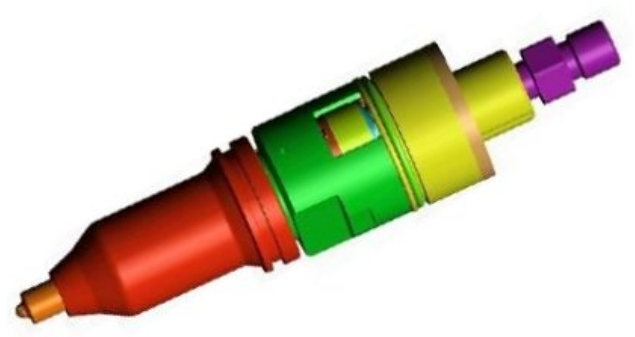

Figure 1.4.9.2. Model of the Advanced Research Injector. 
Figure 1.4.9.3 is measured data showing a variety of very small injections and combinations of pilots, posts and main injections similar to what will be investigated during engine testing. In all cases the upper trace labeled is the beginning of injection (BOI) solenoid current signal, the second trace (CURR B) is the end of injection (EOI) solenoid current signal and the bottom trace is the flow rate through the nozzle orifices (delivery to engine).

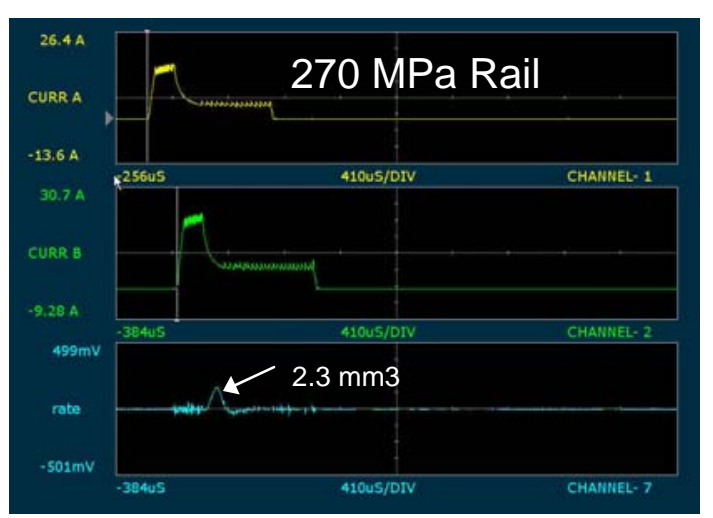

Single Injection

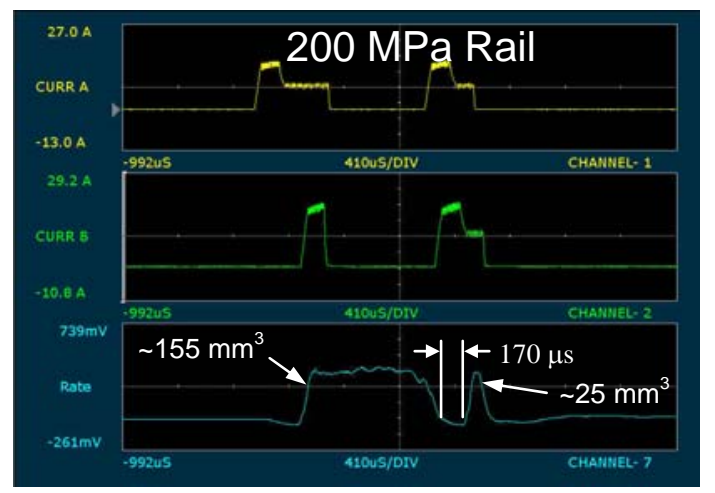

Close-coupled Pilot-Main Injection

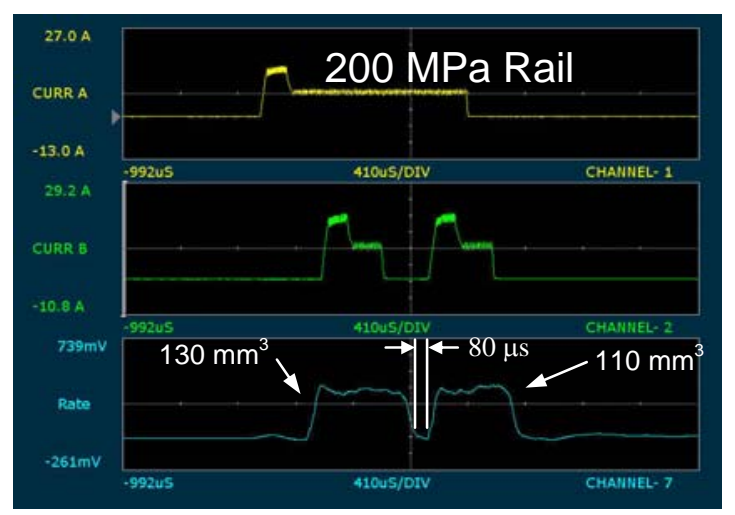

Split Main Injection

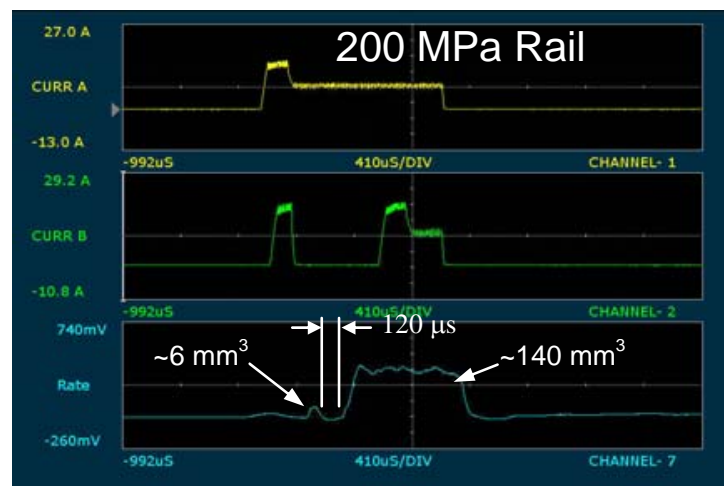

Close-coupled Main-Post Injection

Figure 1.4.9.3. Experimental Bench Results: Various Pilot/Post Combinations 
DOE Final Report

DE-FC05-000R22806

\section{Section 2.0 System Integration (Technology Integration)}

There were two planned system integration projects. The first system integration project was to assemble and evaluate technology aimed at the 2007 emissions levels with fuel economy similar to MY 2002 engines. This was considered a significant challenge because of traditional emissions vs. fuel economy trade-offs. This part of the project occurred from mid 2002 through mid 2004. This work will be covered in section 2.1. The second system integration project was to assemble and evaluate technology aimed at the 2010 emissions levels with 50\% thermal efficiency. There were three basic emissions technology evaluated to meet the 2010 emissions levels. In addition thermal efficiency building blocks were integrated to meet the 50\% thermal efficiency target. This work occurred from 2004 through the end of 2006. This work will be covered in section 2.2.

Three emissions technology paths were developed as options to meet the overall HTCD program goals of 2010 emissions levels with 50\% thermal efficiency. All three options built upon the 2002 baseline engine and the 2007 demonstration engine configuration. The options evaluated were based on 1) Full HCCI over the operating range 2) HCCI Mixed-Mode operation and 3) High-Efficiency NOx Aftertreatment. The three options were evaluated as integrated systems in 2003 and 2004 and a technology down selection was made in 2005. In parallel with the system integration work which started in 2003 with the integration of technology to meet 2007 emissions, simulation and test work continued in parallel to development component technologies to improve BSFC, engine-out emissions and aftertreatment devices. The HCCI technology development was primarily done under this program and is reported above. Further technology development and system integration for the HCCI continues under the High Efficiency Clean Combustion program (HECC). In 2006, the focus of the rest of the HTCD program was integrating technologies to meet the $50 \%$ efficiency target. The building blocks for $50 \%$ thermal efficiency were reported in Section 1.1.5. The integration of the building blocks with a High Efficiency Aftertreatment system which will enable 2010 emissions compliance at $50 \%$ overall thermal efficiency is covered below in section 2.2 .

\section{Section 2.1. - 2007 (Phase1)}

This was the first systems integration project. This project was aimed at the 2007 emission levels of 1.2 g/bhph NOx and $0.01 \mathrm{~g} / \mathrm{bhph}$ PM with fuel economy similar to MY2002 engines.

\section{Section 2.1.1 - 2007 Emissions Capable System Development with competitive Fuel Economy}

This was the first part of the systems integration study. This project was aimed at the 2007 emission levels of $1.2 \mathrm{~g} / \mathrm{bhph}$ NOx and $0.01 \mathrm{~g} / \mathrm{bhph}$ PM with fuel economy similar to 2002 engines. This task provided an important stepping stone towards the final multi cylinder engine demonstration of the overall program objectives. The plan was to start to integrate technology building blocks from other program elements. Engine data in addition to performance simulation was used to define the system.

The baseline engine platform was a C15 engine at a $475 \mathrm{hp}$ rating. The hardware included a variable intake valve system, series turbochargers, a simplified cooled low pressure loop CGI (Clean Gas Induction) system, conventional MEUI-A injectors, and twin Johnson Matthey CCRT ${ }^{\mathrm{TM}}$ diesel particulate filters for soot cleanup. The layout is shown in Figure 2.1.1.1 and a picture of the actual system in Figure 2.1.1.2. 


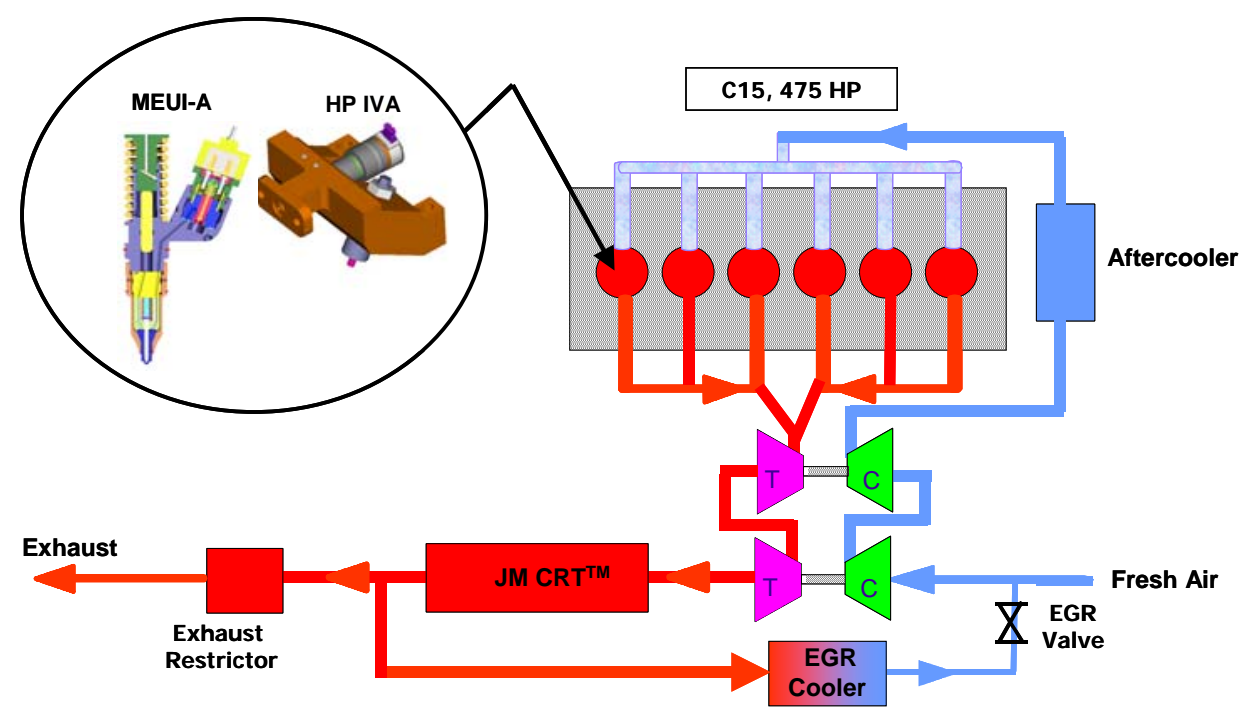

Figure 2.1.1.1: Engine configuration for multi-cylinder demonstration of 2007 emissions.

13-mode steady state tests were completed in quarter 3, 2002 showing results inside the 2007 standard: $\mathrm{NOx}+\mathrm{HC}=1.18 \mathrm{~g} / \mathrm{bhph}$ (target 1.2), $\mathrm{PM}=0.005 \mathrm{~g} / \mathrm{bhph}$ (target 0.01), and competitive BSFC. $\mathrm{NOx}+\mathrm{HC}$ emissions were below $1.5 \mathrm{~g} / \mathrm{bhph}$ and PM emissions were below $0.012 \mathrm{~g} / \mathrm{bhph}$ at all operating conditions. These results were achieved with exhaust temperatures and cylinder pressure within current production limits.

Diesel particulate filter regeneration issues were not addressed at that point of the study. It was recognized that the CCRT may not passively regenerate at all conditions depending on how the engine was operating in the field. Active regeneration strategy development was planned as part of the future work on this system.

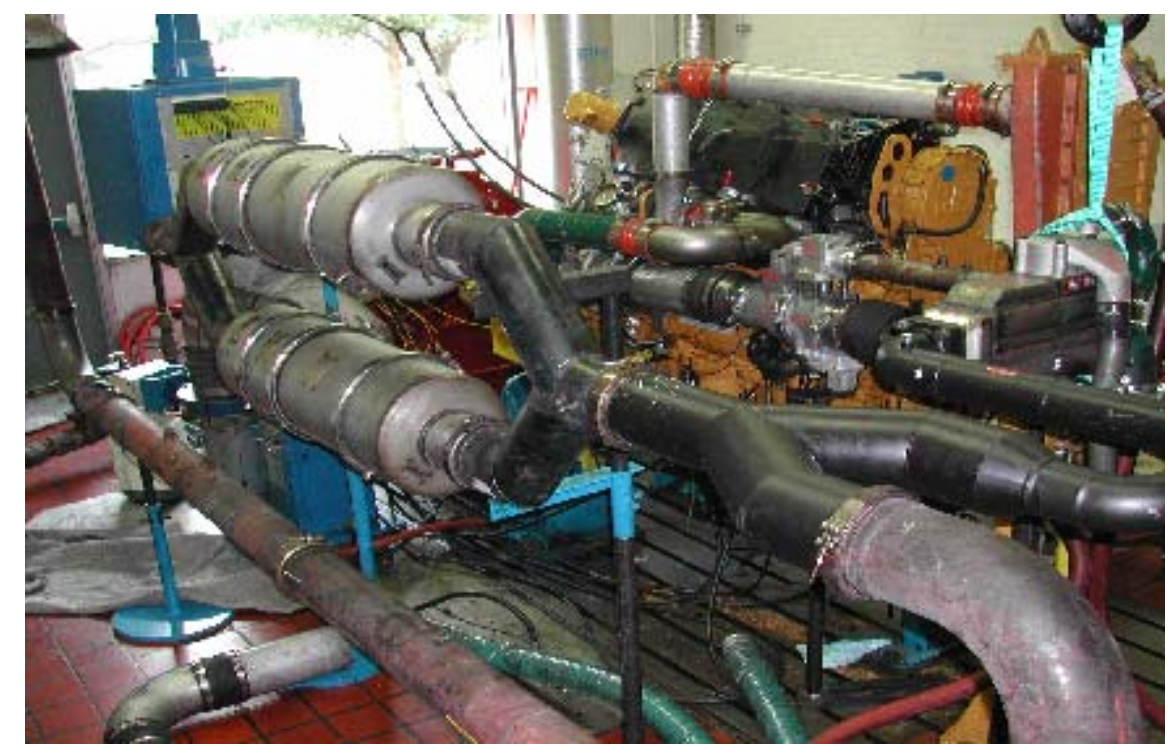

Figure 2.1.1.2: Engine configuration of multi-cylinder demonstration of 2007 emissions.

Test cell data acquired on the 2007 emissions demonstrator engine was matched and validated in a 1-D thermodynamic cycle simulation (internal code named 973). The simulation was then used to quantify the 
DOE Final Report

DE-FC05-000R22806

overall tank bsfc advantage of various possible air-system changes and improvements. This work was in support of an interim goal of $45 \%$ thermal efficiency. Table 2.1.1.1, shows the results of the analysis.

Table 2.1.1.1: Possible Air-System bsfc Building Blocks

\begin{tabular}{|l|c|}
\hline 2007 bsfc building blocks & \% Improvement \\
\hline Air-to-air interstage cooling & $1.2 \%$ \\
\hline Air-to-air EGR cooling & $0.8 \%$ \\
\hline Turbocharger component efficiency improvements & $1.4 \%$ \\
\hline Intake valve close timing re-optimization & $1.1 \%$ \\
\hline
\end{tabular}

Air-to-air interstage cooling and EGR cooling reduce the compression work required for the turbocharger and thus reduces engine backpressure on the engine. Turbocharger component efficiency improvements refer to aerodynamic optimization and mechanical friction reduction that would improve the overall turbocharger efficiency from around $60 \%$ to $68 \%$. Those three options were considered to be independent and additive improvements for a total of $3.4 \%$ are possible. These improvements will also change the optimum intake valve close timing strategy presently in place and enable an additional 1.1\% BSFC improvement as shown in Figure 2.1.1.3 giving a total of up to $4.5 \%$ bsfc improvement.

These benefits were also considered for their usefulness on the 2010 emissions strategies. All of these BSFC gains were considered directly applicable to engines which rely on aftertreatment devices to move from 1.2 $\mathrm{g} / \mathrm{bhph}$ NOx down to $0.2 \mathrm{~g} / \mathrm{bhph}$ which is the 2010 emissions level. Limited cycle simulation indicates that air-to-air intercooling, EGR cooling, and turbocharger optimization would have larger efficiency improvements for an HCCI engine. Intake valve close timing re-optimization was thought to have little effect though, due to much lower turbine inlet temperatures of an HCCI engine.

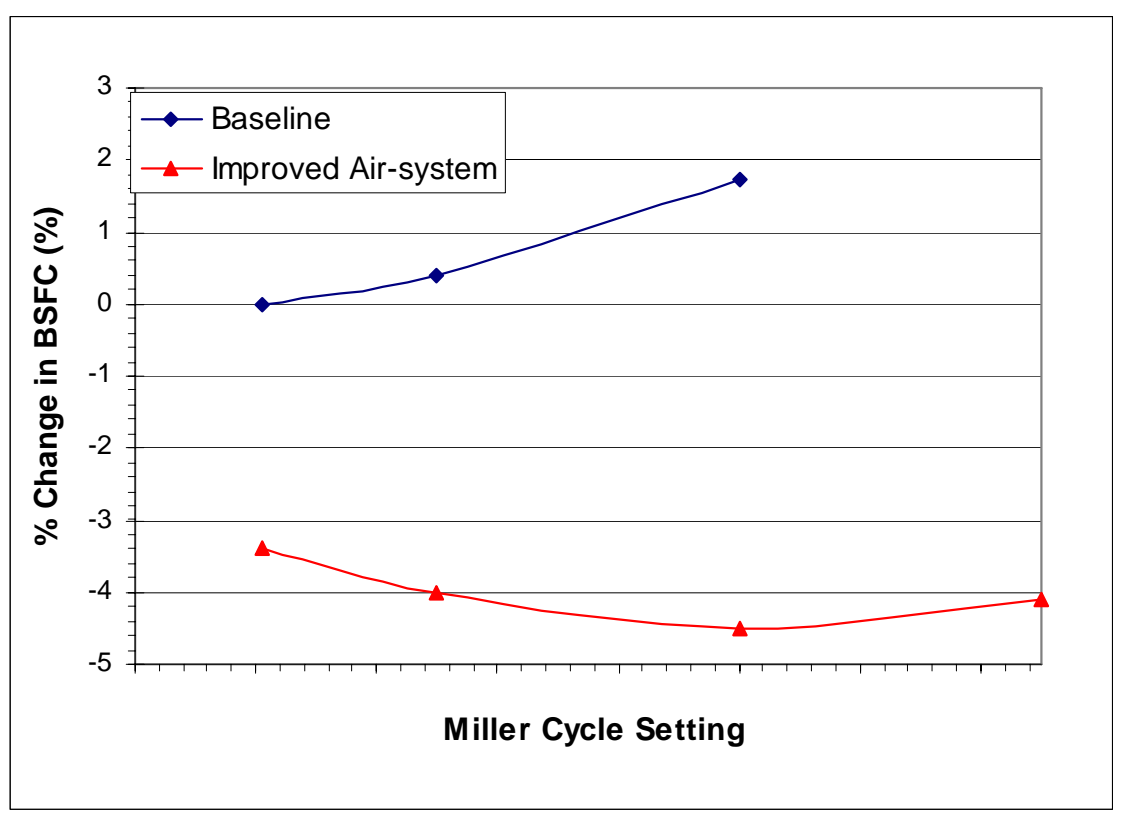

Figure 2.1.1.3: Modeling of Air system options and Miller Cycle Re-optimization

After successful demonstration of steady state performance and emissions in quarter 4 2002, a transient validation was completed and refinements were made to improve thermal efficiency and reduce engine-out particulate. The best transient results obtained were $1.03 \mathrm{~g} / \mathrm{bhph}$ NOx and $0.008 \mathrm{~g} / \mathrm{bhph}$ particulate, see 
DOE Final Report

DE-FC05-000R22806

Figure 2.1.1.4. As stated above, these results were obtained with a conventional cam based fuel system (MEUI-A). Work focused on reducing the engine-out particulate levels in order to reduce the rate that the PM trap would load up in order to reduce the frequency of regenerations needed. The goal was to reach passive regeneration conditions and therefore decrease the in-vehicle fuel consumption penalty associated with active regeneration.

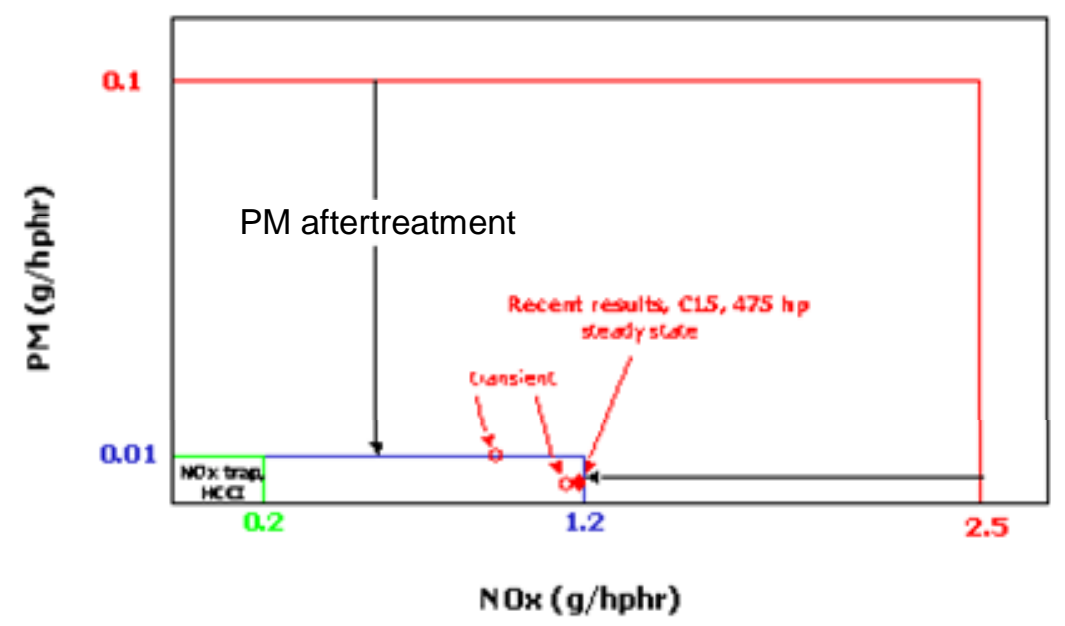

Figure 2.1.1.4: Transient results for multi-cylinder demonstration of 2007 emissions

To accomplish this, an enhanced cam based fuel system (MEUI-C) was tested that provided higher peak injection pressures and substantially higher part load injection pressures. This fuel system reduced the engine-out particulates by approximately a factor of two with no negative effects on NOx, fuel consumption or heat rejection. This increased the engine-out NOx/PM ratio to values closer to that needed by the PM traps to work in a passive manner.

Engine testing of BSFC building blocks during quarter 1, 2003 verified and exceeded simulation predictions showing that improved cooling of the clean gas from the exhaust and interstage cooling between the compressors significantly improve fuel consumption. Simulation suggested a $2 \%$ BSFC

\begin{tabular}{|l|c|c|}
\hline BSFC Building Blocks & Simulated & Demo'ed \\
\hline & \multicolumn{2}{|c|}{$\%$ Improvement } \\
\hline List 1 - Independent Air-System Changes & & \\
\hline Air-to-air interstage cooling & $1.2 \%$ & \multirow{2}{*}{$3 \%$} \\
\hline Air-to-air EGR cooling & $0.8 \%$ & \\
\hline Turbocharger component efficiency- 68\% OTE & $1.4 \%$ & \\
\hline Ultimate Flow Head Port Flow Improvements & $2.5 \%$ & \\
\hline List 2 - Air System Synergies to List 1 & & \\
\hline Turbocompounding- 95\% Transfer Efficiency & $2.5 \%$ & \\
\hline Turbocompounding- 85\% Transfer Efficiency & $1.5 \%$ & \\
\hline Intake valve close timing Optimization & $1.1 \%$ & \\
\hline FMEP Reduction & $2 \%$ & $1 \%$ \\
\hline
\end{tabular}

Table 2.1.1.2: Engine Efficiency Improvement Progress

advantage from the air system modifications, while testing demonstrated 3\% BSFC advantage (see Table 2.1.1.2) due to synergies between technologies. During quarter 1 2003, BSFC building blocks including the 
DOE Final Report

DE-FC05-000R22806

ultimate flow head, FMEP reduction, and turbocompounding were simulated on the 2007 emissions capable system.

\section{Section 2.1.2 - 2007 Emissions Demonstrator Truck}

This section covers work from 2003 to mid 2004. The purpose of this activity was to integrate building blocks for a 2007 emission capable system into a truck chassis while maintaining Caterpillar's industry leading fuel economy.

In quarter 2 2003, the focus moved from demonstrating 2007 emissions in a test cell to demonstrating 2007 technology in-chassis. Several concepts were developed for ways to integrate the subsystems for 2007 on to the demonstration truck. The selection criteria included ease and practicality of packaging, low restriction in the air and CGI systems and timeframe to develop the concept into a design. The timeframe was an important aspect as the program plan was to demonstrate the truck at the DEER conference in August 2003 which was accomplished. A cross-functional team was assembled with a prime and back-up option selected on May 20, 2003. The detailed design was completed on June 13, 2002. Suppliers were selected and procurement of parts began. A portion of the truck hardware arrived in quarter 2 2003, with most arrived early in quarter 32003.

As the design became finalized, software development and ECM procurement also began. Basic software strategies for the closed loop control of the CGI system and trap regeneration were developed.

In quarter 3, 2003 the challenge of bringing all of the 2007 subsystems into a complete system that would package nicely into a class 8 Truck chassis was completed. As stated above, the foundation for the 2007 demonstration truck was a C15 engine with ACERT ${ }^{\circledR}$ technology. The engine baseline hardware includes a variable valve actuation system, series turbochargers and MEUI-A fuel system. Supporting 2007 technologies such as an clean gas induction (CGI) system, which routes gas from after the particulate system in the exhaust stream back into the intake to be used as an in-cylinder diluent, including necessary actuators, sensors and cooler were part of the consist. In addition twin Johnson Matthey CRT ${ }^{\mathrm{TM}}$ diesel particulate filters were integrated onto the truck for particulate matter reduction. Ultra low sulfur diesel fuel $(<15 \mathrm{ppm})$ was also used in the truck. Other key subsystems included advanced electronics capable of interfacing with smart actuators, capable of additional I/O and capable of additional processing of advanced algorithms. A schematic of the system is shown below. 


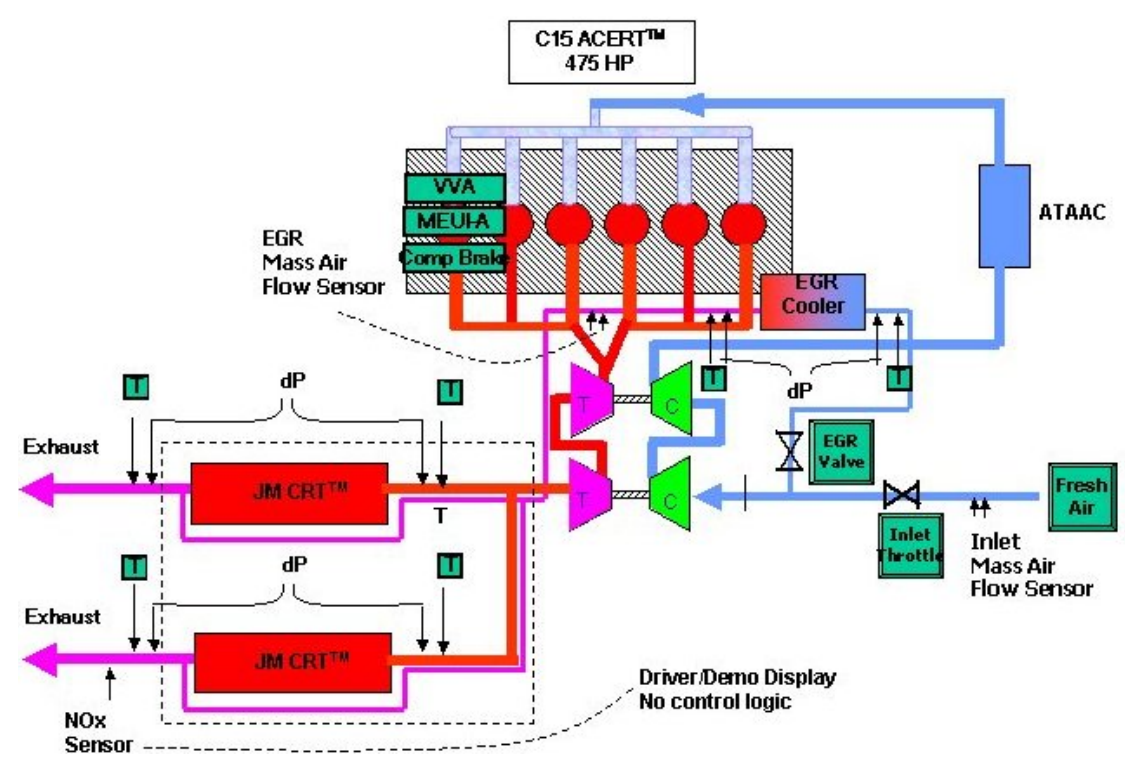

Figure 2.1.2.1. 2007 Demonstration Truck Schematic.

As part of this activity, the 2007 compliant engine with the above-mentioned systems was integrated into a design package that could be installed in a truck for field demonstration and exhibited at the $2003 \mathrm{DOE}$ DEER conference. The package was also stealth to avoid divulging the details of the strategy. This added to the integration challenge but also provided for more creative thinking towards solutions. As seen in the schematic, the truck was equipped with on board emissions equipment, a portable data acquisition system and seating for 6 passengers. It was capable of 2007 emissions and has fuel consumption equal to current production.

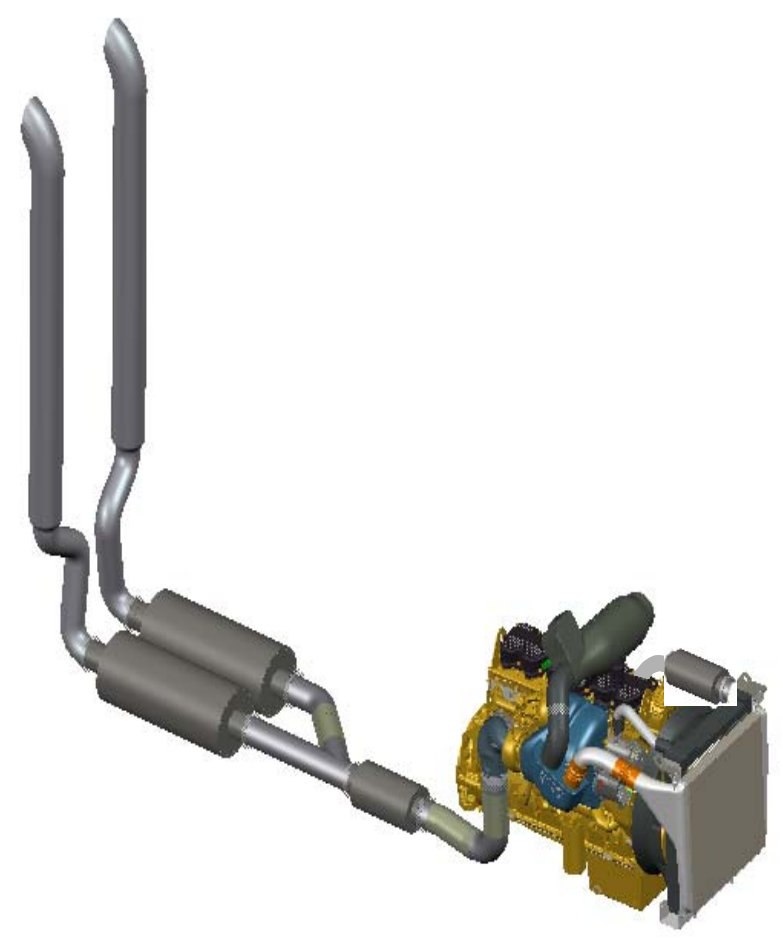

Figure 2.1.2.2. Overview of 2007 Demo Truck with subsystems integrated into the chassis 


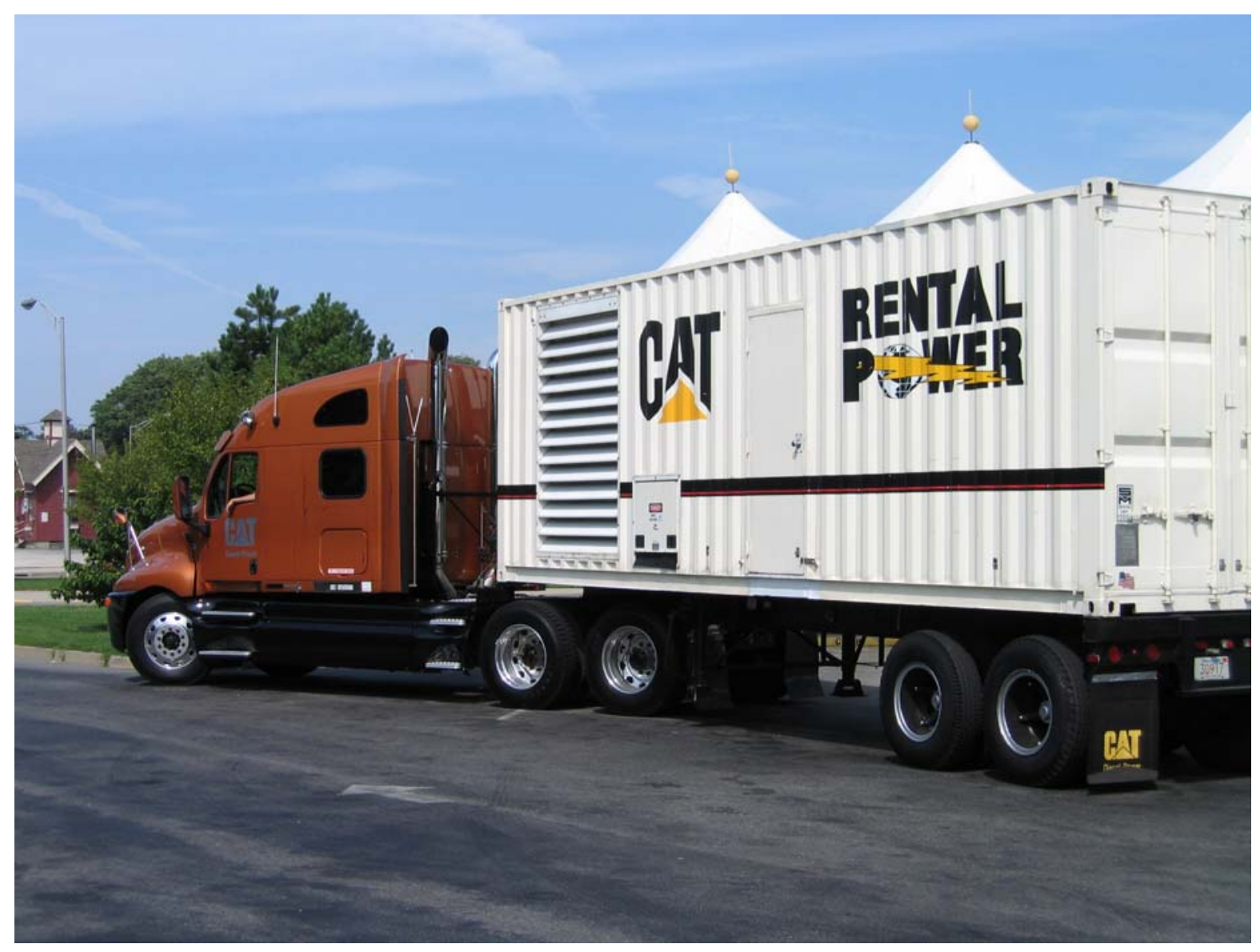

Figure 2.1.2.3. Picture of 2007 Demo Truck at the conference during ride and drive session.

One of the key benefits of this activity was that the demonstration truck activity pulled forward areas of technology that would normally occur later in a program.

Chassis dynamometer tests were conducted in which the cooling system ambient capability and engine fan power requirements were measured. The overall objective of this work was to provide a cooling package for the truck that provides good ambient capability while drawing minimal power from the engine, thus leading to lower in-vehicle fuel consumption. Tests were conducted for two fans, one a current production fan and the other an improved version. Results of these tests were planned to be used as a baseline for other chassis dynamometer tests in which a new hood design and cooling system package were to be tested.

Information from this demonstration truck was used by new technology introduction teams. Part of the work was fully funded by Caterpillar but is listed to illustrate the value of the HTCD program. By providing a viable technology strategy early, the development schedule allowed time to develop products with better bsfc, lower cost, and higher reliability.

1) Noise testing (internally funded)

2) DPF regeneration under various drive cycles (internally funded)

3) Data for 2007 virtual truck simulation

4) Cooling system concepts testing (partially internally funded) 
In 2004, in order to allow further testing a portable data acquisition system (DAS) was obtained that was capable of acquiring sixteen temperature measurements and sixteen additional analog signals such as strain, frequency, current, or voltage signals depending upon the signal conditioning module included in the DAS system. The system is also equipped with a SuperComm communications unit that could interface with the truck ECM through several different protocols.

The engine and exhaust systems were instrumented with industrial grade pressure transducers, magnetic pickups (for turbo speed), and type $\mathrm{K}$ thermocouples. Temperatures and pressures monitored by the ECM using standard production sensors were recorded. These pressure and temperature measurements along with additional ECM channels that were recorded ( 30 additional ECM channels) to allow the engine, truck, and emissions reduction system performance to be monitored and provide the detailed data needed for truck model validation (to be discussed in the following section). A wedge probe was been mounted on the front of the truck that allows the wind speed and yaw angle to be determined through the measurement of a total pressure and two static pressures. The ambient wind speed was measured using a handheld wind speed indicator prior to each test. The wind speed information was used to validate the vehicle drag and cooling system models in the truck simulation as well as to aid in the engine and truck performance analysis.

The truck was also equipped with a GPS system that will allow the truck's location to be recorded. The GPS data can then be used to create a virtual roadway as discussed in Section 2.1.3. A Siemens electrochemical smart $\mathrm{NO}_{\mathrm{x}}$ sensor was mounted in the exhaust to provide transient emissions measurement and will be used to ensure that the truck continues to meet $2007 \mathrm{NO}_{\mathrm{x}}$ emissions regulations as it is tested. A Celesco opacity meter for transient smoke measurements was implemented on the truck upstream of the particulate filters. The smoke measurement allowed the amount of particulate matter entering the particulate traps to be estimated and thus aid in the analysis of the particulate filter performance. The smoke level in the exhaust down stream of the particulate filters is below the detectable limits for smoke meters of this type and thus a sensor was not included in this location.

In quarter 2, 2004, the 2007 Demonstration Truck was taken to the SAE Government and Industry Meeting held in Washington DC May 10 - 12. As part of a press event held, a white handkerchief test of the exhaust and demonstration rides were conducted. During the three day event, EPA Administrator Michael Leavitt, James Connaughton of Bush’s Council for Environmental Quality, Caterpillar Group President Doug Oberhelman, reporters from CNN, and reporters from other organizations were given rides in the truck during which the performance and $\mathrm{NO}_{\mathrm{x}}$ emissions were displayed on a 27" flat screen TV installed in the truck prior to the event. The truck was also on static display two afternoons of the meeting for the attendees to view and ask questions. A movie describing the work being conducted with the truck and the Virtual Truck simulation was played on the flat screen TV during the display. As a result of this event the 2007 Truck was shown on CNN.

Prior to leaving for the SAE Government and Industry Meeting the truck went through a week of intensive chassis dynamometer testing. These tests allowed the engine operating maps to be further tuned for improved emissions and performance (BSFC). Using internal funding, the truck was also used to simulate a transit bus. The truck was loaded in order to provide a comparable weight to engine power ratio and was then driven in a stop and go fashion. Speed, load, exhaust temperature, etc. histograms from actual transit buses were used to validate the drive cycle used.

In quarter 3 2004, additional specialized tests were conducted in order to aid in development of the virtual truck model. Some of the areas improved included clutch engagement, ECM operation, brake system operation, and transmission gear shifting. Also an advanced cooling package and a hood arrangement that allows flow through the cooling package and then back outside the hood have been fitted on the truck. This ultimate flow hood, shown in Figure 2.1.2.4, was designed to achieve better flow through the cooling package while maintaining or improving the truck drag coefficient. The objective is to demonstrate lower fan power 
requirements and thus improved fuel economy. The advanced cooling package includes an advanced compact primary surface (ACIPS) CGI cooler and ATAAC. Cooling system tests evaluating the performance of the system were conducted on several configurations of the advanced cooling package.
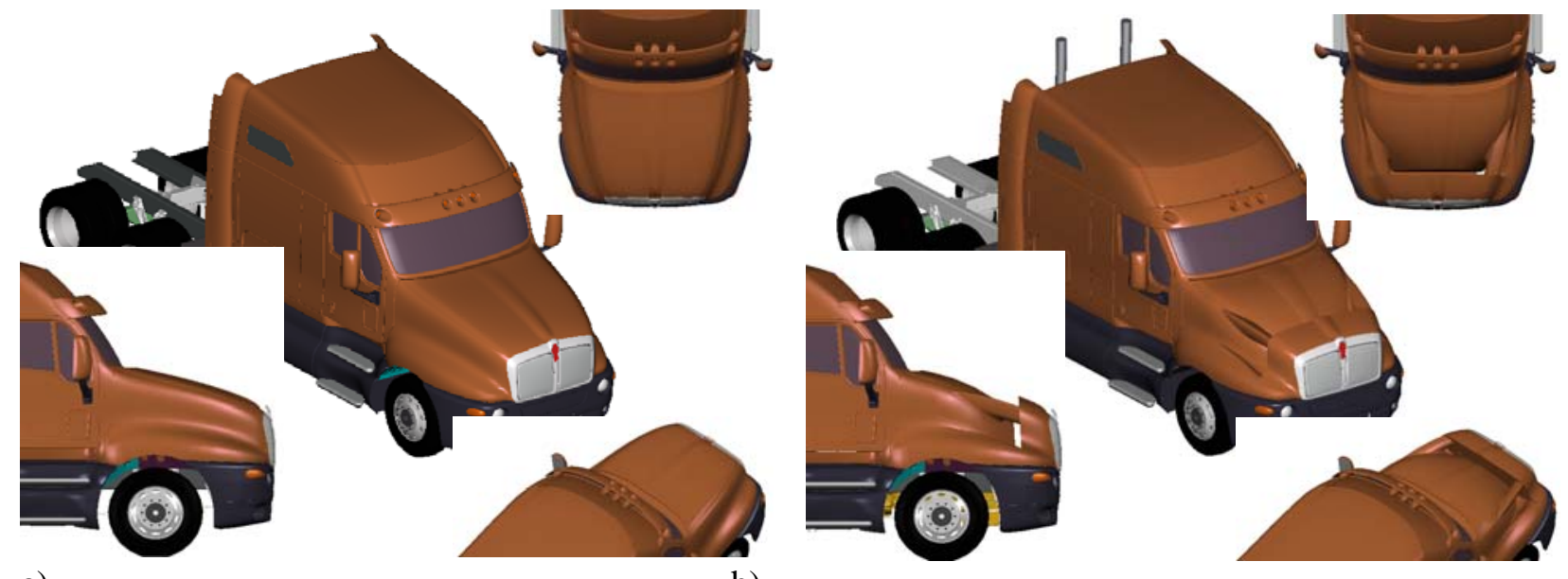

a)

b)

Figure 2.1.2.4: Comparison of the a) production 2000 model year Kenworth T2000 hood (b) with the "ultimate flow hood".

Improvements to the truck data acquisition systems continued in order to complete an in-depth calibration of the virtual truck model, allow the truck's operating conditions to be compared more completely with those in the test cell, and allow better troubleshooting of engine operating problems. The analog to digital converter was upgraded to provide for more robust operation, the drive shaft was replaced with an instrumented version to provide driveline torque measurement, and a portable AVL combustion analysis system was installed to provide measurement of cylinder pressure and injection pressure.

After the advanced cooling system tests were completed, the 2007 truck was converted back to its original configuration. It was then used to acquire additional test data for validation of the 2007 chassis transient simulation. The truck was also used for internally funded research. This work was focused on ensuring that the 2007 product is reliable under all ambient operating conditions. The truck was eventually retired as 2007 field evaluation and production intent trucks (internally funded) became available.

In summary, the 2007 emissions demonstrator truck allowed the development and testing of new technology that would not normally occur until later in a program.

\section{Section 2.1.3 - 2007 Virtual Test Cell and Truck Development}

An initial demonstration of transient emissions for the 2007 truck engine using the MEUI-A fuel system was completed in 2002 and 2003. These tests indicate the need for additional transient development of CGI (Clean Gas Induction) control and particulate filter active regeneration. A full transient model of the 2007 demonstration engine configuration used in the transient lab demo to help develop the control strategies was created. The baseline variable valve actuation and CGI control strategies used in the lab demo were implemented in the virtual test cell model in Caterpillar Dynasty ${ }^{\mathrm{TM}}$ transient simulation software.

The process of building a transient simulation model of the 2007 demo truck engine in Caterpillar's Dynasty simulation software included coupling the model to Caterpillar's engine cycle simulation code “973”. A new model was made available in quarter 2, 2003, and excellent results were obtained from the model when compared to 13 mode data from the 2007 demonstrator engine. A representative example from the 1200rpm, full load point is shown in Figure 2.1.3.1. 

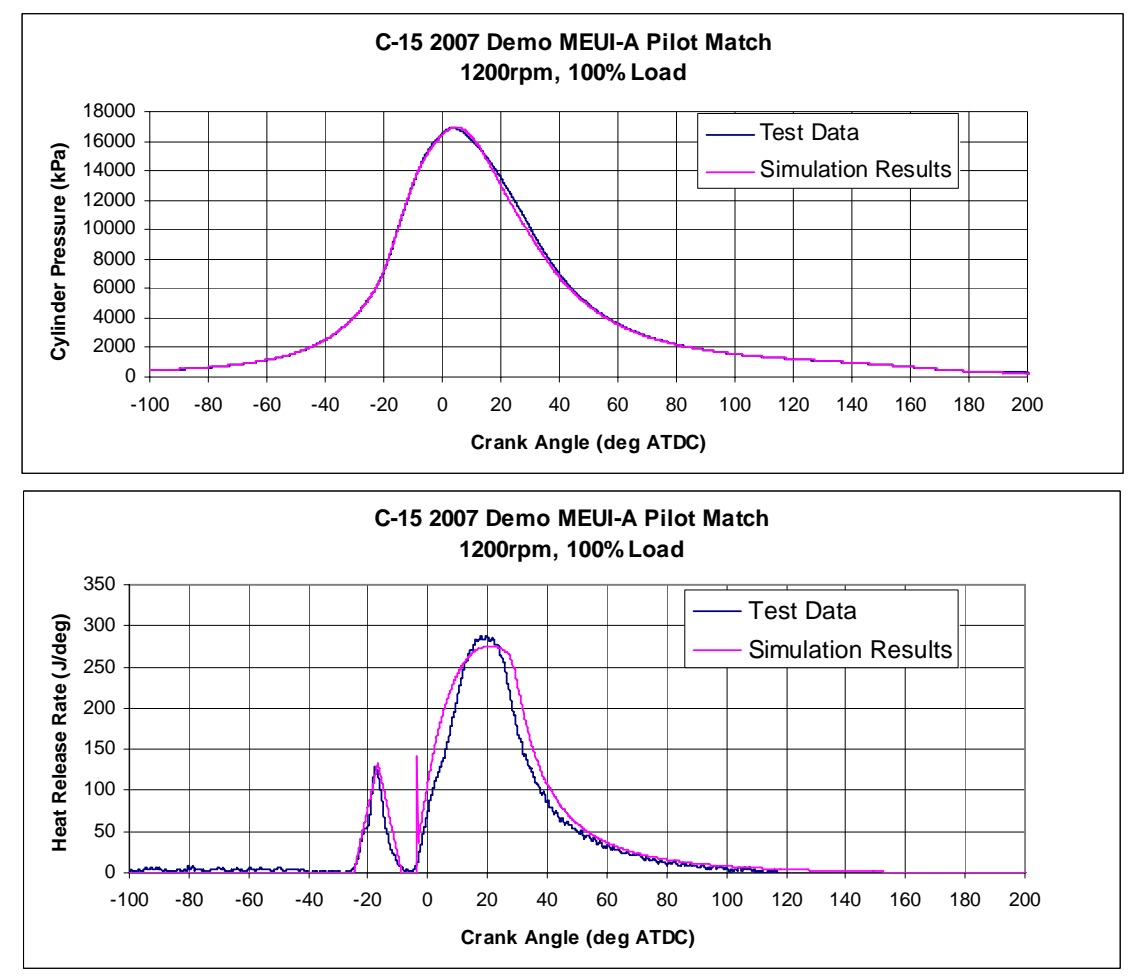

Figure 2.1.3.1: 2007 MEUI-A Pilot Heat Release Simulation

The blue lines are derived from test measurements, the red lines are simulation results.

In quarter 3, 2003 the process of building a transient simulation model of the 2007 demo truck engine continued made significant progress. The model included dynamics of a transient emissions test cell dynamometer and controller and details of the 2007 demo C-15 including series turbos, inlet valve actuation, pilot fuel injection, low pressure loop CGI, particulate trap, and control software. The diesel particulate filter model simulates soot loading, oxidation, and pressure drop of a catalyzed filter.

Initial validation of the model against a limited set of transient cell data was completed. Representative results are shown below in a set of plots for a 20-minute FTP transient emissions test cycle. 


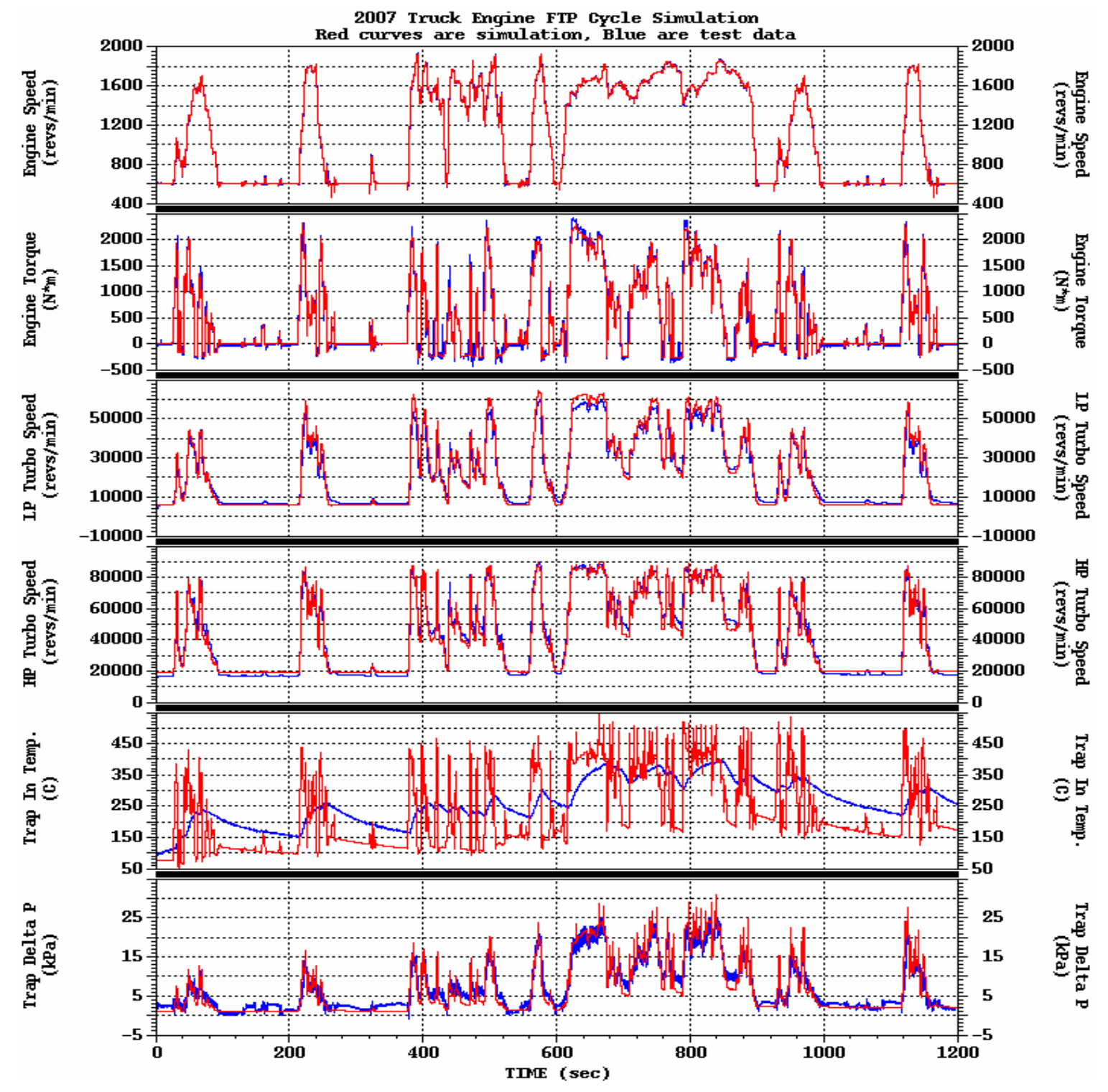

Figure 2.1.3.2: 2007 C-15 Simulation Results for FTP Cycle

The results shown versus time from top to bottom are engine speed, torque, low pressure turbo speed, high pressure turbo speed, oxidation catalyst inlet temperature (immediately in front of the PM filter), and PM filter pressure drop. The blue curves are test measurements and red curves are simulation results. The oxidation catalyst inlet temperature prediction is a good example of how the model adds information that is not available from test measurements. The test measurement was averaged due to the slow response of the thermocouple used in this test, but the simulation provides instantaneous temperature to accurately model PM trap regeneration performance. Notice the excellent correlation of diesel particulate filter pressure drop with the test measurement. There are some discrepancies in torque and turbo speed during the high load parts of the cycle due to differences in CGI line flow characteristics and CGI cooler performance of the model as compared to the test engine.

In quarter 4, 2003, the engine part of the transient model was improved by adding a more accurate model of the CGI system duct work, cooler, and valves was implemented. Steady-state matching to test data showed 


\section{DE-FC05-000R22806}

that it matcheds performance more accurately over the entire operating range with only changes to control parameters that are varied in the real engine, for example valve positions.

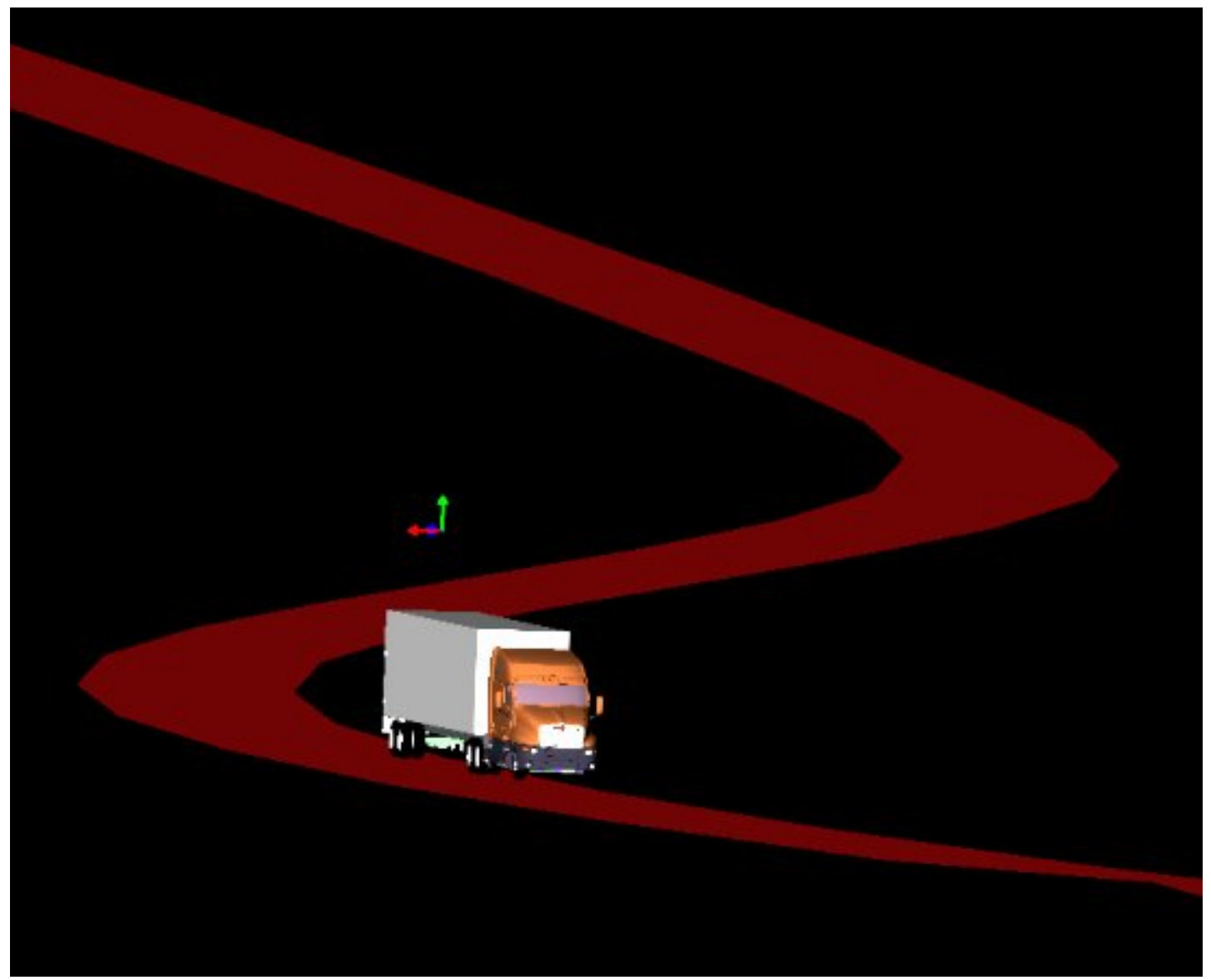

\section{Figure 2.1.3.3 - Virtual Truck Model}

A virtual truck chassis model was assembled. The model includes three-dimensional motion of the truck chassis, a driveline, realistic tire models including friction, and accessory loads on the engine such as the cooling fan. Global Positioning System (GPS) data measured on the 2007 emissions demonstrator truck in the field was used to recreate a full three-dimensional representation of the roads that the truck is driven on in field tests (see the Figure 2.1.3.3 above). 
DOE Final Report

DE-FC05-000R22806

In quarter 1 2004, final validation of the virtual test cell model with respect to transient lab data was completed. The new clean gas induction subsystem model improved the transient data match (see figure 2.1.3.4 below). This matching and validation exercise demonstrated that the model was very accurate. Note that this was not a simple map or interpolation of test data as is used in many vehicle-level simulations, but a predictive thermodynamic simulation of the engine with a one-to-one correspondence of physical submodels to the real engine. This process was another first completed under the HTCD program.

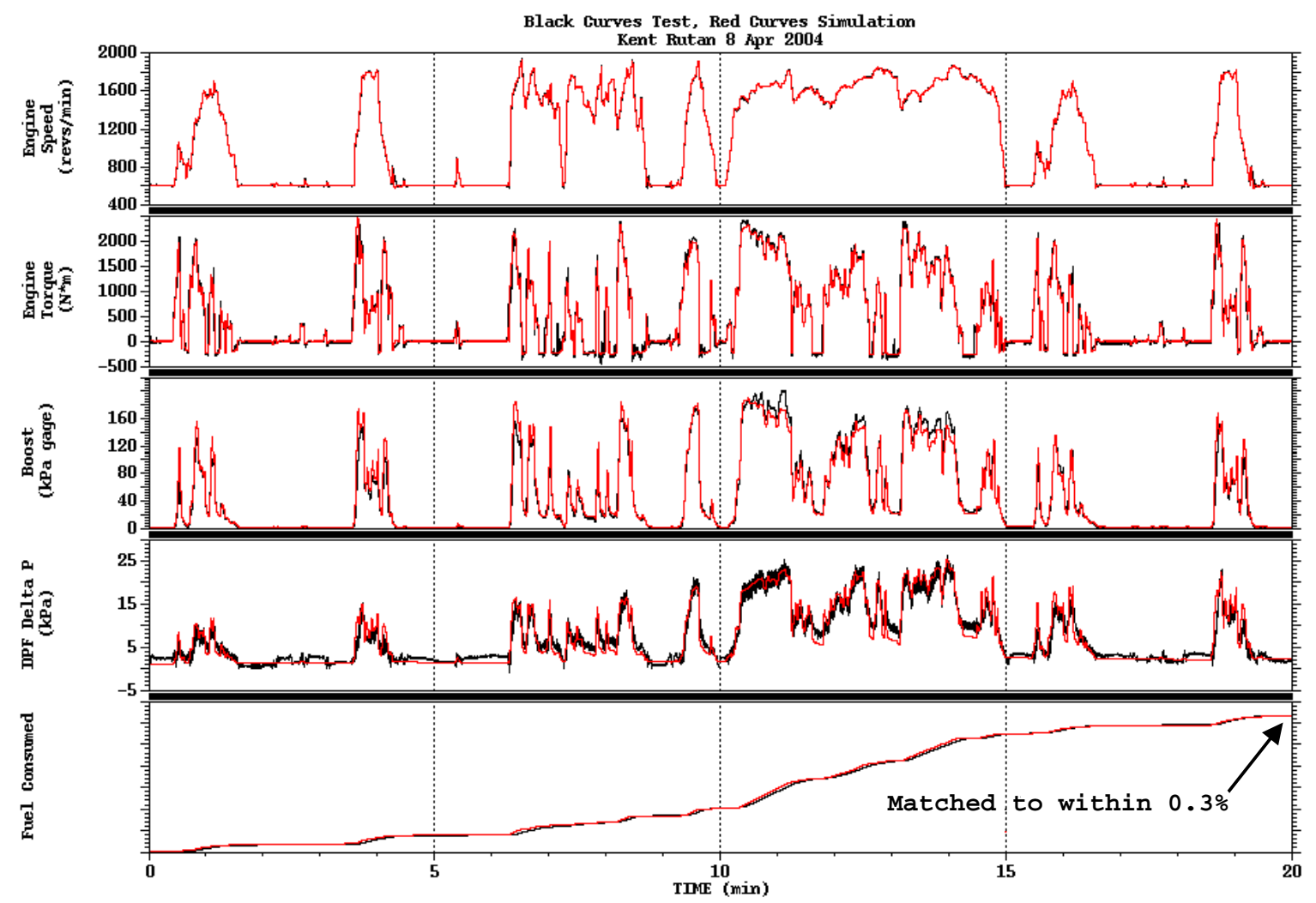

Figure 2.1.3.4. C-15 2007 demo engine speed, torque, boost, PM trap pressure drop, and fuel consumption validation results for the full FTP cycle. Black curves are test data, red are simulation results.

In quarter 2, 2004 further virtual truck model validation continued. In quarter 3, 2004, these results were presented at the DEER conference in San Diego.

In quarter 4 2004, on-highway performance measurements were acquired using the 2007 demonstrator truck and the same driving conditions simulated using the virtual truck model. For the driving conditions shown in Figure 2.1.3.5, the fuel consumption was predicted to within $2.2 \%$ of that measured.

The top two graphs in Fig. 2.1.3.5 show the fuel pedal position and the air brake application pressure, respectively. Both are measured values. The third graph in Figure 2.1.3.5 shows the driver desired gear (measured) and the actual gear. With the Eaton Autoshift ${ }^{\mathrm{TM}}$ transmission, the driver inputs the desired gear and then the transmission ECM conducts the shift process. The transmission ECM is modeled and so the measured actual gear is compared with the predicted value. The final graph in Figure 2.1.3.5 contains the measured and predicted vehicle speeds. 
Additional truck testing was conducted to further investigate aerodynamic drag, rolling resistance, and drive train losses. Improvements were made to the model to more accurately capture the effects of each of these losses.

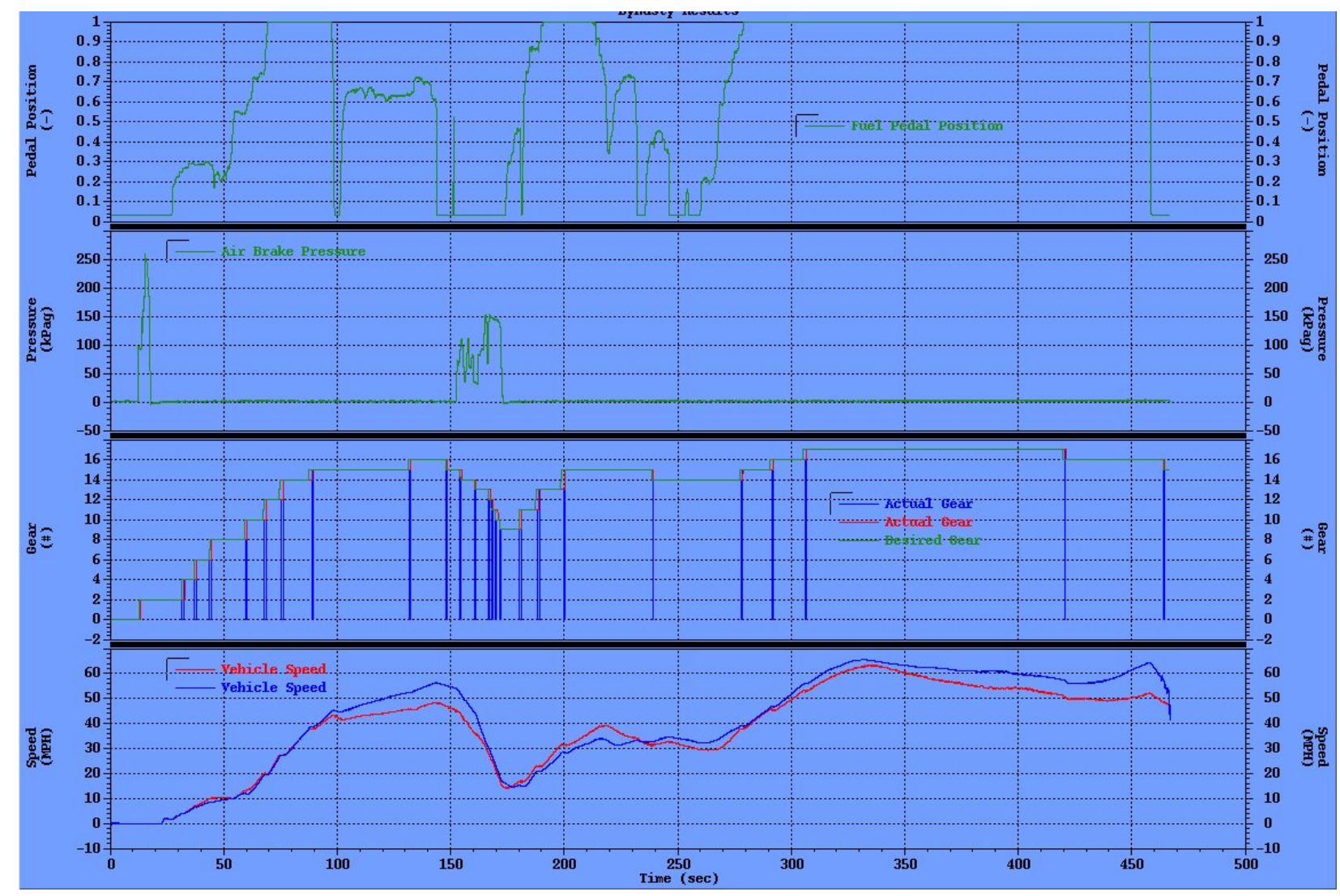

Figure 2.1.3.5. Measurements taken on-highway using the 2007 demonstrator truck compared with predictions made using the virtual truck simulation. Green lines are inputs to the code, red lines are measurements, and blue lines are predictions.

\section{Section 2.2 High Efficiency Engine Demonstration at 2010 emissions (Phase 2)}

The objective of this demonstration is 50\% thermal efficiency at 2010 on-highway truck emissions levels while packaging the system within a Class VIII on-highway truck and meeting durability targets.

There were three basic emissions technology evaluated to meet the 2010 emissions levels. In addition thermal efficiency building blocks were integrated to meet the 50\% thermal efficiency target. This work occurred from 2004 through the end of 2006. This work is described in this section.

Three emissions technology paths were developed as options to meet the overall HTCD program goals of 2010 emissions levels with 50\% thermal efficiency. All three options built upon the 2002 baseline engine and the 2007 demonstration engine configuration. The options evaluated were based on 1) Full HCCI type combustion over the operating range 2) HCCI type combustion mixed with traditional combustion operation (Mixed-Mode operation) and 3) High-Efficiency NOx Aftertreatment. The three options were evaluated as 
DOE Final Report

DE-FC05-000R22806

integrated systems in 2003 and 2004 and a technology down selection was made in 2005. In 2006, the focus was on integrating technologies to meet the $50 \%$ efficiency target. The building blocks for $50 \%$ thermal efficiency were reported in Section 1.1.4. Section 2.2 is divided into

2.2.1 HCCI System Demonstration of technology described in Section 1.1

2.2.2 HCCI Mixed Mode Operation described in Section 1.1.3.2.

2.2.3 High Efficiency NOx Aftertreatment System Demonstration of technology described in Section 1.3

2.2.4 System Optimization for 50\% thermal efficiency at 2010 emissions: Integration and system optimization of High Efficiency NOx Aftertreatement with thermal efficiency building blocks reported in section 1.4 to meet 2010 emissions at 50\% thermal efficiency.

2.2.5 System Design and Packaging

\section{Section 2.2.1 HCCI System Demonstration of technology described in Section 1.1}

To initiate system integration work on option 1 (Full load range HCCI), a C-15 multi-cylinder HCCI engine was been installed in quarter 1, 2003 and debugged in a steady state test cell. A C15 multi-cylinder engine was configured to evaluate HCCI combustion concepts previously demonstrated on the single cylinder. A production-intent C15 engine with ACERT ${ }^{\circledR}$ technology was modified to include a low pressure loop CGI system, special cam with HCCI injection lobes, showerhead nozzles, lower compression ratio pistons, a particulate filter and customized electronics. Testing focused on replicating the successful single cylinder data with actual air systems and with across multiple cylinders. Work also continued in parallel to expand the operating range compared to the single cylinder work to lower and higher loads as well as evaluating air system enhancements needed to improve system performance. It was recognized that matching an air system would be critical for the success of an MCTE HCCI engine.

\section{Expanding lower load operation on a MCTE}

Work included part load performance and emissions tests for two different showerhead nozzle configurations. A set of wider spray angle tips as compared to the baseline tips allowed for more retarded injection timings which resulted in lower $\mathrm{HC}$ and $\mathrm{CO}$ levels, hence better combustion efficiency and lower fuel consumption. Data is shown in the EPACT protected appendix. All data collected for this test met the criteria of less than 5 ppm NOx. Similar results were obtained for other speed/load points. Approximately 300 data points were taken which spanned the 1200-1800 rpm speed range and up to approximately $1 / 2$ load. Air flow deficiencies of with the installed turbocharging system limited the maximum achievable power before engine-out smoke levels increased to unacceptable levels.

A series of five ultra low temperature oxidation catalysts were provided by several different catalyst companies. These oxidation catalysts were designed to reduce CO and HC under high concentration, low temperature catalyst inlet conditions, like those found with HCCI combustion type engines. Tests on the MCTE HCCI engine at light loads revealed that none of the oxidation catalysts performed exceptionally well. Light-off temperatures (50\% HC conversion) for the oxidation catalysts with baseline Pt loading were approximately $210 \mathrm{C}$ which occurred at about $270 \mathrm{kPa}$ BMEP at $1200 \mathrm{rpm}$. To be successful, these catalysts would have need to be active at temperatures as low as $150 \mathrm{C}$ which is typical for portions of the transient cycle, but no $\mathrm{HC}$ or $\mathrm{CO}$ conversion was observed until catalyst inlet temperatures reached $175 \mathrm{C}$. Target HC conversions of $90 \%$ are needed to meet $2010 \mathrm{HC}$ levels, and none of the catalysts tested reached that level, even at $1 / 4$ load. The light-off temperature for a catalyst with 3 times the Pt loading was lowered to $180 \mathrm{C}$, but this $30 \mathrm{C}$ reduction would likely not justify the increase in cost for the $3 \mathrm{X}$ higher Pt loading. The results were shared with select suppliers to provide motivation for improved future performance. 
DOE Final Report

DE-FC05-000R22806

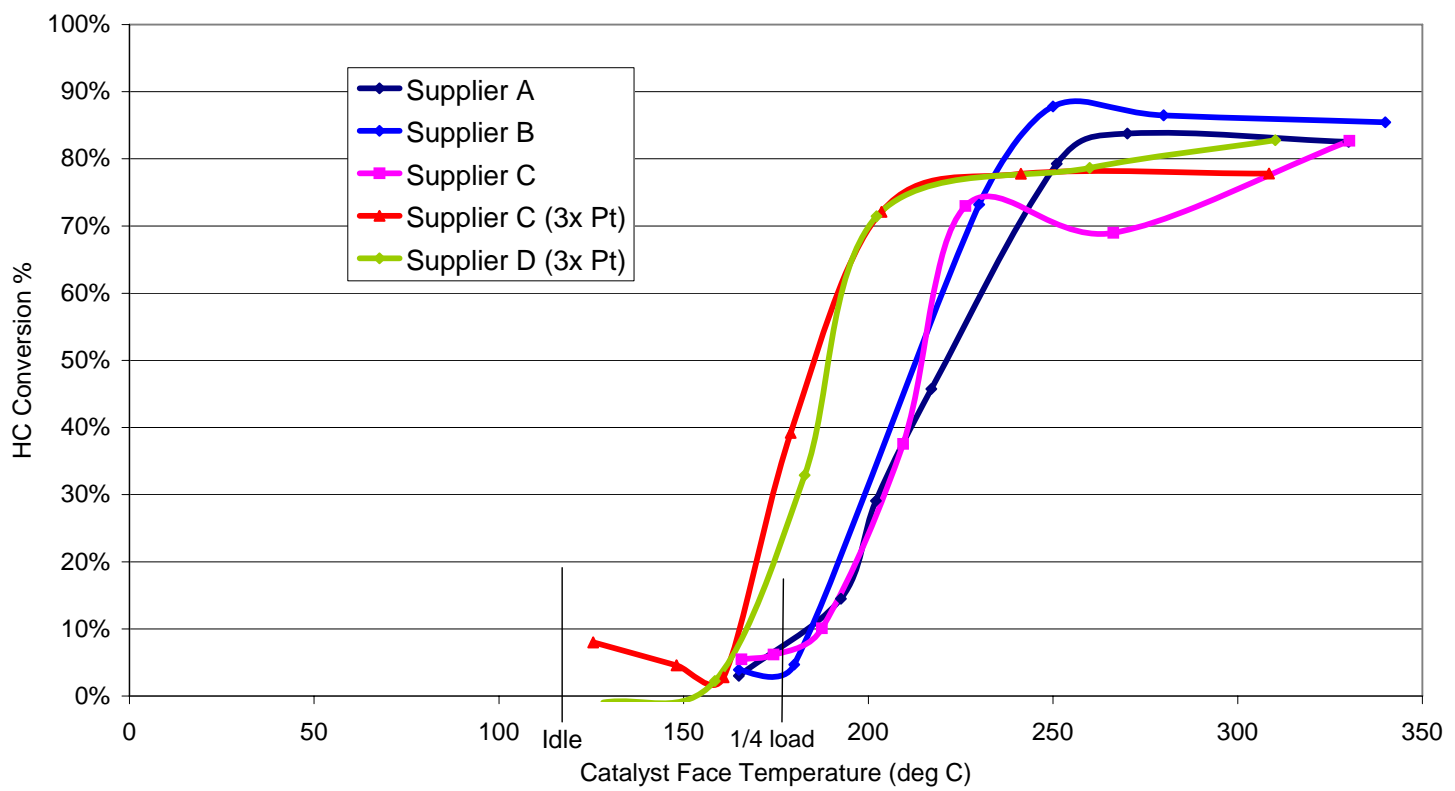

Figure 2.2.1.1. Light-off curves for low temperature oxidation catalyst tests.

\section{Expanding to higher load operation on a MCTE}

Several air system modifications were made in an attempt to increase the load range of the multi-cylinder engine. A single variable geometry turbo was installed as well as a VGT + conventional turbo. Slight load increases were achieved ( $\sim 0 \mathrm{kPa}$ BMEP) with the single VGT, but due to the high backpressure required to achieve the higher boost levels of approximately $15 \mathrm{kPa}$, the fuel consumption increased. Tests with the VGT + conventional turbo were also ineffective for similar reasons.

Several nozzle tip and air system modifications were made in an attempt to increase the load range of the multi-cylinder engine. A range of showerhead tips were tested. Additional air system arrangements were tested. This included a variable geometry turbo with several different low pressure turbochargers arranged with it in a series arrangement. The VGT vane position was adjusted to achieve different boost levels. The MCTE engine was at 12:1 CR for these tests. The injection timing, CG rate, and boost levels determined on the single cylinder were repeated and the strategies appear to scale between the two platforms.

Approximately $60 \%$ load was achieved at three speeds before smoke limited further power output. This agreed well with the SCTE data obtained at this 12:1 CR. The SCTE was also limited to approximately this $60 \%$ load when configured at 12:1 CR. Full load as described above in section 1.1 was done at a compression ratio of 8:1. The 12:1 CR was chosen to allow starting with the AC dyno (non-motoring). These results further validated the need to develop variable compression ratio technology.

\section{Controls improvements for stable MCTE operation}

For a multi-cylinder HCCI engine a key challenge is control of the cylinder to cylinder combustion phasing. Uneven charge air distributions due to port flow variations can lead to combustion phasing differences (and hence emissions differences) in certain cylinders. Typical results for a part load operating condition are shown in figure 2.2.1.2. Notice cylinders 3 and 4 exhibit a 3 degree shift in main combustion phasing relative to the other cylinders. A variable inlet valve timing (IVA) system was used to trim air flow to individual cylinders and match combustion phasing characteristics which is also shown in 
figure 2.2.1.2. IVA and later fuel trims were explored for its use as a combustion phasing and controls tool under this program and completed under the HECC program.
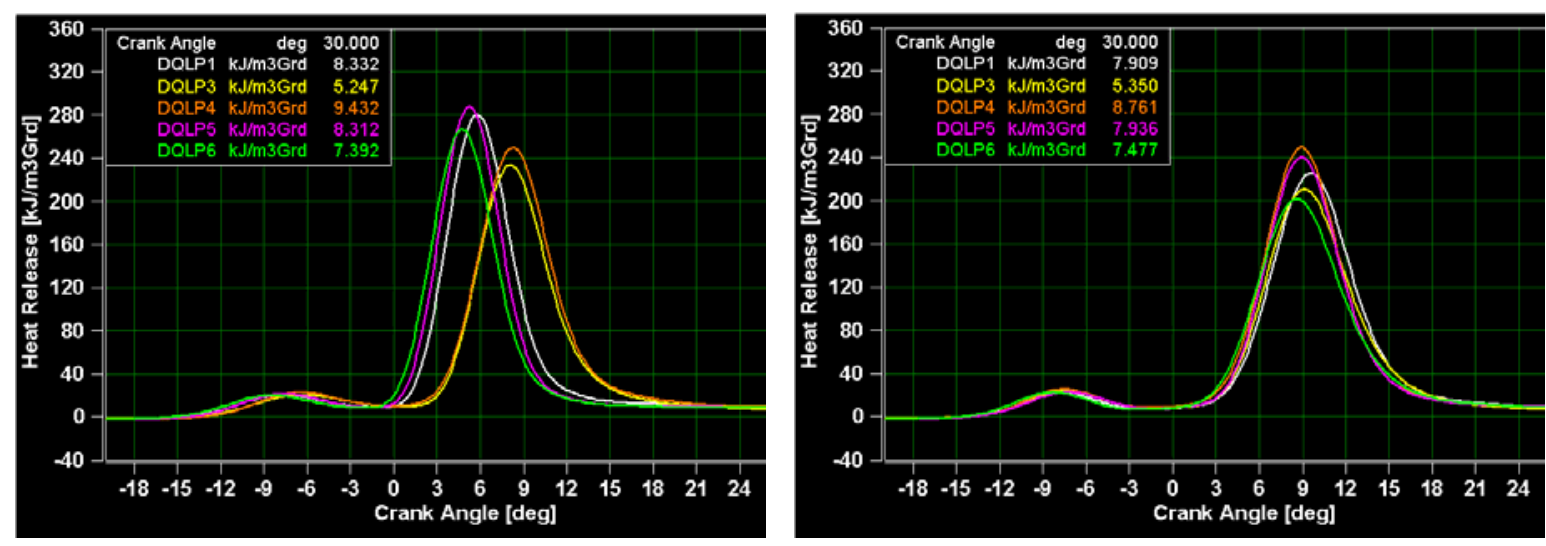

Figure 2.2.1.2: HCCI Combustion Phasing without and with inlet valve timing (IVA) adjustment.

\section{Section 2.2.2 HCCI Mixed Mode Operation described in Section 1.1.3.2.}

Due to the focus on full load capability for HCCI and the limited success with implementation of the Mixed Mode Injection concepts, a system integration program was not undertaken for this path option. The program did recognize that a combination of mixed mode HCCI at lighter loads augmented by NOx Aftertreatment at higher loads could be a promising option for 2010. An injection system like the mixed mode injector provided would be a key enabler.

\section{Section 2.2.3 System High Efficiency NOx Aftertreatment System Demonstration of technology described in Section 1.2}

The objective of this work was to test a C15 equipped with a NOx adsorber system to evaluate the viability for 2010 emission levels. As part of this development, a simulation study was started to assess the viability of in-cylinder enrichment for NOx adsorber regeneration. In the simulation study 2 tools were used: 973 thermodynamic cycle simulation and CAT3D combustion software. The 973 program was used to evaluate the effects on the air systems and to investigate air system strategies for rich combustion. The CAT3D was used to evaluate rich combustion and develop low soot combustion strategies.

To evaluate the potential of a NOx adsorber catalyst system for application in 2010, a NOx adsorber system was evaluated on a C15 engine. The engine system consisted of a C15 engine with ACERT ${ }^{\circledR}$ technology with PM filters and low pressure loop CGI (clean gas induction) system. The engine system was calibrated to generate sufficiently low engine-out NOx levels as to allow the NOx adsorber to perform at a realistic NOx conversion of $85-90 \%$. The NOx adsorber system was set up as a dual leg configuration for regeneration. This system consisted of two flow paths with a NOx adsorber in each path, including an exhaust valve and fuel injector in each path. In order to still allow testing of the 2007 engine setup, the exhaust system was setup in a flexible way. This allowed for switching back and forth between the 2007 and 2010 setup. The total NOx adsorber volume is 25 liters. This is shown in Figure 2.2.3.1. 


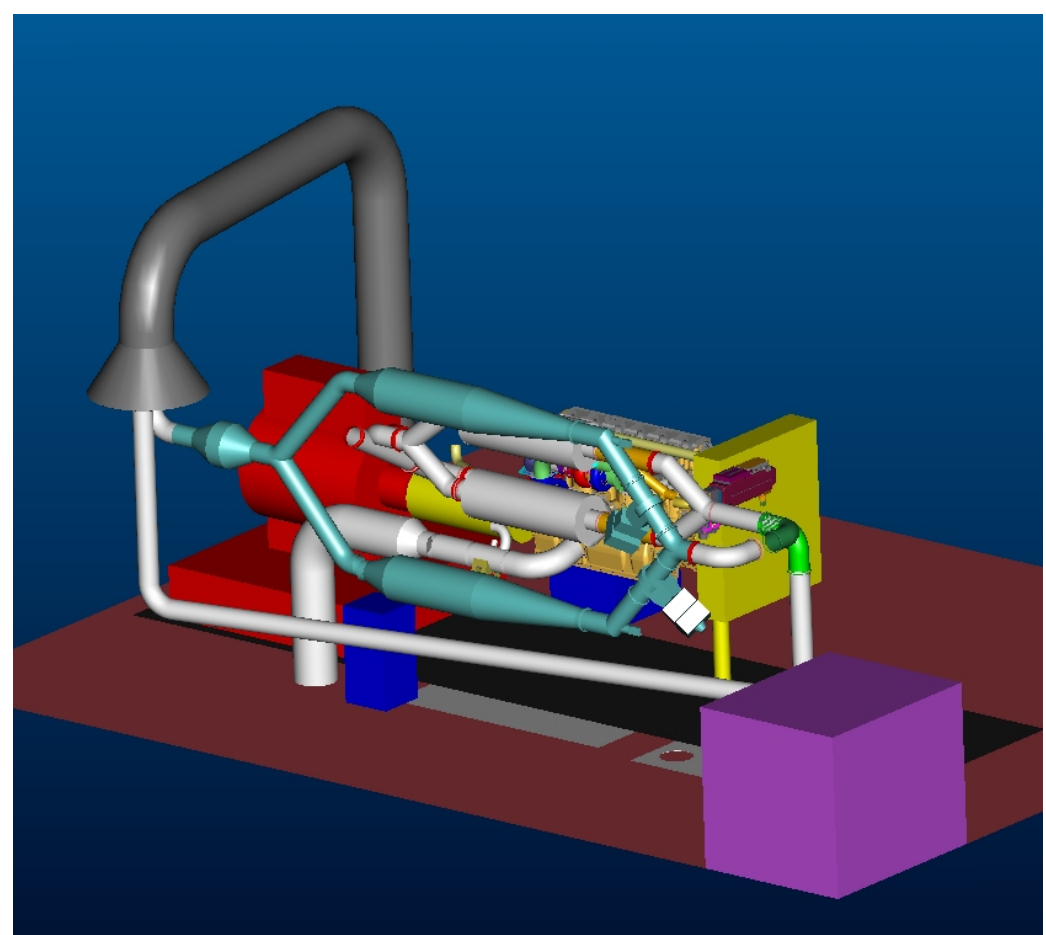

Figure 2.2.3.1. Layout for NOx adsorber system with C15 engine in multi-cylinder engine test cell

The engine was calibrated for an ESC cycle average of $1.4 \mathrm{~g} / \mathrm{hp} \mathrm{hr} \mathrm{NOx,} \mathrm{while} \mathrm{keeping} \mathrm{the} \mathrm{conditions} \mathrm{at} \mathrm{all}$ operating points favorable for PM filter regeneration (sufficient NOx/PM ratio). Regeneration strategies for the NOx adsorbers were developed, and calibrations were made for the various engine operating conditions. The NOx adsorbers regeneratation strategy was to close the flow through one leg and inject diesel in front of the catalyst to enrich the exhaust gas. The rich environment allowed for regeneration. Then after the exhaust gas becomes lean again, the valve is opened and the other leg is being regenerated in the same way. After regeneration of both legs, the catalyst will store NOx for a set amount of time (usually 2-5 minutes). The following figure 2.2.3.2 and table 2.2.3.1 show the results obtained. 


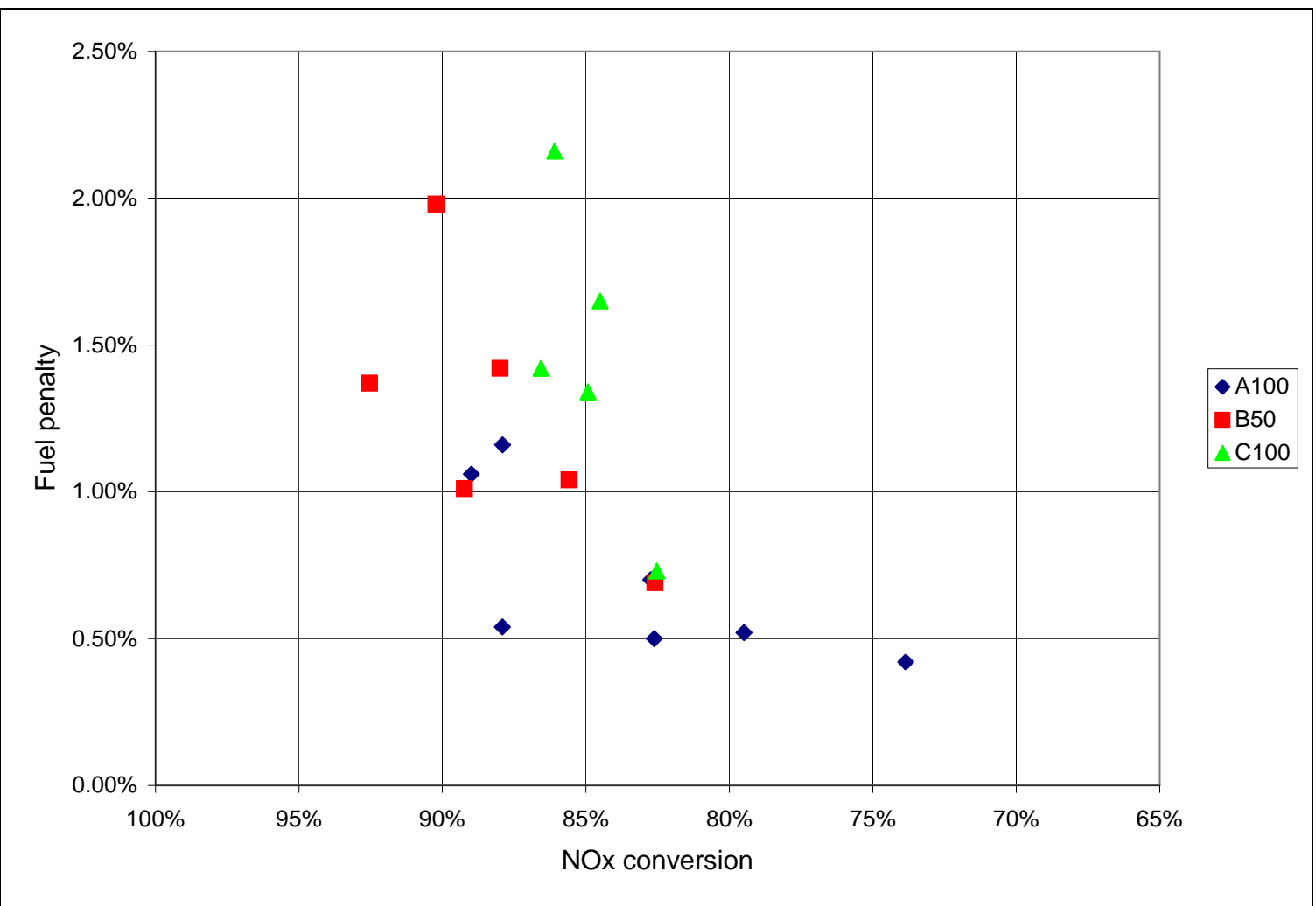

Figure 2.2.3.2: NOx-BSFC trade-off for Catalyst performance

Table 2.2.3.1: NOx BSFC results for 2010 C15

$\begin{array}{ccc}\text { NOx conversion } & \text { BSFC penalty } & \begin{array}{c}\text { Catalyst out NOx } \\ \%\end{array} \\ \% & 0.5 & 0.12 \\ 88 & 1.4 & 0.06 \\ 93 & 1.3 & 0.2 \\ 85 & & 0.2\end{array}$

As can be seen from the table, the NOx emissions out of the NOx adsorber were below the legal limit. This good conversion efficiency allowed some further recalibration of the engine/catalysts system to produce higher engine out NOx emissions which trades off favorably with fuel consumption. It was demonstrated that fuel consumption for this system could be better than the baseline 2007 system.

In the later reporting periods of 2004, other operating conditions were tested with similar results. Most operating conditions showed a NOx level of below $0.2 \mathrm{~g} / \mathrm{hphr}$ and $<0.01 \mathrm{~g} / \mathrm{hphr}$ PM level, both well within the 2010 emission requirements. Corresponding fuel penalties were very low as shown in the following figure 2.2.3.3. Notably, the B50 conditions (road load) showed very low NOx emissions which results in room for BSFC optimization. 
DOE Final Report

DE-FC05-000R22806

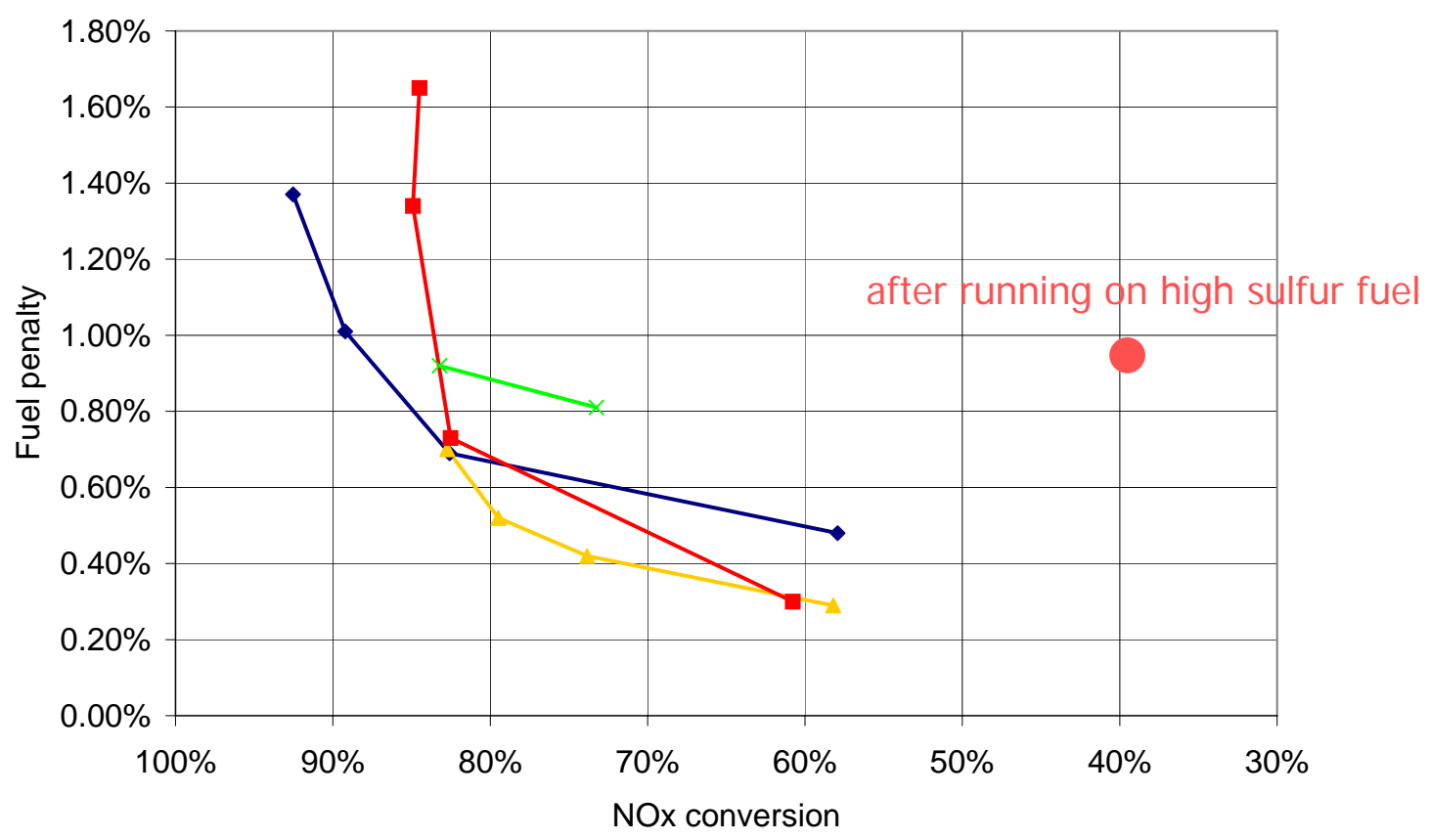

$\leftarrow \mathrm{C} 25 \rightarrow \mathrm{B} 50 \div \mathrm{A} 100 \multimap-\mathrm{C} 100$

Figure 2.2.3.3. Fuel Penalty versus NOx Conversion for MCTE NOx adsorber testing.

Further work during 2004 was delayed because of problems with sulfur levels in the fuel that was used. These higher sulfur levels deteriorated the performance of the catalysts beyond expectations which required the project to refocus to address the challenge. The resulting performance is shown as a red dot on figure 2.2.3.3.

Project focus then turned to catalyst durability testing on a 3126-engine test platform. The main durability challenge with NOx adsorber catalysts is the deactivation by sulfur and the high temperatures required to remove the sulfur and restore the catalyst performance. Multiple catalysts were aged for increasing times and temperature to understand the effects of these parameters and to predict durability.

Fig. 2.2.3.4 shows the results for 1 of these catalysts. The figure represents the capability to store NOx at different operating temperatures $\left(250-450^{\circ} \mathrm{C}\right)$. Multiple 10 -minute desulfations were performed at increasing temperatures $\left(600-750^{\circ} \mathrm{C}\right)$. This test shows the impact of both total desulfation time and desulfation temperature. It is clear that both these parameters have a negative effect on the storage capacity. Noteworthy is that the performance at $450^{\circ}$ initially improves, before it decreases at very high temperatures. 
Stored NOx vs Desulf time and Temperature (10 minute desulfation runs)

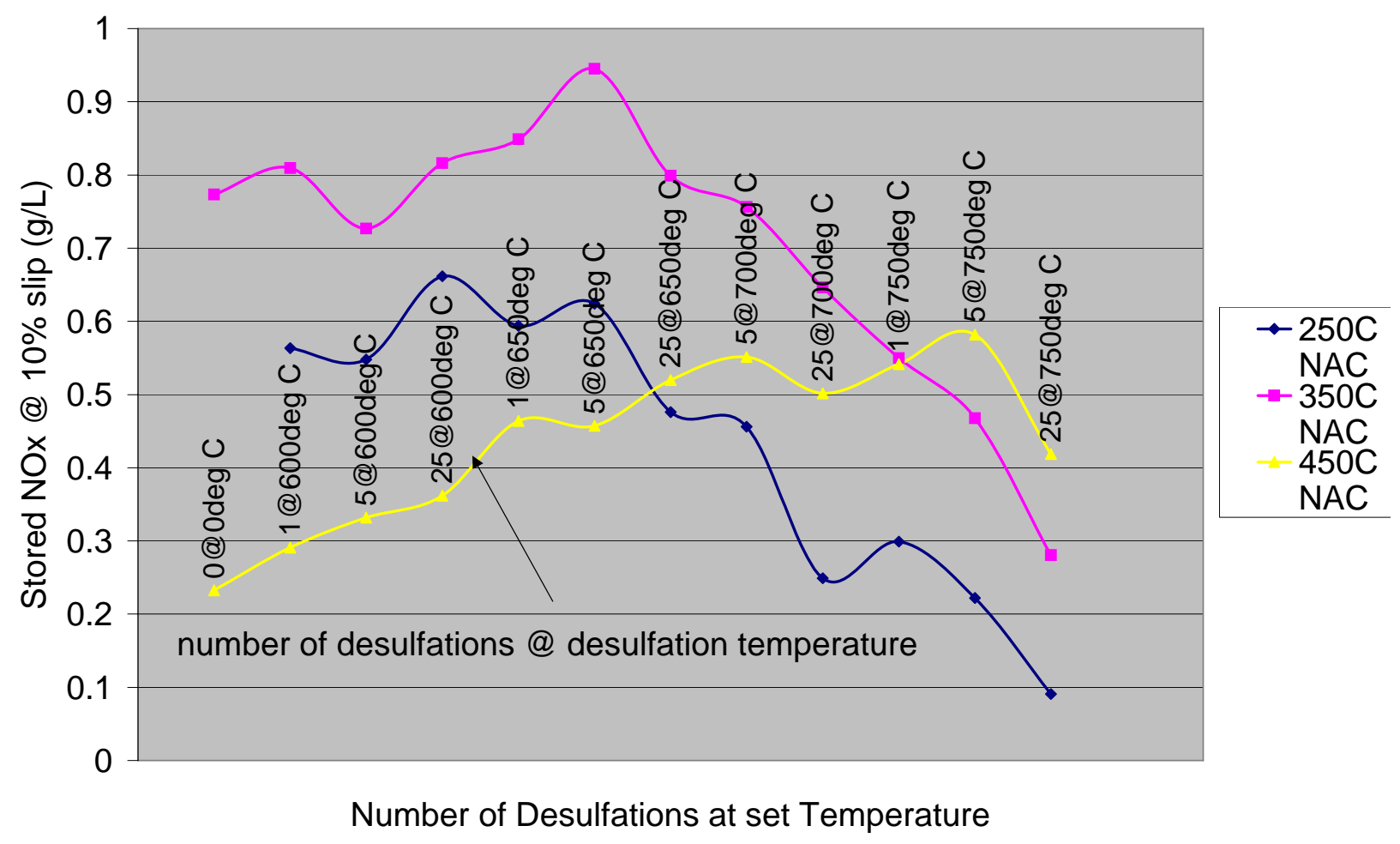

Figure 2.2.3.4. Effect of desulfation on NOx storage

Knowledge of thermal deactivation was better understood, through the test. Information on the sulfur release would also be needed to be measured as a function of temperature as well. This information would feed into a trade-off to choose the optimum desulfation temperature, while allowing sufficient durability.

Another deactivation mechanism is caused by phosphorus. The Xytel catalyst test bench was used to evaluate this type of deactivation. Preliminary results suggested that the system will be deactivated by phosphorus, but that the level of deactivation might be acceptable. Further investigation would be necessary to understand the deactivation mechanisms and better protect the catalyst.

To further understand NOx adsorber performance, a C15 with CGI and DPF was equipped with a RPAC2 system (flexible control system). The engine was used to develop very low air/fuel ratio strategies to enable catalyst desulfations. One of the challenges during a desulfation is to provide a very low $\mathrm{O} 2$ concentration to the catalyst and to be able to control the temperature during rich conditions. Fig. 2.2.3.5 supports this. The green line represents the desired air/fuel ratio in the catalyst during a desulfation, being slightly rich. This line shows the theoretical temperature increase as a function of engine out air/fuel ratio. In order for the catalyst to reach about $700^{\circ}$, the temperature increase needs to be anywhere in the red box. 


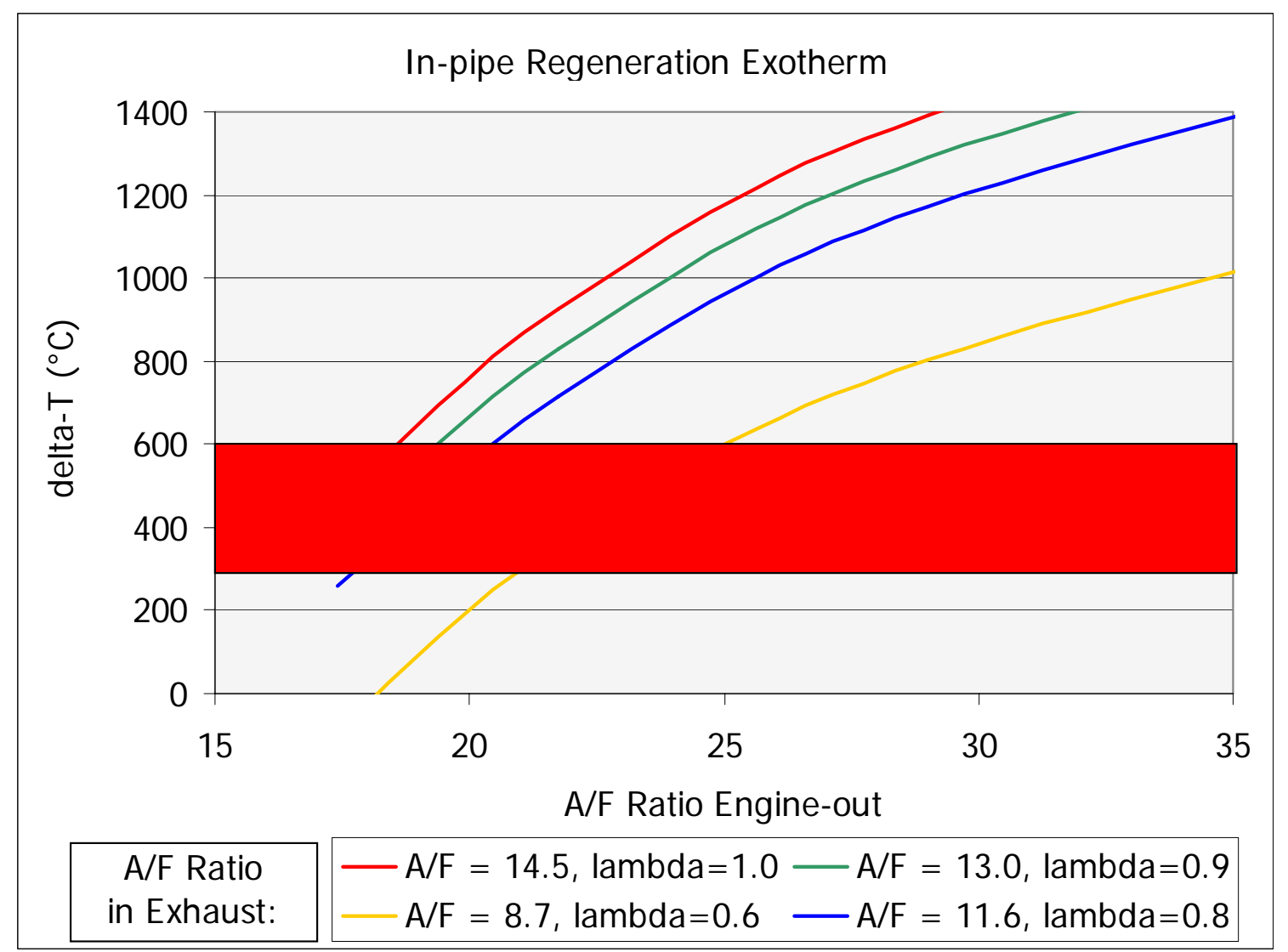

Figure 2.2.3.5.

The focus was on developing the control strategies to run the engine transiently over a FTP cycle and find settings to obtain very low engine-out air/fuel ratios.

Two different vendor's NOx adsorber catalysts were tested to determine performance degradation after being exposed to repeated temperature excursions. These excursions would typically occur during the life of the catalyst to rid the catalyst of residual sulfur that would be present in the fuel (known as desulfations). Desulfation temperature and number of desulfations at that temperature were varied per the test plan.

As stated above, a Cat 3126 engine was used for testing and also used ultra low sulfur fuel (less than $15 \mathrm{ppm}$ sulfur) so as to measure only the thermal effect on the catalyst bricks. Catalysts were exposed to high temperatures for 10 minute intervals and followed up with measuring its ability to store NOx after 1, 5, and 25 cycles. Desulfation temperatures ranged from 600C to 750C in 50C increments.

Results from this test clearly showed a thermal degradation pattern for both catalysts tested, and furthermore proved that one formulation had better NOx holding capacity than the other.

Best holding capacity occurred at a catalyst temperature of approximately 350C and thermal degradation began to occur at temperatures higher than 650C. This data could then be used to help size the aftertreatment system. The focus from this point forward was to work with catalyst suppliers to identify and test higher durability formulations. Activity in this area was ultimately stopped due to lack of a higher durability formulations being identified. 
DOE Final Report

DE-FC05-000R22806

\section{Section 2.2.4. System Optimization for $50 \%$ thermal efficiency at 2010 emissions}

The objective of this work was to combine high efficiency NOx aftertreatment with high efficiency components discussed in Section 1.4 into one optimized engine system capable of achieving 2010 emissions with $50 \%$ thermal efficiency.

\section{Year 5 - Achievement of $\mathbf{5 0 \%}$ through simulation and focused testing}

During the $5^{\text {th }}$ year of the program, the program identified the technologies to reach the $50 \%$ thermal efficiency mark. Two steps towards $50 \%$ were defined.

1. $\quad 45 \%$ overall brake thermal efficiency at 2007 emissions

2. $\quad 50 \%$ overall brake thermal efficiency at 2010 emissions

The focus of the $5^{\text {th }}$ year was to achieve $50 \%$ thermal efficiency using a combination of analysis and proof-ofconcept focused testing. During the sixth year, even after required matching funding level were met by Caterpillar, Caterpillar chose to demonstrate the path identified in year 5.

The starting point for the work on 45\% thermal efficiency at 2007 on-highway truck emissions levels was a C15 550 HP demonstration engine capable of 2007 emissions levels. This engine system was not optimized in regards to air system sizing, piston bowl optimization, injector performance, etc for the 2007 emissions target. To improve to $45 \%$ thermal efficiency it was necessary to include the following:

- reduced piston-ring-liner (PRL) friction

- high efficiency air system (series turbochargers)

- improved port flow (ultimate flow head with improved port design improved flow significantly, but it was projected in analysis that a 3 intake, 1 exhaust head may improve thermal efficiency even further)

- high efficiency compact cooling system

- system optimization (use of higher cylinder pressure limit, intake valve actuation, compression ratio, combustion chamber optimization)

The improvement in thermal efficiency obtained using each of these building blocks is shown in Figure 2.2.4.1 for a 1500 RPM, full load operating condition. Combining all of the building blocks resulted in a system thermal efficiency just over $45 \%$. 


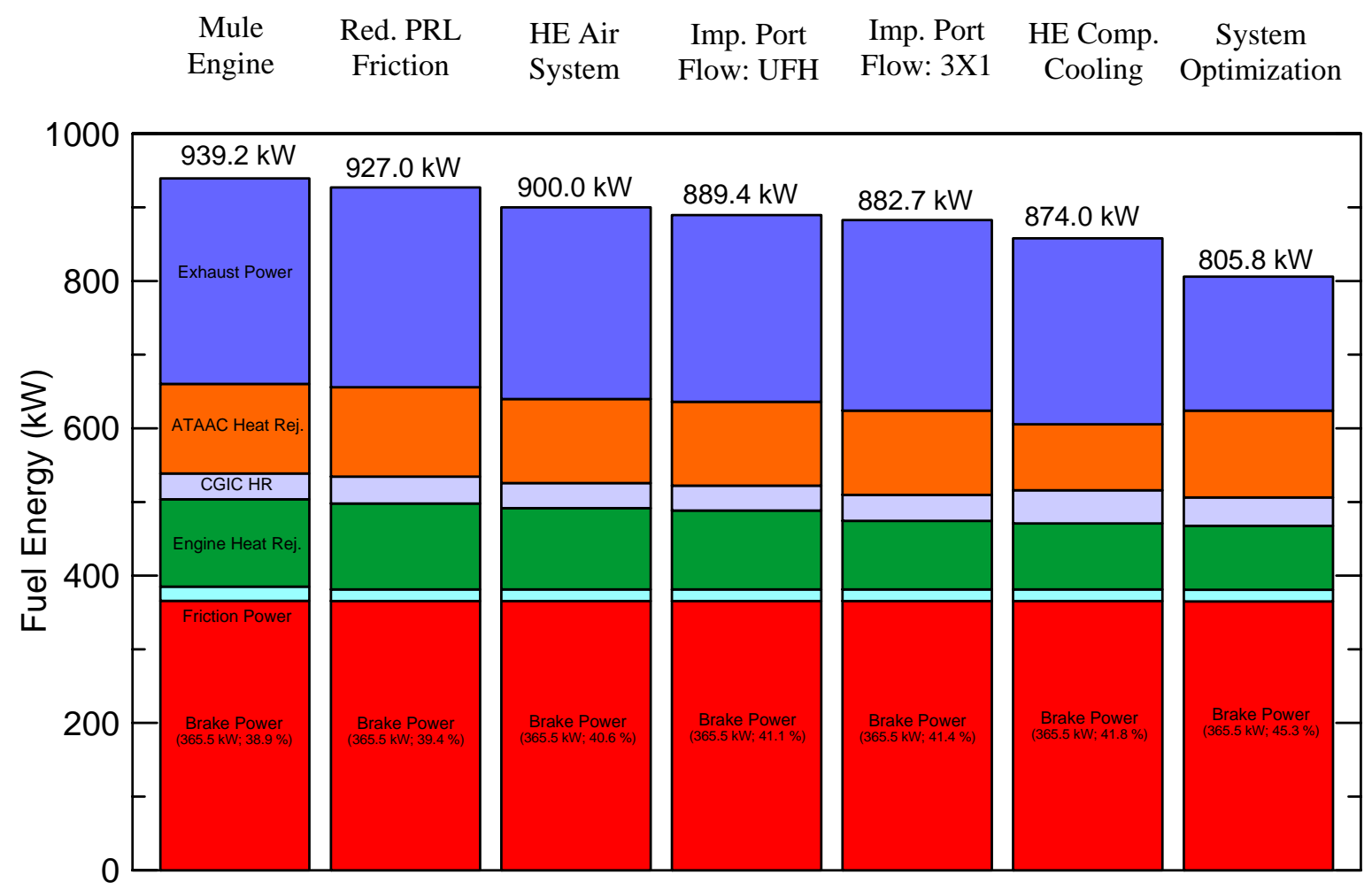

Figure 2.2.4.1: Fuel energy distributions showing the effect of each of the thermal efficiency building blocks used to achieve $45 \%$ thermal efficiency. The brake power remains constant in each step, but the amount of fuel energy needed to achieve that power level is decreased with the addition of each building block. The total fuel energy required to reach the simulation power level is provided above each column. The thermal efficiency (brake power divided by the fuel energy provided) is shown in percent in the parenthesis just below the Brake Power heading. Results are for a C15 engine operating at 1500 RPM, full load.

The $50 \%$ thermal efficiency starts from the $45 \%$ thermal efficiency effort point. To the $45 \%$ thermal efficiency system, the following building blocks were added using a combination of analysis and proof-ofconcept focused testing:

- $\mathrm{NO}_{\mathrm{x}}$ aftertreatment (to reach the 2010 emissions level)

- improved air system (includes even higher efficiency turbo-machinery and the addition of intercooling)

- reduced heat rejection (thermal barrier coated or air gap pistons, exhaust port liners, and increased coolant temperatures)

- mechanical turbocompound

- system optimization (use of higher cylinder pressure limit, intake valve actuation, compression ratio, combustion chamber optimization)

The improvement in thermal efficiency obtained using each of these building blocks is shown in Figure 2.2.4.2 for a 1200 RPM, full load operating condition. Combining all of the building blocks resulted in a system thermal efficiency of just over $50 \%$. 


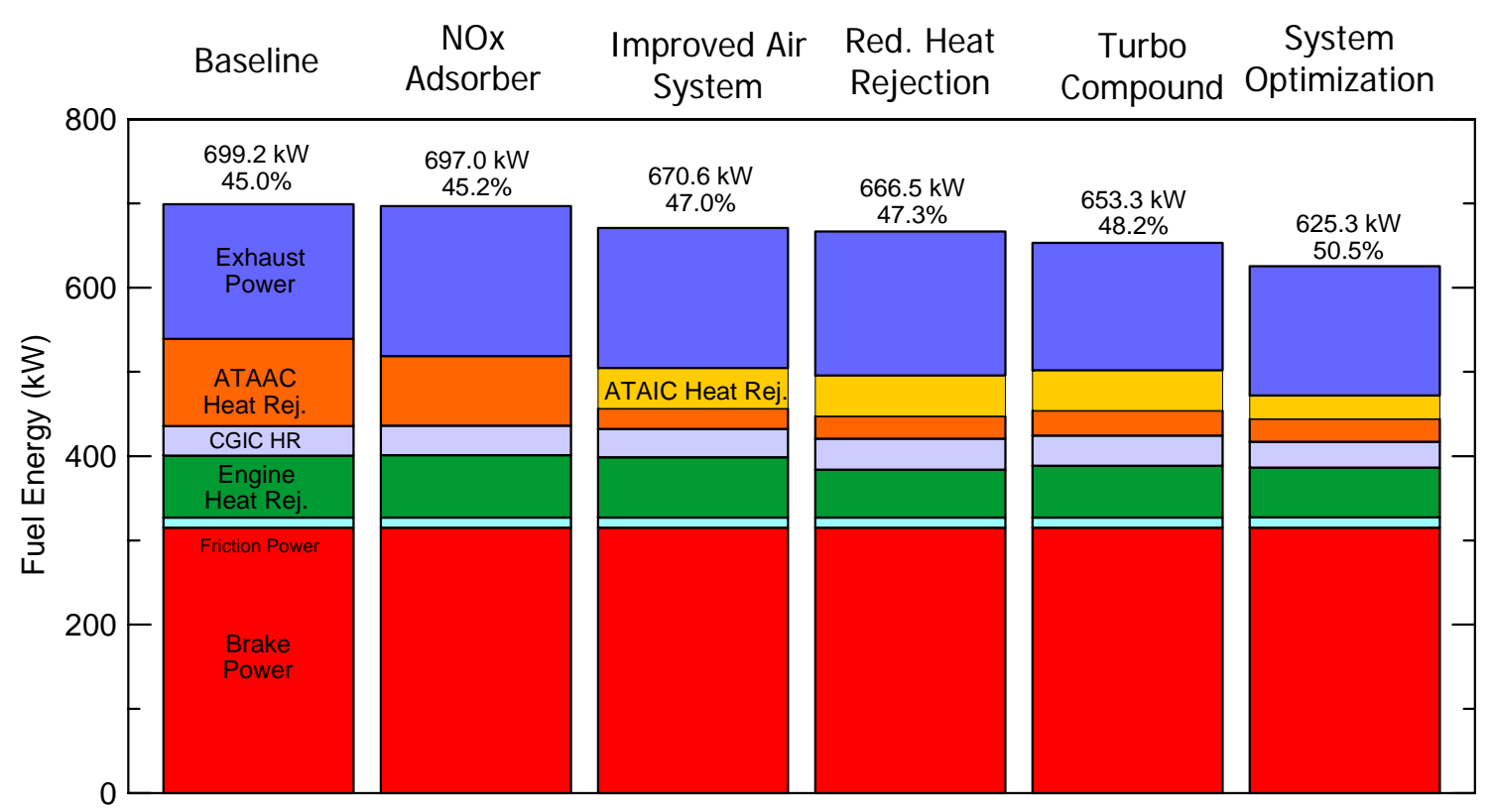

Figure 2.2.4.2: Fuel energy distributions showing the effect of each of the thermal efficiency building blocks used to achieve $50 \%$ thermal efficiency. The brake power remains constant in each step, but the amount of fuel energy needed to achieve that power level is decreased with the addition of each building block. The total fuel energy required to reach the simulated power level is provided above each column. The thermal efficiency (brake power divided by the fuel energy provided) is shown in percent in the parenthesis just below the fuel energy supplied. Results are for a C15 engine operating at 1200 RPM, full load.

\section{Year 6 - Demonstration of $50 \%$ in engine system hardware}

In the $6^{\text {th }}$ year, there were four milestones identified to monitor progress to move towards the final goal of 50\% thermal efficiency at 2010 emissions. To understand the system interactions and additive nature of the thermal efficiency building blocks, the system has been analyzed and optimized using a Caterpillar cycle simulation code. This analysis was also used to monitor performance of the system relative to the goal of the project as data was collected during the 4 milestones (see Table 2.2.4.1). The analysis was used to produce a prediction of how much thermal efficiency benefit would be derived from each building block discussed in section 1.4. It is important to note that the order of application can determine the amount of benefit. The increase in thermal efficiency is shown in the Figure 2.2.4.3 below. 


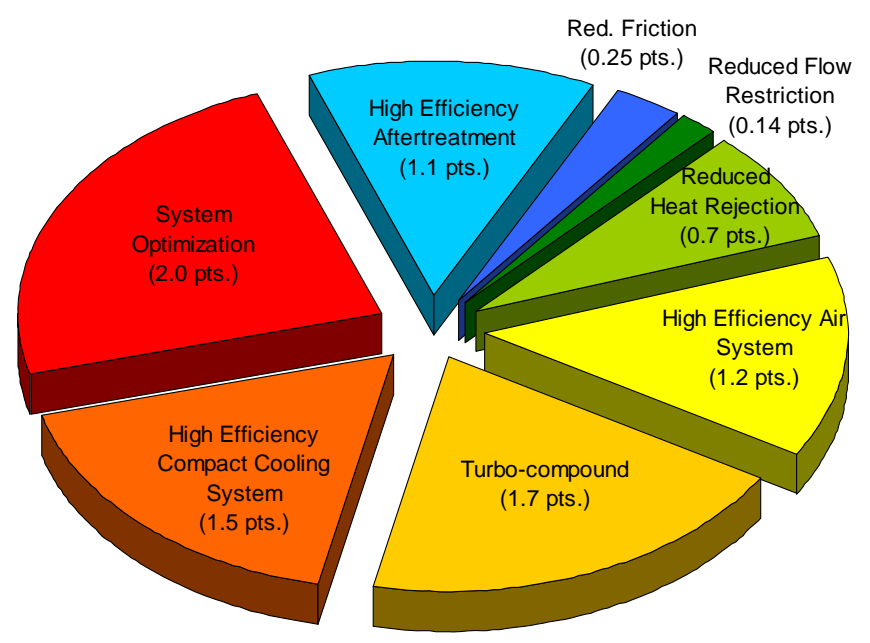

Figure 2.2.4.3 Contribution of the year 6 demonstration engine building blocks to achieve 50\% thermal efficiency.

The demonstration point was $1200 \mathrm{rpm}, 2508 \mathrm{Nm}$ load or peak torque. This point was chosen as it is one of the most important single points in calculating cycle level fuel economy for an on-highway truck using Gear Fast Run Slow (1325 engine rpm at 65 mph vehicle speed) engine \& transmission combination.

An overview of the system specifications at the demonstration point is provided in Fig. 2.2.4.4. As shown at the top of the figure, the predicted system thermal efficiency at the time of when the program moved from into hardware procurement was $49.9 \%$ for the integrated system. During the program, the system model was frequently recalibrated based on the results of proof of concept component hardware tests, detailed analysis results, etc. In addition, it was planned to be have final correlation to the High Efficiency Engine System Demonstration (milestone 4 engine).

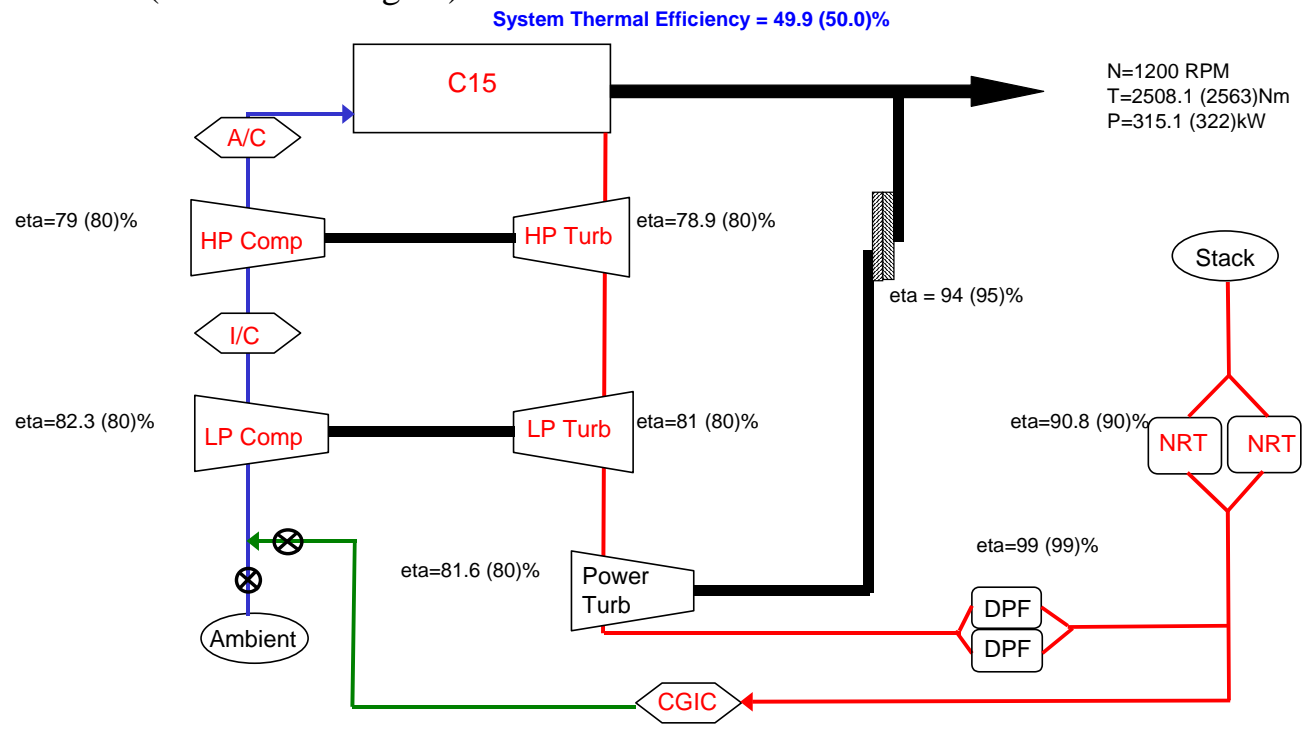

Figure 2.2.4.4: System specifications for the high efficiency demonstration engine. Values shown immediately after the equals sign are the predicted values while those in parenthesis are the original design goals. 
Table 2.2.4.1 shows the combination of building blocks and the results obtained at each milestone. In addition there is a column showing where other focused testing was completed. This includes gas stand testing and thermal cycle testing. The $2^{\text {nd }}$ to the last column shows the final consist that would be tested to reach $50 \%$ and the last column indicates where additional research should be placed for further improvement.

\begin{tabular}{|c|c|c|c|c|c|c|c|c|c|}
\hline & Building Block & Detail & Milestone 1 & Milestone 2 & Milestone 3 & Milestone 4 & $\begin{array}{l}\text { Other Focused } \\
\text { Testing } \\
\text { Completed }\end{array}$ & \begin{tabular}{|l|} 
Continued \\
Future \\
Testing
\end{tabular} & \begin{tabular}{|l|} 
Areas for \\
further \\
improvement
\end{tabular} \\
\hline 1 & \begin{tabular}{|l|} 
High Efficiency \\
Aftertreatment
\end{tabular} & & & & $\mathrm{x}$ & $\mathrm{x}$ & & $\mathrm{x}$ & \\
\hline \multirow[t]{3}{*}{2} & Reduced Friction & & & & & & & & $x$ \\
\hline & & PRL coating & & $x$ & & & & & \\
\hline & & Improved ring design & & & $x$ & $x$ & & $x$ & \\
\hline \multirow[t]{4}{*}{3} & Reduced Pumping & & & & & & & & \\
\hline & & Gen 1 UFH & & & & & $x$ & & \\
\hline & & Gen 2 UFH & & & $x$ & $x$ & $\mathrm{x}$ & & \\
\hline & & Gen 3 UFH & & & & & $\mathrm{x}$ & $x$ & $x$ \\
\hline \multirow[t]{3}{*}{4} & Reduced Heat Rejection & & & & & & & & \\
\hline & & Air Gap Piston & & & $x$ & & & $x$ & $x$ \\
\hline & & Exhaust Port Liners & & & & & $x$ & $x$ & \\
\hline \multirow[t]{4}{*}{5} & $\begin{array}{l}\text { High Efficiency Air } \\
\text { Systems }\end{array}$ & & & & & & & & \\
\hline & & Low Pressure Turbine & & & & $x$ & $x$ & $x$ & $x$ \\
\hline & & High Pressure Turbine & & & & $x$ & $x$ & $x$ & $x$ \\
\hline & & $\begin{array}{l}\text { High Pressure } \\
\text { Compressor }\end{array}$ & & & & & $\mathrm{x}$ & $x$ & $\mathrm{x}$ \\
\hline 6 & Turbocompound Unit & & & & & $x$ & & $x$ & $x$ \\
\hline & $\begin{array}{l}\text { High Efficiency Compact } \\
\text { Cooling }\end{array}$ & & & & & & & & \\
\hline & & $\begin{array}{l}\text { Increased Oil and Coolant } \\
\text { Temps }\end{array}$ & $\mathrm{x}$ & & $x$ & $\mathrm{x}$ & & $\mathrm{x}$ & \\
\hline & & \begin{tabular}{|l|} 
Improved Aftercooler \\
(lower IMT)
\end{tabular} & $\mathrm{x}$ & & $\mathrm{x}$ & $x$ & & $\mathrm{x}$ & \\
\hline & & Intercooler & $\mathrm{x}$ & & $x$ & $\mathrm{x}$ & & $x$ & \\
\hline & & & & & & & & & \\
\hline \multirow[t]{7}{*}{8} & System Optimization & & & & & & & & \\
\hline & & $\begin{array}{l}\text { Increased Compression } \\
\text { Ratio }\end{array}$ & $\mathrm{x}$ & & $\mathrm{x}$ & $\mathrm{x}$ & & $\mathrm{x}$ & \\
\hline & & $\begin{array}{l}\text { Increased Peak Cylinder } \\
\text { Pressure }\end{array}$ & $\mathrm{x}$ & & $\mathrm{x}$ & $\mathrm{x}$ & & $\mathrm{x}$ & \\
\hline & & $\begin{array}{l}\text { Optimized IVA settings } \\
\text { with improved air system }\end{array}$ & & & & $\mathrm{x}$ & & $\mathrm{x}$ & \\
\hline & & $\begin{array}{l}\text { Optimized CGI settings } \\
\text { with improved air system }\end{array}$ & & & & $\mathrm{x}$ & & $\mathrm{x}$ & \\
\hline & & $\begin{array}{l}\text { Increased Injection } \\
\text { Pressure }\end{array}$ & $\mathrm{x}$ & & $\mathrm{x}$ & $\mathrm{x}$ & & $\mathrm{x}$ & $\mathrm{x}$ \\
\hline & & Optimized Valve Timings & & & $x$ & $x$ & & $x$ & \\
\hline \multicolumn{2}{|c|}{ Net Result } & & 44.5 & & 45 & $47^{*}$ & & & \\
\hline
\end{tabular}

Table 2.2.4.1. Summary of Testing in 2006

As indicated by the table, significant future testing would be required for developing any of the technologies beyond the proof of concept level of this program.

\section{Clarification of year 6 progress relative to year 5.}

As seen above, the milestone 4 engine did not demonstrate $50 \%$ achieved in year 5 . Clarification as to performance relative the DOE Joule milestone (milestone \#4) is given. Below was the Joule milestone for the project.

Achieve 41 percent brake thermal efficiency for light vehicle combustion engines and 50 percent brake thermal efficiency, while meeting EPA 2010 emission standards ( $0.2 \mathrm{~g} / \mathrm{hp}-\mathrm{hr} \mathrm{NOx})$, for heavy vehicle combustion engines. 
In 2005 at the DEER conference (public information), Caterpillar presented a path to reach 50\% thermal efficiency at 2010 emissions. This path was a combination of high fidelity simulation with results from focused proof-of-concept testing to insure the path was viable. In essence, at that point Caterpillar achieved the $50 \%$ brake thermal efficiency at 2010 emissions through a combination of tests and simulation and presented the information in the presentation. This is an important note since it appears that thermal efficiency levels presented by other participants in the solicitation are for a combination of engine testing along with analytical prediction results. It is critical to note that Caterpillar still stands by their ability to reach 50\% at a proof-of-concept level and has in 2005 effectively achieved those levels through the combination of analytical predictions in addition to engine test results. This again is at a proof-of-concept level and significant additional work would still be required to investigate the commercial viability of the building blocks.

However, to further strengthen the output from the cooperative research agreement, Caterpillar continued on with the program on its own funding during the $6^{\text {th }}$ year of the program and demonstrated $47 \%$ brake thermal efficiency in a hardware demonstration of an engine system that actually demonstrated 2010 emissions levels and was a potentially viable package for a class 8 truck. The $47 \%$ achievement was an actual iron demonstration with 2010 emissions aftertreatment included in the demonstration. No analytical simulations were reported with $47 \%$ because the analytical predictions, combined with engine testing, were reported a year earlier. For the $47 \%$ demonstration, the program produced a complete set of performance measurements showing the efficiency level with while meeting engine out emissions levels that can be reduced after passing through the aftertreatment to the 2010 levels. The demonstration included as many of the thermal efficiency building blocks as could be combined within the program timeline. The achievement of $47 \%$ is viewed internally as successful proof-of-concept validation of the $50 \%$ path components. It is viewed as a solid point which confirmed our 2005 analytical plus test results achievement of 50\% thermal efficiency. Caterpillar has confidence that through the redesign of the turbo-compound unit along with the addition of the reduced heat rejection building blocks (air gap piston and port liners), the addition of the $80 \%$ efficient - high pressure stage compressor, and a redesigned low pressure stage turbine to reach the $80 \%$ level would allow a proof-ofconcept demonstration of the $6^{\text {th }}$ year goal of $50 \%$ in a complete iron demonstration.

In summary, when the combination of test results and analytical predictions are included, the $50 \%$ demonstration was achieved in 2005. Also as stated above the demonstration engine did not contain all of the $50 \%$ thermal efficiency building blocks so $50 \%$ was not expected until the additional components could be added. However, with the $47 \%$ results plus the additional building blocks analytically added, $50 \%$ is achieved.

To more completely clarify, the following would need to be done to bring together a complete iron proof-ofconcept demonstration of the $50 \%$ engine.

a. Redesigned turbocompound mechanically to eliminate the rubbing friction caused by undamped shaft dynamics. Design improvements have been identified

b. Redesign the LP stage turbine to reach the $80 \%$ analytical predictions.

c. Add the high efficiency (80\% efficient) HP stage compressor

d. Add the air gap piston

e. Add the exhaust port liners.

f. Higher injection pressure

\subsubsection{System Design and Packaging}

The design for the $50 \%$ thermal efficiency demonstration engine met the package constraints of a class 8 chassis. The turbocompound design is shown in Figure 2.2.2.1. Further, additional components have been 
packaged while maintaining the fit within the Kenworth T2000 frame rails as shown in Figure 2.2.2.2. A schematic of the entire engine system packaged within the Kenworth T2000 is shown in Figure 2.2.2.3.

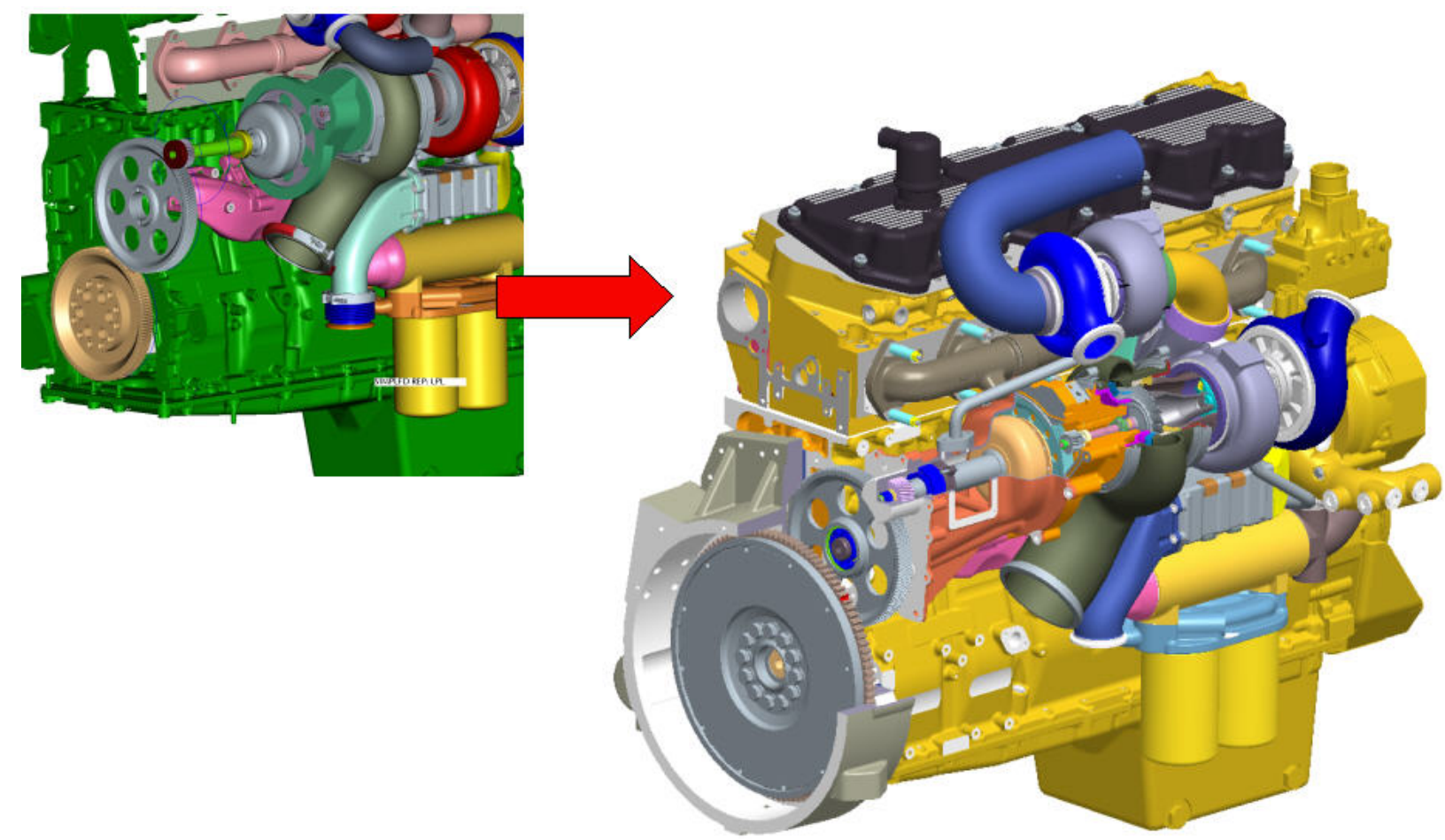

Figure 2.2.2.1: 50\% thermal efficiency engine system design transformation from concept to procured design.

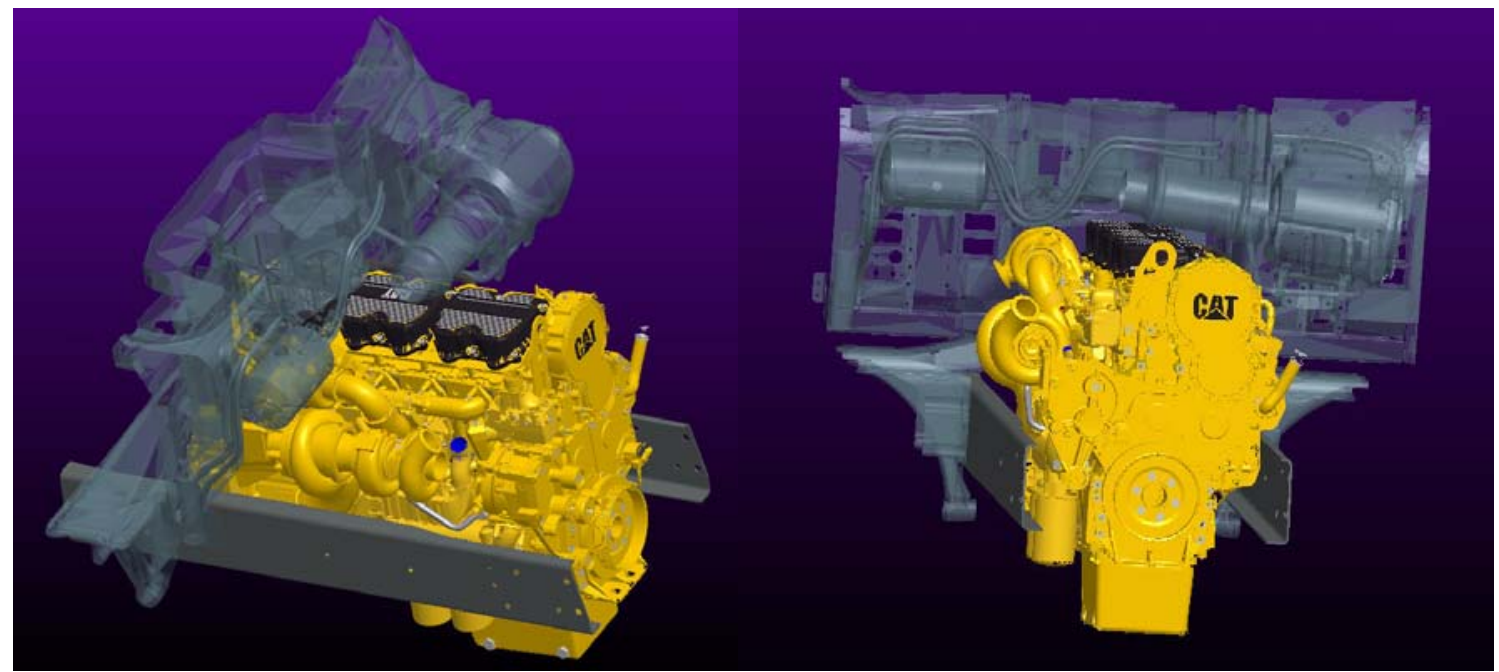

Figure 2.2.2.2: 50\% thermal efficiency demonstration engine packaged within a Kenworth T2000 class VIII chassis. 


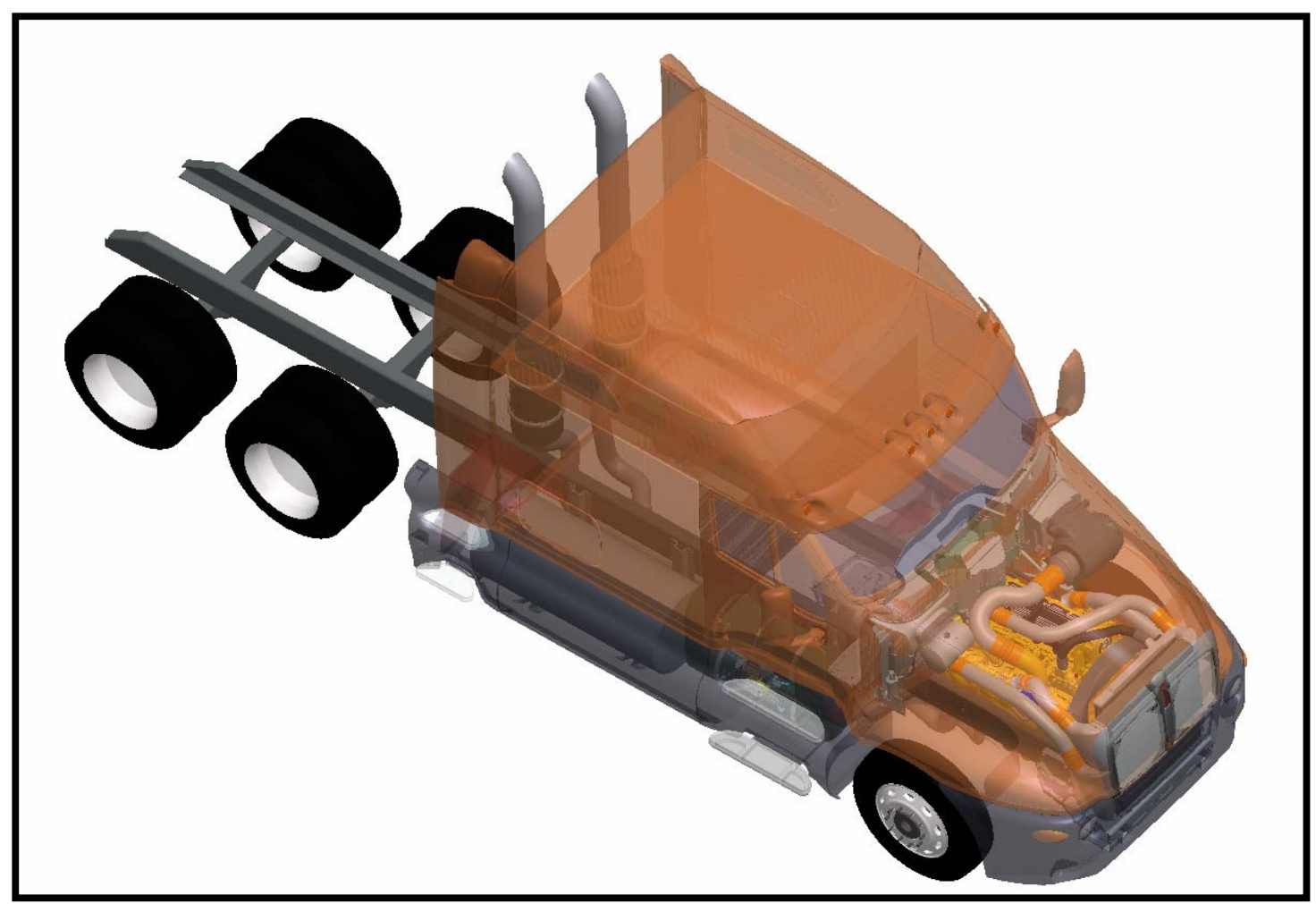

Figure 2.2.2.3: Complete 50\% thermal efficiency demonstration system packaged with the Kenworth T2000 chassis. 
DOE Final Report

DE-FC05-000R22806

Acronyms:

$\mathrm{A} / \mathrm{F}$

Air/Fuel

ACERT Advanced Combustion Emission Reduction Technology

ACIPS Advanced Compact Primary Surface

ATAAC Air to Air After Cooled

AVL Engine Consulting company providing emissions equipment

BMEP Brake Mean Effective Pressure

BSFC Brake Specific Fuel Consumption

BSNOx Brake Specific Oxides of Nitrogen

BTDC Before Top Dead Center

CCRT Catalytic Continuously Regenerated Trap

CEI Clean Exhaust Induction

CFD Computational Fluid Dynamics

CGI Clean Gas Induction

CR Compression Ratio

DAS Data Acquisition System

DPF Diesel Particulate Filter

ECM Engine/Electronic Control Module

EGR Exhaust Gas Recirculation

ERPM Engine Rotation Per Minute

ESC Steady Cycle

EVO Exhaust Valve Opening

EWHR Exhaust Waste Heat Recovery

FEA Finite Element Analysis

FMEP Friction Mean Effective Pressure

FTP First Test Pass

GPS Global Positioning System

HC Hydrocarbon

HCCI Homogeneous Charge Compression Ignition

HECC High Efficiency Clean Combustion

HEUI Hydraulic Electronic Unit Injector

HPL High Pressure Loop

HTCD Heavy Truck Clean Diesel

HTRLS Heat Release

IMEP Indicated Mean Effective Pressure

IMT Inlet Manifold Temperature

IVA Intake Valve Actuation

L/D Lift/Diameter

LIVC Late Intake Valve Closing

LPL Low Pressure Loop

MCTE Multi Cylinder Test Engine 
DOE Final Report

DE-FC05-000R22806

MEC Mossville Engine Center

MEUI Mechanically Electronic Unit Injector

MMEP Motoring Mean Effective Pressure

MMI Mixed Mode Injector

PCP Peak Cylinder Pressure

PM Particulate Matter

PMEP Pumping Mean Effective Pressure

PRL Piston Ring Liner

RCPC Regenerative Cylinder Pressure Control

SCOTE Single Cylinder Oil Test Engine

SCTE Single Cylinder Test Engine

SLA Stereo Lithography

SMD Sauter Mean Diameter

UFH Ultimate Flow Heat

VCR Variable Compression Ratio

VGT Variable Geometry Turbo

CAT, CATERPILLAR, their respective logos, "Caterpillar Yellow" and the POWER EDGE trade dress, as well as corporate and product identity used herein, are trademarks of Caterpillar and may not be used without permission.

(C)2008 Caterpillar. This paper was written with support of the U.S. Department of Energy under Contract No. DE-FC26-00OR22806. The Government reserves for itself and others acting on its behalf a royaltyfree, nonexclusive, irrevocable, worldwide license for Governmental purposes to publish, distribute, translate, duplicate, exhibit and perform this copyrighted paper. 